Rodrigo Pagnussat

\title{
Análise numérica do comportamento de blocos sobre quatro estacas com cálice parcialmente embutido - Estudos de casos reais
}

VERSÃO CORRIGIDA

Dissertação apresentada à Escola de Engenharia de São Carlos da Universidade de São Paulo, como parte dos requisitos para obtenção do título de Mestre em Engenharia de Estruturas.

Orientador: José Samuel Giongo

São Carlos

2011 
AUTORIZO A REPRODUÇÃO E DIVULGAÇÃO TOTAL OU PARCIAL DESTE TRABALHO, POR QUALQUER MEIO CONVENCIONAL OU ELETROONICO, PARA FINS DE ESTUDO E PESQUISA, DESDE QUE CITADA A FONTE.

Ficha catalográfica preparada pela Seção de Tratamento da Informação do Serviço de Biblioteca - EESC/USP

\begin{tabular}{|c|c|}
\hline \multirow[t]{3}{*}{ P139a } & $\begin{array}{l}\text { Pagnussat, Rodrigo } \\
\text { Análise numérica do comportamento de blocos sobre } \\
\text { quatro estacas com cálice parcialmente embutido: estudos } \\
\text { de casos reais / Rodrigo Pagnussat; orientador José } \\
\text { Samuel Giongo.-- São Carlos, 2011. }\end{array}$ \\
\hline & $\begin{array}{l}\text { Dissertação (Mestrado - Programa de Pós-Graduação em } \\
\text { Engenharia de Estruturas) -- Escola de Engenharia de São } \\
\text { Carlos da Universidade de São Paulo, } 2011 \text {. }\end{array}$ \\
\hline & $\begin{array}{l}\text { 1. Concreto armado. 2. Blocos sobre quatro estacas. } 3 . \\
\text { Bloco pré-moldado. 4. Cálice parcialmente embutido. } 5 . \\
\text { Blocos submetidos a momento. I. Título. }\end{array}$ \\
\hline
\end{tabular}




\section{FOLHA DE JULGAMENTO}

Candidato: Engenheiro RODRIGO PAGNUSSAT

Título da dissertação: "Análise numérica do comportamento de blocos sobre quatro estacas com cálice parcialmente embutido - estudos de casos reais”.

Data da defesa: 06/12/2011:

Comissão Julgadora:

Prof. Dr. José Samuel Giongo (Orientador)

(Escola de Engenharia de São Carlos/EESC)

Prof. Dr. Angelo Rubens Migliore Junior

(Centro Universitário de Lins)

Prof. Dr. Ricardo Carrazedo

(Escola de Engenharia de São Carlos/EESC)
Resultado:

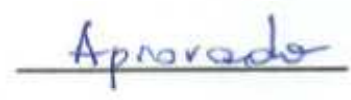

Aprovado

ATROVADO

Coordenador do Programa de Pós-Graduação em Engenharia Civil (Engenharia de Estruturas):

Profa. Associada Ana Lucia Homce de Cresce El Debs

Presidente da Comissão de Pós-Graduação:

Prof. Associado Paulo Cesar Lima Segantine 

Dedico este trabalho aos meus Pais Desidério e Aldina. 



\section{AGRADECIMENTOS}

A Deus, por ter me guiado em mais uma etapa de crescimento.

Aos meus pais Desidério e Aldina pela formação dos meus princípios, pela minha vida e pelo amor que sempre me deram.

Aos meus irmãos, Luciano, Lucídio, Luci Ana, Luiz Carlos e Fernando, que sempre me apoiaram cada um de seu modo e a todos meus sobrinhos.

A meu orientador José Samuel Giongo pela orientação, paciência e ensinamento.

Ao professor Doutor Angelo Rubens Migliore Jr., por disponibilizar os dados dos modelos reais estudados e pelas sugestões de variáveis.

À minha namorada Tatiana Fonseca, pessoa maravilhosa que conheci nesta caminhada, pelas horas dispensadas na ajuda da elaboração do texto desta dissertação e principalmente pela convivência, pelo carinho, pela paciência, atenção, pelo apoio e confiança.

Aos amigos, Carlos Marek e Rodrigo Barros, pela ajuda com o Diana, e com o tema da pesquisa.

Aos meus amigos em especial a Charles Jaster de Oliveira e Pedro Bergamasco por dividir o peso nas horas mais difíceis, meu muito obrigado.

Aos amigos que ingressaram comigo nesta empreitada: Rafael Tamanini, Rafael, Rafael Eclache, Davi, Eunice, Juliana, Fabrício, Indara, Orieta, Winston, Daniel, Marcelo, Nero, André, Luiz e Markus.

Aos amigos de outras turmas: Andreilton, Ellen, Luiz, Hidelbrando, Valmiro, Wellison, Higor, Wagner, Jonas, Dênis, Danielle, André Ramos, Érica, Marcela Filizola, Denis, Jesus Daniel, Jesus Sánchez, Aref, Dorival, Hugo, Wanderson, Giovani.

Aos funcionários do Departamento de Estruturas.

Aos meus professores de graduação, Moacir Kripka e Zacarias Martin Chamberlain Pravia, pelo incentivo.

Ao amigo $\mathrm{Eng}^{\mathrm{O}}$ Demoncel Duarte Stunpf, por horas de convivência durante vários anos de iniciação científica e pela amizade.

A todos que direta ou indiretamente contribuíram para meu crescimento. 

"O desejo natural dos homens bons é o conhecimento, o único alimento verdadeiro da alma, pois não se pode amar a coisa alguma antes de conhecê-la." 



\section{RESUMO}

PAGNUSSAT, R. (2011). Análise numérica do comportamento de blocos sobre quatro estacas com cálice parcialmente embutido - Estudos de casos reais. Dissertação (Mestrado) - Escola de Engenharia de São Carlos, Universidade de São Paulo, São Carlos.

Entre os diversos elementos estruturais, um que apresenta certas carências de conhecimento é o bloco de fundação. Os poucos estudos referentes a este elemento se limitam ao caso de blocos com força centrada e blocos sem elementos de ligação. Assim este trabalho tem como objetivo esclarecer algumas dúvidas a respeito do comportamento de blocos de fundação sobre quatro estacas, com cálice parcialmente embutido e solicitado por momentos nas duas direções. Estudou-se por meio de análise numérica não linear o comportamento de dois blocos que fazem parte de edifícios industriais e comerciais tomados como modelos. Para verificar a representatividade do modelo numérico adotado, foi simulado um bloco sobre quatro estacas submetido à força centrada e dois modelos de colarinho, um com ligação rugosa e outro com ligação lisa; os resultados da análise numérica foram comparados com resultados experimentais obtidos por outros pesquisadores. As variações realizadas nos dois modelos foram relacionadas às armaduras adotadas e ao tipo de ligação entre pilar e colarinho. A análise dos resultados teve como norteadoras a verificação da força última, as tensões no concreto e nas barras de aço, a fissuração e as reações nas estacas. Os resultados indicaram que para o caso de ligação rugosa, ocorreu a formação de bielas que se formam a partir do topo do colarinho. Entretanto o modelo espacial e o método das bielas não descrevem com precisão o seu comportamento, pois há uma tendência das bielas se formarem com grandes ângulos de inclinações e, assim, as forças são transmitidas diretamente para as estacas. Já para o caso de ligação lisa, observou-se que a transferência das ações atuantes no pilar para o bloco ocorre por meio da força de atrito das paredes do pilar com o colarinho e principalmente pelo contato da base do pilar com o bloco.

Palavras-chave: Concreto Armado. Blocos sobre quatro estacas. Bloco pré-moldado. Cálice parcialmente embutido. Blocos submetidos a momento. 



\begin{abstract}
PAGNUSSAT, R. (2011). Numerical Analysis of the Behavior of four-pile Caps of Partially Embedded Socket - Studies of Real Cases. Thesis (MA) - Engineering School of São Carlos, University of São Paulo, São Carlos.

There is a lack of knowledge about pile caps. Studies concerning these elements are limited to the case of pile-caps subjected to centered forces without connection elements. In this context this research aims to clarify some doubts about the behavior of pile caps under centered forces and bending moment. The behavior of four pile-caps with partially embedded socket subjected to moment in two directions was studied. A nonlinear numerical study was conducted to analyze two pile-caps models designed as part of industrial and commercial buildings. To verify the representativeness of the numerical model adopted, comparative analyze were performed using numerical and experimental data found in previous researches. The reinforcement and connection type were the variable parameters in the analysis of the two pile-caps. The results have shown that in the case of rough connection there occurs the formation of struts from the top of the socket wall. In the case of smooth connection, the transfer of forces from the column to pile-cap occurs through friction forces in the socket/column connection.
\end{abstract}

Keywords: Concrete. Four pile-caps. Precast pile-caps. Partially embedded Socket. Pile-caps subjected to moment. 



\section{LISTA DE FIGURAS}

Figura 1 - Configurações possíveis dos cálices.

Figura 2 - Distribuições de armaduras estudadas por Blevót e Fremy (1967), para blocos sobre quatro estacas. (Adaptado de Blevót e Frémy (1967)).

Figura 3 - Distribuição de armaduras estudadas por Blevót e Fremy (1967), para blocos sobre três estacas. (Adaptado de Blevót e Frémy (1967)).

Figura 4 - Tipo de ruína do bloco ensaiado por Mautoni (1972). (Fonte: Mautoni (1972))......8 Figura 5 - Distribuições das armaduras estudadas por Taylor e Clarke (1976). (Adaptada de Taylor e Clarke (1976)).

Figura 6 - Tipos de ancoragem ensaiados por Taylor e Clarke (1976). (Adaptada de Taylor e Clarke (1976)).

Figura 7 - Ruína dos modelos ensaiados por Taylor e Clarke (1976). (Fonte: Taylor e Clarke (1976)).

Figura 8 - Blocos ensaiados por Adebar et. al (1990). (Adaptada de Adebar et. al (1990)).... 11 Figura 9 - Deformação horizontal ao longo da altura do bloco. (Fonte: Adebar et al. (1990)).

Figura 10 - Bloco Ensaiado por Chan e Poh (2000). (Adaptado de Chan e Poh (2000))........ 14 Figura 11 - Modelo de bielas e tirantes proposto por Souza et al. (2007). (Fonte: Souza et al. (2007)).

Figura 12 - Distribuição de reação nas estacas proposta por Schiel (1957). ..........................21

Figura 13 - Representação da seção do modelo sugerido pelo CEB-FIP (1970).....................23

Figura 14 - Modelo para blocos sobre quatro estacas submetidos à força vertical. (Fonte:

Munhoz (2004)).

Figura 15 - Representação das seções de referencia para a verificação do cisalhamento de acordo com o CEB FIP 1970.

Figura 16 - Seções de referencia para verificação cisalhamento CEB - FIP 1970..................31 Figura 17 - Esquema de distribuição das forças atuantes nas paredes do colarinho. (Adaptado

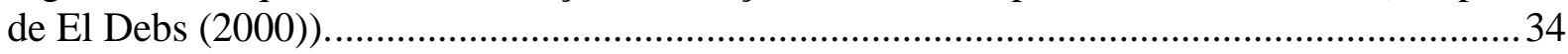
Figura 18 - Modelo de distribuição de tensões no cálice para o caso de paredes com chave de cisalhamento. (adaptado ABNT NBR 9062:2006)). ............................................................ 36

Figura 19 - Modelos de distribuição de esforços no cálice proposto por Canha (2004). ........ 37 Figura 20 - Distribuição da força superior na parede 1 proposta por Canha (2004). (Fonte:

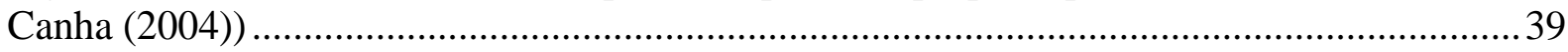
Figura 21 - Distribuição da força na parede 1 proposta por Canha (2004). (Fonte: Canha (2004)).

Figura 22 - Modelos constitutivos disponíveis para a compressão. (Fonte: DIANA 9.4 (2005a)).

Figura 23 - Modelos constitutivos disponíveis para a tração. (Fonte: DIANA 9.4 (2005-a)). 50 Figura 24 - Fator de redução por causa da tração transversal a direção principal. ...................50

Figura 25 - Armadura embutida no elemento finito. (Fonte: DIANA 9.4 2005-b)................52

Figura 26 - Elemento finito CHX-60. (Fonte: DIANA 9.4 2005-b) ......................................53

Figura 27 - Elemento finito de interface CQ48I. (Fonte: DIANA 9.4 2005-b) ........................54

Figura 28 - Fenômenos da curva força/deslocamento possíveis de serem detectados com o método do comprimento de arco. (Fonte: DIANA 9.4 2005-c)) .............................................56

Figura 29 - Geometria dos modelos ensaiados por Canha (2004) .......................................58

Figura 30 - Detalhamento do bloco, modelo rugoso. (Fonte: Canha (2004))........................59

Figura 31 - Detalhamento do cálice, modelo rugoso. (Fonte: Canha (2004))........................60

Figura 32 - Detalhamento do bloco, modelo liso IL3. (Fonte: Canha (2004)) .......................61 
Figura 33 - Detalhamento do cálice, modelo liso IL3. (Fonte: Canha (2004)). ..................... 62 Figura 34 - Modelo ensaiado por Chan e Poh (2000). (Adaptado de Chan e Poh (2000)). .... 64

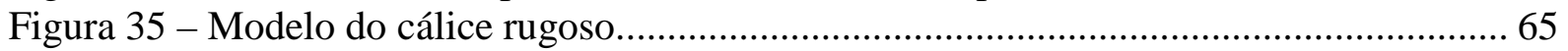
Figura 36 - Posição onde foi medida a deformação dos tirantes: adaptado de Canha (2004). 66

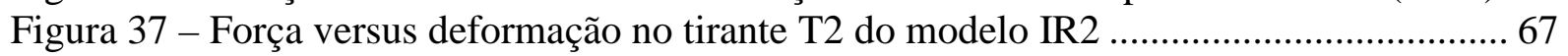

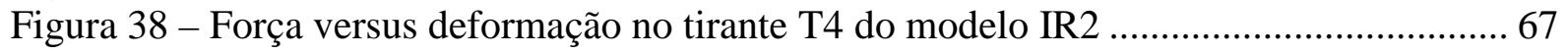

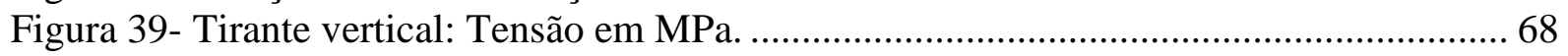

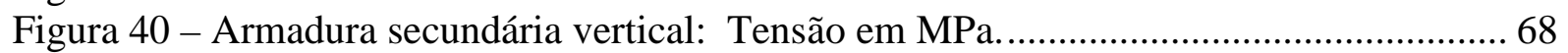

Figura 41 - Fissuração das paredes 3 e 4 modelo IR2: a) fotografia ensaio experimental (Canha 2004); b) resultado obtido numericamente $52 \%$ força última; c) resultado obtido numericamente $76 \%$ força última; d) resultado obtido numericamente $100 \%$ força última. .. 69 Figura 42 - Parede 2 modelo IR2: a) fotografia ensaio experimental (Canha 2004); b) resultado obtido numericamente $60 \%$ força última; c) resultado obtido numericamente $100 \%$

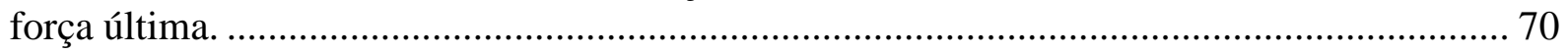
Figura 43 - Fissuração parede 1 modelo IR2: a) fotografia ensaio experimental (Canha 2004);

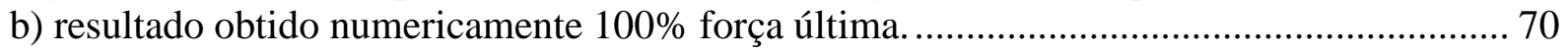

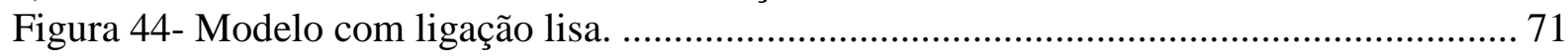

Figura 45 - Critério de atrito de Coulomb. (Fonte: DIANA 9.4 2005-a)............................... 71

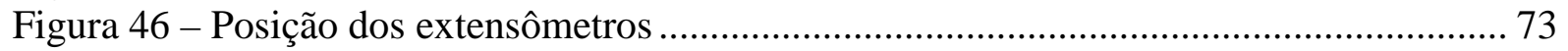

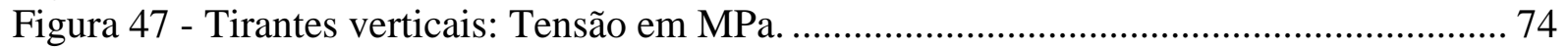

Figura 48 - Força versus deformação tirante T2 ligação lisa. ............................................. 74

Figura 49 - Armaduras verticais secundárias: Tensão em MPa. ............................................ 74

Figura 50 - Tirantes horizontais da parede transversal: Tensão em MPa. ............................. 75

Figura 51 - Força versus deformação armadura horizontal HSL1 ligação lisa...................... 75

Figura 52 - Armadura principal superior da parede da frente: Tensão em MPa.................... 76

Figura 53 - Fissuração parede frente 1 IL3: a) e e) fotografia ensaio experimental (Canha 2004); b) resultado obtido numericamente para $73 \%$ força última; c) resultado obtido numericamente para $100 \%$ força última; d) resultado obtido numericamente para $100 \%$ força

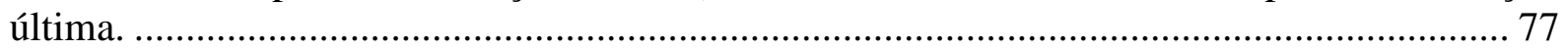

Figura 54 - Fissuração Posterior: a) fotografia ensaio experimental (Canha 2004); b) resultado obtido numericamente para $73 \%$ força última; c) resultado obtido numericamente para $100 \%$

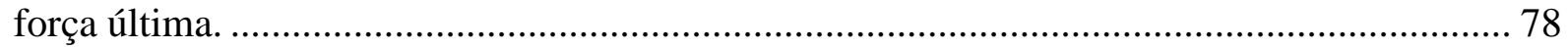
Figura 55 - Fissuração paredes laterais: a) e b) fotografia ensaio experimental (Canha 2004); c) resultado obtido numericamente $51 \%$ força última; d) resultado obtido numericamente para $83 \%$ força última; d) resultado obtido numericamente para $100 \%$ força última. .................... 78 Figura 56 - Bloco Chan e Poh (2000): a) tensão máxima em MPa; b) tensão mínima em MPa.

Figura 57 - Força-deslocamento vertical no meio do bloco modelo de Chan e Poh (2000) ... 80 Figura 58 - Fissuração do modelo de Chan e Poh (2000): a) resultado obtido numericamente para $45 \%$ força última; b) resultado obtido numericamente $50 \%$ força última; c) resultado obtido numericamente para 100\% força última; e) figura adaptada de Chan e Poh (2000)... 81 Figura 59 - Armaduras: Tensão em MPa. .......................................................................... 81 Figura 60 - Geometria do modelo MO1-IR. (Fonte: Migliore e Pastore Engenharia)............ 85 Figura 61 - Detalhamento MO1 vista topo e de fundo. (Fonte: Migliore e Pastore Engenharia).

Figura 62 - Detalhamento MO1 parte 1. (Fonte: Migliore e Pastore Engenharia). ................. 88 Figura 63 - Detalhamento do modelo MO1 parte 2. (Fonte: Migliore e Pastore Engenharia). 89 Figura 64- Geometria do modelo MO2. (Fonte: Migliore e Pastore Engenharia)................... 90 Figura 65 - Detalhamento MO2 vista topo e de fundo. (Fonte: Migliore e Pastore Engenharia). 
Figura 66 - Detalhamento do modelo MO2. (Fonte: Migliore e Pastore Engenharia)............92

Figura 67 - esquema de carregamento dos modelos ...........................................................94

Figura 68 - Modelo MO1_IR_AR6: a) e b) cortes diagonais para visualização da tensão máxima em $\mathrm{MPa}$; c) e d) cortes diagonais para visualização da tensão mínima em MPa. ......99 Figura 69 - Modelo MO2_IR_AR6: a) e b) cortes diagonais para visualização da tensão máxima em $\mathrm{MPa}$; c) e d) cortes diagonais para visualização da tensão mínima em MPa. .... 100 Figura 70 - Modelo MO1_IL_AR6: a) e b) cortes diagonais para visualização da tensão máxima em MPa; c) e d) cortes diagonais para visualização da tensão mínima em MPa. .... 101 Figura 71 - Modelo MO2_IL_AR6: a) e b) cortes diagonais para visualização da tensão máxima em MPa; c) e d) cortes diagonais para visualização da tensão mínima em MPa. .... 102 Figura 72 - Fissuração MO1_IR_AR6: a) bloco para 75\% força última; b) bloco para 92\% força última; c) bloco para $94 \%$ força última; d) bloco para $100 \%$ força última; e) colarinho para $70 \%$ força última; f) colarinho para $100 \%$ força última.

Figura 73 - Fissuração MO2_IR_AR6: a) bloco para 64\% força última; b) bloco para $71 \%$ força última; c) bloco para $77 \%$ força última; d) bloco para $84 \%$ força última; e) bloco para $100 \%$ força última; f) colarinho para $100 \%$ força última.

Figura 74 - Fissuração MO1_IL_AR6: a) bloco para 61\% força última; b) bloco para 69\% força última; c) bloco para $82 \%$ força última; d) bloco para $100 \%$ força última; e) colarinho para $85 \%$ força última; f) colarinho para $100 \%$ força última.

Figura 75 - Fissuração MO2_IL_AR6: a) bloco para 67\% força última; b) bloco para 74\% força última; c) bloco para $89 \%$ força última; d) bloco para $100 \%$ força última; e) colarinho para $83 \%$ força última; f) colarinho para $100 \%$ força última.

Figura 76 - Tensão nas armaduras modelo MO1_IR_AR6 em MPa: a) armaduras dos tirantes e distribuída do bloco; b) armadura vertical do colarinho; c) armaduras horizontais do colarinho; d) armadura de fretagem do bloco; e) armadura de fissuração do bloco; f) armadura horizontal para fissuração. 109 Figura 77 - Tensão nas armaduras modelo MO2_IR_AR6 em MPa: a) armaduras dos tirantes e distribuída do bloco; b) armadura vertical do colarinho; c) armaduras horizontais do colarinho; d) armadura de fretagem do bloco; e) armadura de fissuração do bloco; f) armadura horizontal para fissuração. 110

Figura 78 - Tensão nas armaduras modelo MO1_IL_AR6 em MPa: a) armaduras dos tirantes e distribuída do bloco; b) armadura vertical do colarinho; c) armaduras horizontais do colarinho; d) armadura de fretagem do bloco; e) armadura de fissuração do bloco; f) armadura horizontal para fissuração.

Figura 79- Tensão nas armaduras modelo MO2_IL_AR6 em MPa: a) armaduras dos tirantes e distribuída do bloco; b) armadura vertical do colarinho; c) armaduras horizontais do colarinho; d) armadura de fretagem do bloco; e) armadura de fissuração do bloco; f) armadura horizontal para fissuração. 113 Figura 80 - Modelo espacial adaptado de Souza et al (2007). 116 



\section{LISTA DE TABELAS}

Tabela 1 - Comprimento de embutimento do pilar no cálice................................................... 33

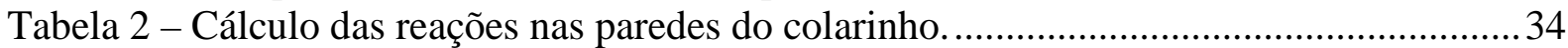

Tabela 3 - Valores de $G_{F O}$ em função do diâmetro do agregado. .........................................47

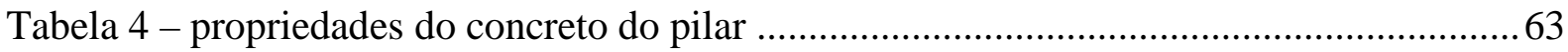

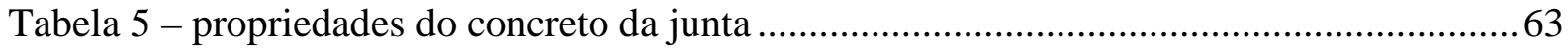

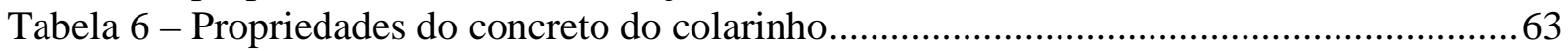

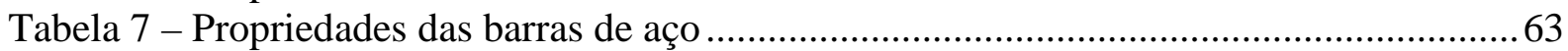

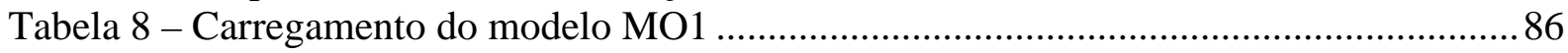

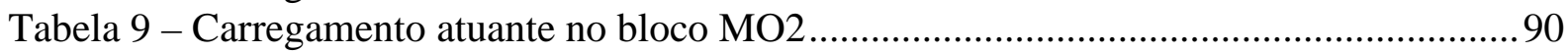

Tabela 10 - Propriedades do concreto adotadas nos modelos e modelo constitutivos ............93

Tabela 11 - Propriedades dos elementos de interface .........................................................94

Tabela 12 - Resultado das forças máximas dos modelos MO1-IR........................................96

Tabela 13 - Resultado das forças máximas dos modelos MO2-IR .........................................96

Tabela 14 - Resultado das forças máximas dos modelos MO1-IL .........................................97

Tabela 15 - Resultado das forças máximas dos modelos MO2-IL ..........................................97

Tabela 16 - Reações nas estacas para o modelo MO1-IR-AR6............................................114

Tabela 17 - Reações nas estacas para o modelo MO1-IL-AR6.............................................. 114

Tabela 18 - Reações nas estacas para o modelo MO2-IR-AR6.............................................. 114

Tabela 19- Reações nas estacas para o modelo MO2-IL-AR6............................................. 115

Tabela 20 - Forças nos tirante obtidos pelos modelos analíticos e pelo modelo numérico...116

Tabela 21 - inclinação das bielas determinadas pelos diferentes métodos ............................117

Tabela 22 - Forças nas bielas obtidas pelos modelos analíticos e pelo resultado numérico.. 117 



\section{SUMÁRIO}

RESUMO … -

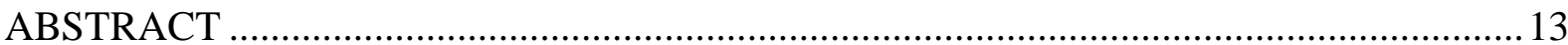

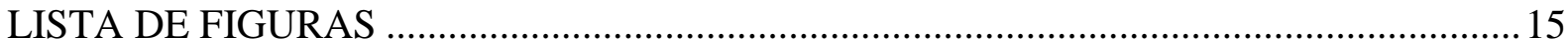

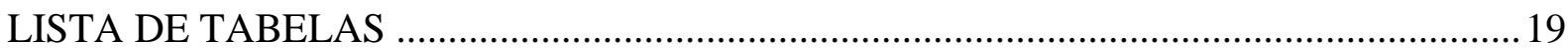

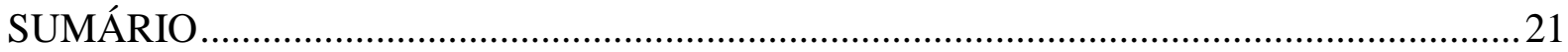

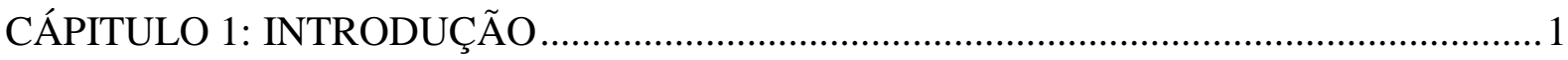

1.1 Considerações iniciais ........................................................................................

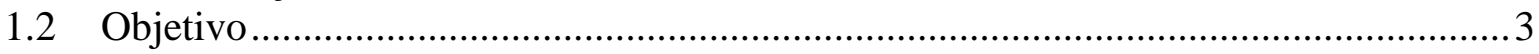

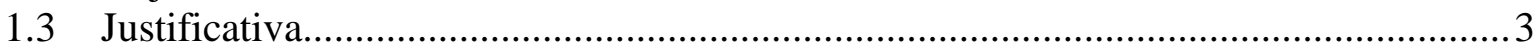

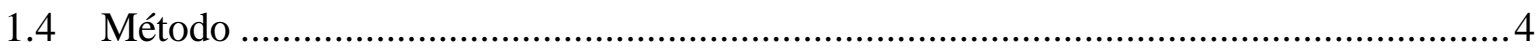

1.5 Estrutura da dissertação..................................................................................

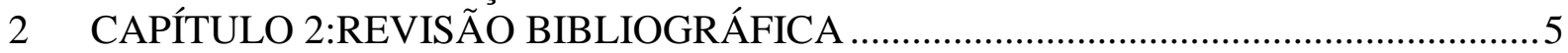

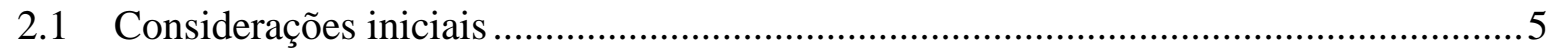

2.2 Pesquisas com ênfase em blocos de fundação .........................................................5

2.2.1 Blévot e Frémy (1967) ...............................................................................5

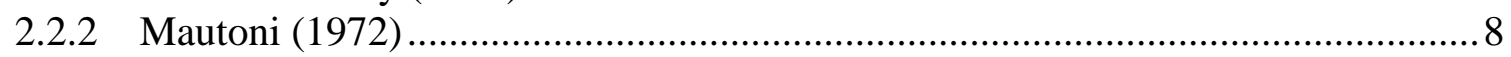

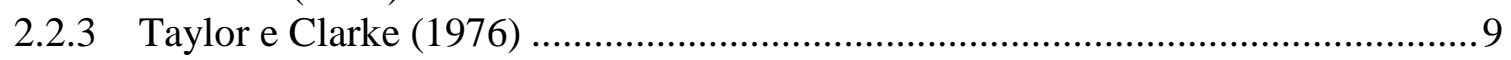

2.2.4 Adebar et al. (1990) ……………....................................................... 10

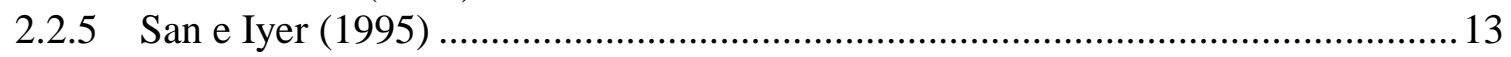

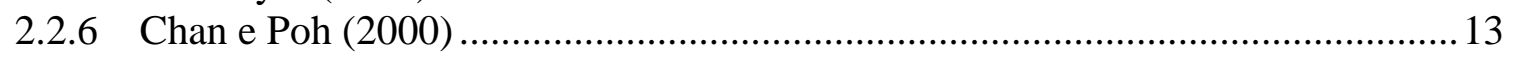

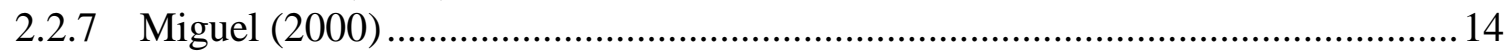

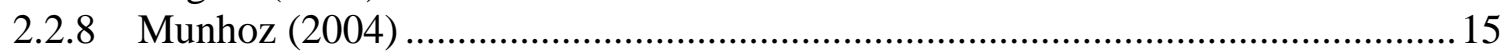

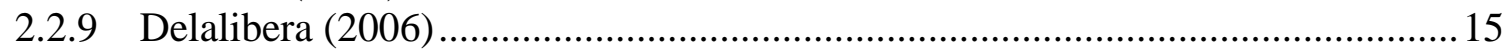

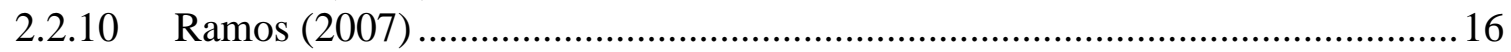

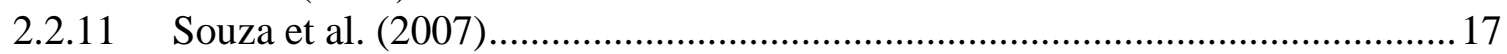

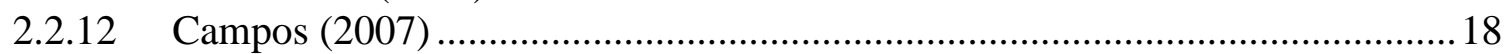

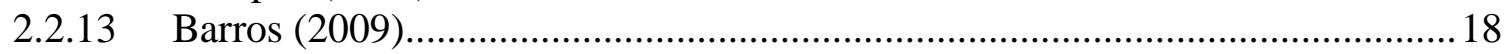

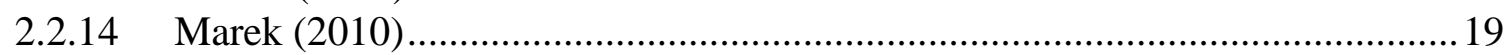

2.2.15 Buttignol (2011) ..................................................................................

2.3 Critérios de dimensionamento de blocos sobre estacas ...........................................21

2.3.1 Reações nas estacas ....................................................................................21

2.3.2 Classificação dos blocos .................................................................................22

2.3.3 Espaçamento entre estacas...............................................................................2

2.3.4 Distância entre eixo da estaca e face externa do bloco e ligação das estacas com o bloco 25

2.3.5 Método das bielas sugerido por Blévot e Frémy (1967) ………………………....2

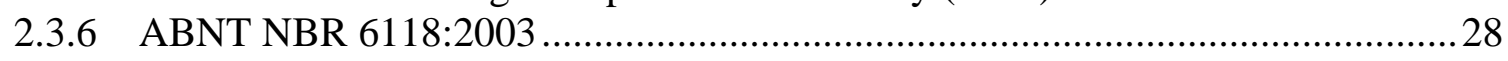

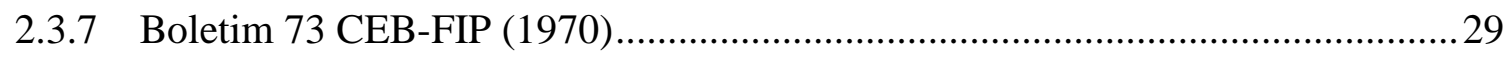

2.3.8 CSA A23.3 (2004) ..............................................................................

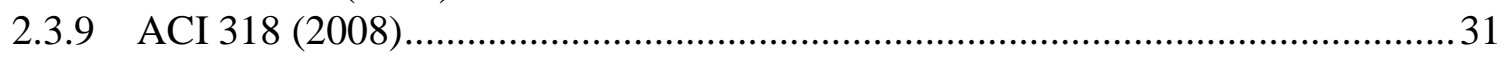

2.3.10 Armaduras secundárias e disposições construtivas ............................................32

2.4 Pesquisa com ênfase em colarinho de fundação ………………………………….....32

2.4.1 Método de Leonhardt e Mönnig (1977) e ABNT NBR 9062:2006 e El Debs (2000) 33

2.4.2 Modelo apresentado por Canha (2004) ...............................................................36

2.4.3 Outros estudos e modelos propostos ....................................................................4 


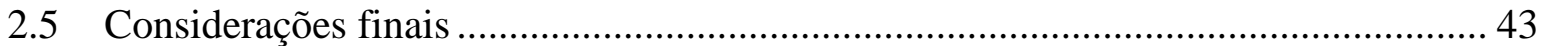

3 CAPÍTULO 3:APRESENTAÇÃO E COMPROVAÇÃO DO MODELO NUMÉRICO 45

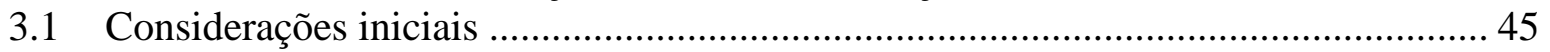

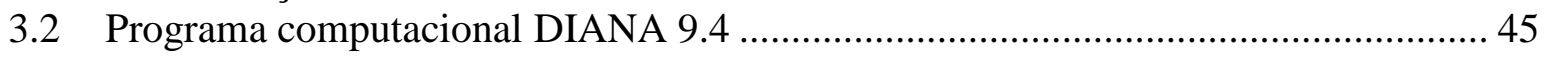

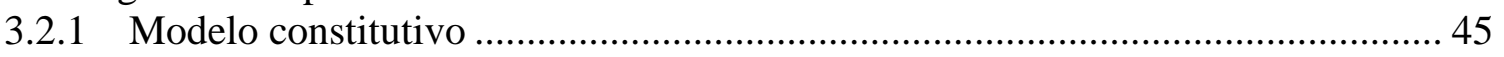

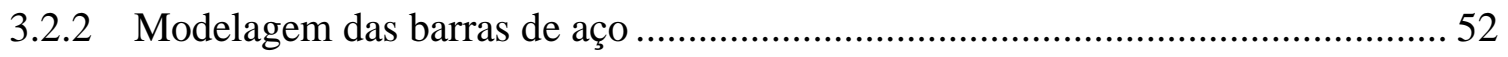

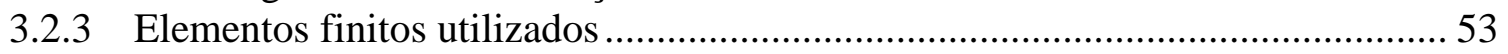

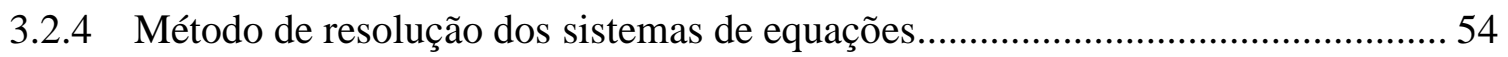

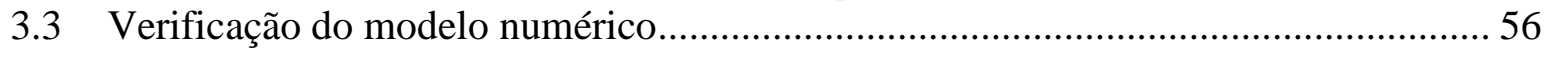

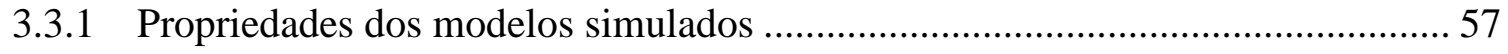

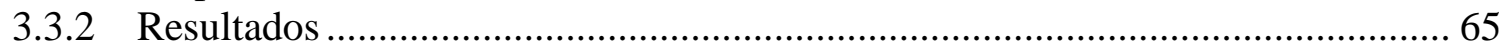

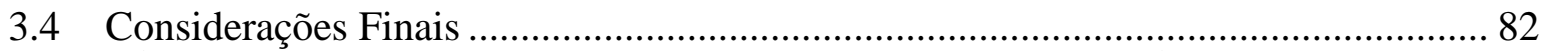

4 CAPÍTULO 4: BLOCOS SOBRE QUATRO ESTACAS COM CÁLICE

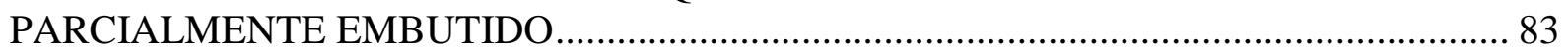

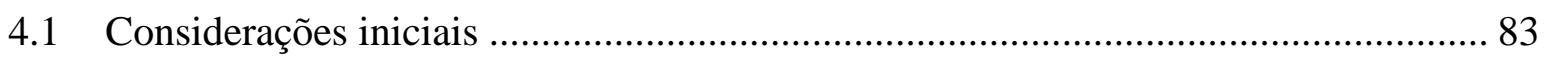

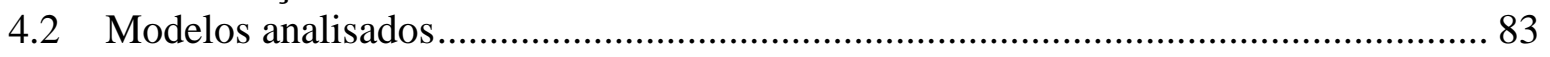

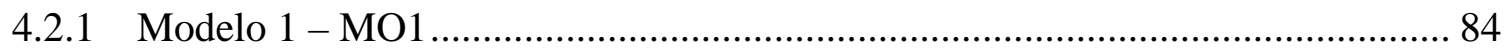

4.2.2 Modelo 2 - MO2 _................................................................................ 89

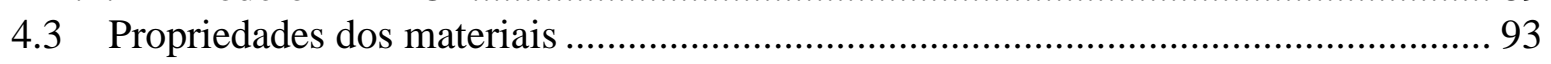

4.4 Forma da aplicação de forças e restrições das estacas .............................................. 94

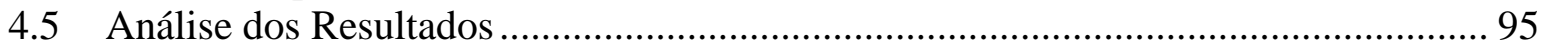

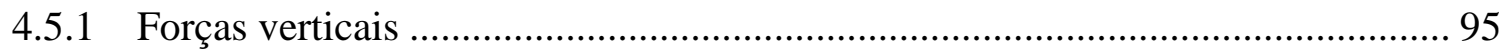

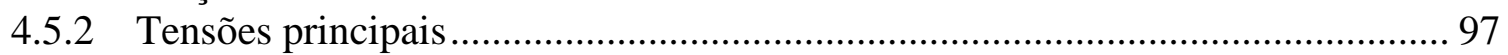

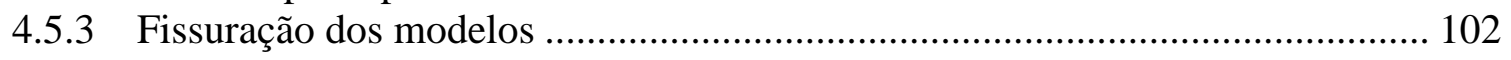

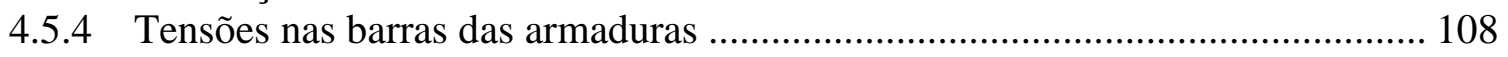

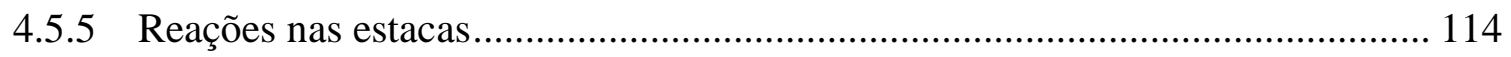

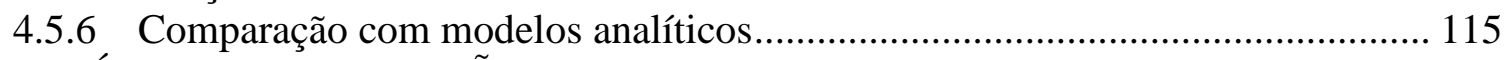

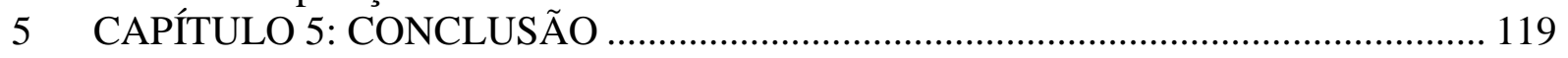




\section{INTRODUÇÃO}

\subsection{Considerações iniciais}

O tipo de fundação adotada para uma determinada obra depende da geologia da região, das propriedades mecânicas do solo, das intensidades das forças a serem transferidas ao solo e da viabilidade econômica da solução. No caso de solos das camadas superiores com pouca capacidade resistente ou em casos em que as forças a serem transferidas são de grande intensidade, uma das alternativas a se adotar é o uso de estacas. O número de estacas necessárias para se transferir as ações depende da sua seção transversal e da resistência do solo. Adotando-se a alternativa em estacas faz-se necessário o emprego de blocos de fundação que distribuem as ações oriundas do pilar para as diversas estacas.

Os blocos são elementos de volume sujeitos a perturbações de tensões localizadas. Não apresentam, assim, linearidade de deformações na seção transversal, não sendo possível considerar a hipótese de Bernoulli de que as seções planas permanecem planas após a deformação.

A ligação do pilar com o bloco, em estruturas de concreto em que se utilizam elementos pré-moldados, é realizada, na maioria dos casos, por meio de cálice. Este tipo de ligação consiste em deixar uma cavidade no bloco de fundação para embutir um determinado comprimento do pilar, ou então criar um elemento denominado de colarinho. $\mathrm{O}$ cálice pode estar posicionado acima do bloco, totalmente embutido no bloco e parcialmente embutido no bloco, conforme ilustrado na Figura 1. 

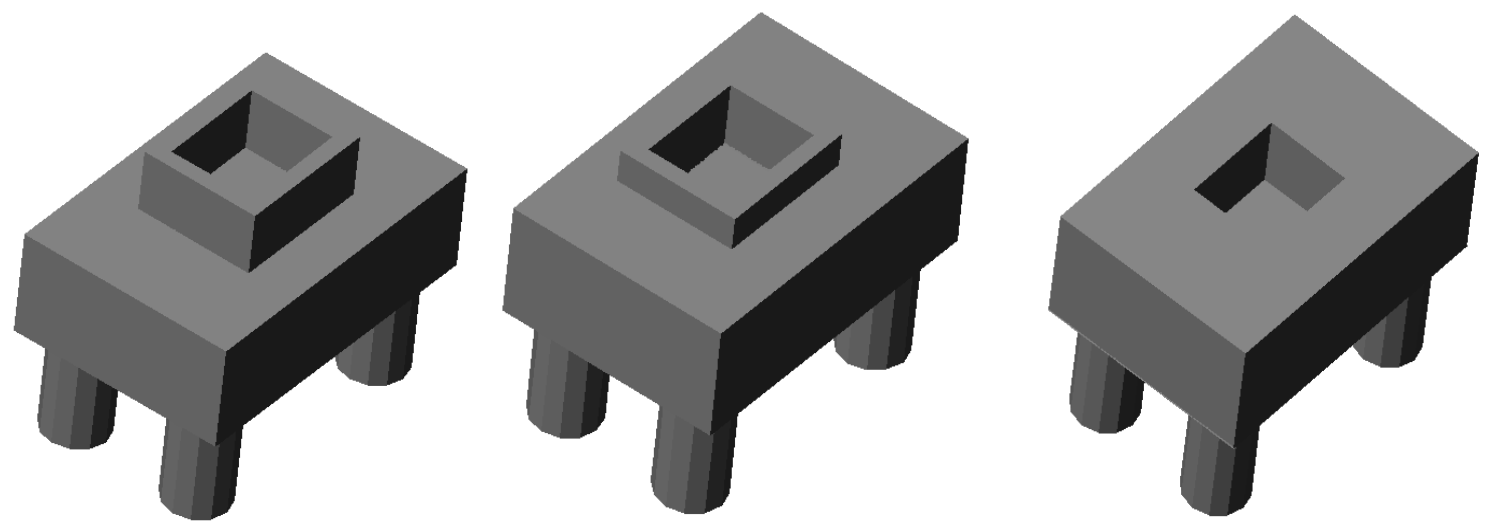

Figura 1 - Configurações possíveis dos cálices.

Normalmente os blocos são dimensionados pela teoria da flexão ou pelo método das bielas sugerido por Blévot e Frémy (1967), com algumas adaptações.

A norma brasileira de concreto ABNT NBR 6118:2003 sugere que se adotem dois modelos de cálculo: o modelo linear tridimensional e o modelo de bielas e tirantes, sendo o último mais recomendável. Este modelo também é recomendado pelo código normativo canadense CSA A23-3 (2004). Outros textos, como o CEB-FIP (1970) e ACI-318 (2008), sugerem que estes elementos sejam dimensionados pela teoria da flexão.

Leonhardt e Mönnig (1977) apresentam um modelo de cálculo para as paredes do colarinho, que norteia a maioria dos projetos realizados atualmente, mas os próprios autores afirmam que o comportamento deste tipo de estrutura não era totalmente conhecido.

Outros métodos para o cálculo das paredes do colarinho são encontrados na literatura, como os propostos por Canha (2004), Willert e Kesser (1983), Olin et al. (1985), Bruggeling e Huygue (1991), dentre outros.

No entanto, não existe um procedimento de cálculo que leve em conta o comportamento conjunto do bloco com o colarinho.

Estruturas compostas por pilar, bloco de fundação e cálice, apresentam comportamento pouco conhecido no meio técnico. Diversas são as dúvidas quanto à forma de transmissão das ações atuantes no pilar para o bloco por meio do cálice, quanto ao fluxo e a intensidade das tensões no conjunto e quanto ao tipo de ruína. O comportamento deste conjunto se torna ainda mais abstrato quando momentos, força horizontal e força vertical atuam de forma simultânea nestes elementos. Conhecer o comportamento do conjunto é fundamental para dimensionar corretamente os elementos. Este conhecimento pode ser obtido por meio de ensaios experimentais ou simulação numérica pelo método dos elementos finitos, que permitem a consideração da não linearidade física dos materiais. A segunda alternativa 
apresenta-se adequada, desde que os modelos estejam devidamente ajustados com resultados experimentais e apresentam as vantagens de maior rapidez e economia.

\subsection{Objetivo}

O objetivo geral deste trabalho é verificar o comportamento dos blocos sobre quatro estacas com cálice parcialmente embutido para ligação de pilar pré-moldado solicitado por força centrada e momentos nas duas direções.

Os objetivos específicos são:

- Verificar a influência da ligação entre o cálice e o pilar e a transferência de tensões na interface;

- Verificar o comportamento do conjunto bloco-colarinho quando solicitado à força centrada e momentos nas duas direções;

- Verificar a influência das diversas armaduras adotadas;

- Analisar a formação das bielas de compressão por meio de análise numérica;

- Analisar a inclinação e a intensidade das tensões nas bielas;

- Comparar os resultados com alguns procedimentos analíticos de cálculo encontrados na literatura.

\subsection{Justificativa}

Os blocos de fundação com cálice são uma solução bastante utilizada para transmissão de ações dos pilares pré-moldados para as estacas e, geralmente, são solicitados de forma simultânea por momentos nas duas direções e força centrada. A utilização de cálice parcialmente embutido tem se tornado uma tendência, já que pretensamente possuem um comportamento melhor e menor custo se comparado com cálice embutido ou cálice externo. No entanto, os estudos sobre o comportamento dos blocos com cálice encontrados na bibliografia são escassos. No caso de blocos com cálice parcialmente embutido, não foi encontrado, nenhum trabalho publicado. Isto justifica a realização deste trabalho. 


\subsection{Método}

Para atingir os objetivos deste trabalho, o conjunto bloco, cálice e pilar foi analisado por meio de simulação numérica. Para isto, foi utilizado o programa DIANA 9.4 baseado no método dos elementos finitos (M. E. F.). Nas análises variaram-se as ações, a distribuição das barras de aço, a geometria do modelo, e o tipo de ligação (lisa e rugosa). Os seguintes passos foram seguidos na realização do estudo:

- Levantamento da bibliografia existente a respeito do assunto;

- Estudo do programa que foi utilizado nas simulações numéricas;

- Análise numérica dos modelos propostos;

- Avaliação dos resultados, fluxos de tensões, inclinação e intensidade das tensões nas bielas e nas armaduras, panorama de fissuração e reação nas estacas;

-Conclusão

\subsection{Estrutura da dissertação}

A presente dissertação está estruturada em cinco capítulos, descritos na sequência.

Capítulo 1 - Introdução: apresentam-se o assunto abordado, os objetivos da dissertação, o método empregado, as justificativas para a elaboração do trabalho e a estrutura desta dissertação;

Capitulo 2 - Revisão bibliográfica: apresenta-se um relato de pesquisas realizadas a respeito de blocos de fundação, métodos de dimensionamento destes, pesquisas e métodos de cálculo relativos às paredes de colarinhos, utilizados como ligação do pilar pré-moldado com os blocos de fundação;

Capitulo 3 - Apresentação e comprovação do modelo numérico: é apresentado o modelo numérico utilizado, os parâmetros envolvidos nas análises, e os resultados de testes realizados com modelos que foram ensaiados anteriormente por outros pesquisadores com o objetivo de analisar o modelo adotado.

Capitulo 4 - Blocos sobre quatro estacas com cálice parcialmente embutido: neste capitulo, são apresentados os modelos simulados, assim como os resultados obtidos e a análise destes resultados;

Capitulo 5 - Conclusão: apresentam-se as principais conclusões obtidas a partir na análise dos resultados encontrados. 


\section{REVISÃO BIBLIOGRÁFICA}

\subsection{Considerações iniciais}

As pesquisas a respeito de blocos de fundação tiveram inicio na década de 60 , com os ensaios em modelos físicos realizados por Blévot e Frémy (1967). Desde então, alguns outros trabalhos foram desenvolvidos tanto em caráter experimental quanto numérico.

Também é possível encontrar na literatura técnica diversos estudos a respeito do comportamento das ligações de pilares pré-moldados a blocos de fundação por meio de colarinhos.

O objetivo deste capítulo é apresentar uma síntese bibliográfica a respeito dos blocos de fundação, das ligações entre pilar e bloco por meio de colarinho e dos principais métodos de dimensionamento destes elementos.

\subsection{Pesquisas com ênfase em blocos de fundação}

\subsubsection{Blévot e Frémy (1967)}

Entre os anos de 1955 e 1961 Blévot e Frémy (1967) realizaram ensaios experimentais em mais de 100 blocos de fundação sobre duas, três e quatro estacas. O objetivo de Blévot e Frémy (1967) era observar o comportamento dos mesmos quanto ao tipo de ruína e analisar a relação entre força experimental e teórica associadas à forma de ruína para os blocos dimensionados pelo método das bielas. Os pesquisadores buscaram, também, verificar a eficácia em relação à capacidade resistente e à fissuração dos modelos com diversas distribuições de barras de armaduras com áreas teoricamente equivalentes.

Os testes foram realizados em duas etapas. Na primeira, entre os anos de 1955 a 1958, os pesquisadores ensaiaram 94 modelos de blocos de fundação em escala reduzida (1/2 e 1/3 do tamanho original). Na segunda etapa, durante o período de 1958 a 1961, foram ensaiados 22 modelos de blocos de fundação construídos em tamanho real. 
Para os blocos de fundação sobre três e quatro estacas, os pesquisadores variaram a altura dos mesmos, a disposição e a natureza da superfície das barras de aço.

Para os blocos sobre quatro estacas, as disposições de armaduras adotadas por Blévot e Frémy (1967) foram: 1) armaduras dispostas segundo os lados e distribuídas somente na região limitada pela seção transversal das estacas; 2) armadura distribuída segundo os lados com distribuição no contorno das estacas; 3) armaduras dispostas segundo as diagonais e distribuída na região limitada pela seção transversal das estacas; 4) armaduras dispostas num sistema misto, mesclando armaduras dispostas nas diagonais e no contorno da estaca (mistura dos modelos 2 e 3) ; 5) armaduras distribuídas em malhas, em que a área das barras de aço adotada é equivalente à área adotada no modelo 1. Estas distribuições estão representadas na Figura 2.

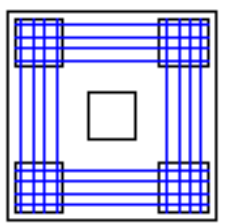

Modelo 1

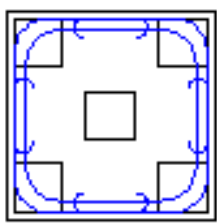

Modelo 2

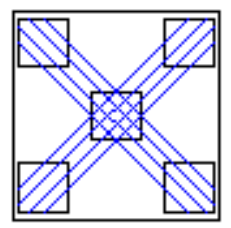

Modelo 3

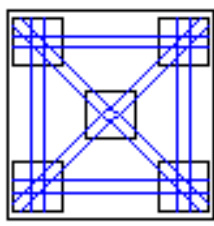

Modelo 4

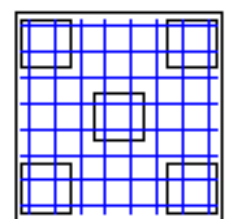

Modelo 5

Figura 2 - Distribuições de armaduras estudadas por Blevót e Fremy (1967), para blocos sobre quatro estacas. (Adaptado de Blevót e Frémy (1967)).

O modelo 5 apresentou uma relação entre força de ruína experimental e teórica cerca de $20 \%$ inferior aos demais modelos. Quando a inclinação das bielas ficou próxima a $45^{\circ}$ (entre $35^{\circ}$ e $55^{\circ}$ ), os autores verificaram que aquela relação teve uma grande variação, entre 1,6 e 2,4. Para inclinações inferiores a $35^{\circ}$ e superiores a $55^{\circ}$, as relações entre força de ruína experimental e teórica são menores. Segundo os autores, isto se deve, no primeiro caso, a fenômenos de ruína complexos difíceis de serem analisados e, no segundo caso, em virtude do esmagamento do concreto.

Quanto à fissuração na parte inferior e no meio do bloco, os autores notaram que os blocos com disposição de armaduras segundo as diagonais (modelo 3 e 4) são mais favoráveis que os outros modelos, no entanto as fissuras nas laterais abriram nas primeiras etapas do ensaio, isso é compreensível já que não existem armaduras segundo os lados. Os blocos com armaduras segundo os lados (modelos 1 e 2), por não possuírem armaduras na região entre os tirantes, foram mais afetados por fissuras nesta região, as quais se propagaram de forma significativa a partir de uma determinada força. A melhor distribuição para controlar a fissuração, segundo os pesquisadores, seria a armadura em malha. No entanto, esta apresenta 
uma eficácia na resistência de $80 \%$ em relação ao bloco com as barras de armadura disposta segundo os lados, assim Blévot e Frémy (1967) sugerem que se utilize um sistema misto em que a maior parte da força é equilibrada pelo sistema 1 ou 2, com uma parcela de armadura distribuída.

Pela complexidade do fenômeno de punção, os autores citam que não foi possível relacionar com precisão a resistência à punção com a intensidade das tensões normais, com a seção das armaduras inferiores e com as propriedades mecânicas do concreto.

Os autores afirmam que em nenhum modelo houve ruína por punção nos blocos. Os pesquisadores indicam que blocos calculados pelo método das bielas não apresentam riscos de ruína por punção, desde que respeitadas as inclinações das bielas e as propriedades mecânicas do concreto.

Para os blocos sobre três estacas, da mesma forma que para aqueles sobre quatro estacas, variaram-se as disposições da armadura, sendo elas: 1) armaduras dispostas segundo os três lados; 2) armaduras dispostas segundo as laterais de forma a abraçar as estacas; 3) armaduras dispostas segundo as três medianas do triângulo formado pelo centro da seção das estacas; 4) combinação do modelo 1 e 3 com armaduras dispostas segundo os lados e as diagonais; 5) armadura dispostas em malha. Estas distribuições estão representadas na Figura 3.

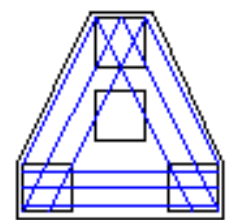

Modelo 1

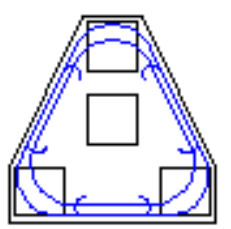

Modelo 2

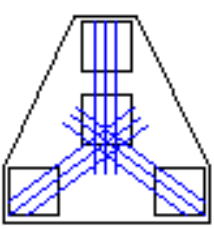

Modelo 3

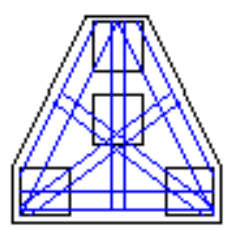

Modelo 4

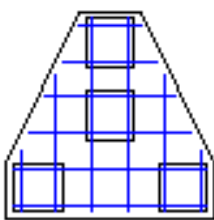

Modelo 5

Figura 3 - Distribuição de armaduras estudadas por Blevót e Fremy (1967), para blocos sobre três estacas. (Adaptado de Blevót e Frémy (1967)).

Para os modelos de 1 a 4, as armaduras foram determinadas pelo modelo das bielas e tirantes. Para o modelo 5 como não é possível se determinar a área de aço pelo modelo de bielas e tirantes os pesquisadores adotaram a mesma área de aço utilizada para os outros modelos.

Os modelos 1, 2 e 4 apresentaram comportamentos equivalentes nos casos de forças de ruína. Os blocos com armaduras dispostas segundo as medianas (modelo 3), apresentaram uma relação entre força de ruína experimental e teórica, menor que seus correspondentes do modelo 1 e 2. Para o caso de armadura distribuída em malha, esta mesma relação foi pequena, de modo que Blevót e Fremy (1967) não recomendam seu uso. 
A relação entre a força de ruína experimental e a teórica para os blocos com inclinação das bielas entre $40^{\circ}$ e $55^{\circ}$ nos modelos 1 , 2, e 4 ficaram entre 1,6 e 2,4. Para inclinações inferiores a $40^{\circ}$ e superiores a $55^{\circ}$, esta relação foi menor.

Quanto ao comportamento à fissuração, foi verificado que o sistema 1 apresenta resultados melhores que os sistemas 2 e 3. O sistema que se demonstrou mais favorável foi o 4, no qual as armaduras estão dispostas segundo as laterais e as diagonais. De uma forma geral os sistemas 1 e 2 apresentaram os melhores resultados por retardarem o aparecimento das fissuras.

Os pesquisadores não observaram ruína por punção, apenas fissuras inclinadas por causa das reações das estacas.

\subsubsection{Mautoni (1972)}

Mautoni (1972) apresentou um trabalho pioneiro no Brasil na área de análise de blocos de fundação. Ele ensaiou blocos sobre duas estacas, com a finalidade de verificar o tipo de ruína e a força última dos modelos.

Mautoni (1972) utilizou vinte modelos e adotou dois tipos de armadura; em laçada na horizontal e em forma de bigode.

Os modelos romperam por fendilhamento das bielas, e as fissuras se desenvolveram inclinadas e paralelas às bielas de compressão. Observando-se a Figura 4, percebe-se claramente que a ruína ocorreu por causa das tensões transversais à biela.

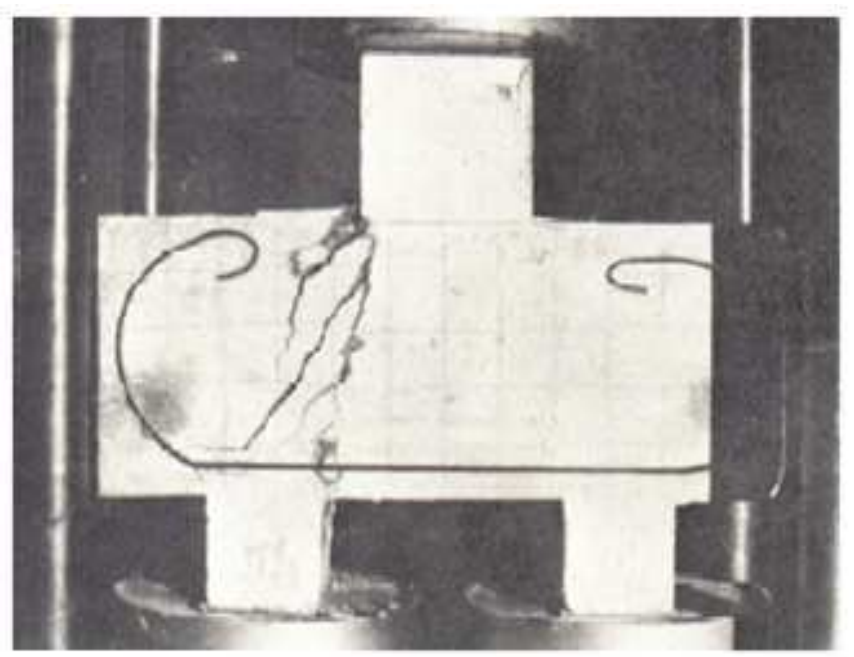

Figura 4 - Tipo de ruína do bloco ensaiado por Mautoni (1972). (Fonte: Mautoni (1972)). 
Quanto ao tipo de armadura, o pesquisador, concluiu que a armadura em bigode apresenta um elevado consumo de aço. Já a armadura em laçada diminuiu a altura útil do bloco além de ser de difícil montagem.

Mautoni (1972), baseado nos estudos, propõe um procedimento para determinar a força última.

\subsubsection{Taylor e Clarke (1976)}

Os pesquisadores ensaiaram blocos de fundação com o objetivo de avaliar três tipos de arranjos de armaduras e quatro tipos de ancoragens. Foram analisadas as distribuições em malha, armaduras dispostas segundo os lados e segundo as diagonais sendo as duas últimas concentradas sobre as estacas. A Figura 5 apresenta os tipos de arranjo das armaduras. Os tipos de ancoragem estudados foram: ancoragens com barra reta; com gancho; com gancho prolongado até a superfície do bloco e armadura com gancho na superfície. Estes arranjos estão representados na Figura 6.

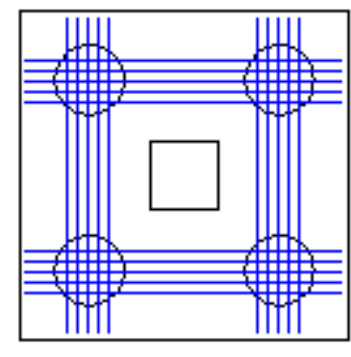

Armadura segundo os lados

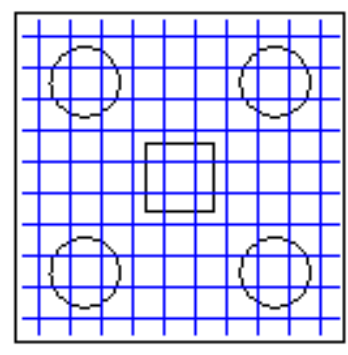

Armadura em malha

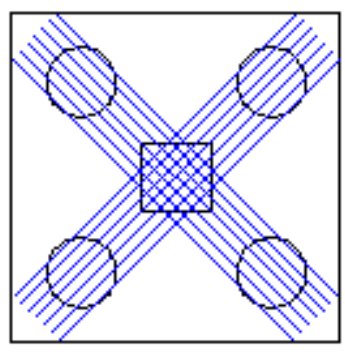

Armadura segundo as diagonais

Figura 5 - Distribuições das armaduras estudadas por Taylor e Clarke (1976). (Adaptada de Taylor e Clarke (1976)).
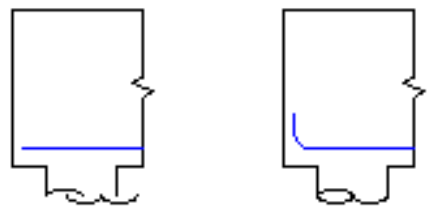

Ancoragem A Ancoragem B
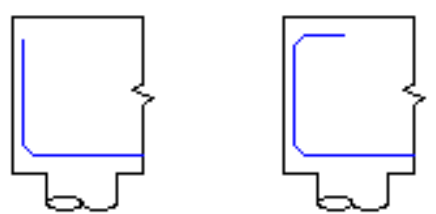

Figura 6 - Tipos de ancoragem ensaiados por Taylor e Clarke (1976). (Adaptada de Taylor e Clarke (1976)).

Os blocos com armadura segundo os lados e com tipo de ancoragem A e B suportaram uma força última cerca de $15 \%$ superior à dos blocos com os outros dois tipos de disposição 
das barras das armadura, no entanto o modo de ruína foi praticamente o mesmo, conforme pode ser visto na Figura 7. A ruína ocorreu basicamente por dois tipos de cisalhamento, um semelhante ao cisalhamento de vigas e outro, por punção na região central do bloco.
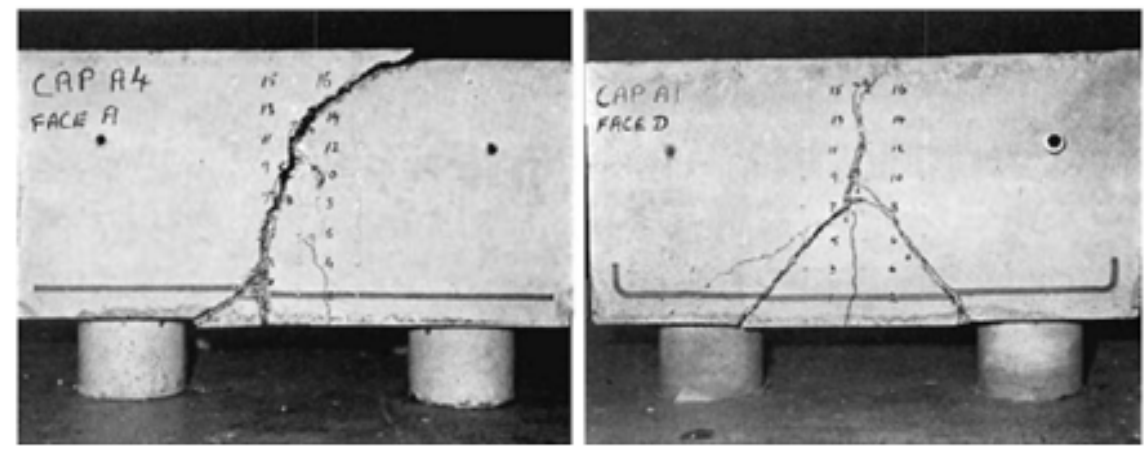

Figura 7 - Ruína dos modelos ensaiados por Taylor e Clarke (1976). (Fonte: Taylor e Clarke (1976)).

O tipo de ancoragem influenciou de maneira mais significativa a força de ruína do bloco com armadura distribuída em malha, sendo que a força última para o tipo de ancoragem do tipo C foi $30 \%$ superior aos blocos com armadura ancorada com o tipo A. Já o tipo B teve força última cerca de $5 \%$ superior em relação ao tipo A.

\subsubsection{Adebar et al. (1990)}

Adebar et al. (1990) ensaiaram cinco blocos sobre quatro estacas e um sobre seis estacas, com o objetivo de verificar os procedimentos de dimensionamento propostos pela norma de concreto americana ACI 318 (1983) e o método das bielas e tirantes.

Os blocos foram construídos com altura de $60 \mathrm{~cm}$. Os pilares possuíam seção quadrada com $30 \mathrm{~cm}$ de lado e as estacas pré-moldadas, seção circular com de $20 \mathrm{~cm}$ de diâmetro. As disposições das barras das armaduras estão representadas na Figura 2, assim como a geometria dos blocos. 

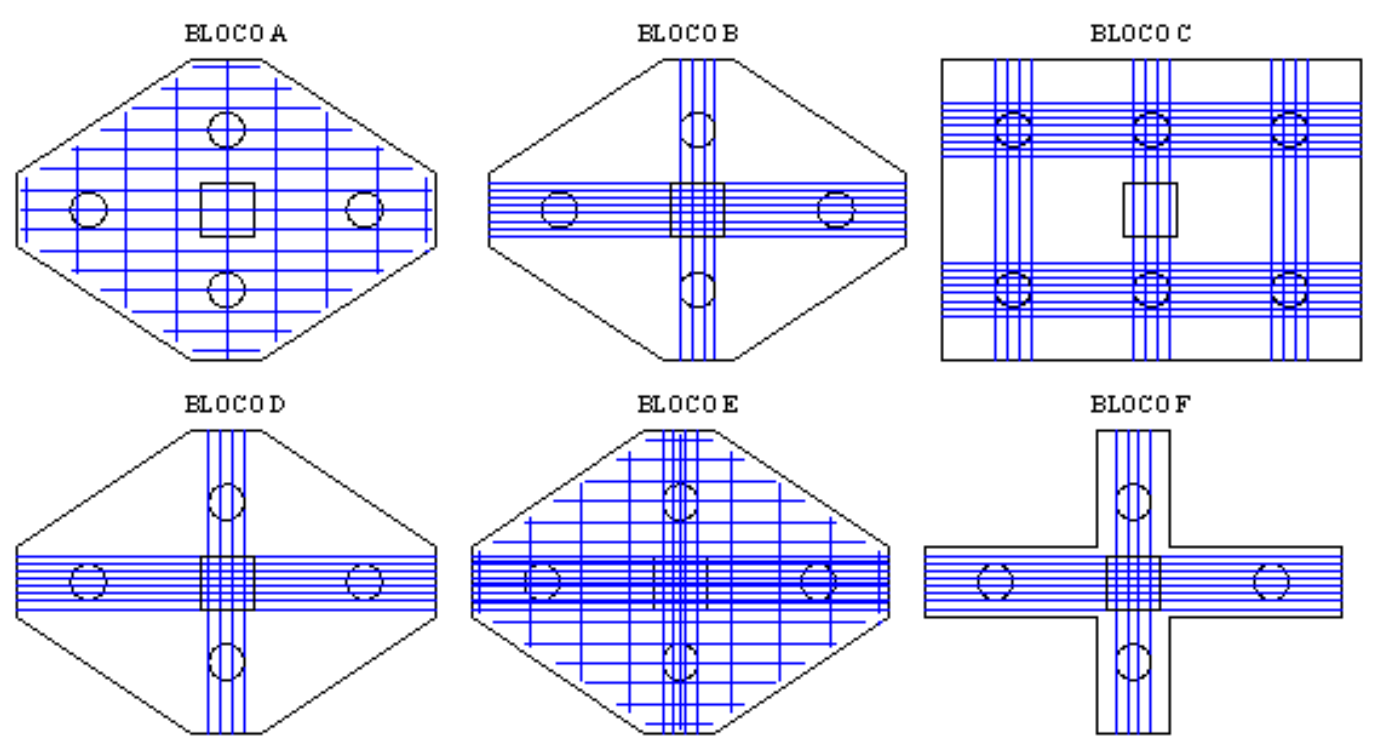

Figura 8 - Blocos ensaiados por Adebar et. al (1990). (Adaptada de Adebar et. al (1990)).

Considerando as recomendações de projeto do ACI 318 (1983), os pesquisadores dimensionaram o bloco A para uma força de ruína de $2000 \mathrm{kN}$. Os blocos B e D foram projetados pelo método das bielas para uma força de $2000 \mathrm{kN}$, no entanto o bloco D foi armado com o dobro de armadura do bloco B pois os pesquisadores queriam investigar o comportamento do bloco antes da ruína por plastificação das armaduras. As armaduras adotadas no bloco F são semelhantes às empregadas no bloco D. As diferenças existentes entre os modelos podem ser observadas na Figura 8.

O bloco C foi projetado pelo método das bielas para uma força de $3000 \mathrm{kN}$, porém, este apoiado sobre seis estacas, com distribuição das armaduras sugeridas pelo ACI 318 (1983). O bloco E foi construído com a mesma área de aço do bloco D, contudo, com armadura em malha.

Os pesquisadores observaram que a força de ruína do bloco A foi cerca de $83 \%$ da esperada e a ruptura ocorreu por tensões de tração transversais à biela. A ruína do bloco B ocorreu com uma força 9\% superior à estimada em projeto. No ensaio deste bloco, os pesquisadores constataram que, até o escoamento das armaduras do tirante posicionados nas direções de menor distância entre o pilar e as estacas, a maior parte da força aplicada era resistida pelas estacas mais próximas ao pilar. Após o escoamento do tirante nesta direção, houve uma redistribuição significativa das forças nas estacas, até a ruína por fendilhamento da biela. O tirante na outra direção não escoou. 
A ruína do bloco $\mathrm{C}$ e a distribuição da reação nas estacas foram semelhantes as que ocorreram no bloco $\mathrm{B}$, sendo que as estacas mais próximas ao pilar resistiram à maior parte da força.

O bloco E suportou mais força que o D por causa da distribuição das barras da armadura e da maior resistência do concreto, e ocorreu a ruptura do concreto antes do escoamento das armaduras dos tirantes.

No bloco D, a ruína ocorreu para uma força semelhante a do bloco F. A diferença foi de apenas 7\% entre elas, ficando ambas próximas às previsões feitas pelo método das bielas. Inicialmente, a previsão de força de ruína do bloco D, feita pelo método do ACI 318 (1983), era de $63 \%$ da força de ruína do bloco $\mathrm{F}$. O bloco $\mathrm{F}$ foi ensaiado com o objetivo de verificar o método de dimensionamento proposto pelo ACI 318 (1983) e foi observado que este não se comporta como um elemento à flexão, pois as tensões de tração nas armaduras do tirante não diminuem de forma significativa ao longo do vão.

Apesar do escoamento observado nas armaduras situadas sobre as duas estacas menos espaçadas, a deformação vertical no meio do bloco foi pequena. Isso ocorreu por causa da redistribuição das forças para as outras estacas.

Também foram obtidas, por meio de extensômetros fixados na armadura, as deformações horizontais ao longo da altura em uma seção do meio do vão entre o pilar e a estaca do bloco A, e as deformações ao longo do tirante. Os resultados são apresentados na Figura 9. Percebe-se que as deformações não variam linearmente, comprovando-se que estes modelos não se comportam como elementos fletidos.
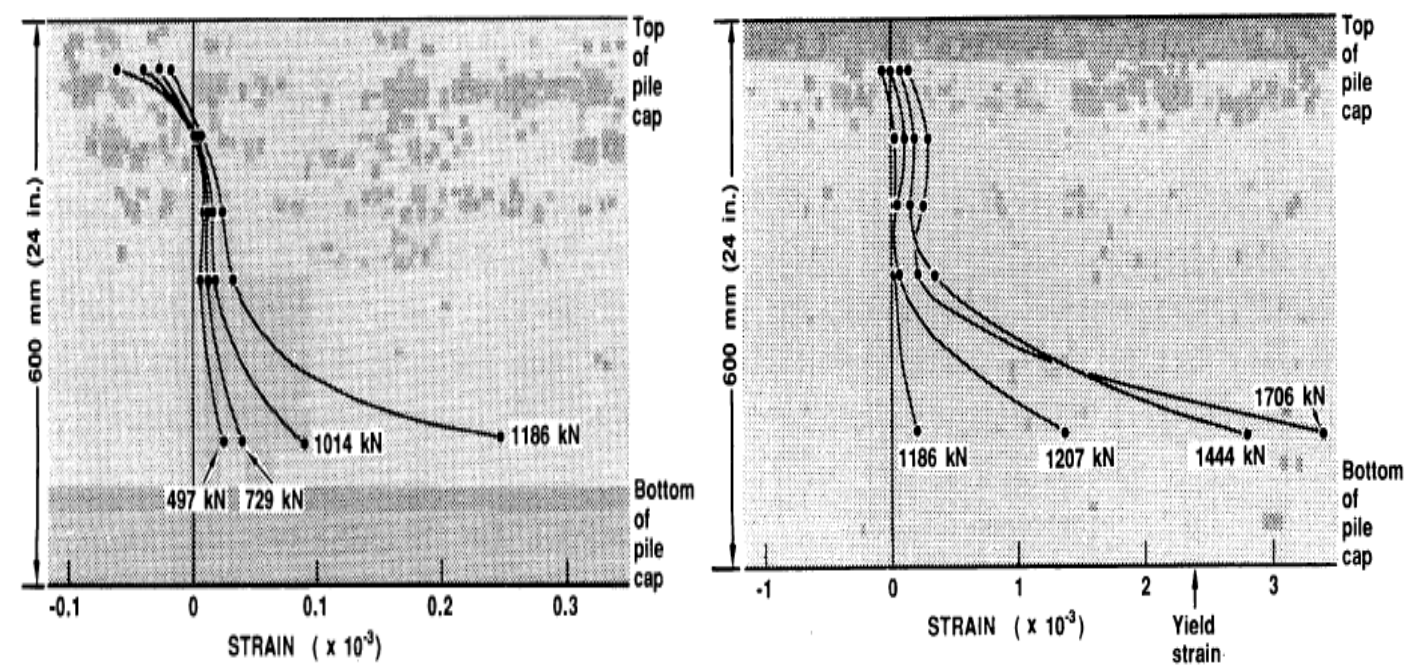

Figura 9 - Deformação horizontal ao longo da altura do bloco. (Fonte: Adebar et al. (1990)). 
A tensão nas barras da armadura do tirante é máxima no meio do vão e, sobre as estacas, vale $75 \%$ do valor máximo. Por causa disso, essa armadura funciona basicamente como um tirante.

A ruína em todos os blocos ensaiados ocorreu por fendilhamento, assim, Adebar et al. (1990) propuseram um modelo de bielas e tirantes, com um tirante disposto transversalmente a biela, de forma que estas armaduras resistam às tensões transversais que provocam o fendilhamento destas bielas.

\subsubsection{San e Iyer (1995)}

San e Iyer (1995) estudaram, por meio de ensaios experimentais e simulações numéricas, o comportamento de blocos sobre quatro estacas, submetidos a carregamento centrado, e com três distribuições das barras das armaduras, sendo elas: segundo os lados; segundo as diagonais e barras distribuídas em duas direções perpendiculares.

Os pesquisadores observaram nos ensaios experimentais que os blocos com armadura em malha e armadura segundo as diagonais resistiram a uma força maior que os blocos com armaduras segundo os lados (cerca de 10\% mais para o caso de armadura em malha e $8 \%$ no caso de armadura segundo as diagonais).

Esta mesma tendência foi observada nos modelos numéricos, sendo que a força de ruína foi cerca de 7\% maior para os blocos com armadura distribuída e segundo as diagonais se comparados com a força de ruptura dos blocos com armadura segundo os lados.

Estes resultados não condizem com os resultados obtidos por Blévot e Frémy (1967) nem com os de Adebar et al. (1990) que indicaram que a melhor distribuição de armaduras é a com os tirantes segundo os lados.

Outro fato observado pelos pesquisadores é que, antes da fissuração, o bloco trabalha como uma viga e, após a fissuração, as deformações nas armaduras são uniformes ao longo do comprimento, funcionando como um tirante e formando uma biela de compressão.

\subsubsection{Chan e Poh (2000)}

Com o objetivo de comparar o comportamento de blocos pré- moldados com os blocos convencionais Chan e Poh (2000) ensaiaram três blocos, dois pré-moldados e um moldado no local. 
Os blocos pré-moldados foram construídos criando-se uma caixa de concreto cujas paredes possuíam espessura de 7,5 cm com todas as armaduras do bloco ancoradas nestas paredes de concreto. O interior do bloco foi preenchido com concreto moldado in loco. A configuração dos blocos é apresentada na Figura 10.
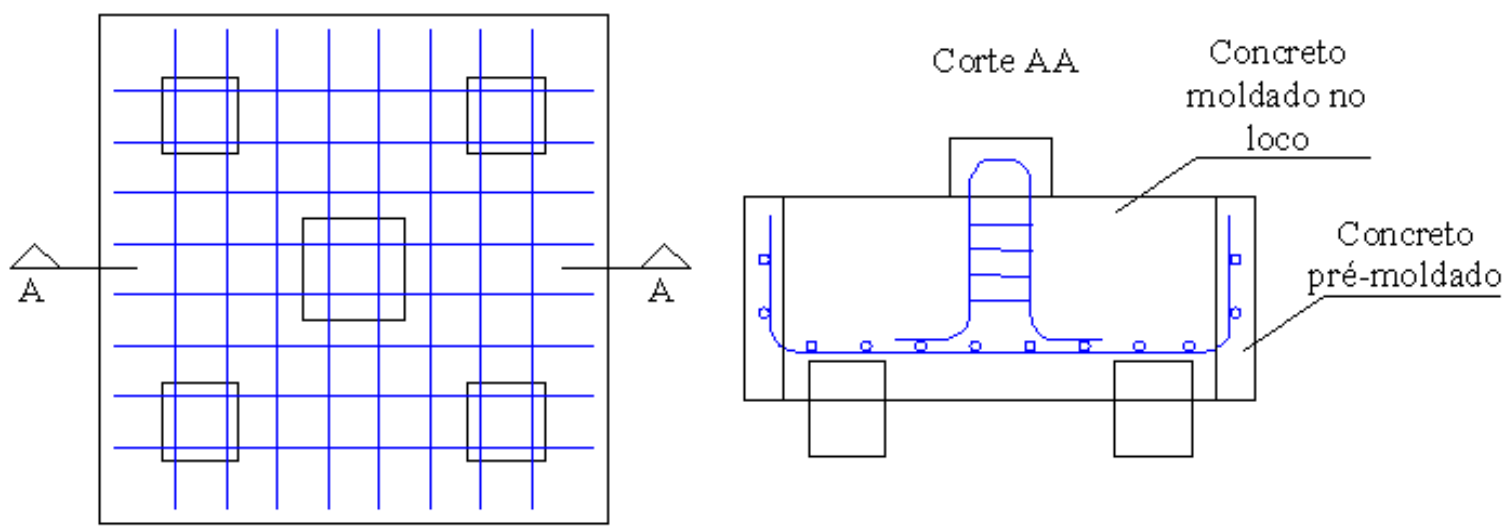

Figura 10 - Bloco Ensaiado por Chan e Poh (2000). (Adaptado de Chan e Poh (2000)).

Chan e Poh (2000) notaram que os blocos pré-moldados tiveram comportamento semelhante ao bloco convencional tanto na fissuração quanto na força de ruína. O que foi observado nesta pesquisa é compreensível, já que não se trata, de certa forma, de blocos prémoldados, e sim da criação de uma fôrma de concreto, que facilita a concretagem no canteiro de obra.

\subsubsection{Miguel (2000)}

Miguel (2000) ensaiou e simulou numericamente blocos sobre três estacas. O objetivo da pesquisadora era estudar o comportamento destes blocos e verificar a influência da seção transversal das estacas assim como da armadura secundária.

Os resultados indicaram que a ruptura dos modelos ocorreu por fendilhamento das bielas, e pelo escoamento das barras da armadura longitudinal.

A pesquisadora também sugeriu valores para as tensões na ligação entre as estacas e bloco e entre a ligação pilar e bloco.

Miguel (2000) também concluiu que os resultados obtidos através do método das bielas sugerido por Blévot \& Frémy (1967) é conservador em relação aos resultados obtidos em sua pesquisa. 


\subsubsection{Munhoz (2004)}

Munhoz (2004) estudou blocos de fundação sobre duas, três, quatro, e cinco estacas submetidos à força centrada por meio de simulações numéricas. Seu objetivo foi verificar a influência da seção transversal das estacas e dos pilares no comportamento do bloco e a viabilidade do emprego dos processos de dimensionamento adotados na literatura.

A pesquisadora adotou, em seus modelos numéricos, comportamento elástico linear para os materiais. Por meio da análise dos resultados, constatou, para os blocos sobre quatro estacas, que o fluxo de tensão é dependente da geometria do pilar. Observou ainda que a intensidade das tensões de compressão ao longo das bielas foi maior para os pilares quadrados, diminuindo gradativamente conforme se alongou o pilar. Já as tensões de tração foram semelhantes.

A mudança na forma de distribuição das tensões também foi verificada no caso de variação da seção da estaca. Neste caso, as tensões principais de tração foram diferentes, sobretudo para os blocos sobre duas estacas. No caso de blocos sobre quatro estacas, estas diferenças não foram tão significativas.

Munhoz (2004) conclui que a configuração das bielas e dos tirantes deve ser adaptada conforme a geometria do pilar e que o modelo adotado na literatura que considera um pilar quadrado equivalente não é adequado na maioria das vezes.

\subsubsection{Delalibera (2006)}

Delalibera (2006) analisou experimentalmente quatorze blocos sobre duas estacas, e simulou oito modelos, numericamente, no programa ANSIS. O objetivo deste trabalho foi verificar a formação das bielas, a contribuição dos ganchos das armaduras principais e propor um modelo refinado de bielas e tirantes. O pesquisador dimensionou os modelos segundo as recomendações de Blévot e Frémy (1976) e ABNT NBR 6118:2003

Os modelos ensaiados por Delalibera (2006) possuíam variação na geometria e dimensão do pilar e da estaca, na altura dos blocos, na excentricidade do carregamento e no arranjo das armaduras.

O pesquisador observou que a ruína ocorreu por ruptura da biela junto ao pilar ou junto à estaca, após intensa fissuração paralela à biela em todos os blocos.

Quanto à altura dos blocos, Delalibera (2006) observou que os blocos com maiores inclinações das bielas tiveram maior capacidade resistente. O pesquisador constatou que a 
geometria do pilar tem influência significativa na capacidade resistente do bloco. Houve aumento da força resistente no caso da utilização de armaduras complementares, no entanto Delalibera (2006) alerta que estas só contribuem quando cruzam as bielas, absorvendo assim as tensões de fendilhamento.

Delalibera (2006) verificou que, para o caso de força excêntrica, as bielas são solicitadas de maneira diferente, assim a ruína do bloco, ocorreu por ruptura da biela mais solicitada e a força de ruína do bloco diminuiu.

Semelhante ao constatado nos trabalhos de Adebar et al. (1990), Delalibera também observou que há uma redução significativa da tensão dos tirantes do bloco na seção central da estaca, deduzindo assim a possibilidade de não detalhar as barras dos ganchos nas extremidades. A ABNT NBR 6118:2003, sugere que as armaduras dos tirantes sejam ancoradas nas suas extremidades com ganchos.

Após as observações feitas nas investigações experimentais e numéricas, Delalibera (2006) propõe um modelo de bielas e tirantes para o dimensionamento de blocos sobre duas estacas, assim como o dimensionamento de uma armadura de fendilhamento com o objetivo de limitar a fissuração paralela às bielas para aumentar a capacidade resistente destas.

\subsubsection{Ramos (2007)}

Ramos (2007) estudou o fluxo de tensões e suas direções principais, em blocos sobre dez estacas solicitados por força centrada e força centrada e momento por meio de análise numérica baseada no método dos elementos finitos

Além do carregamento, o pesquisador variou a altura do bloco, a resistência à compressão do concreto e a vinculação das estacas.

Ramos (2007) observou que as reações nas estacas, no caso de apoios deformáveis e carregamento centrado, têm uma tendência de uniformização. O mesmo não ocorre no caso de apoio indeformável sendo que as estacas mais próximas ao pilar são mais solicitadas. Para força excêntrica, em ambos os casos de vinculação, a distribuição das reações nas estacas não é uniforme e as diferenças entre os valores obtidos na simulação numérica e no modelo analítico são significativas.

A resistência do concreto não alterou o comportamento do bloco. Já a altura dos blocos interferiu principalmente na distribuição das tensões principais. O pesquisador observou que nos blocos com maior altura, apesar de todos os modelos serem classificados como rígidos, as tensões nas cabeças das estacas foram mais uniformes. 
Para os blocos solicitados a momento, o pesquisador observou que as reações nas estacas não são iguais ao cálculo analítico feito por meio da equação deduzida da análise considerando uma seção transversal submetida a flexão normal composta. A diferença superou $200 \%$ em alguns casos.

Ramos (2007) conclui que o tipo de vinculação tem grande influência no comportamento dos blocos, sendo necessária uma adequada adaptação das vinculações ao comportamento do solo.

\subsubsection{Souza et al. (2007)}

Os pesquisadores propuseram um modelo de bielas e tirantes adaptado ao caso de forças com excentricidade limitada pelo perímetro do pilar, conforme Figura 11.

Neste modelo, as bielas originam-se do ponto de aplicação da força (ponto excêntrico) e terminam nas faces superiores das estacas. Desta forma, as bielas possuem inclinações diferentes. Para o cálculo das forças nos tirantes e nas bielas, é feito o equilíbrio dos nós coincidentes com as estacas.
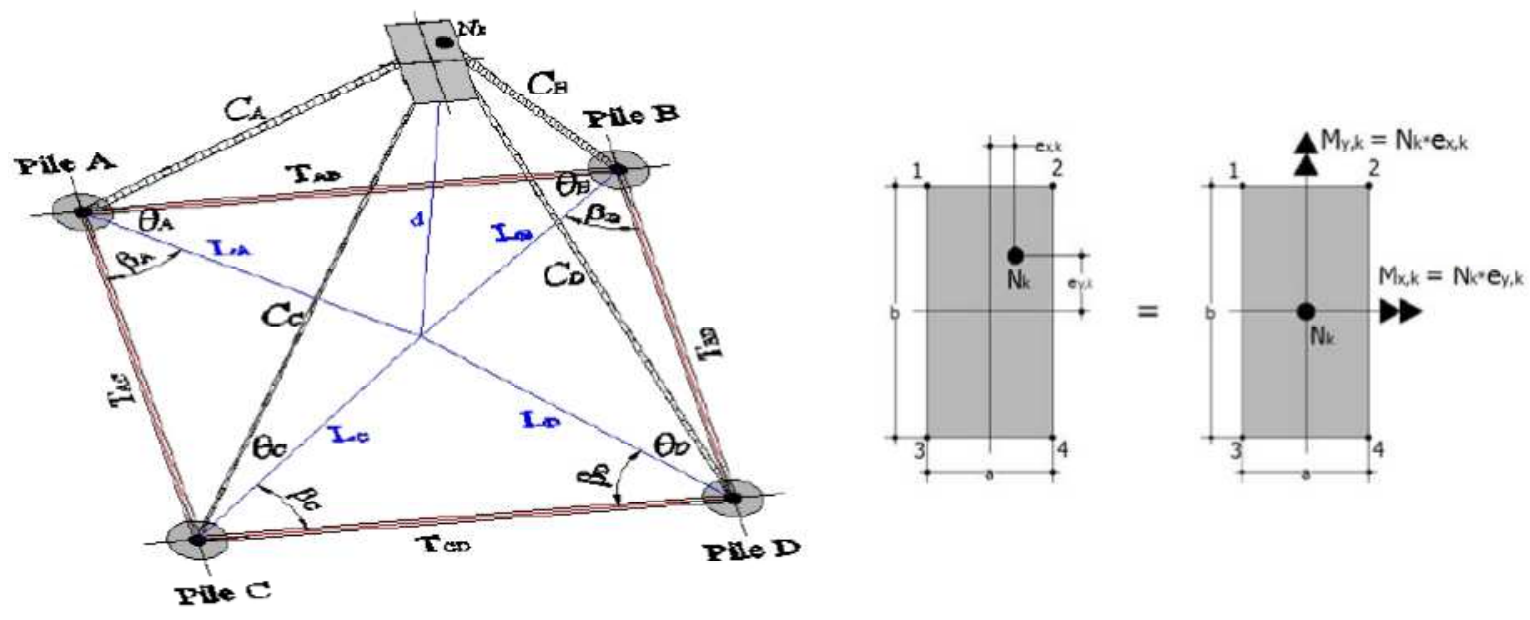

Figura 11 - Modelo de bielas e tirantes proposto por Souza et al. (2007). (Fonte: Souza et al. (2007)).

Para confirmar o modelo proposto, Souza et al. (2007) compararam os resultados obtidos a partir do modelo proposto com os resultados de simulações numéricas de blocos ensaiados experimentalmente e encontrados na literatura, e observaram que o modelo de bielas e tirantes conduz a resultados satisfatórios e a favor da segurança. 
Souza et al. (2007), observando os resultados obtidos nas simulações numéricas, sugerem que o valor limite da resistência à compressão do concreto junto ao pilar seja admitida igual à resistência característica do concreto à compressão.

\subsubsection{Campos (2007)}

Campos (2007) estudou três blocos sobre duas estacas com cálice externo. Os modelos ensaiados pelo pesquisador foram construídos em escala reduzida de 1:2 e solicitados por força centrada. O objetivo era investigar a influência do colarinho e do comprimento de embutimento, no caso de ligação com chave de cisalhamento entre pilar e colarinho, no comportamento do bloco.

O pesquisador observou durante os ensaios, que a primeira fissura surgiu na face inferior e na região central do bloco, quando a força atingiu aproximadamente $60 \%$ da força de ruína. Esta fissura propagou-se na sequência do ensaio para as laterais do bloco.

A ruína do bloco ocorreu por ruptura simultânea das bielas junto à estaca e junto ao pilar.

As deformações dos tirantes medidas no meio do vão do bloco e na seção central da cabeça das estacas apresentaram a mesma ordem de grandeza.

As reações nas estacas foram praticamente as mesmas para cada ensaio. A pequena diferença, provavelmente foi ocasionada por excentricidades acidentais na aplicação da força.

Campos (2007) concluiu que os cálices com comprimentos de embutimento maiores melhoram o comportamento do bloco e diminuem a quantidade de aço.

\subsubsection{Barros (2009)}

Entre os poucos estudos realizados a respeito de blocos com cálice para ligação de pilar pré-moldado encontra-se o de Barros (2009) que, por meio de análise numérica, estudou blocos sobre duas estacas com cálice embutido. Seus objetivos foram: verificar o comportamento dos blocos com a ligação entre pilar e bloco feitas com e sem chave de cisalhamento; estudar a influência da viga de travamento nestes tipos de blocos de fundação.

Barros (2009) simulou, utilizando o programa DIANA 9.4, 24 modelos que possuíam variação na altura dos blocos, na conformação da ligação entre pilar e bloco, e presença ou não de viga de travamento. 
A viga de travamento não alterou significativamente o comportamento do bloco. Esse fato só não foi verificado quando a inclinação da biela foi de $55^{\circ}$ e ligação rugosa, sendo que a viga de travamento diminuiu a força de ruína em $7 \%$ a $14 \%$.

O pesquisador constatou que o fluxo de tensões principais iniciou a partir do encontro do pilar com o bloco, tanto para ligação lisa quanto para ligação rugosa. No caso de ligação sem chave de cisalhamento, o fluxo inicia de forma menos intensa. Barros (2009) observou, ainda, que existe um fluxo de tensões na parte inferior ao pilar que poderia ocasionar punção.

Barros (2009) constatou que as armaduras do tirante são mais solicitadas na região central do bloco, com significativa redução na região central das estacas, por causa da contribuição da força de compressão da biela. Este fato também foi observado por Delallibera (2006) e por Adebar et al. (1990).

Quando Barros (2009) comparou os resultados analíticos com os numéricos observou que os ângulos de inclinação das bielas foram maiores para o caso numérico.

O autor concluiu que a presença da viga de travamento não influência de modo significativo o comportamento do bloco, que a distribuição de tensões nas estacas pode variar em função da vinculação adotada e que as inclinações das bielas são maiores que as adotadas nos procedimentos analíticos.

\subsubsection{Marek (2010)}

Marek (2010) estudou blocos sobre quatro estacas com cálice embutido, com o objetivo de verificar a influência do comprimento de embutimento, da conformação da parede do cálice, da altura do bloco, e da excentricidade da força atuante.

As dimensões dos blocos estudados por Marek (2010) eram de $190 \mathrm{~cm}$ x $190 \mathrm{~cm}$. Os pilares e as estacas tinham seção quadrada com $40 \mathrm{~cm}$ e $30 \mathrm{~cm}$ de lado, respectivamente. Para a laje de fundo, o autor analisou duas alturas: $20 \mathrm{~cm}$ e $30 \mathrm{~cm}$.

O pesquisador observou que, nos blocos com ligação rugosa, o fluxo das tensões principais de compressão começa a se formar no inicio da ligação entre o pilar e o bloco e seguem até a cabeça das estacas, caracterizando a formação das bielas. Para o caso de força excêntrica, este fluxo foi mais pronunciado no sentido do momento e as forças de ruína foram menores.

Para o caso dos blocos com interface lisa, o pesquisador observou que não houve a formação das bielas, sendo a força transferida diretamente para o fundo do bloco. 
O aparecimento e a abertura das fissuras ocorreram de forma gradual no caso da ligação sem chave de cisalhamento. No caso de ligação com chave de cisalhamento, observou-se o aumento repentino do número de fissuras e da abertura das mesmas no limite do regime elástico dos modelos.

Marek (2010) observou que, para o caso de ligação com chave de cisalhamento, as armaduras do tirante e as armaduras distribuídas no meio do bloco atingiram o escoamento com as tensões variando ao longo do comprimento das barras com significativa redução na seção central da estaca. As outras armaduras foram pouco solicitadas. Para o caso de ligação lisa, as armaduras de distribuição no fundo do bloco atingiram o escoamento e as armaduras dos tirantes não foram tão solicitadas, assim como as demais armaduras.

$\mathrm{O}$ pesquisador observou que as primeiras fissuras surgiram na face inferior e no meio do bloco e progrediram em direção as faces laterais.

Marek (2010) determinou a inclinação das bielas calculando a força nas mesmas e com isso fazendo o equilíbrio do nó. Observou que, para o último passo de força, as inclinações das bielas são maiores que os valores analíticos.

As principais conclusões de Marek (2010) foram: para as duas alturas $20 \mathrm{~cm}$ e $30 \mathrm{~cm}$, independente do tipo de ligação adotada, deve-se verificar a punção já que as armaduras de distribuição foram bastante solicitadas; o comportamento dos blocos com chave de cisalhamento assemelha-se ao comportamento de bielas e tirantes sugerido por Blévot e Frémy (1967); nos modelos com ligação sem chave se cisalhamento não se verificou a formação das bielas.

\subsubsection{Buttignol (2011)}

Buttignol (2011), utilizando o programa computacional Atena 3D, baseado no método dos elementos finitos, verificou o comportamento de blocos de fundação sobre duas e três estacas, utilizando análise não linear.

Os modelos escolhidos pelo autor, para realizar a análise numérica, foram os ensaiados nas pesquisas de Miguel (2000) e Delalibera (2006). Além disso, Buttignol (2011) fez variações na geometria e na vinculação das estacas nestes modelos.

Analisando os resultados, Buttignol (2011) observou que existem divergências entre os resultados numéricos e experimentais, dentre as quais o autor destaca a rigidez dos modelos, (modelos numérico mais rígido) e a redistribuição do fluxo de tensão nas estacas devido à variação da vinculação. 
Buttignol (2011) concluiu que a capacidade portante do bloco é influenciada pela vinculação, geometria das estacas e do pilar, embutimento da estaca no bloco e da existência da armadura de fendilhamento.

Além disso, o pesquisador observou a existência de tensões de tração ao longo das bielas, o que ocasionou o fendilhamento do bloco.

Buttignol (2011) concluiu que todos os blocos simulados tiveram ruína frágil, com ruptura do concreto.

\subsection{Critérios de dimensionamento de blocos sobre estacas}

\subsubsection{Reações nas estacas}

As reações nas estacas dependem muito das propriedades mecânicas do solo em que estão inseridas e da flexibilidade do bloco de fundação. No caso de blocos considerados rígidos, as reações nas estacas podem ser determinadas pela Equação 2.1 apresentada por Schiel (1957) com as posições das reações definidas na Figura 12, sendo que a equação 2.1 foi baseada na equação que rege seções transversais submetidos à flexão composta, nos casos de meios infinitamente rígidos.

Quando se adotam blocos flexíveis, essas reações devem ser verificadas de forma mais detalhada, tendo em vista que os blocos não distribuem uniformemente as forças para as estacas, devido a sua deformabilidade.

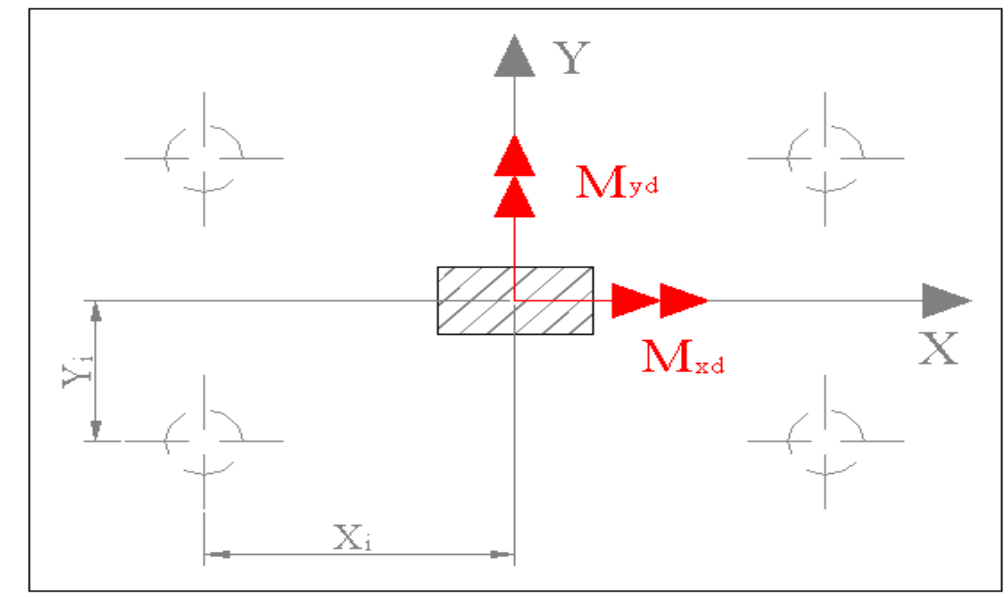

Figura 12 - Distribuição de reação nas estacas proposta por Schiel (1957). 


$$
R_{i d}=\frac{N_{S d}}{n} \pm \frac{M_{S y d} \cdot X_{i}}{\sum_{i=1}^{n} X_{i}^{2}} \pm \frac{M_{S x d} \cdot Y_{i}}{\sum_{i=1}^{n} Y_{i}^{2}}
$$

Sendo:

$R_{i d}=$ reação na estaca $\mathrm{i} ;$

$N_{S d}=$ força centrada aplicada;

$M_{S y d}=$ momento atuante em torno eixo Y;

$M_{S x d}=$ momento atuante em torno eixo X;

$n=$ número de estacas;

$X_{i}$ e $Y_{i}=$ coordenadas dos centro da estaca $\mathrm{i}$.

Munhoz (2004), Adebar et.al (1990) e Ramos (2007) observaram que a maior parte da força é absorvida pelas estacas mais próximas ao pilar, o que não traduz os resultados calculados pela expressão anterior. Uma possível justificativa é o fato dos blocos não possuírem rigidez infinita e o equilíbrio das forças internas seguir o princípio da mínima energia.

\subsubsection{Classificação dos blocos}

Os blocos de fundação são classificados como rígidos ou flexíveis. Essa classificação indica o método de dimensionamento que deve ser adotado e, geralmente, é feita comparandose a altura útil do bloco, com uma altura limite. A altura limite depende da geometria do pilar, do bloco e da estaca e varia de acordo com a bibliografia consultada.

A ABNT NBR 6118:2003 classifica os blocos a partir da Equação 2.2. Para valores da altura do bloco que respeitem a Equação 2.2, os blocos são classificados como rígidos.

$$
h=\frac{a-a_{p}}{3}
$$

Sendo:

$h=$ altura do bloco;

$a=$ distância entre o centro de gravidade do pilar e o de uma estaca;

$a_{p}=$ dimensão do pilar na mesma direção de a. 
No caso de blocos rígidos, estes podem ser dimensionados pelo modelo de bielas e tirantes e modelos tridimensionais lineares, sendo o primeiro o mais recomendado pela ABNT NBR 6118:2003. No caso de blocos flexíveis, a norma recomenda que seja verificada, de forma detalhada, a distribuição de forças nas estacas e nos tirantes. Também é necessária a verificação à punção.

Blévot e Frémy (1967) recomendam a Equação 2.3 para a determinação das alturas limites dos blocos sobre quatro estacas. Estas alturas correspondem às inclinações das bielas no intervalo entre $40^{\circ}$ e $55^{\circ}$. Na Equação $2.3, \ell_{\mathrm{e}}$ é o espaçamento entre estacas medido a partir do centro das mesmas.

$$
0,71 \cdot\left(\ell_{e}-\frac{a_{p}}{2}\right) \leq d<\left(\ell_{e}-\frac{a_{p}}{2}\right)
$$

De acordo com o Boletim 73 do CEB-FIP (1970), os blocos são considerados rígidos quando sua altura respeita os limites determinados pela Equação 2.4, sendo, $\ell_{c}$ é a distância da face do pilar à linha central da estaca, conforme Figura 13.

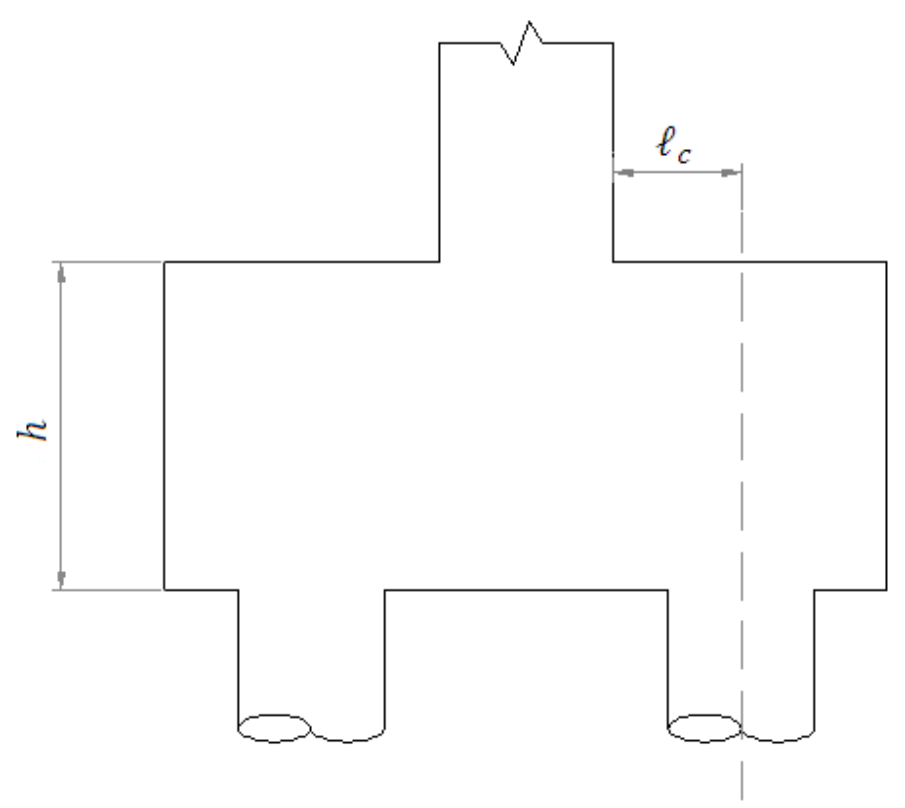

Figura 13 - Representação da seção do modelo sugerido pelo CEB-FIP (1970).

$$
\frac{2}{3} \cdot \ell_{c} \leq h \leq 2 \cdot \ell_{c}
$$


No caso em que a altura do bloco seja inferior ao limite da Equação 2.4, este é considerado flexível, e o CEB FIP (1970) recomenda que seja projetado pela teoria da flexão de vigas ou de placas.

Montoya (2000) diferencia os blocos rígidos dos flexíveis pela Equação 2.5. Para o bloco ser rígido a sua altura deve ser superior à metade da distância entre a face do pilar e o centro da estaca.

$$
h \geq \frac{\ell_{c}}{2}
$$

Montoya (2000) recomenda que a altura útil do bloco seja determinada pela Equação 2.6. Adotando-se este procedimento de cálculo, na maioria das vezes não é necessário verificar o bloco à força cortante $\left(V_{s d}\right)$.

$$
d=\frac{V_{d}}{500 \cdot b}-0,14 \leq 0,34
$$

A norma espanhola EHE (2008) adota a mesma distinção entre blocos rígidos e flexíveis recomendada por Montoya (2000).

Calavera (2000) faz distinção entre blocos rígidos e flexíveis comparando a altura do bloco com a distância entre os eixos das estacas $\left(\ell_{e}\right)$, neste caso os blocos são considerados rígidos quando a altura respeitar a Equação 2.7.

$$
h \geq \frac{\ell_{e}}{3}
$$

Segundo Calavera (2000), os blocos devem possuir altura inferior a uma vez e meia a distância entre as estacas e superior a $40 \mathrm{~cm}$ ou uma vez e meia o diâmetro da estaca.

Fusco (2000) sugere que, a inclinação das bielas em relação à horizontal deve estar entre $33^{\circ}$ e $45^{\circ}$.

\subsubsection{Espaçamento entre estacas}

O número de estacas para suportar as forças oriundas dos pilares depende da capacidade resistente do solo, do tipo de estaca e da seção da mesma. Para evitar a sobreposição de tensões no solo em virtude das várias estacas, faz-se necessário limitar a distância entre as mesmas. A ABNT NBR 6118:2003 delimita o espaçamento entre 2,5 a 3 
vezes o diâmetro da estaca para que se possa admitir plana a distribuição de forças nas estacas. Segundo Montoya (2000), a distância mínima entre os eixos das estacas deve ser de 2 vezes o diâmetro da mesma e não menor que $75 \mathrm{~cm}$. Calavera (2000) limita o espaçamento entre estacas num mínimo de duas vezes e no máximo de três vezes o diâmetro da estaca. Alonso (1983) e Moraes (1976) recomendam que não se adote um espaçamento entre estacas menor que duas vezes e meia o diâmetro das estacas.

\subsubsection{Distância entre eixo da estaca e face externa do bloco e ligação das estacas com o bloco}

A distância entre o eixo da estaca e a face externa do bloco deve ser, segundo Alonso (1983), o maior valor determinado pela Equação 2.8.

$$
u \geq\left[\begin{array}{l}
\frac{\phi}{2}+15 c m \\
r+c+\Phi
\end{array}\right]
$$

Sendo:

$\phi=$ diâmetro da estaca;

$\Phi=$ diâmetro da armadura longitudinal;

$r$ = raio de dobramento da armadura longitudinal;

$c=$ cobrimento da armadura.

Montoya (2000) e Calavera (2000) recomendam que esta distância seja de $25 \mathrm{~cm}$.

Montoya (2000) recomenda que o embutimento da estaca no bloco seja maior que 10 $\mathrm{cm}$ e menor que $15 \mathrm{~cm}$.

\subsubsection{Método das bielas sugerido por Blévot e Frémy (1967)}

Blévot e Frémy (1967) analisaram o método das bielas e tirantes por meio de ensaios experimentais. A aplicação do método para o dimensionamento dos blocos consiste em admitir uma treliça espacial no interior do bloco composta por elementos comprimidos, denominados de bielas, e elementos tracionados, denominados de tirantes.

O método sugerido por Blévot e Frémy (1967) é aplicado para os casos em que há o mesmo espaçamento entre estacas e o centro do pilar e força centrada no bloco, no entanto os pesquisadores indicam que o método pode ser adotado, com ressalvas, para casos em que a seção do pilar é retangular e nos casos que o bloco está submetido a momento. 
Nos casos em que a seção do pilar for retangular, os pesquisadores admitem que seja utilizada a mesma formulação do método das bielas, no entanto deve-se adotar a menor largura do pilar. No caso do bloco estar sujeito a momento, Blévot e Frémy (1967) recomenda que este seja dimensionado para uma força concentrada de valor $n \cdot R_{\max }$, sendo $n$ o número de estacas e $R_{\max }$ o valor da maior reação das estacas calculada para atuação do momento e considerando o bloco como um meio infinitamente rígido. Estas considerações, segundo o pesquisador, podem conduzir a fatores de seguranças elevados.

O dimensionamento consiste em determinar as forças nas barras da treliça por equilíbrio dos nós, definir uma área de aço necessária para absorver a força no tirante localizado na parte inferior do bloco e verificar a resistência à compressão da biela de concreto.

A seguir, é apresentada a formulação para o dimensionamento de bloco sobre quatro estacas pelo método das bielas.
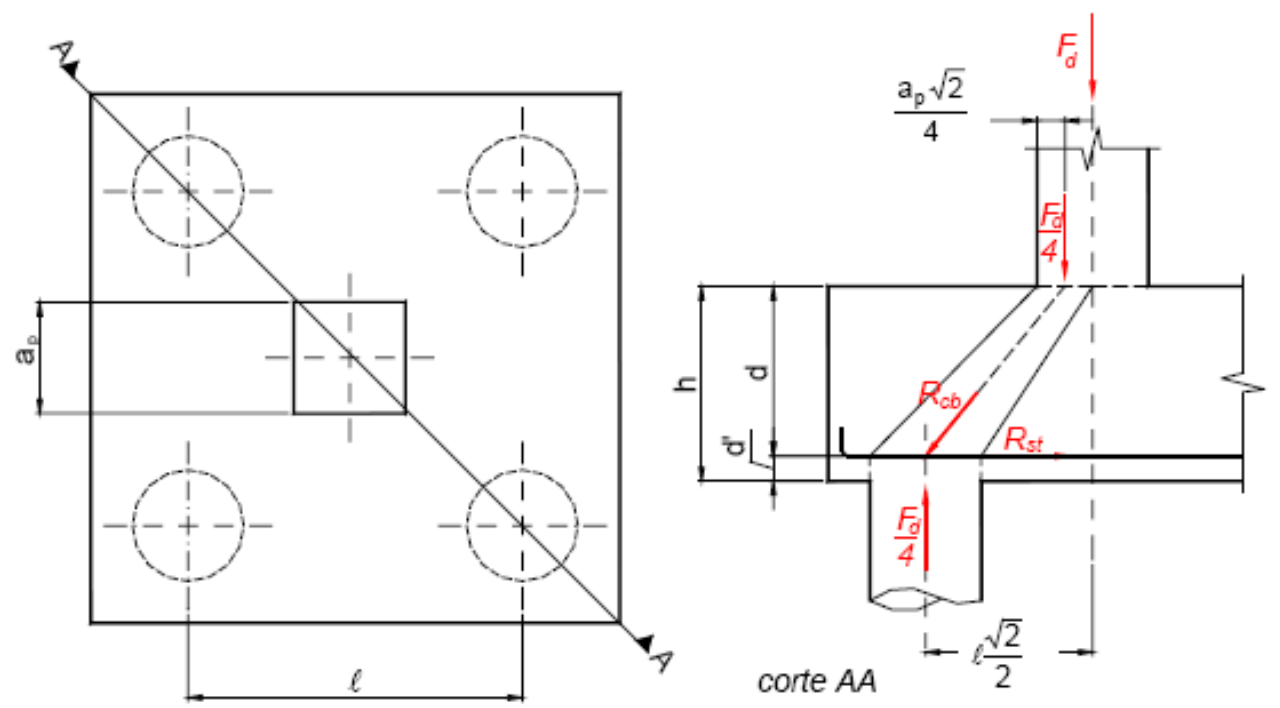

Figura 14 - Modelo para blocos sobre quatro estacas submetidos à força vertical. (Fonte: Munhoz (2004)).

Com base na Figura 14, fazendo o equilíbrio de forças do nó da treliça fictícia, as forças no tirante para a armadura disposta nas diagonais e segundo os lados são determinadas respectivamente pelas Equações 2.9 e 2.10.

$$
R_{s t}=\frac{F_{s d} \cdot \sqrt{2} \cdot\left(2 \cdot \ell-a_{p}\right)}{16 \cdot d}
$$




$$
R_{s t}=\frac{F_{s d} \cdot\left(2 \cdot \ell-a_{p}\right)}{16 \cdot d}
$$

Sendo:

$R_{s t}=$ força atuante no tirante;

$d=$ altura útil do bloco;

$a_{p}=$ largura do pilar;

$\ell=$ distância entre eixos das estacas;

$F_{s d}=$ força vertical atuante no bloco.

Quando se utiliza esse método, devem-se avaliar as tensões nas bielas junto aos nós, assim, para os blocos de fundação, esta verificação é feita na seção da biela junto ao pilar e junto à estaca.

Segundo Blévot e Frémy (1967), a tensão atuante e os limites de resistência nas bielas junto ao pilar são determinados pela Equação (2.11) e junto à estaca pela Equação 2.12.

$$
\begin{gathered}
\tau_{c p}=\frac{F_{d}}{A_{p} \sin ^{2} \theta} \leq 0,9 \cdot f_{c k} \\
\tau_{c e}=\frac{F_{d}}{4 \cdot A_{e} \cdot \sin ^{2} \theta} \leq 0,9 \cdot f_{c k}
\end{gathered}
$$

Sendo:

$\tau_{c p}=$ tensão na biela junto ao pilar;

$\tau_{c e}=$ tensão na biela junto à estaca;

$A_{p}=$ área da seção transversal do pilar;

$A_{e}=$ área da seção transversal da estaca;

$\theta$ = inclinação das bielas;

$f_{c k}=$ resistência característica à compressão do concreto.

Segundo Blévot e Frémy (1967), para os blocos que respeitam os limites de inclinação das bielas sugeridos pelos autores, a verificação ao cisalhamento e a punção é dispensável. 


\subsubsection{ABNT NBR 6118:2003}

A norma brasileira ABNT NBR 6118:2003 não apresenta um procedimento de cálculo para blocos de fundação, ela apenas recomenda que os blocos rígidos sejam dimensionados por modelos de bielas e tirantes tridimensionais, ou modelos tridimensionais lineares. No caso de blocos flexíveis, deve-se atender aos mesmos requisitos de dimensionamento e detalhamento de lajes. Neste caso, é necessária a verificação quanto à punção.

A ABNT NBR 6118:2003 recomenda que a punção seja verificada em seções criticas. No caso de transmissão de força excêntrica, a tensão de punção nas seções críticas pode ser determinada pela expressão 2.13 .

$$
\tau_{s d}=\frac{F_{s d}}{u \cdot d}+\frac{k \cdot M_{s d}}{w_{p} \cdot d}
$$

Sendo:

$F_{s d}=$ força concentrada atuante no pilar;

$u \cdot d=$ área do perímetro crítico;

$M_{s d}=$ momento solicitante;

$k=$ coeficiente que fornece a parcela do momento transmitida do pilar por cisalhamento.

O coeficiente $w_{p}$ é determinado em função da geometria do pilar, pela Equação 2.14.

$$
w_{p}=\frac{c_{1}^{2}}{2}+c_{1} \cdot c_{2}+4 \cdot c_{2} \cdot d+16 \cdot d^{2}+2 \cdot \pi \cdot d \cdot c_{1}
$$

Sendo:

$c_{1}=$ dimensão do pilar paralela à excentricidade da força;

$c_{2}=$ dimensão do pilar perpendicular à excentricidade da força.

A tensão resistente $\left(\tau_{R d 1}\right)$ na seção crítica distante $2 \cdot \mathrm{d}$ do contorno do pilar, no caso de não existir armadura de punção, deve ser calculada pela Equação 2.15.

$$
\tau_{s d} \leq \tau_{R d 1}=0,13 \cdot\left(1+\sqrt{\frac{20}{d}}\right) \cdot\left(100 \cdot \rho \cdot f_{c k}\right)^{1 / 3}
$$


Sendo $\rho$ a taxa de armadura de flexão, determinada em função da taxa de armadura nas direções $\mathrm{X}$ e $\mathrm{Y}$.

$$
\rho=\sqrt{\rho_{x}+\rho_{y}}
$$

A altura útil d é a média entre a altura útil em cada direção dx, dy.

A tensão resistente $\tau_{R d 2}$ da seção no contorno do pilar e da estaca é determinada pela Equação 2.17.

$$
\tau_{s d} \leq \tau_{R d 2}=0,27 \cdot\left(1-\frac{f_{c k}}{250}\right) \cdot f_{c d}
$$

Se a tensão de cálculo for maior que a resistente, pode-se armar o bloco à punção. Neste caso a tensão resistente $\tau_{R d 3}$ é determinada pela Equação 2.18.

$$
\tau_{s d} \leq \tau_{R d 3}=0,10 \cdot\left(1+\sqrt{\frac{20}{d}}\right) \cdot\left(100 \cdot \rho \cdot f_{c k}\right)^{1 / 3}+1,5 \cdot \frac{d}{S_{r}} \cdot \frac{A_{s w} \cdot f_{y w d .} \cdot \sin \alpha}{u \cdot d}
$$

Sendo:

$S_{r}=$ espaçamento radial entre linhas de armadura a punção, menor que $0,75 \mathrm{~d}$;

$A_{s w}=$ área de armadura a punção no contorno paralelo a seção crítica;

$\alpha=$ inclinação da armadura;

$f_{y w d}=$ resistência de cálculo da armadura (não pode ser maior que $300 \mathrm{MPa}$, para conectores, e que $250 \mathrm{MPa}$, no caso de estribos e lajes com espessura até $15 \mathrm{~cm}$, ou $435 \mathrm{MPa}$, para o caso de lajes com espessura maior que $35 \mathrm{~cm}$ ).

\subsubsection{Boletim 73 CEB-FIP (1970)}

O CEB-FIP (1970) adota a teoria de vigas como método de cálculo dos blocos sobre estacas. A armadura do bloco é dimensionada para suportar um momento fletor calculado na seção $S_{1}$ distante $0,15 a_{p}$ da face externa do pilar.

A verificação das tensões tangenciais deve ser feita numa seção que dista da face externa do pilar a metade da altura útil do bloco (seção $S_{2}$ representada na Figura 15). No caso 
de existirem estacas situadas mais próximas do que esta distancia, a seção de verificação da força cortante é a que coincide com a face do pilar.

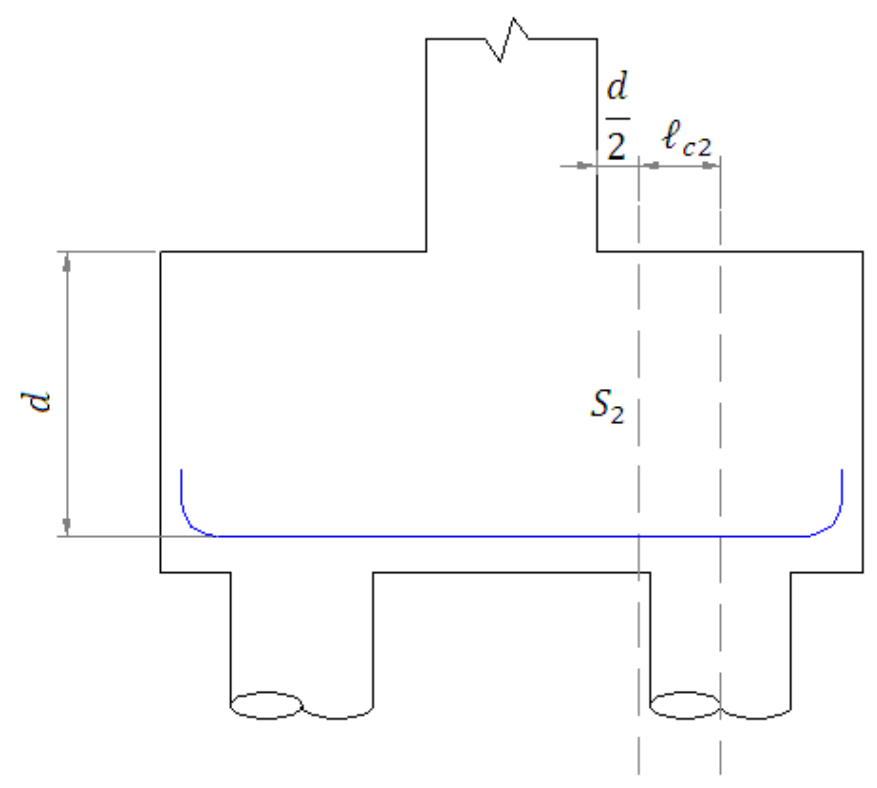

Figura 15 - Representação das seções de referencia para a verificação do cisalhamento de acordo com o CEB FIP 1970.

A largura $b_{2}$ é determinada pela Equação 2.19 e o valor da força cortante não pode ser maior que o limite calculado pela Equação 2.20. Onde $\mathrm{d}_{2}$ deve ser menor ou igual que 1,5 $\mathrm{lc}_{2}$

$$
\begin{gathered}
b_{2}=b_{p}+d \\
V_{s d} \leq V_{s d . l i m}=\frac{0,25}{\gamma_{c}} \cdot\left(1-\frac{\ell_{c}}{5 \cdot d}\right) \cdot b_{2} \cdot d_{2} \cdot \sqrt{f_{c k}} \rightarrow f_{c k} \text { em } \mathrm{kN} / \mathrm{cm}^{2}
\end{gathered}
$$

O Boletim 73 CEB-FIP (1970), também recomenda que se verifiquem as forças cortantes em seções que se apresentam mais criticas que a seção de referência $S_{2}$. Uma seção que o código normativo recomenda que se verifique é aquela distante $\mathrm{d}_{1} / 2$ da face da estaca, representada na Figura 16. 

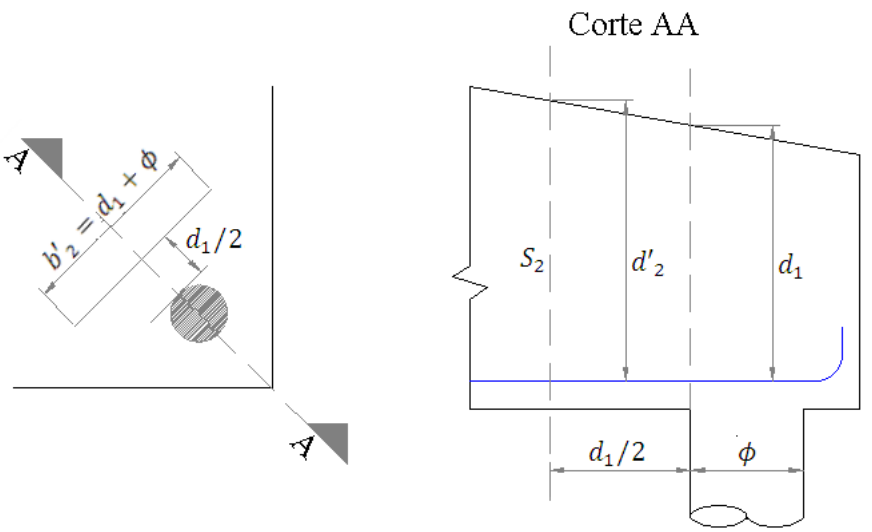

Figura 16 - Seções de referencia para verificação cisalhamento CEB - FIP 1970.

Neste caso, o boletim 73 CEB-FIP (1970) recomenda que a reação da estaca não supere o valor determinado pela Equação 2.21.

$$
R_{d} \leq R_{d . l i m}=\frac{0,12}{\gamma_{c}} \cdot b_{2}^{\prime} \cdot d_{2}^{\prime} \cdot \sqrt{f_{c k}} \rightarrow f_{c k} \text { em } \mathrm{kN} / \mathrm{cm}^{2}
$$

\subsubsection{CSA A23.3 (2004)}

A norma canadense CSA A23.3 (2004) recomenda que, para blocos rígidos, o dimensionamento seja feito pelo modelo de bielas e tirantes sugerido por Adebar e Zhou (1996). Deve-se determinar uma altura que impeça a ruína por punção na seção da estaca e do pilar. No caso de blocos flexíveis, as tensões tangenciais devem ser verificadas nas duas direções em seções pré-determinadas.

\subsubsection{ACI $318(2008)$}

O ACI 318 (2008) recomenda a teoria de flexão de vigas para o dimensionamento dos blocos. As armaduras devem absorver as tensões relativas a um momento determinado na seção do bloco que coincide com a face do pilar. O cisalhamento deve ser verificado em uma seção com distância da face do pilar igual à altura útil do bloco ou, no caso em que a força cortante é predominante, nas duas direções na seção com perímetro igual à metade da altura útil do bloco.

A norma permite cálculo pelo modelo de bielas e tirantes nos casos em que o bloco tem altura maior que duas vezes a distância entre estacas. 


\subsubsection{Armaduras secundárias e disposições construtivas}

A ABNT NBR 6118:2003 recomenda uma armadura em forma de malha distribuída nas duas direções para o máximo de $20 \%$ dos esforços totais calculada com uma resistência do aço de $80 \%$ de $f_{y d}$.

Para blocos sobre mais de duas estacas, Calavera (2000) e Montoya et al. (2000), baseados na Norma Espanhola EHE (2008), recomendam uma armadura secundária em forma de malha com área (em cada direção) não inferior a 1/4 da área da armadura colocada nas faixas delimitadas pelas estacas e uma armadura vertical em forma de estribos.

Se a largura superar a metade da altura do bloco, a seção de referência deve ser tomada com uma largura de metade da altura. Estas armaduras, segundo Calavera (2000), são recomendadas para blocos sobre duas estacas por estes estarem sujeitos à torção por causa de possíveis excentricidades acidentais da força.

A ABNT NBR 6118:2003 indica que deve ser determinada uma área de armadura de suspensão para a parcela da força a ser equilibrada, se for prevista uma armadura de distribuição maior que $25 \%$ dos esforços totais ou o espaçamento entre estacas for maior que 3 vezes o diâmetro da estaca.

De acordo com a ABNT NBR 6118:2003, as armaduras devem ser dispostas de face a face do bloco e possuir gancho nas duas extremidades. Se a barra tiver diâmetro maior que 20 mm esta deve terminar em ganchos com ângulo de $135^{\circ}$ ou $180^{\circ}$. O comprimento de ancoragem deve ser medido a partir da face da estaca e determinados segundo as recomendações da mesma norma.

\subsection{Pesquisa com ênfase em colarinho de fundação}

O colarinho de fundação é utilizado nas ligações entre pilares e elementos de fundação, e tem como função transmitir para os elementos de fundação as forças atuantes nos pilares.

Este tipo de ligação é bastante empregado pela agilidade e facilidade que proporciona na montagem dos pilares pré-moldados, e também por proporcionar uma boa transferência das forças. 


\subsubsection{Método de Leonhardt e Mönnig (1977) e ABNT NBR 9062:2006 e El Debs (2000)}

Para uma adequada avaliação deste elemento, devem-se levar em conta as propriedades das superfícies das paredes internas do cálice e dos pilares. Leonhardt e Mönnig (1977) consideram dois casos extremos, superfícies muito rugosas e superfícies lisas. Cada uma destas apresenta uma forma de transmissão das ações por meio da ligação.

Segundo Leonhardt e Mönnig (1977), para que as paredes possam ser consideradas como rugosas, devem possuir rugosidade mínima de $1 \mathrm{~cm}$ a cada $10 \mathrm{~cm}$.

Para que os as ações sejam transmitidas do pilar para o bloco de forma adequada, o pilar deve estar embutido em um comprimento mínimo $\left(\ell_{\mathrm{emb}}\right)$. Este comprimento depende das ações atuantes, momento e força vertical e da geometria do pilar. A ABNT NBR 9062:2006 e Leonhardt e Mönnig (1977) recomendam diferentes comprimentos de embutimento para os dois tipos de superfície da ligação. Estas recomendações estão indicadas naTabela 1.

Tabela 1 - Comprimento de embutimento do pilar no cálice.

\begin{tabular}{c|c|c|c|c}
\hline \multirow{2}{*}{} & \multicolumn{2}{|c|}{ ABNT NBR 9062:2006 } & \multicolumn{2}{c}{ Leonhardt e Mönnig (1977) } \\
\cline { 2 - 5 } & $\frac{M_{d}}{N_{d} \cdot h} \leq 0,15$ & $\frac{M_{d}}{N_{d} \cdot h} \geq 2,0$ & $\frac{M_{d}}{N_{d} \cdot h} \leq 0,15$ & $\frac{M_{d}}{N_{d} \cdot h} \geq 2,0$ \\
\hline Parede lisa & $\ell_{e m b} \geq 1,5 \cdot h$ & $\ell_{e m b} \geq 2,0 \cdot h$ & $\ell_{e m b} \geq 1,68 \cdot h$ & $\ell_{\text {emb }} \geq 2,8 \cdot h$ \\
\hline Parede rugosa & $\ell_{e m b} \geq 1,2 . h$ & $\ell_{\text {emb }} \geq 1,6 . h$ & $\ell_{\text {emb }} \geq 1,2 . h$ & $\ell_{\text {emb }} \geq 2,0 . h$ \\
\hline
\end{tabular}

Leonhardt e Mönnig (1977) recomendam que as espessuras das paredes do colarinho sejam da ordem de um terço da menor largura interna do cálice, mas nunca inferior a $10 \mathrm{~cm}$. A ABNT NBR 6118:2003 limita somente a espessura mínima de $10 \mathrm{~cm}$.

Quando a ligação entre as paredes for rugosa, é possível considerar o conjunto como monolítico. Conforme a ABNT NBR 9062:2006, neste caso, pode ser considerada uma força de atrito de $90 \%$ da resultante combinada entre a força normal e o momento, aplicada na distância média entre o pilar e o cálice, não se tomando tensões de atrito maiores que $40 \%$ da resistência de cálculo à compressão do concreto (correspondente ao menor valor da resistência do concreto, existente no colarinho e no pilar).

Nas ligações lisas, a ABNT NBR 9062:2006 permite que se suspenda, por meio de uma armadura em toda a volta do cálice, $70 \%$ da força vertical. 
Para o dimensionamento das paredes do colarinho, Leonhardt e Mönnig (1977) indicam um modelo de distribuição de tensões conforme representado na Figura 17. Este modelo também é adotado pela ABNT NBR 9062:2006.

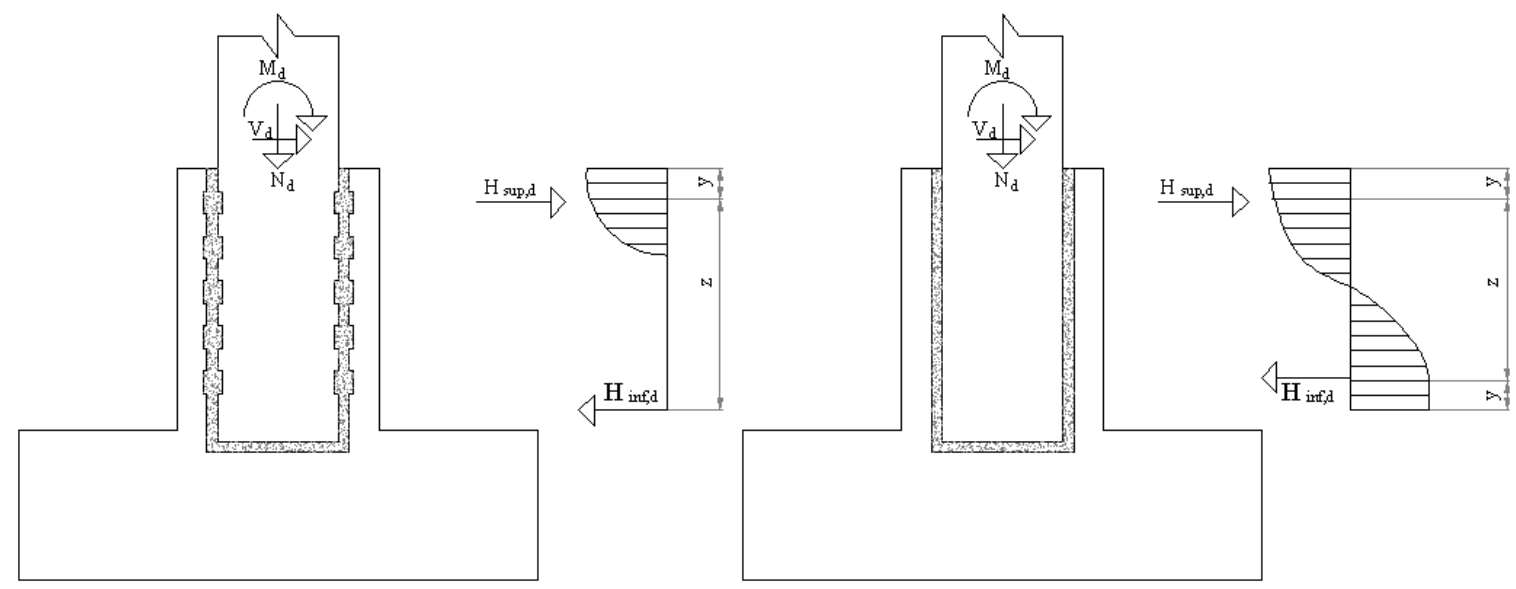

Figura 17 - Esquema de distribuição das forças atuantes nas paredes do colarinho. (Adaptado de EI Debs (2000)).

As forças atuantes no topo do colarinho $\left(H_{\text {sup,d }}\right)$ e na base do mesmo $\left(H_{\text {inf,d }}\right)$ e a posição destas resultantes $y$ e $y^{\prime}$ são determinados pelas Equações da Tabela 2. O modelo proposto por Leonhardt e Mönnig (1977) diverge da ABNT NBR 9062:2006 apenas na posição da resultante da força superior $\left(H_{\text {sup,d }}\right)$ para a ligação com chave de cisalhamento. Enquanto os pesquisadores indicam esta posição a $0,167 \cdot \ell_{e m b}$ abaixo do limite superior do colarinho, a norma recomenda esta posição a $0,15 \cdot \ell_{e m b}$.

Tabela 2 - Cálculo das reações nas paredes do colarinho.

\begin{tabular}{c|c|c}
\hline & Lisa & Rugosa \\
\hline$H_{\text {sup }, d}$ & $\frac{3 \cdot M_{d}}{2 \cdot \ell_{e m b}}+\frac{5 \cdot V_{d}}{4}$ & $\frac{6 \cdot M_{d}}{5 \cdot \ell_{e m b}}+\frac{6 \cdot V_{d}}{5}$ \\
\hline$H_{\text {inf }, d}$ & $\frac{3 \cdot M_{d}}{2 \cdot \ell_{e m b}}+\frac{V_{d}}{4}$ & $\frac{6 \cdot M_{d}}{5 \cdot \ell_{e m b}}+\frac{V_{d}}{5}$ \\
\hline$Y$ & $\frac{\ell_{e m b}}{6}$ & $0,15 . \ell_{e m b}$ \\
\hline$Y^{\prime}$ & $\frac{\ell_{e m b}}{6}$ & \\
\hline
\end{tabular}

Segundo Leonhardt e Mönnig (1977), a força $\mathrm{H}_{\text {sup,d }}$ provoca uma flexão na parede. A flexão é significativa apenas na faixa $\frac{\ell_{\mathrm{emb}}}{3}$ localizada na parte superior da parede do cálice. Este esforço solicitante deve ser absorvido por uma armadura horizontal em anel localizada na largura da faixa $\frac{\ell_{\text {emb }}}{3}$ e transmitido para as paredes longitudinais. Para pequenas 
excentricidades, $\frac{\mathrm{M}_{\mathrm{d}}}{\mathrm{N}_{\mathrm{d}}} \leq 0,15$, pode-se dispor de armaduras apenas na parte externa da parede. Caso contrário, deve-se dispor de armadura na parte interna. Canha (2004) e Canha e El Debs (2006) verificaram, em estudos experimentais que, na parede em que atua a força $\left(\mathrm{H}_{\text {sup,d }}\right)$, a flexão anteriormente citada é pequena por causa da pequena rigidez da parede do cálice frente à do pilar, sendo esta solicitada principalmente por esforço de tração.

Leonhardt e Mönnig (1977) indicam que as paredes transversais ao sentido de atuação da força $\left(H_{\text {sup }, d}\right)$ trabalham como consolos engastados no bloco (Figura 18), podendo-se utilizar o modelo de bielas e tirantes para dimensionamento das mesmas.

A partir da geometria da parede e da configuração das bielas e dos tirantes indicados na Figura 17, pode-se determinar a força $\left(R_{c}\right)$ pela Equação $(2.22)$, e a força vertical nos tirantes deste consolo $\left(F_{c d}\right)$, conforme Equação (2.23).

$$
\begin{gathered}
R_{c}=\frac{H_{\text {sup }, d}}{2 \cdot \cos \beta} \\
F_{v d}=\frac{H_{\text {sup }, d}}{2} \cdot \tan \beta
\end{gathered}
$$

A inclinação $(\beta)$ da biela determinada pela Equação (2.24)

$$
\beta=\tan ^{-1} \frac{\ell_{c a}-y}{0,85 \cdot h_{e x t}-h_{c} / 2}
$$

Sendo:

$\ell_{c a}=$ altura da parede do cálice a partir do engastamento do bloco;

$h_{\text {ext }}=$ largura da parede medida a partir da face externa.

A tensão na biela dever ser verificada de acordo com a Equação (2.25), não podendo ultrapassar $0,85 \cdot f_{c d}$.

$$
\sigma_{c}=\frac{R_{c}}{h_{\text {bie }} \cdot h_{c}} \leq 0,85 \cdot f_{c d}
$$

Sendo que a largura da biela $\left(h_{\text {bie }}\right)$ é calculada pela Equação (2.26):

$$
h_{\text {bie }}=0,3 \cdot h_{\text {ext }} \cdot \sin \beta
$$


A força vertical $F_{v d}$ nesta parede é absorvida por estribos verticais com área total de aço no tirante determinado pela Equação (2.27). A força horizontal $H_{s u p, d / 2}$ deve ser resistida por uma armadura com área determinada pela expressão (2.28). Geralmente estas armaduras também são dispostas no formato de estribos.

$$
A_{v d}=\frac{F_{v d}}{f_{y d}}
$$

$$
A_{\text {hod }}=\frac{H_{\text {sup }, d}}{2 \cdot f_{y d}}
$$

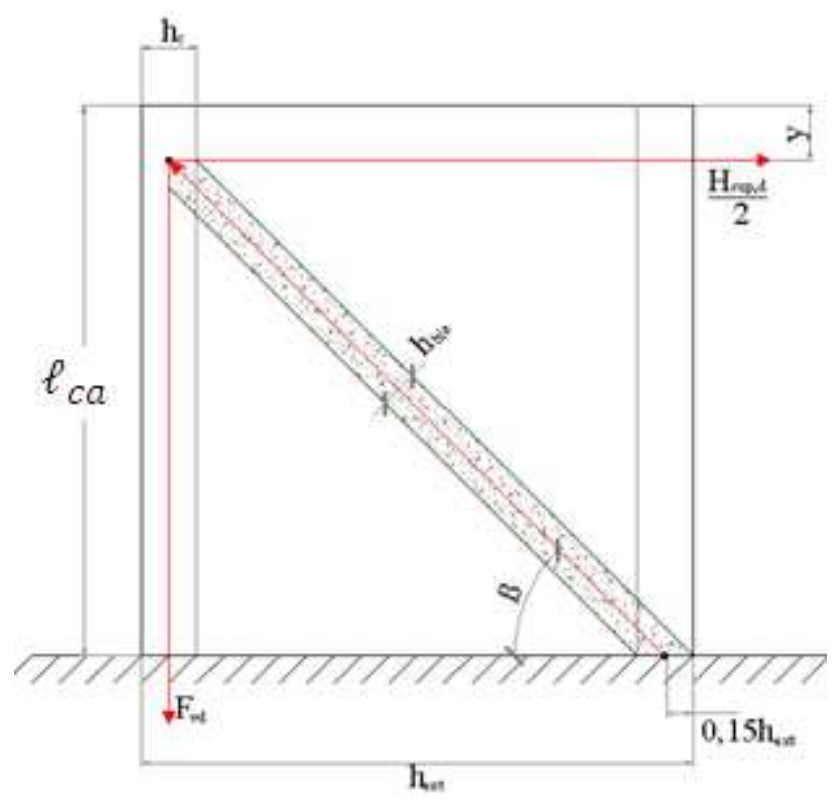

Figura 18 - Modelo de distribuição de tensões no cálice para o caso de paredes com chave de cisalhamento. (adaptado ABNT NBR 9062:2006)).

El Debs (2000) sugere que as paredes devem possuir uma armadura suplementar, em forma de malha, disposta na vertical e na horizontal, com área de $0,4 \cdot A_{v d}$ e $0,25 \cdot A_{v d}$, respectivamente. Estas armaduras são utilizadas com a finalidade de distribuir as ações na parede e controlar a fissuração.

\subsubsection{Modelo apresentado por Canha (2004)}

O modelo proposto por Canha (2004) está fundamentado nas observações feitas a partir dos ensaios experimentais realizados em seis modelos, quatro destes com interface lisa e outros dois com interface rugosa, sujeitos a flexão normal composta com grande
36 
excentricidade. O modelo leva em conta a contribuição do atrito nas interfaces do colarinho com o pilar e a excentricidade da reação do pilar. As forças de atrito estão distribuídas conforme a Figura 19 e são calculadas pelas Equações (2.29), (2.30) e (2.31), em função do coeficiente de atrito $(\mu)$.
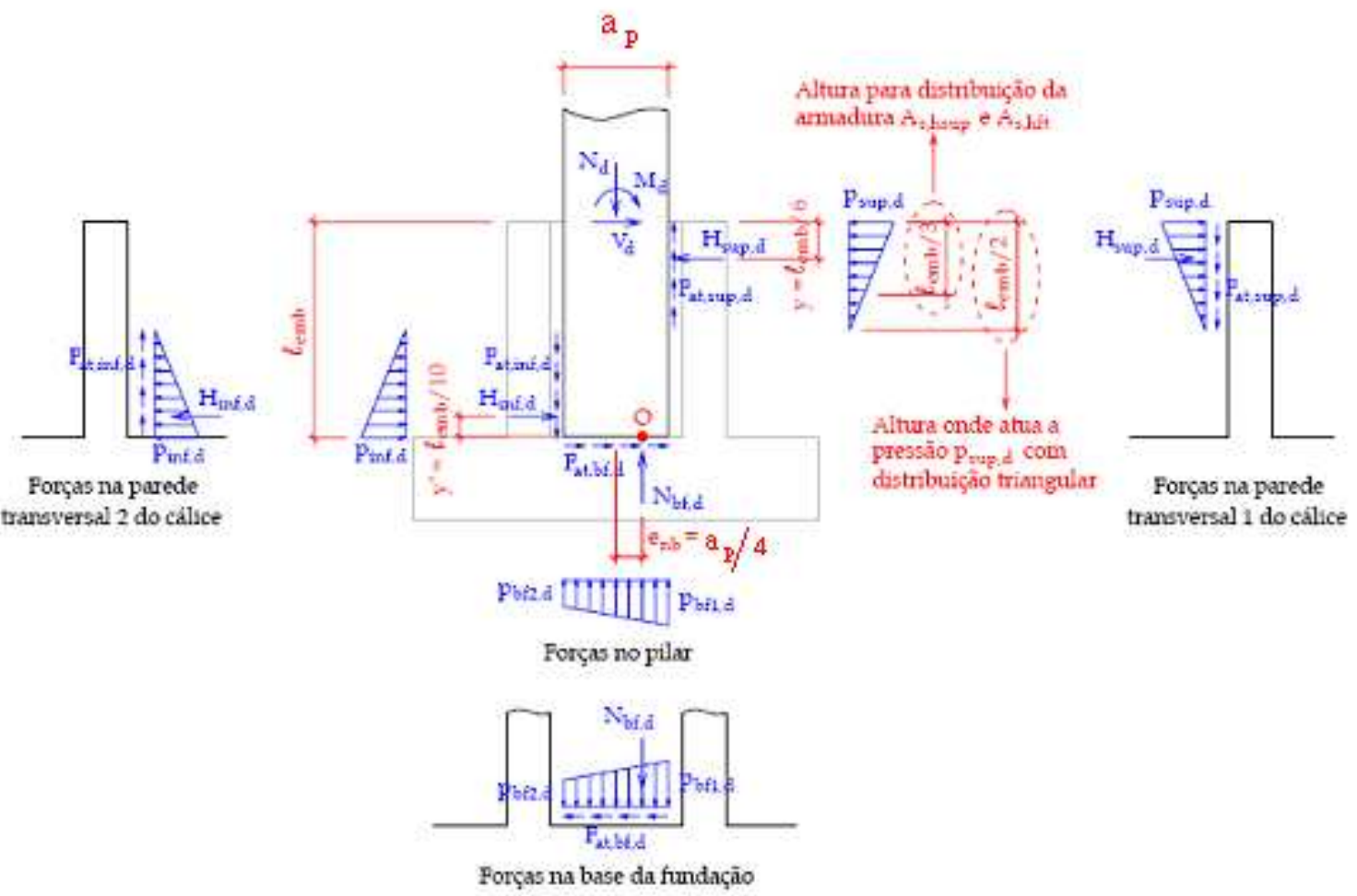

Figura 19 - Modelos de distribuição de esforços no cálice proposto por Canha (2004). (Fonte: Canha (2004)).

$$
\begin{aligned}
& F_{a t, s u p, d}=\mu \cdot H_{\text {sup }, d} \\
& F_{a t, \text { inf }, d}=\mu \cdot H_{\text {inf }, d} \\
& F_{a t, b f, d}=\mu \cdot H_{b f, d}
\end{aligned}
$$

Realizando-se o somatório das forças verticais e horizontais atuantes na ligação e igualando a zero o momento em torno do ponto O, conforme Figura 19, chegam-se nas equações (2.32), (2.33) e (2.34).

$$
0=N_{d}-N_{b f, d}-F_{a t, s u p, d}+F_{a t, i n f, d}
$$




$$
\begin{gathered}
0=V_{d}-H_{\text {sup }, d}+F_{a t, b f, d}+H_{\text {inf }, d} \\
0=M_{d}-N_{d} \cdot e_{h b}+V_{d} \cdot \ell_{e m b}-H_{\text {supd }} \cdot\left(\ell_{e m b}-y\right)+H_{\text {inf }, d} \cdot y \\
-F_{a t, \text { sup }, d} \cdot\left(0,5 \cdot a_{p}-e_{h b}\right)-F_{a t, i n f, d} \cdot\left(0,5 \cdot a_{p}+e_{h b}=0\right.
\end{gathered}
$$

A partir das equações $2.32,2.33$ e 2.34, é possível obter a resultante da força de atrito (Equação (2.35)) e as resultantes das forças inferior e superior, exercidas pelo pilar nas paredes do colarinho, Equações (2.36) e (2.37).

$$
\begin{gathered}
F_{a t, b f, d}=\frac{\mu \cdot N_{d}-\mu^{2} \cdot V_{d}}{1+\mu^{2}} \\
H_{\text {inf }, d}=H_{\text {sup }, d}-\frac{\mu \cdot N_{d}+V_{d}}{1+\mu^{2}} \\
H_{\text {sup }, d}=\frac{M_{d}-N_{d} \cdot\left(e_{h b}+\frac{\mu \cdot y^{\prime}-\mu^{2} \cdot\left(0,5 \cdot a_{p}+e_{h b}\right)}{1+\mu^{2}}\right)+H_{d} \cdot\left(\ell_{e m b}-\frac{y^{\prime}-\mu \cdot\left(0,5 \cdot a_{p}\right)+e_{h b}}{1+\mu^{2}}\right)}{\ell_{e m b}-y-y^{\prime}+\mu \cdot a_{p}}
\end{gathered}
$$

Canha (2004) recomenda que, para projeto do cálice com interface lisa, se adote coeficiente de atrito de $\mu=0,6$, excentricidade da reação do pilar de $e_{h b}=a_{p} / 2$, e as posições da resultante da força nas paredes do colarinho iguais a $y=\ell_{e m b} / 6$ e $y^{\prime}=\ell_{e m b} / 10$. Esses valores são indicados para os casos em que se utiliza comprimento de embutimento recomendado pela ABNT NBR 9062:1985 e para o caso de força com grande excentricidade.

A força exercida pelo pilar na parede 1 possui uma distribuição conforme Figura 20. Esta distribuição de força causa flexo-tração nesta parede.

O modelo propõe que esta parede seja verificada como uma viga bi-apoiada com o carregamento dividido em duas parcelas, conforme Figura 21. Estas duas forças são determinadas pelas Equações (2.38) e (2.39).

$$
H_{\text {sup } 2, d}=2 \cdot N_{d}
$$




$$
H_{\text {sup } 1, d}=\frac{M_{d} \cdot\left(4 \cdot\left(n_{1}+2\right)\right)}{b_{\text {int }}+h_{c}}
$$

Sendo:

$n_{1}=$ grau da curva que rege a distribuição da força;

$h_{c}=$ espessura da parede do colarinho;

$b_{\text {int }}=$ distância interna entre as paredes 3 e 4.
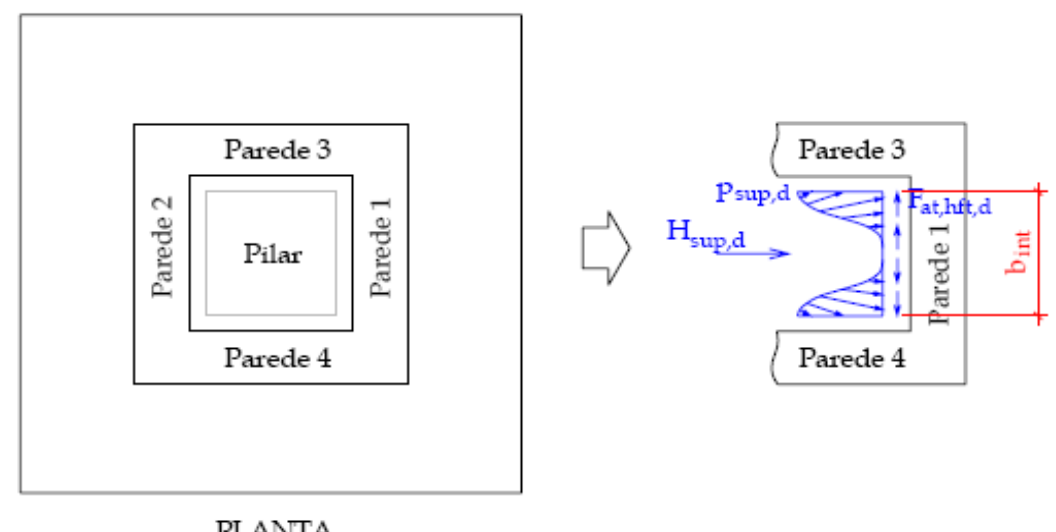

PLANTA

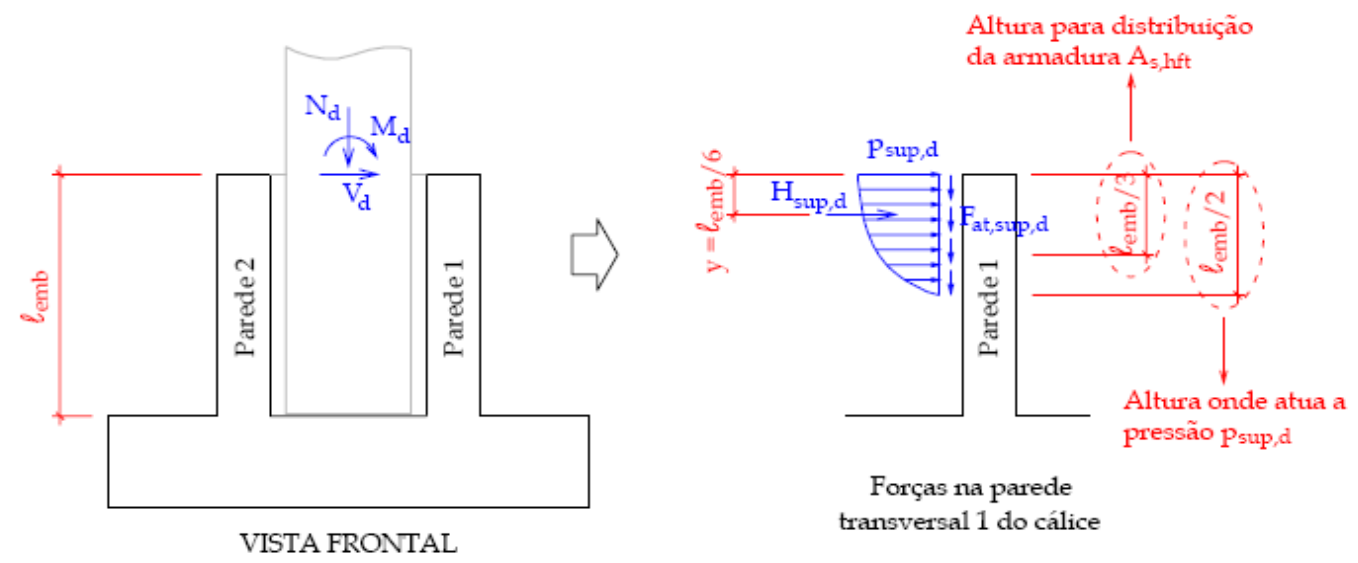

Figura 20 - Distribuição da força superior na parede 1 proposta por Canha (2004). (Fonte: Canha (2004)) 


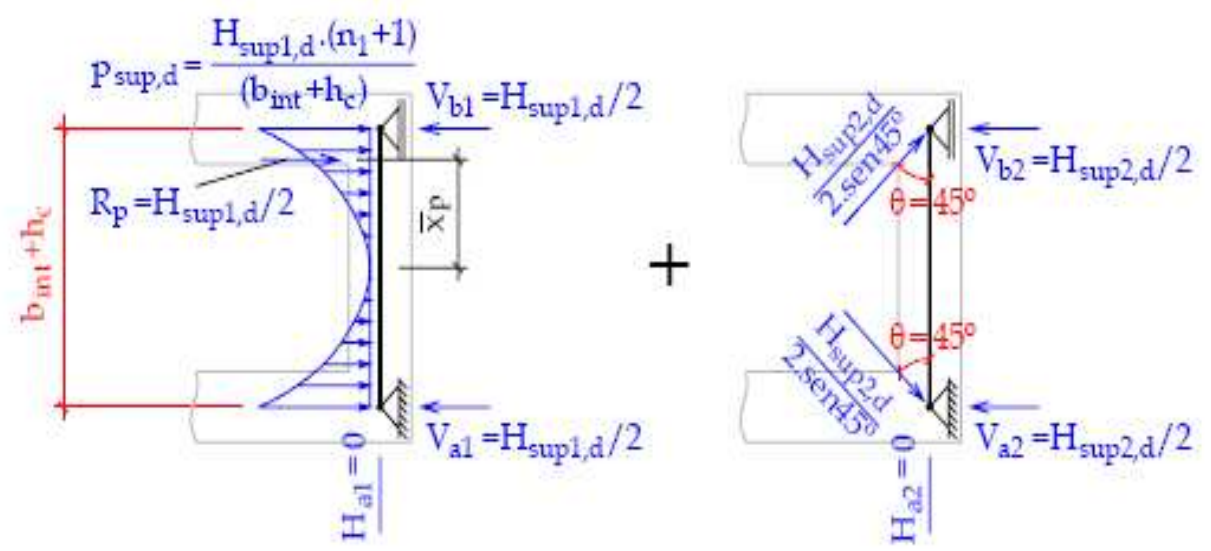

PLANTA

Figura 21 - Distribuição da força na parede 1 proposta por Canha (2004). (Fonte: Canha (2004)).

As paredes 3 e 4 devem ser dimensionadas pelo modelo de bielas e tirantes apresentado no item 2.1.1.

Para o caso de ligação rugosa, o modelo sugere que se adote o coeficiente de atrito igual à unidade, ou então que se dimensione o colarinho considerando situação de flexotração.

\subsubsection{Outros estudos e modelos propostos}

Willert e Kesser (1983) sugerem um modelo de cálculo que leva em conta a rugosidade da superfície considerando coeficiente de atrito. No caso de ligação lisa, os pesquisadores indicam o valor de $\mu$ igual a 2/3. Para ligações rugosas, os pesquisadores não indicam valores do coeficiente de atrito, mas, com um adequado ajuste deste fator, o modelo pode ser utilizado.

O comprimento de embutimento recomendado no modelo de Willert e Kesser (1983) é determinado pela Equação 2.40. Este é diferente do comprimento recomendado por Leonhardt e Mönnig (1977), pois não leva em conta as propriedades da ligação e nem a excentricidade do carregamento.

$$
1,5 \cdot a_{p} \leq \ell_{e m b} \leq 3,0 \cdot a_{p}
$$

Olin et al. (1985) desenvolveram um procedimento de cálculo que considera além das forças de atrito nas faces laterais da ligação, as forças de aderência e a excentricidade da 
reação na parte inferior do pilar. Diferentemente de outros modelos, os pesquisadores desprezam a força de atrito no fundo do pilar por julgarem que esta não atue de forma plena.

O comprimento de embutimento sugerido neste modelo é de 1,3. $a_{p}$, sendo $a_{p}$ a maior dimensão da seção transversal do pilar.

No modelo de Olin et al. (1985), a excentricidade da reação do pilar depende da intensidade das forças atuantes e da geometria do colarinho. Os pesquisadores sugerem que se adote a excentricidade igual a $a_{p} / 6$ no caso de ligação rugosa. Quanto ao coeficiente de atrito da ligação, as recomendações são de que se adote um valor de $\mu=0,3$ para ligações lisas e $\mu=0,6$ para ligações com interface rugosas.

Bruggeling e Huygue (1991) sugerem um modelo de bielas e tirantes para simular a transferência das ações atuantes no pilar para a fundação. Este modelo depende do comprimento de embutimento. No caso em que o embutimento é menor que o valor recomendado por Leonhardt e Mönnig (1977), a transferência do momento atuante ocorre por meio de bielas inclinadas localizadas na junta entre as chaves de cisalhamento das duas interfaces. A força centrada é transferida por meio de duas bielas que vão desde o inicio do embutimento até o fundo da laje.

Quando o comprimento de embutimento respeitar as recomendações de Leonhardt e Mönnig (1977), o esquema das bielas e tirantes sugerido por Bruggeling e Huygue (1991) é semelhante ao modelo proposto por Leonhardt e Mönnig (1977).

Elliott (1996) apresenta dois modelos para a consideração das ações na ligação entre pilar e fundação feitos por meio de cálice. Um para o caso que atuam forças excêntricas e outro para os casos em que atua também força cortante na base do pilar. O pesquisador recomenda que o comprimento de embutimento seja maior ou igual a uma vez e meia a maior largura do pilar.

O pesquisador não considera no seu modelo as forças de atrito na ligação, apesar de admitir que elas existam. Elliott (1996) recomenda também que a largura da junta no topo seja igual a $7,5 \mathrm{~cm}$ e na base $5 \mathrm{~cm}$.

Osanai et al. (1996) realizaram ensaios experimentais de modelos reduzidos de cálices de fundação nos quais variaram o comprimento de embutimento e a rugosidade das paredes da ligação. Com base nas observações, sugerem um modelo de cálculo que leva em conta as forças de atrito nas interfaces da ligação.

Os pesquisadores observaram que, para comprimentos de embutimento igual a 1,5 $a_{p}$ a ligação se comportou como monolítica, mesmo para os modelos com interface lisa. Nos 
modelos com interface lisa, o cálice não apresentou rigidez suficiente para o comprimento de embutimento inferior a $1,2 \cdot a_{p}$. Para os casos de ligação rugosa, os modelos com embutimento $1,0 \cdot a_{p}$ tiveram comportamento semelhante aos modelos com comprimento de embutimento de $1,5 \cdot a_{p}$.

Osanai et al. (1996) sugerem que se adote um coeficiente de atrito igual a $\mu=1$ nos casos em que a ligação for rugosa com comprimento de embutimento superior a 1,25. $a_{p}$. ou nos casos de ligação lisa com comprimento de embutimento maior que $1,5 \cdot a_{p}$. e $\mu=0,5$, para os casos de interface rugosa com comprimento de embutimento igual a $1 \cdot a_{p}$.

Jaguaribe Junior (2005), seguindo na mesma linha de pesquisa de Canha (2004), ensaiou dois modelos físicos de ligação entre pilar pré-moldado e fundação feita por colarinho. Os modelos foram submetidos a força com grande excentricidade. O objetivo da pesquisa era verificar o comportamento da ligação quando o comprimento de embutimento é inferior aos valores recomendados pela ABNT NBR 9062 (1985).

Jaguaribe Junior (2005) observou que os modelos encontrados na literatura não representam o comportamento da ligação dos modelos ensaiados com comprimento da ligação inferiores aos recomendados.

Ebeling (2006) ensaiou e simulou dois modelos com diferentes comprimentos de embutimento e ligação entre pilar e cálice lisas e rugosas, com o objetivo de verificar o comportamento do pilar na região da ligação com o colarinho.

O pesquisador observou que em nenhum ponto da região do embutimento se verificou o escoamento das armaduras verticais do pilar, fato que só foi observado na região externa à ligação. A plastificação da armadura só começou a meia altura do embutimento, justificando, assim, que o comprimento de ancoragem desta armadura deve ser levado em conta a partir desta posição, como sugerido por Leonhardt e Mönnig (1977).

Ebeling (2006) verificou uma pequena deformação das armaduras transversais na região da ligação apesar de se utilizar uma armadura mínima o que indica o dimensionamento a favor da segurança.

Nunes (2009), dando continuidade aos estudos de Canha (2004) e Jaguaribe Junior (2005), ensaiou mais dois modelos, um com interface lisa e outro com interface rugosa. Os modelos utilizados eram semelhantes aos dos dois pesquisadores citados. Contudo, Nunes (2009) priorizou em suas análises as paredes transversais, as quais foram construídas com espessuras inferiores à recomendada por Leonhardt e Mönnig (1977) de um terço da menor distância interna entre as paredes. 
Nunes (2009) observou que as paredes transversais são solicitadas, na região do terço superior do comprimento de embutimento, a flexo-tração, sendo que o modelo apresentado por Canha (2004) fornece resultados da força nos ramos internos e externos da armadura horizontal principal, próximos aos obtidos nos ensaios experimentais. O modelo que possuía chave de cisalhamento na ligação apresentou comportamento semelhante a uma ligação monolítica e a parede transversal localizada na parte contrária ao sentido do momento atuante foi mais solicitada que a parede da frente. Também, neste caso, os resultados do modelo de Canha (2004) se mostraram próximos aos resultados experimentais. Os dois modelos apresentaram escoamento das armaduras vertical principal e secundaria quando da ruína dos modelos.

Campos (2010) realizou uma síntese dos resultados obtidos nos trabalhos de Canha (2004), Jaguaribe Junior (2005), Ebeling (2006) e Nunes (2009). A partir desta síntese a autora faz recomendações sobre o dimensionamento da base do pilar, da distribuição das pressões nas paredes do colarinho, do comportamento destas paredes e alguns critérios de dimensionamento.

A pesquisadora apresenta ainda exemplos de dimensionamento destes elementos, para alguns casos correntemente encontrados em obras de estruturas pré-moldadas de concreto.

\subsection{Considerações finais}

Neste capítulo, foram apresentadas algumas observações sobre as pesquisas e alguns métodos de dimensionamento encontrados na literatura acerca de blocos de fundação e colarinhos para ligação do pilar pré-moldado com o elemento de fundação.

Os métodos de dimensionamento do colarinho e do bloco de fundação são considerados em separado. Nenhum método considera o comportamento conjunto e isto para o caso de cálice parcialmente embutido pode ser importante.

Os estudos com bloco de fundação são direcionados para modelos com força centrada ou com pequenas excentricidades, e com geometria bem definida. Na maioria das obras reais os blocos de fundação são submetidos a forças centradas e momentos nas duas direções, além de possuir geometria retangular, assim há uma lacuna no conhecimento do comportamento destes tipos de blocos que de certa forma tentar-se-á esclarecer neste trabalho.

Estudos com blocos de fundação com colarinho parcialmente embutido, não foram encontrados na literatura, embora se observe uma tendência de se utilizar esta solução. 
Foi possível, a partir da revisão da bibliografia, verificar alguns pontos ainda a serem estudados, como por exemplo, o caso de blocos com cálice parcialmente embutido submetidos a momentos nas duas direções, objeto de estudo deste trabalho. 


\section{CAPÍTULO}

\section{APRESENTAÇÃO E COMPROVAÇÃO DO MODELO NUMÉRICO}

\subsection{Considerações iniciais}

No mercado, estão disponíveis diversos programas computacionais que utilizam o método dos elementos finitos para análise numérica e não-linear de estruturas. Neste trabalho, foi utilizado o programa DIANA 9.4, desenvolvido pela empresa holandesa TNO. Este programa foi escolhido por contar com modelos constitutivos mais eficientes para a simulação do comportamento do concreto armado.

Três modelos numéricos foram gerados e os resultados obtidos por meio deles foram comparados aos de ensaios experimentais encontrados na bibliografia para verificação da coerência dos mesmos. Esta comparação é apresentada neste capítulo bem como as informações mais relevantes sobre o DIANA 9.4.

\subsection{Programa computacional DIANA 9.4}

O DIANA 9.4 é um programa de elementos finitos fundamentado no método dos deslocamentos. Este programa foi utilizado em outras pesquisas sobre blocos, dentre elas podem-se citar Souza (2004), Barros (2009) e Marek (2010). Em todos os trabalhos, os resultados obtidos foram satisfatórios.

A utilização deste programa permite que se representem os fenômenos complexos do concreto como a fissuração, plasticidade, confinamento, fluência, cura e instabilidade. Neste trabalho são consideradas apenas a fissuração e a plasticidade.

\subsubsection{Modelo constitutivo}


O comportamento do concreto depende muito da zona de transição entre a matriz e o agregado que apresenta microfissuração progressiva. A partir de certa intensidade de tensão, o concreto apresenta elevados acréscimos de deformação em consequência da redução da capacidade resistente por causa da intensidade da fissuração. Esse fenômeno ocorre tanto na compressão quanto na tração e é denominado de amolecimento (strain softening).

O DIANA 9.4 possui, implementado em seu sistema, dois modelos que simulam a fissuração do concreto: o "Smeared Crack Model" e o "Discrete Crack Model". Os dois modelos utilizam parâmetros da mecânica da fratura para descrever o comportamento do concreto após a fissuração.

O "Discrete Crack Model" trata a fissura refinando a malha de elementos finitos na região onde esta se propagará. Uma nova malha é gerada a cada incremento de carga alterando-se a conectividade dos nós. Isto não é conveniente para o método dos elementos finitos e este é um dos fatores adversos citados por Rots e Blaauwendraad (1989) para a aplicação do modelo. Outra desvantagem citada pelos mesmos autores é o fato da fissura só poder abrir em uma direção pré-definida, ao longo da interface dos elementos finitos adjacentes. No entanto, segundo Rots e Blaauwendraad (1989), este modelo pode ser adequado para os problemas de engenharia nos quais a fratura ocorre em linha reta e sua localização é previamente conhecida ou no caso de fissuras na interface do concreto com a armadura.

No modelo "Smeared Crack Model", a região da fissura é tratada como um meio contínuo e o comportamento da fissura é descrito por meio de uma relação tensãodeformação. Este modelo se mostra mais abrangente que o modelo de fissuras discretas pelo fato de não alterar a malha de elementos finitos e não impor restrições às direções dos planos de fissura, como afirmam Rots e Blaauwendraad (1989).

Para se utilizar este modelo, são necessários os seguintes parâmetros: energia de fratura na tração $G_{f}$; energia de fratura na compressão $G_{c}$; resistência à compressão; resistência à tração; fator de retenção ao cisalhamento $\beta$ e a largura de banda da fissura $h_{c r}$.

A energia de fraturamento é a energia necessária para propagação de uma fissura incremental de área unitária e pode ser determinada pelo método sugerido pela RILEM Draft Recommendation TC50-FMC (1985) por meio de ensaios de flexão em três pontos em vigas entalhadas. Neste ensaio, a energia de fraturamento é obtida dividindo a área abaixo da curva força-deslocamento pela área da seção transversal do corpo-de-prova que contém o entalhe. Outra maneira de se obter a energia de fraturamento é realizando ensaio com deformação 
controlada, medindo a abertura da fissura. O valor de $G_{f}$, neste caso, é obtido integrando a curva tensão-abertura de fissura.

Caso não se tenha resultados experimentais, o CEB-FIP Model Code (1990) indica a equação 3.1 para determinar a energia de fraturamento na compressão.

$$
G_{f}=G_{F O} \cdot\left(\frac{f_{c m}}{f_{c m o}}\right)^{0,7}
$$

Sendo:

$f_{c m o}=10 \mathrm{MPa}$

A resistência à compressão média $\left(f_{c m}\right)$ é determinada pela expressão 3.2.

$$
f_{c m}=f_{c k}+8
$$

E o valor da energia de fratura base $\left(G_{F O}\right)$, é função do diâmetro máximo do agregado, conforme Tabela 3.

Tabela 3 - Valores de $G_{F O}$ em função do diâmetro do agregado.
\begin{tabular}{c|c}
\hline $\mathrm{D}_{\text {máx }}(\mathrm{mm})$ & $G_{F O}\left(\mathrm{~N} \cdot \mathrm{mm} / \mathrm{mm}^{2}\right)$ \\
\hline 8 & 0,025 \\
\hline 16 & 0,030 \\
\hline 32 & 0,058 \\
\hline
\end{tabular}

Quanto à energia de fraturamento à compressão, Feenstra (1993) recomenda um valor de 50 a 100 vezes a energia de fratura na tração.

O coeficiente de retenção ao cisalhamento é utilizado para considerar uma parcela da tensão de cisalhamento transferida após a fissuração. Essa parcela é considerada, pois, em materiais heterogêneos como o concreto, esta tensão pode ser transmitida pelo intertravamento dos agregados mesmo após a fissuração. Este coeficiente indica a parcela do módulo de elasticidade transversal considerado após a fissuração.

O comprimento de banda serve para suprir a deficiência de malha do modelo nas regiões fissuradas. O DIANA 9.4 calcula esse comprimento para elementos tridimensionais 
pela expressão 3.3. O programa permite que se entre com um valor pré-definido do comprimento de banda, no entanto, optou-se, neste trabalho, por um valor calculado pela equação 3.3 e definido no programa.

$$
h_{c r}=\sqrt[3]{V_{e}}
$$

Sendo que $V_{e}$ é volume do elemento finito adotado.

O DIANA 9.4, considera que ocorre um dano irreversível no elemento finito da rede de elementos finitos, quando a energia dissipada supera o valor do trabalho inelástico do material $\left(g_{f}\right)$, conforme expressão 3.4. Este valor é função da energia de fratura na tração e do comprimento de banda.

$$
g_{f}=\frac{G_{f}}{h}
$$

Dentro dos modelos de fissura distribuída, o DIANA 9.4 trata a abertura e orientação das fissuras segundo dois modos distintos: os modelos plásticos e os modelos "Total Strain".

\subsubsection{Modelos "Total Strain"}

Segundo DIANA (2005-a) o modelo “Total Strain” descreve o comportamento do concreto, tanto na tração quanto na compressão, por meio da relação tensão-deformação. Esta metodologia é baseada nas teorias da compressão modificada apresentadas por Vecchio e Collins (1986) e por Selbby e Vecchio (1993). Esse modelo fornece bons resultados nos estados limites governados pela fissuração e pela ruína do concreto.

O DIANA 9.4 permite utilizar o modelo "Total strain" adotando fissuras rotacionais ou fissuras fixas. No modelo das fissuras rotacionais "Rotating crack Model", a relação tensão-deformação é avaliada na direção principal do vetor deformação e, durante a propagação, as fissuras tem a mesma direção do vetor das deformações principais, mudando de direção de acordo com a rotação deste. Para estes modelos, segundo Maekawa et al. (2003), pode-se desconsiderar a transferência de cisalhamento, tendo em vista que as direções das tensões principais coincidem com as direções das deformações principais.

DIANA (2005-a) indica que no modelo de fissuras fixas "Fixed crack Model" as fissuras permanecem com orientação fixa e conservam esta orientação nos estágios seguintes. Somente mudam de direção quando a variação do ângulo da fissura for de $90^{\circ}$. Neste modelo, a relação tensão-deformação é avaliada num sistema fixo e as direções principais das tensões 
e das deformações não são coincidentes. Sendo assim, a consideração do cisalhamento tornase necessária. As fissuras são tratadas de forma mais próxima à realidade.

Para os modelos “Total Strain”, é necessário que se forneçam as leis constitutivas que representam o comportamento do concreto na tração e na compressão. O DIANA 9.4 possui algumas relações pré-definidas fundamentadas na energia de fratura e na banda de fissura. Nas Figura 22 e 23, estão representadas as leis constitutivas disponíveis para compressão e tração, respectivamente.

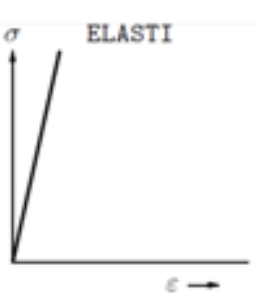

(a) Elástico

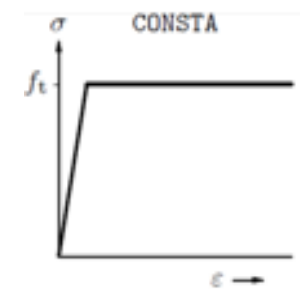

(b) Elasto-plástico perfeito

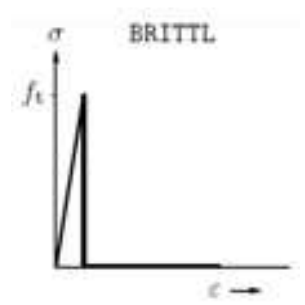

(c) Frágil

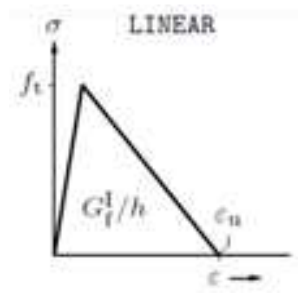

(d) Linear

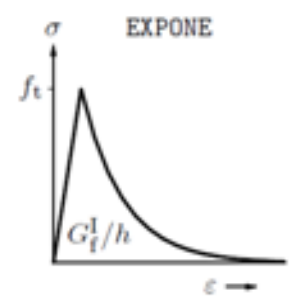

(e) Exponencial

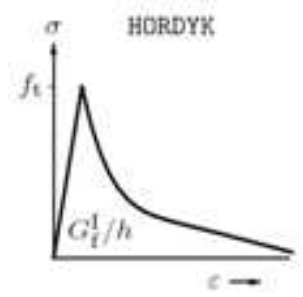

(f) Hordyk

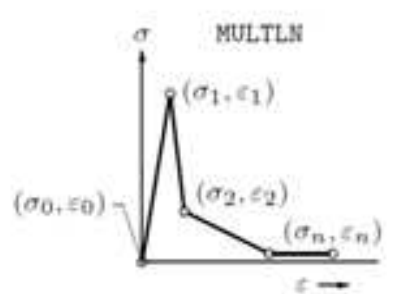

(g) Multi-linear

Figura 22 - Modelos constitutivos disponíveis para a compressão. (Fonte: DIANA 9.4 (2005-a)). 


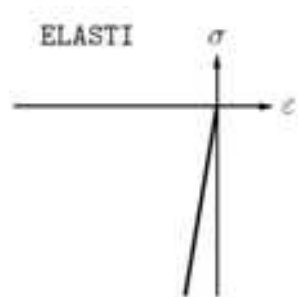

(a) Elástico

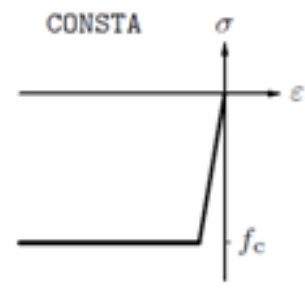

(b) Elasto-plástico perfeito

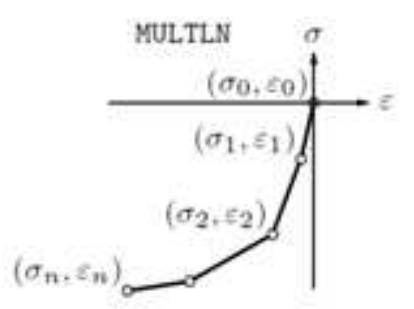

(d) Multi-linear

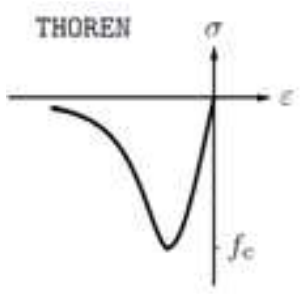

(c) Thoren

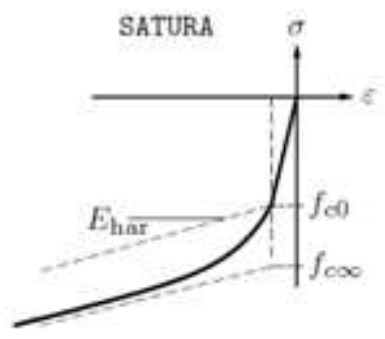

(e) Tipo Saturação

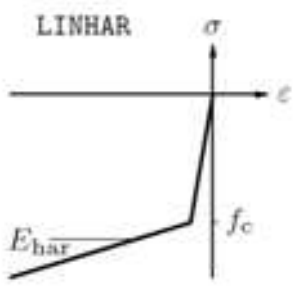

(d) Linear

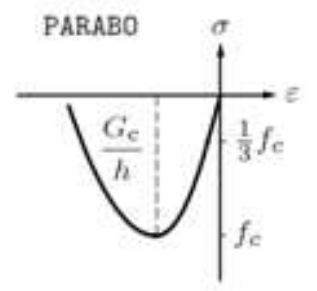

(d) Parabólico

Figura 23 - Modelos constitutivos disponíveis para a tração. (Fonte: DIANA 9.4 (2005-a)).

Em estados multiaxiais de tensão, os materiais apresentam comportamentos diferentes em função da combinação dos esforços nas diferentes direções. No caso do concreto confinado, submetido em todas as direções a forças de compressão, há um acréscimo de resistência pelo confinamento ou, no caso de tração, em um sentido há perda de resistência por causa da fissuração. Estes casos são possíveis de se considerar nos modelos "Total Strain” disponíveis no DIANA 9.4. A redução em virtude da fissuração lateral é determinada segundo a relação apresentada por Collins e Vecchio (1993) representada na Figura 24. O aumento da rigidez por causa do confinamento é determinado pelo modelo de Selby e Vecchio (1993).

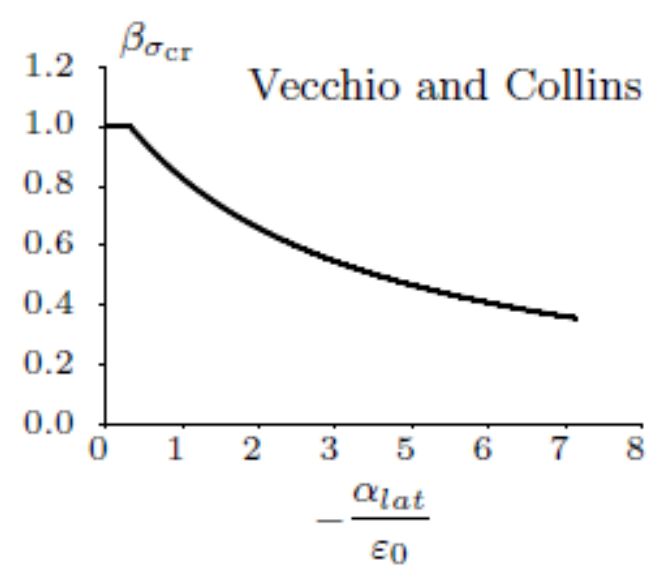

Figura 24 - Fator de redução por causa da tração transversal a direção principal.

(Fonte: DIANA 9.4 2005-a)). 
Barros (2009) e Marek (2010) que comparam os resultados numéricos de simulações com blocos de fundação com resultados experimentais observaram que os modelos numéricos, mesmo sem considerar o efeito do confinamento, mostraram-se mais rígidos que os experimentais. Optou-se, desta forma, por desprezar a parcela do aumento da capacidade resistente em virtude do confinamento.

O comportamento ao cisalhamento também sofre influência da fissuração do concreto. Nos modelos “Total Strain fixed crack Model”, esse efeito é considerado pelo coeficiente de retenção ao cisalhamento. No DIANA 9.4, é possível considerar este fator de três maneiras distintas: retenção completa, retenção constante e retenção variável. No caso de retenção completa, o módulo de elasticidade não sofre redução após a fissuração do concreto. $\mathrm{Na}$ retenção variável, o programa calcula o coeficiente $(\beta)$ de acordo com a abertura das fissuras. Para a retenção constante, o coeficiente $(\beta)$ é adotado como um valor fixo que pode variar de 0 a 1, quanto menor mais significativa a redução do módulo de elasticidade transversal e maior a influência do cisalhamento na ruptura do concreto.

Marek (2010) e Barros (2009) estudaram a influência deste parâmetro nos blocos de fundação e ambos concluíram que é adequado adotar o coeficiente de retenção ao cisalhamento igual a 0,99 . Isso é coerente, pois a influência do cisalhamento na ruína de blocos rígidos é desprezível.

\subsubsection{Modelos Plásticos}

Os modelos plásticos utilizam a teoria da plasticidade sendo que a deformação do material é dividida em duas parcelas, uma elástica e outra plástica. A ruptura ocorre quando, em um ponto, a máxima tensão de tração ultrapassa a resistência do material. Na compressão são adotados os critérios de ruptura de Von Mises, Tresca, Drucker-Prager e Mohr-Coulomb.

O DIANA 9.4 trata os modelos plásticos considerando o modelo de fissuras fixas "Multi-direcional Crack Model" que permite a abertura simultânea de várias fissuras em direções diferentes num mesmo ponto da malha de elementos finitos. No entanto, esse modelo só está disponível para o estado plano de tensão e de deformação e em elementos axissimétricos. 


\subsubsection{Modelagem das barras de aço}

De acordo com DIANA (2005-b) As barras de aço podem ser modeladas de duas maneiras: armadura distribuída e armadura embutida.

A armadura distribuída considera uma área de aço distribuída em uma determinada direção.

A armadura embutida é discretizada por uma barra que cruza os elementos finitos conforme Figura 25. Este elemento é denominado de "embedded reinforcement" e sua função é enrijecer os elementos finitos nos quais estão inseridos.

Estas barras não possuem graus de liberdades próprios e para inseri-las basta indicar o ponto inicial e o final da barra, independentemente se os nós das barras coincidem ou não com os nós da rede de elementos finitos. Com este elemento, o DIANA 9.4 não considera o escorregamento da barra de aço, pois a aderência nestes casos é considerada perfeita.

Além da localização, é necessário fornecer ao programa a área da seção transversal da barra, o módulo de elasticidade, a tensão de escoamento e o coeficiente de Poisson do aço.

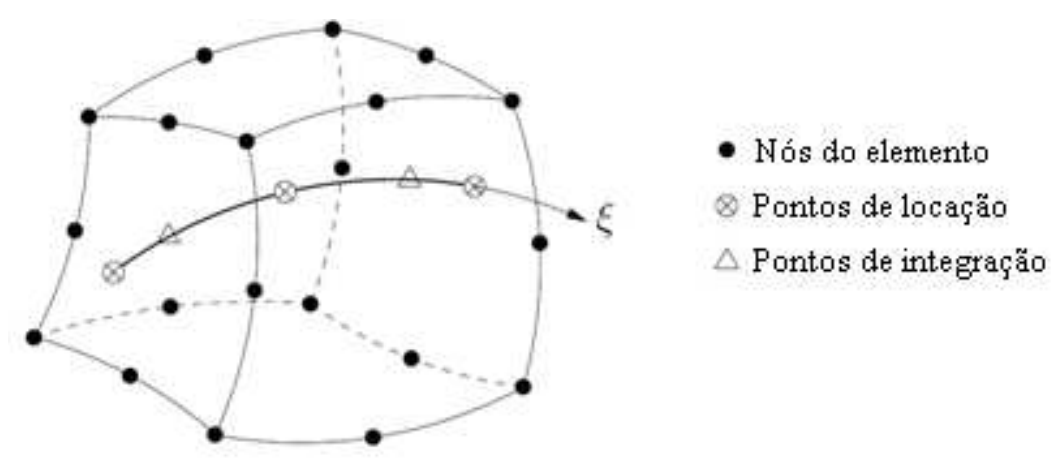

Figura 25 - Armadura embutida no elemento finito. (Fonte: DIANA 9.4 2005-b).

Por se tratar de uma modelagem mais fácil e que fornece resultados aceitáveis, adotouse neste trabalho a última opção para representar as armaduras nos modelos de bloco sobre quatro estacas com cálice parcialmente embutido.

O comportamento das barras de aço foi considerado elasto-plástico perfeito, sendo a ruptura governada pelo critério de Von Mises. 


\subsubsection{Elementos finitos utilizados}

Para uma adequada análise numérica dos blocos sobre quatro estacas, em função do tipo de solicitação, fez-se necessário criar modelos tridimensionais. Em se utilizando o método dos elementos finitos, a modelagem nestes casos deve ser com elementos sólidos.

Dentre os elementos finitos sólidos disponíveis na biblioteca do DIANA 9.4, um dos recomendados para a análise não linear é o elemento finito $\mathrm{CHX60,} \mathrm{sendo} \mathrm{este} \mathrm{um} \mathrm{elemento}$ finito isoparamétrico com 20 nós (Figura 26) e com função aproximadora quadrática, representada pela equação 3.4 .

A escolha do elemento com interpolação quadrática se deve ao fato de que, segundo o DIANA (2005-b), os elementos de interpolação linear, disponíveis na sua biblioteca, não são indicados para análise não linear.

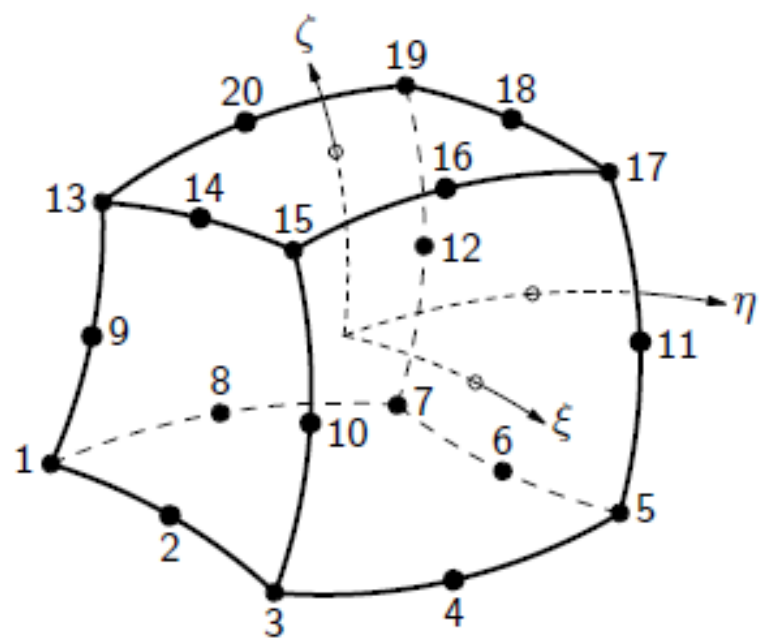

Figura 26 - Elemento finito CHX-60. (Fonte: DIANA 9.4 2005-b)

$$
\begin{aligned}
u_{i}(\xi, \eta, \zeta)= & a_{0}+a_{1} \xi+a_{2} \eta+a_{3} \zeta+a_{4} \xi \eta+a_{5} \eta \zeta+ \\
& a_{6} \xi \zeta+a_{7} \xi^{2}+a_{8} \eta^{2}+a_{9} \zeta^{2}+a_{10} \xi \eta \zeta+ \\
& a_{11} \xi^{2} \eta+a_{12} \xi^{2} \zeta+a_{13} \xi \eta^{2}+a_{14} \xi \zeta^{2}+a_{15} \eta^{2} \zeta+ \\
& a_{16} \eta \zeta^{2}+a_{17} \xi^{2} \eta \zeta+a_{18} \xi \eta^{2} \zeta+a_{19} \xi \eta \zeta^{2}
\end{aligned}
$$

Nas simulações dos modelos com interface lisa, utilizou-se na interface junta/bloco um elemento finito plano, quadrilateral denominado de CQ48I representado na Figura 27. Este elemento possui função aproximadora quadrática. 


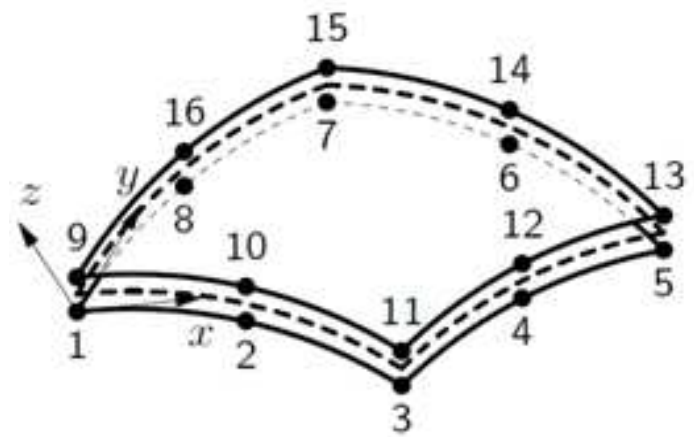

(a) Topologia

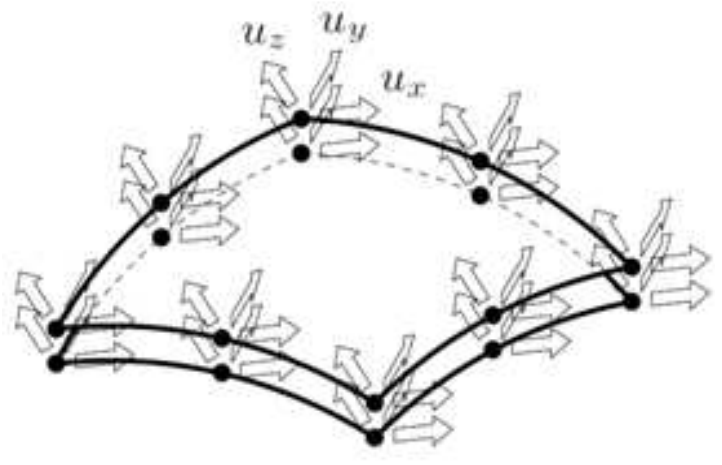

(b) Deslocamento

Figura 27 - Elemento finito de interface CQ48I. (Fonte: DIANA 9.4 2005-b)

Optou-se por utilizar estes dois elementos, pois são indicados para a análise não-linear. Além disso, foram utilizados nos trabalhos de Barros (2009) e Marek (2010) que simularam estruturas semelhantes à desta dissertação e obtiveram bons resultados.

\subsubsection{Método de resolução dos sistemas de equações}

Em análise de estruturas pode-se considerar variação não linear nas leis constitutivas dos materiais empregados, denominada de não linearidade física. Também se pode considerar o equilíbrio levando-se em conta as deformações e os deslocamentos ocorridos, denominada de análise não linear geométrica. Em ambos os casos a relação do vetor de força e deslocamento não é linear, e a solução é determinada por meio de análise incrementaliterativa. A solução para estes casos requer um procedimento iterativo, baseados nas tentativas e correção do erro (Proença 2010). Dentre os procedimentos adotados estão o método direto ou secante e o método tangente.

O DIANA 9.4 fornece os procedimentos de rigidez constante, rigidez linear, NewtonRaphson regular ou modificado e quase-Newton ou secante.

Segundo Proença (2010), a estratégia de Newton-Raphson tem por base que o resíduo seja uma função contínua nas vizinhanças da solução e a solução de um determinado incremento de carga é satisfeita quando o resíduo obedece a uma tolerância pré-determinada.

O procedimento de Newton-Raphson, tanto o regular quanto o modificado, utiliza a matriz de rigidez tangente durante o processo iterativo. A diferença entre eles é que o Newton-Raphson-regular atualiza esta matriz de rigidez a cada iteração dentro de um mesmo passo de carga. Esse processo demanda maior trabalho computacional, porém um número menor de iterações dentro do passo de carga para que o sistema convirja. O Newton-Raphson 
modificado atualiza a matriz de rigidez apenas na primeira iteração de cada passo de carga, mantendo esta matriz para as demais iterações.

Segundo Proença (2010), com a estratégia direta ou método secante, busca-se a solução para certa intensidade de força aplicada mediante iterações que consistem em correções sucessivas da matriz de rigidez. Sendo assim, usam-se as informações de uma iteração r-1 para atualizar a matriz de rigidez da iteração r.

O processo da matriz linear adota uma matriz de rigidez linear única para todas as iterações e passos de carga utilizados na análise. Apesar de apresentar uma facilidade computacional por utilizar a mesma matriz de rigidez, este processo demanda um maior número de iterações para que o sistema consiga convergir.

O método da rigidez constante utiliza a matriz de rigidez calculada no incremento de carga anterior ao que está sendo analisado.

Todos os métodos de iteração descritos são baseados em uma previsão razoável de modo que o processo de iteração convirja para uma solução numérica exata. No entanto, se a previsão de carga de um determinado passo estiver longe da solução, o processo iterativo não converge. Isto ocorre principalmente em estruturas com fortes não-linearidades ocasionadas por fissuração ou perda do equilíbrio de forma brusca. Segundo Proença (2010), nestes casos, fazem-se necessários algoritmos numéricos que permitam de forma mais precisa a solução do problema. Nestes casos, é interessante que seja possível ajustar os incrementos de carga até encontrar estes pontos.

O DIANA 9.4 oferece a possibilidade de se utilizar a estratégia do comprimento de arco que possibilita descrever de uma forma mais adequada o comportamento pós-pico da curva força-deslocamento, sendo possível descrever comportamentos desta curva como o "Snap-through" e o "Snap-back", ambos os fenômenos representado na Figura 28. 


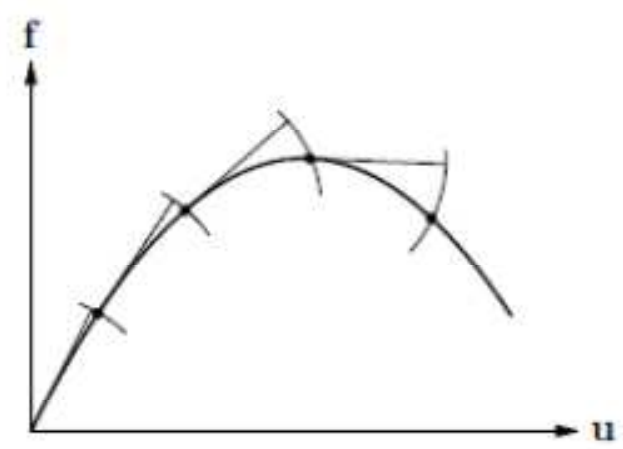

(a) Snap-through

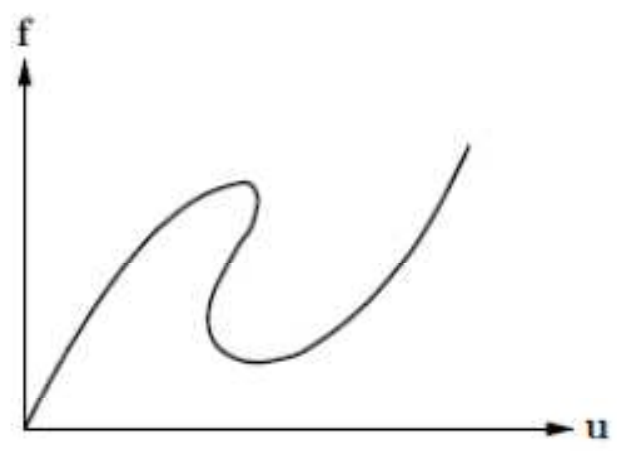

(b) Snap-back

Figura 28 - Fenômenos da curva força/deslocamento possíveis de serem detectados com o método do comprimento de arco. (Fonte: DIANA 9.4 2005-c))

Além do método do comprimento de arco, o DIANA 9.4 possui implementado um algoritmo de otimização denominado de "line search", que determina um fator multiplicador ótimo para a previsão do incremento de deslocamento. Este fator é determinado a partir da minimização da energia potencial do sistema e serve para aumentar a taxa de convergência.

Os critérios de convergência disponíveis no DIANA 9.4 são baseados em norma de energia, norma de força, norma de deslocamento e norma de resíduo. Nos trabalhos de Souza (2004), Barros (2009) e Marek (2010), foram analisados os diferentes critérios de convergência para a análise de blocos sobre estacas, e em todos os trabalhos o critério de convergência em norma de energia foi o que conduziu aos melhores resultados, até por considerar tanto o deslocamento quanto a força interna. Segundo DIANA 9.4 (2005-c) a norma de energia é determinada segundo a equação 3.5.

$$
E=\left|\frac{\delta \cdot u_{i}^{T} \cdot\left(f_{i n t, i+1}+f_{i n t, j}\right)}{\Delta \cdot u_{0 .}^{T} \cdot\left(f_{i n t, 1}+f_{i n t, 0}\right)}\right|
$$

Em função dos resultados obtidos por Barros (2009) e Marek (2010), optou-se por adotar em todas as análises efetuadas nesta dissertação a norma de energia como critério de convergência.

\subsection{Verificação do modelo numérico}

Com o objetivo de verificar se o modelo numérico adotado consegue representar o comportamento de modelos físicos, foram realizadas comparações entre resultados obtidos numericamente e resultados de ensaios experimentais encontrados na bibliografia. Foram 
utilizados neste estudo dois modelos de ligação entre pilar pré-moldado e elemento de fundação com cálice externo apresentados em Canha (2004) e um modelo de bloco sobre quatro estacas submetido à força centrada apresentado em Chan e Poh (2000).

Os modelos de Canha (2004) foram escolhidos, pois apresentam colarinho e foram ensaiados com força excêntrica, condições semelhantes às do bloco cujo estudo é apresentado no Capítulo 4. Além disso, Canha (2004) avaliou experimentalmente diferentes rugosidades na ligação entre pilar e bloco. A rugosidade da ligação tem muita influência na transmissão das tensões entre os elementos. A comparação entre os resultados numéricos e experimentais permitiu o ajustamento dos parâmetros da interface no modelo numérico para que este pudesse simular o atrito e a adesão entre as superfícies do pilar e do colarinho.

O bloco de Chan e Poh (2000) foi escolhido para avaliar se o modelo numérico é capaz de simular de forma aproximada o comportamento de blocos sobre quatro estacas.

\subsubsection{Propriedades dos modelos simulados}

Dentre os modelos ensaiados por Canha (2004), escolheram-se dois: um com interface rugosa e outro com interface lisa denominados pela autora de IR2 e IL3, respectivamente. As geometrias dos dois modelos estão representadas na Figura 29.

Segundo Canha (2004) os modelos foram construídos a partir da dimensão do pilar de $40 \mathrm{~cm}$ x $40 \mathrm{~cm}$ por ser esta dimensão bastante adotada em pilares pré-moldados.

O comprimento de embutimento $\left(\ell_{e m b}\right)$ foi determinado de acordo com a ABNT NBR 9062:1985 que recomenda $1,6 \cdot h$ para ligação rugosa e 2·h para ligação lisa, sendo $h$ a maior dimensão transversal do pilar. Desta forma, para o modelo com chave de cisalhamento, o $\ell_{e m b}$ adotado foi de $64 \mathrm{~cm}$. Para o modelo com ligação lisa, o $\ell_{e m b}$ adotado foi de $80 \mathrm{~cm}$.

A largura das paredes do colarinho foi dimensionada segundo as recomendações de Leonhardt e Mönnig (1977) que sugerem o valor de $\frac{h_{\text {int }}}{3}$.

Os modelos foram dimensionados para força vertical com grande excentricidade, da ordem de $3 \cdot \mathrm{h}$ ou $1,20 \mathrm{~m}$.

A rugosidade do modelo com interface rugosa foi de $1 \mathrm{~cm}$ a cada $4 \mathrm{~cm}$, menor que a recomendada pela ABNT NBR 9062:2006, de $1 \mathrm{~cm}$ a cada $10 \mathrm{~cm}$. 

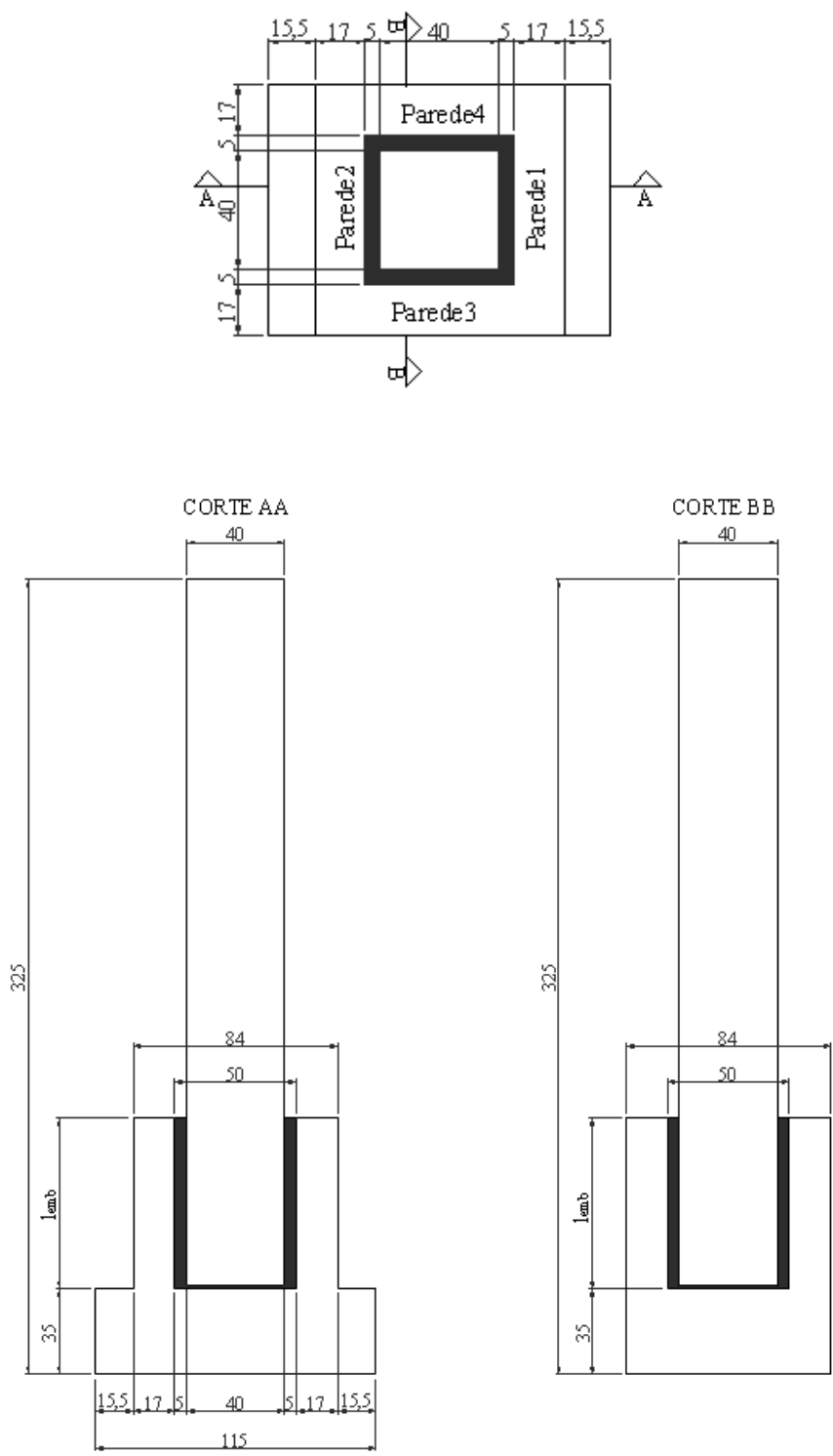

Figura 29 - Geometria dos modelos ensaiados por Canha (2004).

Os modelos foram dimensionados de acordo com as indicações de Leonhart e Mönnig (1977), da ABNT NBR 9062:1985 e de El Debs (2000). Canha (2004) estabeleceu, como critério para o dimensionamento, que durante o ensaio a capacidade de aplicação de força do equipamento de ensaio $(500 \mathrm{kN})$ não fosse excedida.

As áreas das armaduras dos tirantes verticais e das armaduras de costura adotadas nos dois modelos liso e rugoso foram iguais. Segundo Canha (2004), o que diferenciou os dois modelos, além do comprimento de embutimento, foi a área de aço do tirante horizontal. No caso do modelo rugoso, adotaram-se quatro camadas de barras de aço ao invés de três camadas como no modelo liso. Essa medida foi tomada para manter o mesmo diâmetro das barras nos dois modelos e adaptar a área de aço necessária para o modelo. 
Os detalhamentos dos modelos com chave de cisalhamento e sem chave de cisalhamento estão representados nas Figura 30 a Figura 33

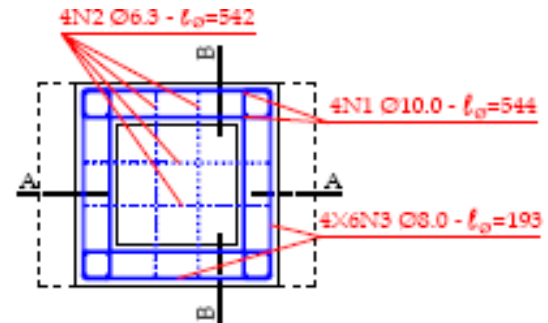

PLANTA DAS ARMADURAS PRINCIPAIS DO COLARINHO

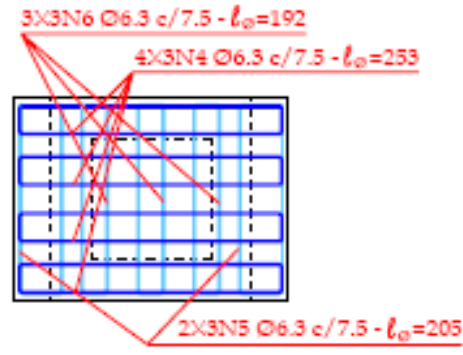

PLANTA DA

ARMADURA DE DISTRIBUTÇÃO

DA BASE DA FUNDAÇÃO

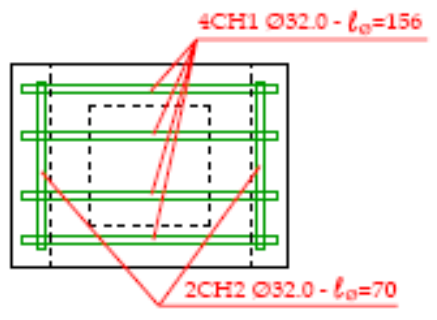

PLANTA DA POSIÇÃO DOS CHUMBADORES

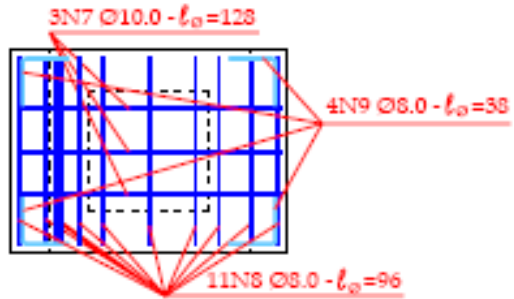

PLANTA DA

ARMADURA INFERIOR

DA BASE DA FUNDAÇÃO
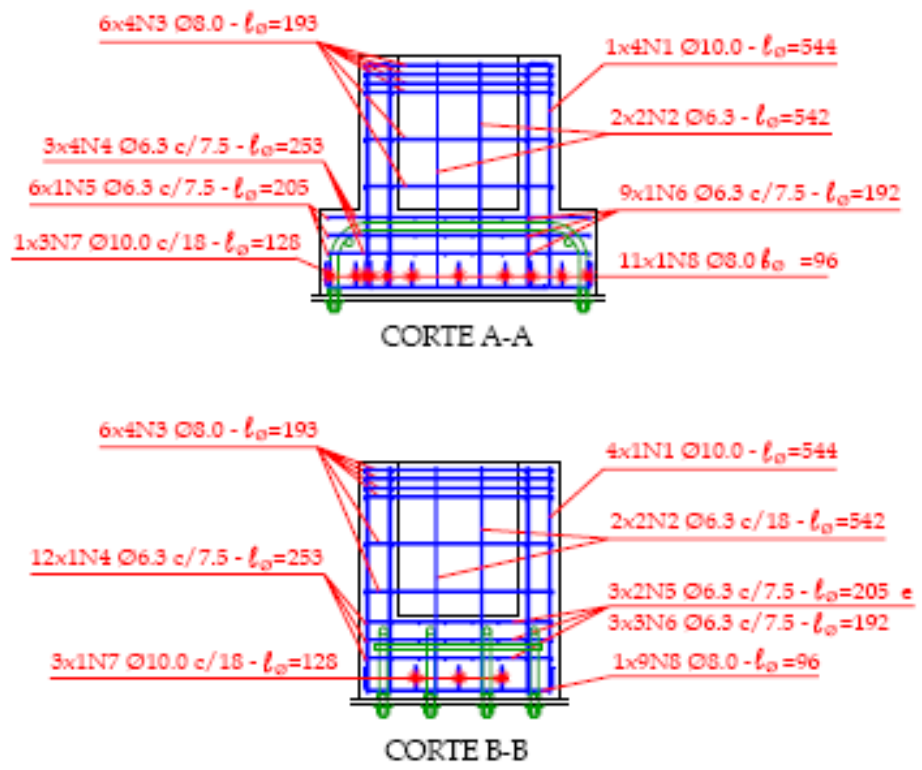

Figura 30 - Detalhamento do bloco, modelo rugoso. (Fonte: Canha (2004)). 


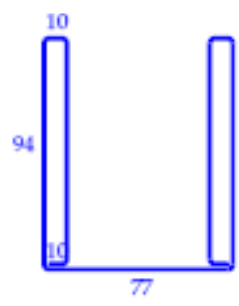

$4 \mathrm{~N} 1 \varnothing 10.0-\ell_{\mathrm{\sigma}}=490$ ARMADURA DO TIRANTE

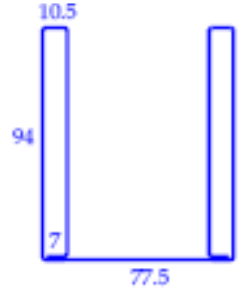

$4 \mathrm{~N} 206.3-\ell_{0}=478$

ARMADURA DE COSTURA
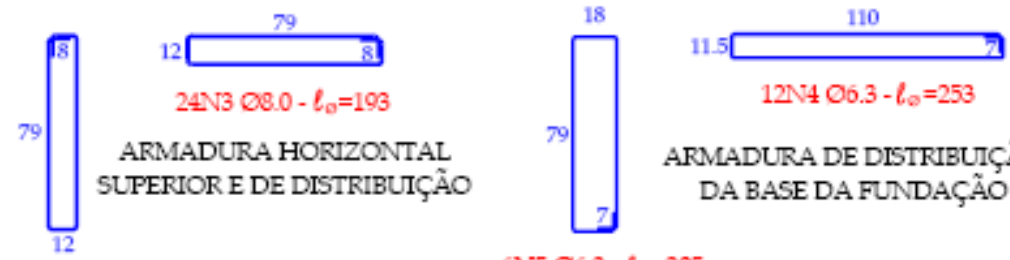

ARMADURA DE DISTRIBUTÇÃO DA BASE DA FUNDAÇÃOO

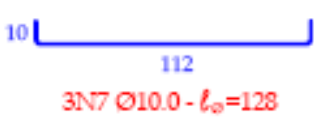

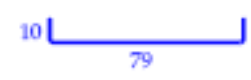

$11 \mathrm{~N} 808.0-\ell_{0}=96$
$19,5 \bigsqcup_{19,5}^{\frac{19,5}{2}} 19,5$

4 N9 $08.0-l_{0}=38$

ARMADURA INFERIOR

DA BASE DA FUNDAÇÃO

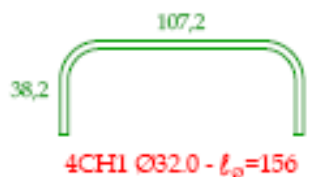

CHUMBADORES DE LIGAÇÃO

DA BASE DA FUNDAÇÂAO AO DISPCSITIVO DE TRANSIÇÃ̃O

$$
\frac{70}{2 \mathrm{CH} 2 \bigcirc 32.0-\ell_{\mathrm{O}}=70}
$$

CHUMBADORES SOLDADOS NOS CHUMRADORES CHI

Figura 31 - Detalhamento do cálice, modelo rugoso. (Fonte: Canha (2004)). 


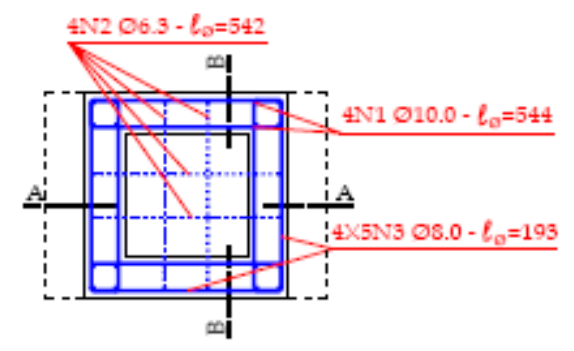

PLANTA DAS ARMADURAS PRINCIPAIS DO COLARINHO

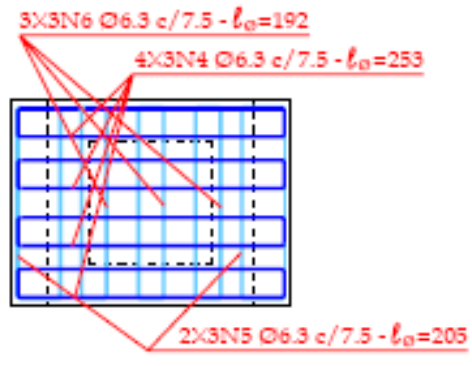

PLANTA DA

ARMADURA DE DISTRIBUTÇÃO

DA BASE DA FUNDAÇÃO

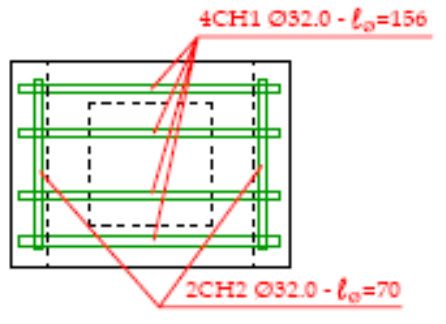

PLANTA DA POSIÇÃO DOS CHUMBADORES

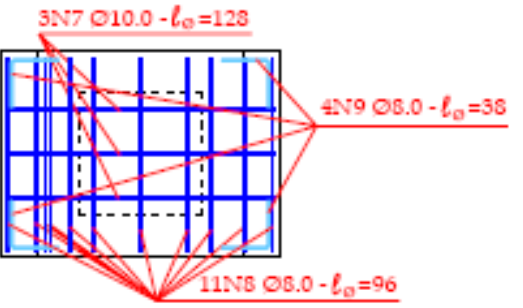

PLANTA DA

ARMADURA INFERIOR

DA BASE DA FUNDAÇÃO
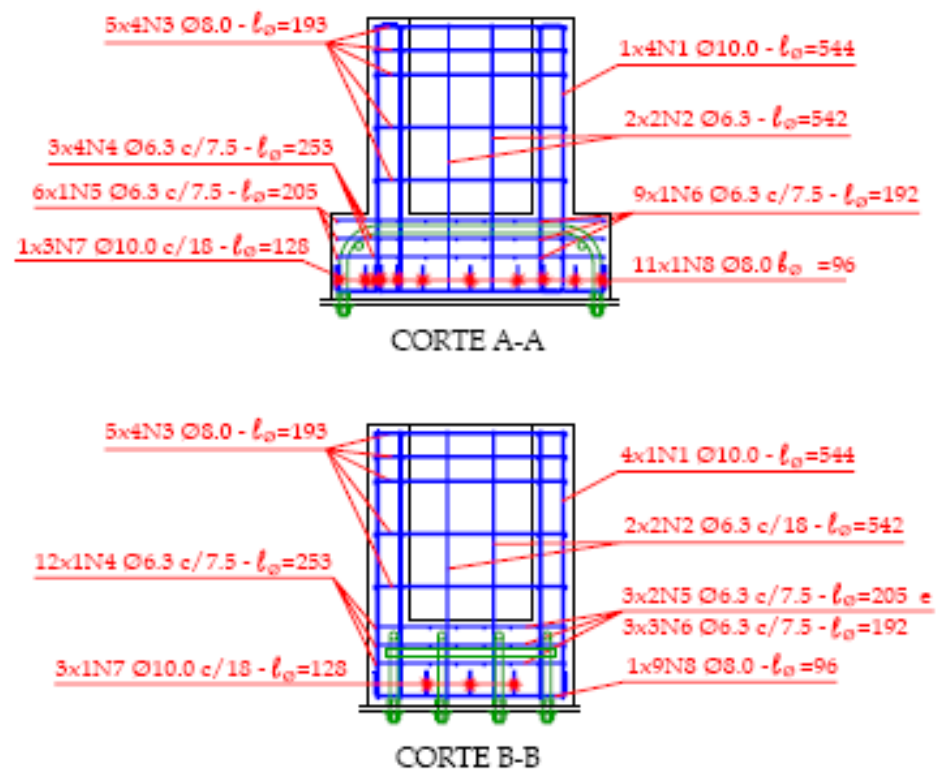

Figura 32 - Detalhamento do bloco, modelo liso IL3. (Fonte: Canha (2004)). 


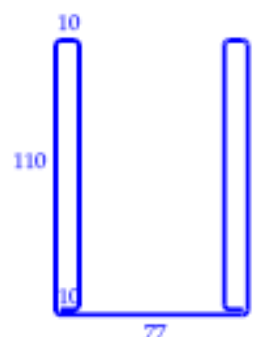

$4 \mathrm{N1} 010.0-\ell_{\sigma}=544$

ARMADURA DO TIRANTE

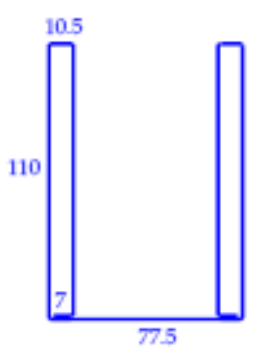

$4 \mathrm{~N} 2063-\ell_{0}=542$

ARMADURA DE COSTURA

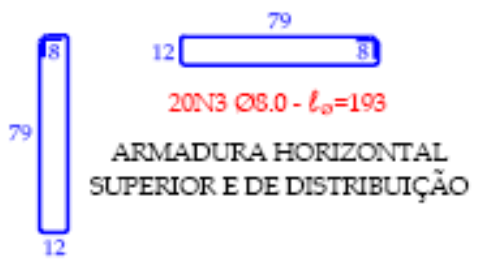

$79{ }_{7}^{18}$

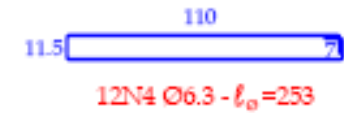

ARMADURA DE DISTRIBUTÇÃO

DA BASE DA FUNDAC ÃO

$6 \mathrm{~N} 506.3-\ell_{0}=205$

$9 \mathrm{~N} 606.3-\ell_{0}=192$

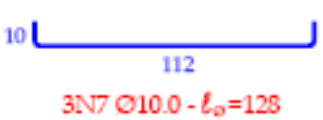

10 L

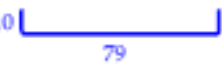

$11 \mathrm{Ns} 08.0-\ell_{0}=96$

ARMADURA INFERIOR

DA BASE DA FUNDAÇÃO

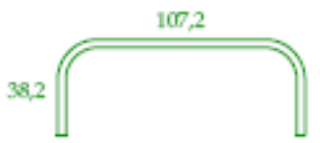

$4 \mathrm{CH} 10320-\ell_{\mathrm{g}}=156$

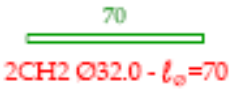

CHUMBADORES DE LIGAÇÃO

DA BASE DA FUNDACÃOAO

DISPOSITIVO DE TRANSTÇÃOO

Figura 33 - Detalhamento do cálice, modelo liso IL3. (Fonte: Canha (2004)).

As propriedades do aço e do concreto utilizados nos dois modelos foram obtidas em ensaios realizados por Canha (2004) e seus valores estão indicados nas Tabela 4 a Tabela 6 . O valor da energia de fratura na tração, $G_{f}$, foi determinado de acordo com a equação 3.1. Para a energia de fratura na compressão, $G_{c}$, foi adotado um valor de $100 \cdot G_{f}$, conforme recomendado por Feenstra (1993). 
Tabela 4 - propriedades do concreto do pilar

\begin{tabular}{c|c|c|c|c|c}
\hline Modelo & \multicolumn{5}{|c}{ Pilar } \\
\cline { 2 - 6 } & $\begin{array}{c}f_{c m} \\
(\mathrm{MPa})\end{array}$ & $\begin{array}{c}f_{c t m} \\
(\mathrm{MPa})\end{array}$ & $\begin{array}{c}E_{c m} \\
(\mathrm{MPa})\end{array}$ & $\begin{array}{c}G_{f} \\
\left(\mathrm{Nmm} / \mathrm{mm}^{2}\right)\end{array}$ & $\begin{array}{c}G_{c} \\
\left(\mathrm{Nmm} / \mathrm{mm}^{2}\right)\end{array}$ \\
\hline IL3 & 56,40 & 3,15 & 36800 & 0,1002 & 10,020 \\
\hline IR2 & 39,67 & 2,79 & 30500 & 0,07778 & 7,778 \\
\hline
\end{tabular}

Tabela 5 - propriedades do concreto da junta

\begin{tabular}{c|c|c|c|c|c}
\hline Modelo & \multicolumn{5}{|c}{ Junta } \\
\cline { 2 - 6 } & $\begin{array}{c}f_{c m} \\
(\mathrm{MPa})\end{array}$ & $\begin{array}{c}f_{c t m} \\
(\mathrm{MPa})\end{array}$ & $\begin{array}{c}E_{c m} \\
(\mathrm{MPa})\end{array}$ & $\begin{array}{c}G_{f} \\
\left(\mathrm{Nmm} / \mathrm{mm}^{2}\right)\end{array}$ & $\begin{array}{c}G_{c} \\
\left(\mathrm{Nmm} / \mathrm{mm}^{2}\right)\end{array}$ \\
\hline IL3 & 61,76 & 3,48 & 40700 & 0,1073 & 10,730 \\
\hline IR2 & 49,72 & 3,10 & 34200 & 0,0921 & 9,210 \\
\hline
\end{tabular}

Tabela 6 - Propriedades do concreto do colarinho

\begin{tabular}{c|c|c|c|c|c}
\hline Modelo & \multicolumn{5}{|c}{ Colarinho } \\
\hline & $\begin{array}{c}f_{c m} \\
(\mathrm{MPa})\end{array}$ & $\begin{array}{c}f_{c t m} \\
(\mathrm{MPa})\end{array}$ & $\begin{array}{c}E_{c m} \\
(\mathrm{MPa})\end{array}$ & $\begin{array}{c}G_{f} \\
\left(\mathrm{Nmm} / \mathrm{mm}^{2}\right)\end{array}$ & $\begin{array}{c}G_{c} \\
\left(\mathrm{Nmm} / \mathrm{mm}^{2}\right)\end{array}$ \\
\hline IL3 & 33,67 & 1,95 & 29100 & 0,06919 & 6,919 \\
\hline IR2 & 24,64 & 1,84 & 29400 & 0,05537 & 5,537 \\
\hline
\end{tabular}

Tabela 7 - Propriedades das barras de aço

\begin{tabular}{c|c|c|c|c|c}
\hline & \multicolumn{5}{|c}{ Diâmetro $(\mathrm{mm})$} \\
\hline & 6,3 & 8 & 10 & 12,5 & 32 \\
\hline$f_{y m}(\mathrm{MPa})$ & 593 & 584 & 639 & 608 & 562 \\
\hline$E_{y m}(\mathrm{MPa})$ & 210238 & 210072 & 210197 & 209655 & 209701 \\
\hline
\end{tabular}

O modelo original ensaiado por Chan e Poh (2000) possuía as estacas circulares, mas, para facilitar a modelagem, estas foram consideradas de seção quadrada, respeitando a seção circular circunscrita.

Quanto às propriedades dos materiais, os pesquisadores forneceram apenas a resistência à compressão do concreto e à tração do aço que valem respectivamente $39,7 \mathrm{MPa}$, 
e 480,7MPa. As demais propriedades foram adotadas segundo as recomendações da ABNT NBR 6118:2003.

$\mathrm{Na}$ vinculação das estacas, restringiu-se apenas a translação vertical. A geometria do modelo e o detalhamento das armaduras estão indicados na Figura 34.
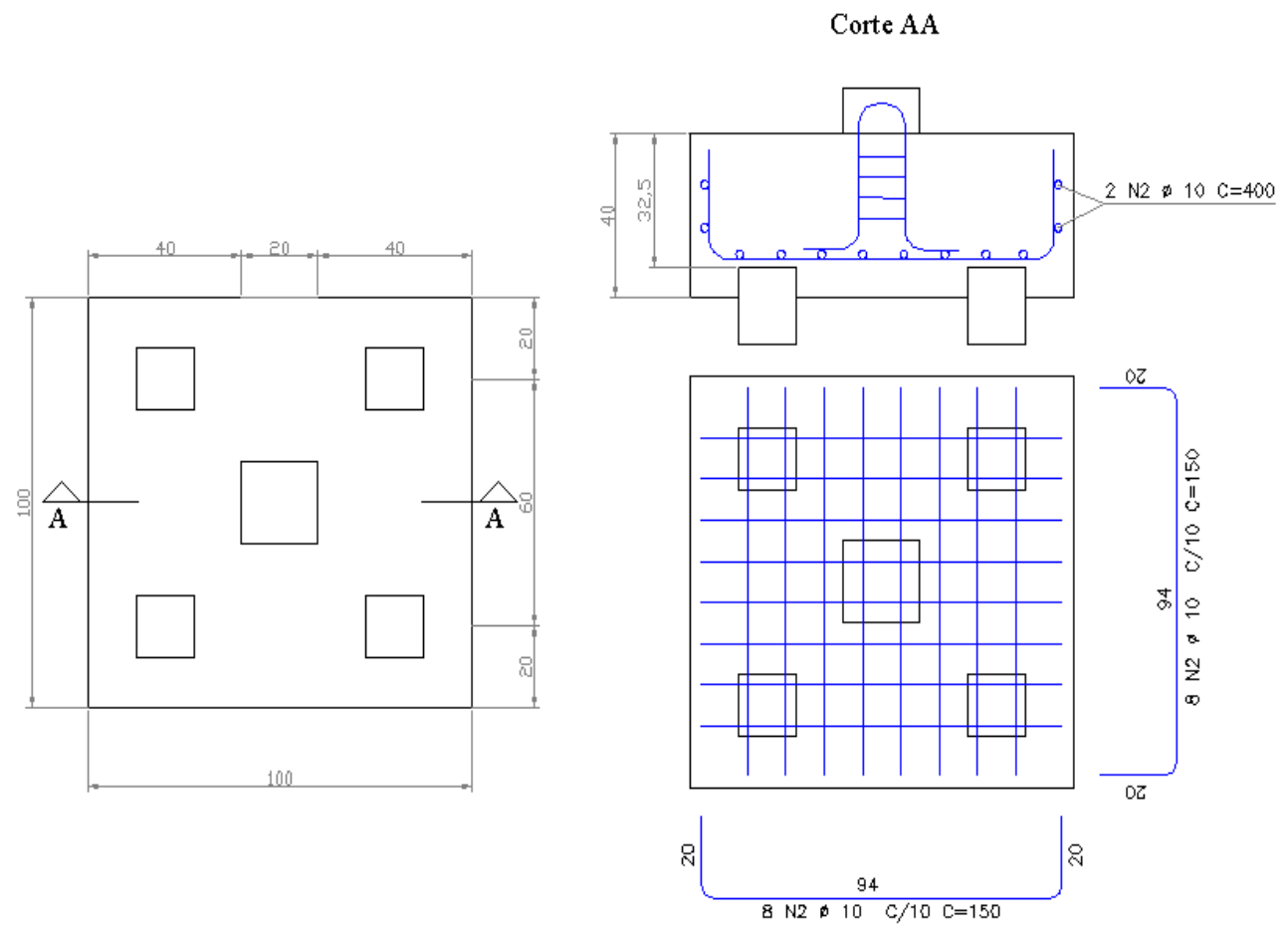

Figura 34 - Modelo ensaiado por Chan e Poh (2000). (Adaptado de Chan e Poh (2000)).

O critério de convergência utilizado para os modelos numéricos foi o critério de norma de energia com tolerância da ordem de 1,5\%. Esta escolha se baseou nos trabalhos de Barros (2009) e Marek (2010), pois ambos adotaram esse critério. Marek (2010) analisou valores de tolerância entre $0,5 \%$ e $2 \%$, e os resultados finais foram praticamente os mesmos. Para tolerâncias menores são necessárias mais iterações o que aumenta o tempo de processamento.

A força, em todos os modelos, foi aplicada em forma de pressão no topo do pilar, e para os modelos com momento, foi gerado um binário a partir da aplicação de pressões nas laterais do pilar.

Para a resolução do sistema de equações, adotou-se o método de Newton Rapshon regular com a estratégia do comprimento de arco e da técnica de "line search".

Para a análise não linear, adotou-se o modelo constitutivo "Total Strain Fixed crack Model" com comportamento ou lei constitutiva do concreto na compressão representado pela 
curva exponencial "expone" e na tração por uma parábola "Parabo", apresentados nas Figuras 22 e 23 , respectivamente.

\subsubsection{Resultados}

\subsubsection{Modelo ligação rugosa}

Segundo Canha (2004), nos casos onde há chave de cisalhamento a ligação entre o pilar e o colarinho pode ser considerada monolítica. Assim, no modelo numérico não foi considerado, na interface entre os diferentes elementos de concreto, elementos finitos de interface ou de contato. O modelo adotado é representado na Figura 35.

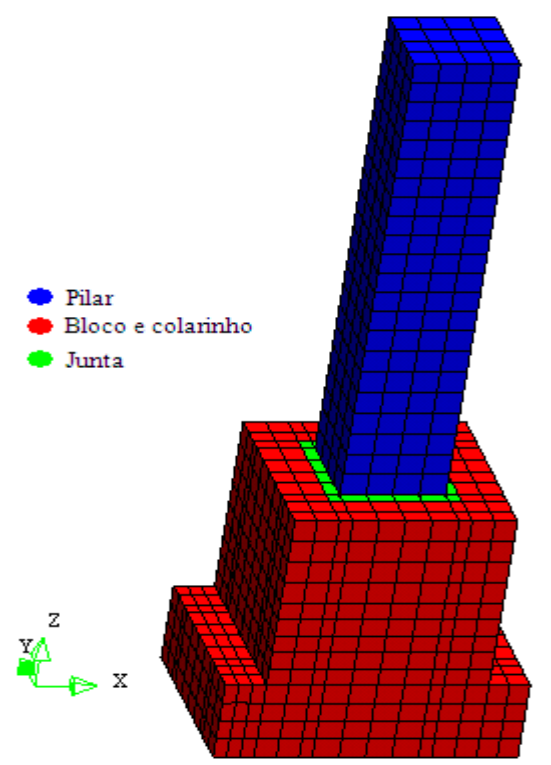

Figura 35 - Modelo do cálice rugoso.

Nas primeiras análises, o modelo se mostrava muito mais rígido que o modelo físico, resistindo a uma força maior que a obtida no ensaio experimental e apresentando deformações nas armaduras menores. Canha (2004) também observou que o modelo numérico apresentavase mais rígido que o modelo experimental e para ajustá-lo variou o módulo de elasticidade do concreto. A autora conseguiu boa aproximação dos resultados numéricos quando foi considerada metade do valor do modulo de elasticidade do concreto. 
Nas análises realizadas nesta dissertação, optou-se por variar a energia de fratura, já que o modelo numérico apresentava poucas fissuras, diferente do que se observava nas fotografias do modelo experimental em etapa próxima da ruína.

Considerando o panorama de fissuração, deformação nas armaduras e força última de convergência, os resultados numéricos que melhor representaram os resultados experimentais foram obtidos quando se adotou $85 \%$ da energia de fratura calculada pela equação 3.1.

Nesse caso, a força última de convergência do modelo numérico $(411 \mathrm{kN})$ atingiu $88 \%$ da força experimental (469 KN).

As deformações obtidas nas barras de aço dos tirantes foram verificadas nas posições indicadas na Figura 36.
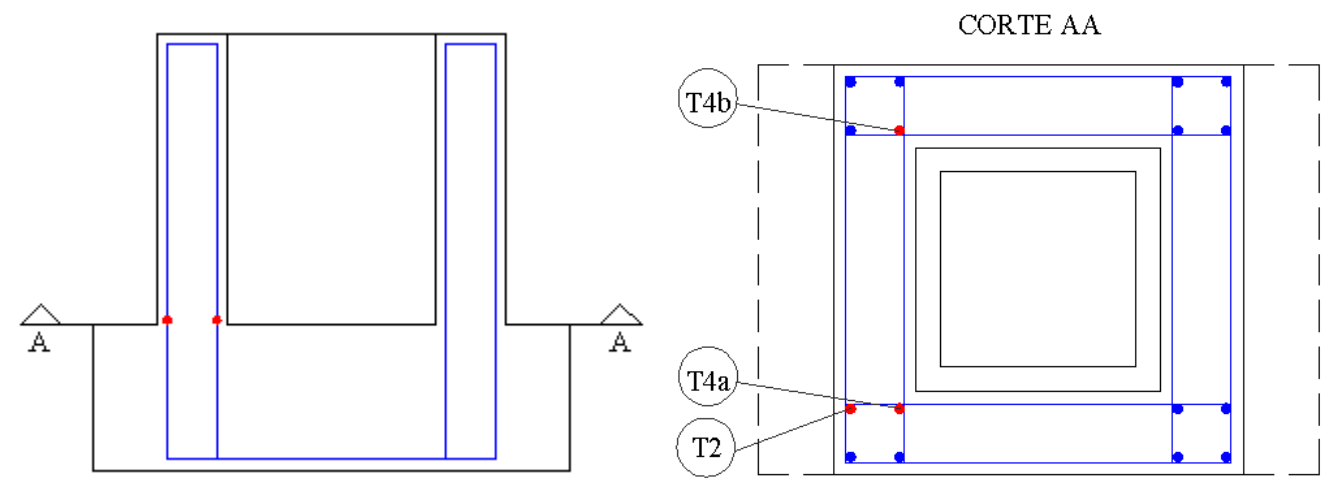

Figura 36 - Posição onde foi medida a deformação dos tirantes: adaptado de Canha (2004)

As curvas força-deformação para os tirantes T-2 e T-4 (média de T-4a e T-4b) do modelo com interface rugosa estão indicadas nas Figura 37 e Figura 38. Observando-se os resultados indicados nos gráficos, percebe-se que a relação força-deformação no tirante T2 seguiu uma tendência próxima a obtida no ensaio experimental, no entanto o modelo numérico mostrou-se menos deformável.

Para a deformação do tirante na posição T4, os resultados numéricos mostraram-se mais rigidos que os experimentais.

Cabe observar que, nos dois casos, o comportamento do modelo mostrou-se mais adequado para forças menores. O modelo não simulou de forma adequada o escoamento das barras das armaduras, principalmente no tirante T4. 


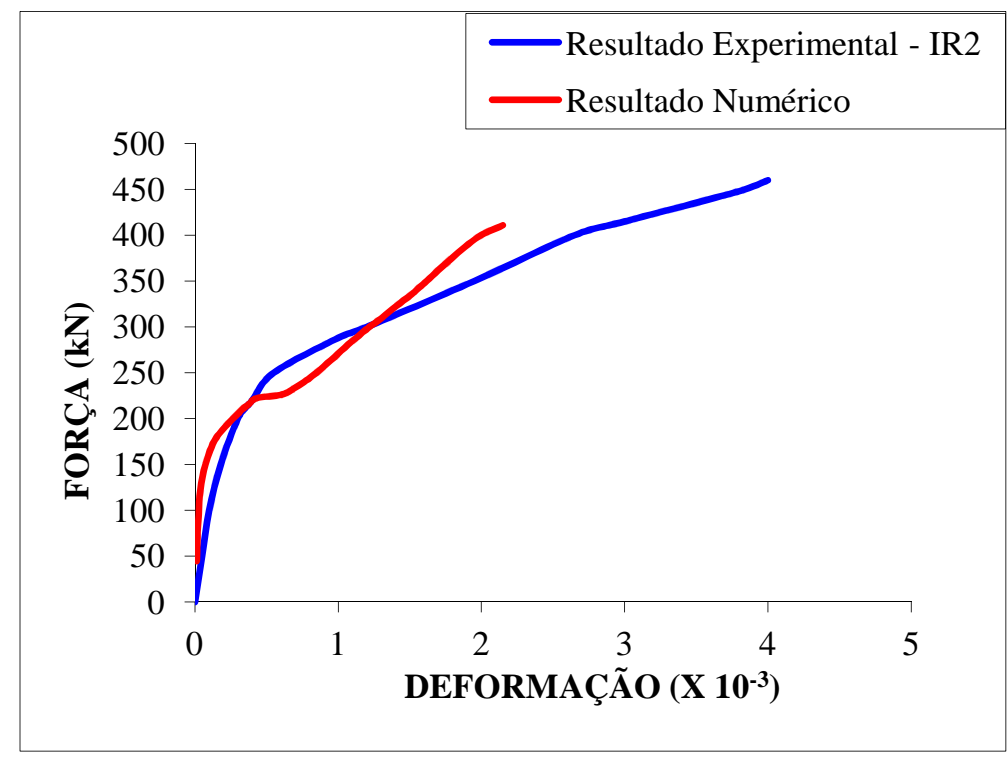

Figura 37 - Força versus deformação no tirante T2 do modelo IR2

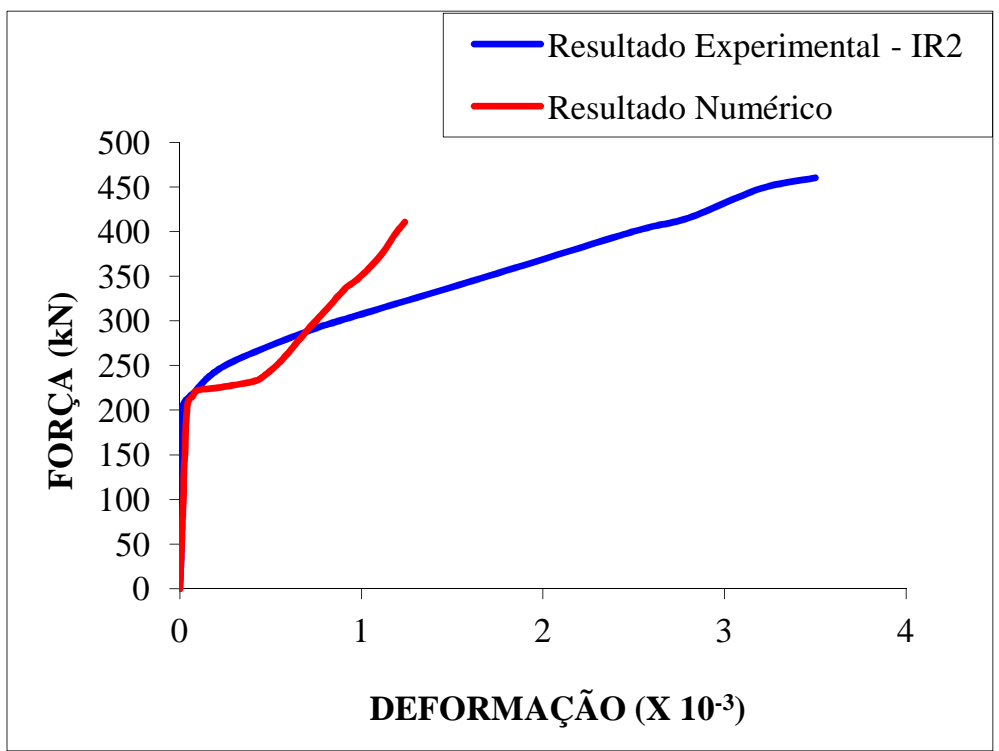

Figura 38 - Força versus deformação no tirante T4 do modelo IR2

Segundo Canha (2004), a ruptura do modelo IR2 foi determinada por plastificação limite das barras das armaduras dos tirantes verticais e das armaduras de costura, na ligação do colarinho com o bloco. Observando as Figura 39 e Figura 40, percebe-se que, no modelo numérico, ambas as armaduras, do tirante e armadura de costura, atingiram o valor da tensão de escoamento do aço. 


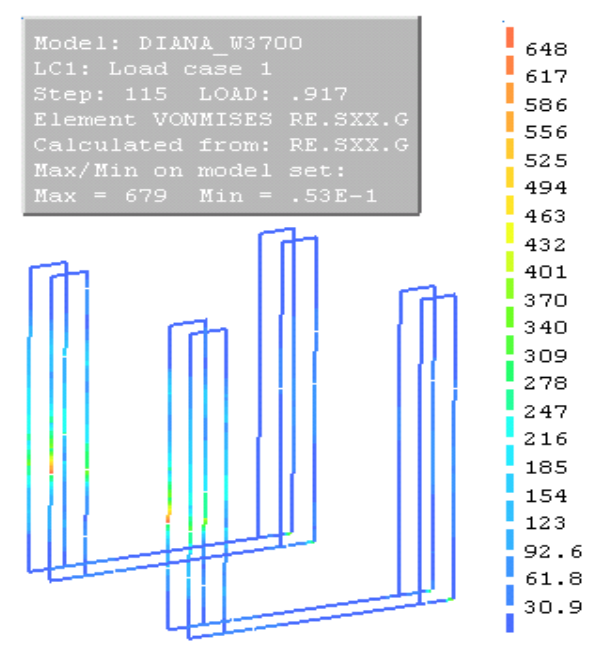

Figura 39- Tirante vertical: Tensão em MPa.

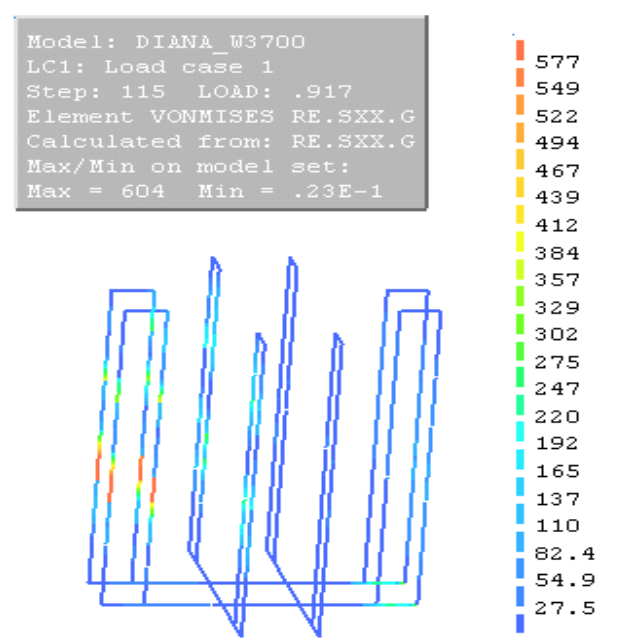

Figura 40 - Armadura secundária vertical: Tensão em MPa.

A evolução da fissuração nas paredes 3 e 4 do colarinho, tanto do modelo numérico como experimental está representada na Figura 41. Observa-se uma configuração de fissuras semelhante. Salienta-se que no ensaio experimental apenas as fissuras visiveis a olho nú são marcadas. Isso justifica um panorama de fissuração mais intenso na ruína no modelo numérico. 


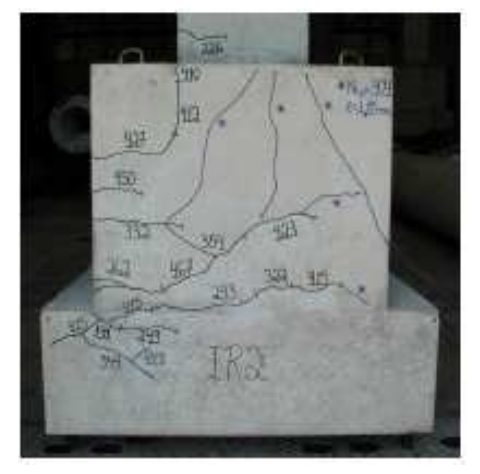

(a)

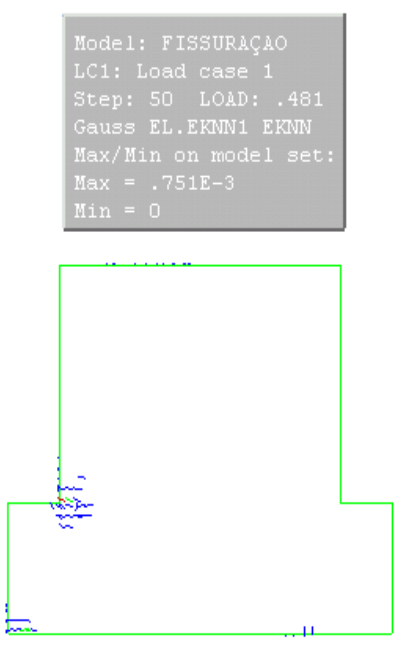

(b)

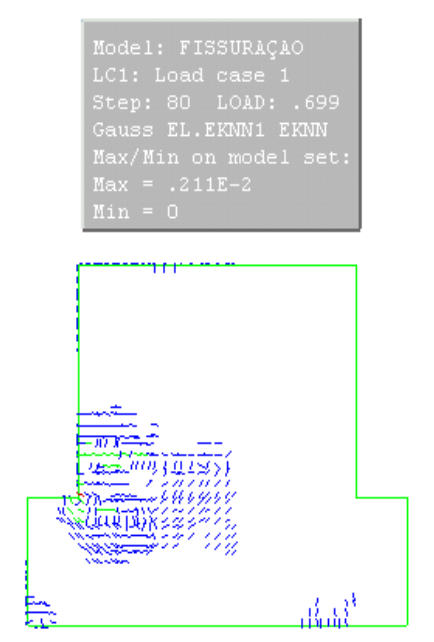

(c)

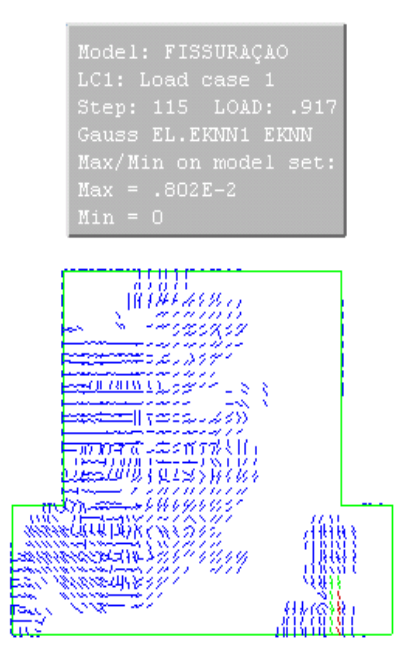

(d)

Figura 41 - Fissuração das paredes 3 e 4 modelo IR2: a) fotografia ensaio experimental (Canha 2004); b) resultado obtido numericamente $52 \%$ força última; c) resultado obtido numericamente $76 \%$ força última; d) resultado obtido numericamente $100 \%$ força última.

Segundo Canha (2004), os modelos de ligação com chave de cisalhamento tiveram comportamento semelhante ao de uma ligação monolítica. No modelo numérico, as fissuras principais foram observadas na parede transversal 2 (Figura 42). Nota-se a fissuração horizontal predominante na ruína do modelo numérico similar ao observado no modelo físico. Canha (2004) afirma que a fissuração foi mais intensa nos cantos da parede 2, o que também foi observado no modelo numérico. 


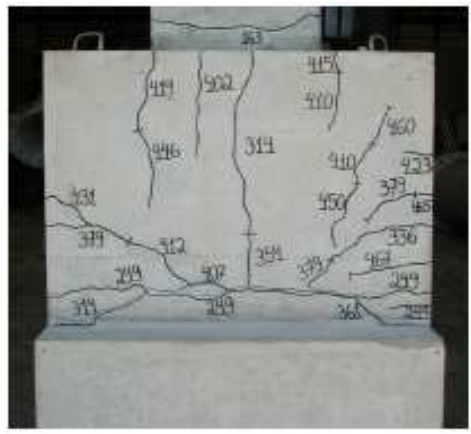

(a)
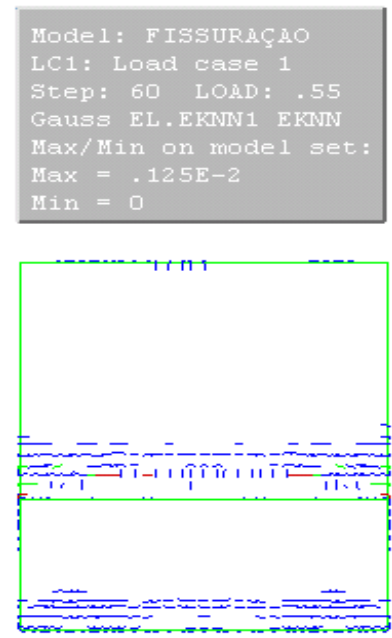

(b)
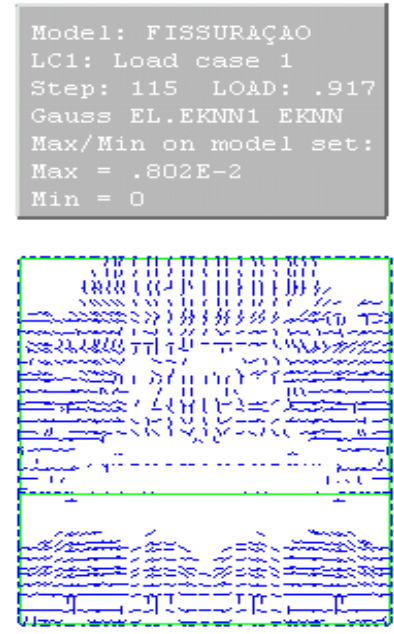

(c)

Figura 42 - Parede 2 modelo IR2: a) fotografia ensaio experimental (Canha 2004); b) resultado obtido numericamente $60 \%$ força última; c) resultado obtido numericamente $100 \%$ força última.

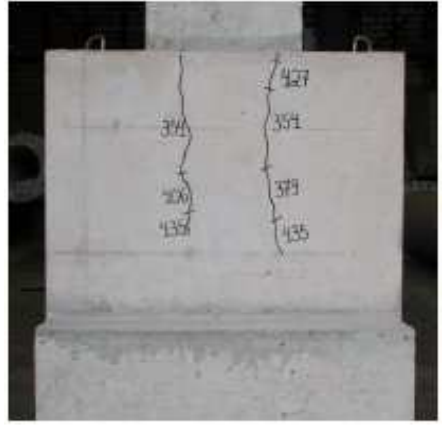

(a)
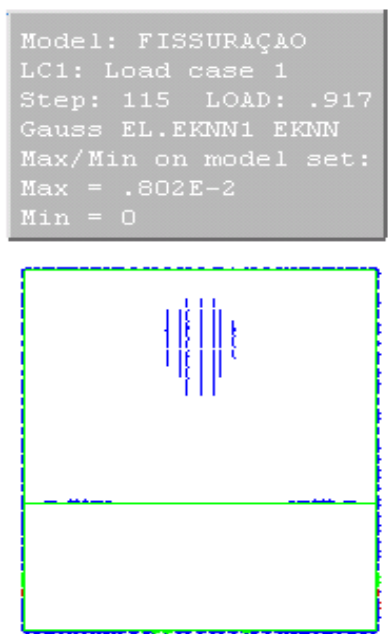

(b)

Figura 43 - Fissuração parede 1 modelo IR2: a) fotografia ensaio experimental (Canha 2004); b) resultado obtido numericamente $100 \%$ força última.

Na Figura 43-a observa-se que parede 1 apresentou poucas fissuras em virtude da pequena transferência da força para esta. Isto também foi observado no modelo numérico.

\subsubsection{Modelo ligação lisa}

No modelo com ligação lisa, adotaram-se os mesmos parâmetros do modelo rugoso. A ligação lisa foi simulada com o emprego de elementos de interface entre o colarinho e o graute, como pode ser observado na Figura 44. 


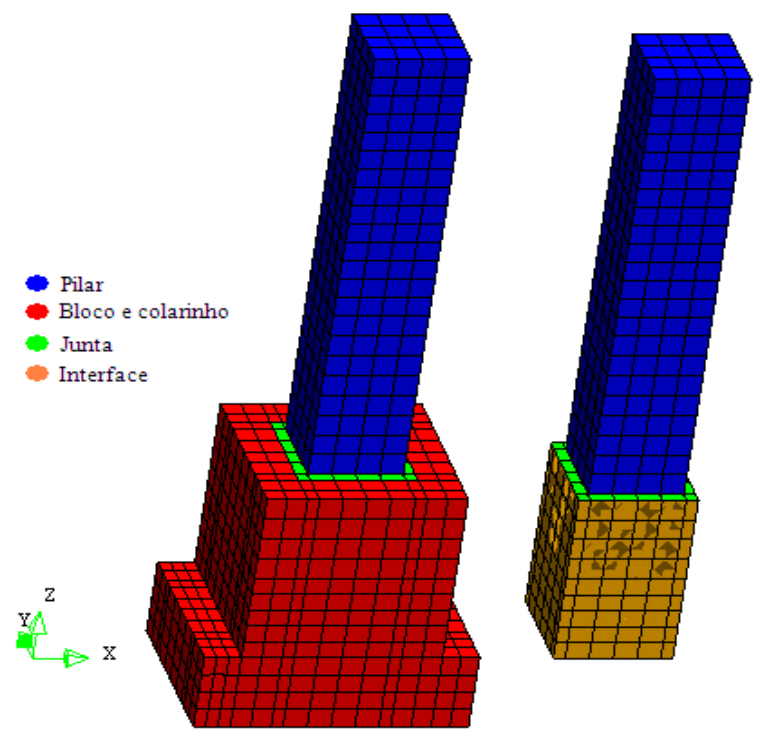

Figura 44- Modelo com ligação lisa.

Para simular o comportamento do material dos elementos de interface CQ48I, o programa DIANA dispõe dos modelos "Linear elasticit", "Nonlin. Elasticity", "Discrete cracking ", "Bond-slip", "Friction" , "Combined Cracking-Shearing-Crushing" e "Usersupplied".

Em geral, segundo DIANA 9.4 (2010-a), a iteração entre duas superficies de elementos de interface pode ser descrita por um comportamento de atrito. Este comportamento pode ser modelado com o modelo de atrito de Coulomb, conforme Figura 45, que tem estreita semelhança com o modelo de plasticidade de Mohr-Coulomb.

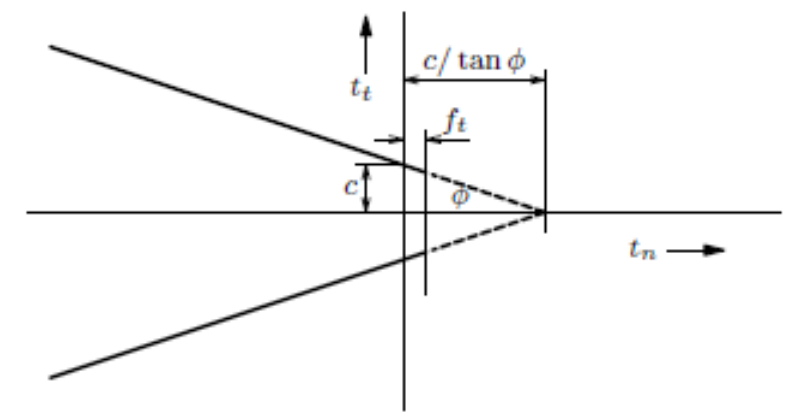

Figura 45 - Critério de atrito de Coulomb. (Fonte: DIANA 9.4 2005-a).

O critério de ruptura de Mohr-Coulomb modificado pode ser dividido em duas partes: critério de deslizamento equação 3.6 e critério de separação equação 3.7. 


$$
\tau=c+\sigma \cdot \tan \phi
$$

$$
\sigma=f_{t}
$$

Sendo:

$c=$ coesão;

$\phi=$ ângulo de atrito;

$f_{t}=$ resitência à tração;

$f_{c}=$ resistência à compressão;

$\tau=$ tensão de cisalhamento;

$\sigma=$ tensão normal.

As propriedades necessárias para descrever o comportamento de atrito de Coulomb são: rigidez tangencial do elemento, rigidez normal, tangente do ângulo de atrito, tangente do ângulo de dilatância, coesão e resistência à tração.

A definição do ângulo de atrito existente entre as superficies de concreto em contato, no caso da ligação lisa, depende de vários fatores. Alguns autores recomendam valores para este parâmetro, conforme descrito no Capítulo 4. Nas simulações realizadas para os modelos com interface lisa, optou-se por adotar o valor de $30,96^{\circ}$, ou um coeficiente de atrito de 0,6 , recomendado por Canha (2004).

Segundo DIANA 9.4 (2005-a), o ângulo de dilatância é igual ao de atrito nos casos deplasticidade associativa. Caso contrário, este ângulo deve ser menor que o ângulo de atrito.

A coesão foi determinada considerando a equação 3.8, apresentada em Chen (1982).

$$
c=\frac{f_{c} \cdot(1-\sin \phi)}{2 \cdot \cos \phi}
$$

Não foram encontrados, na literatura, recomendações ou valores obtidos experimentalmente para as rigidezes tangencial e normal. Sendo assim, os valores das rigidezes foram estimados. No caso da rigidez normal, tomou-se como referência o módulo de elasticidade do concreto da junta.

A tensão normal e a coesão foram calculadas, conforme as equações 3.7 e 3.8 , em função das resistências à compressão e à tração do concreto. 
A força última de convergência do modelo numérico, para o modelo de ligação lisa, foi de $340 \mathrm{kN}$, gerando um momento de $408 \mathrm{kNm}$. A força última no ensaio experimental foi de $336 \mathrm{kN}$ o que gerou um momento de $403 \mathrm{kNm}$. A diferença entre os dois valores é de aproximadamente $1 \%$. Acredita-se que esta força seja a capacidade resitência do modelo numérico pois as armaduras dos tirantes atingiram a tensão de escoamento.

A resistência deste modelo foi limitada pela tensão de escoamento das barras de aço da armadura dos tirantes como se observa na Figura 47.

Para o modelo com interface lisa, também foram comparadas as deformações no tirante vertical na posição T2 e no horizontal na posição HSL1, indicadas na Figura 46. As curvas força-deformação numéricas e experimentais são apresentadas nas Figura 48 e Figura 51.
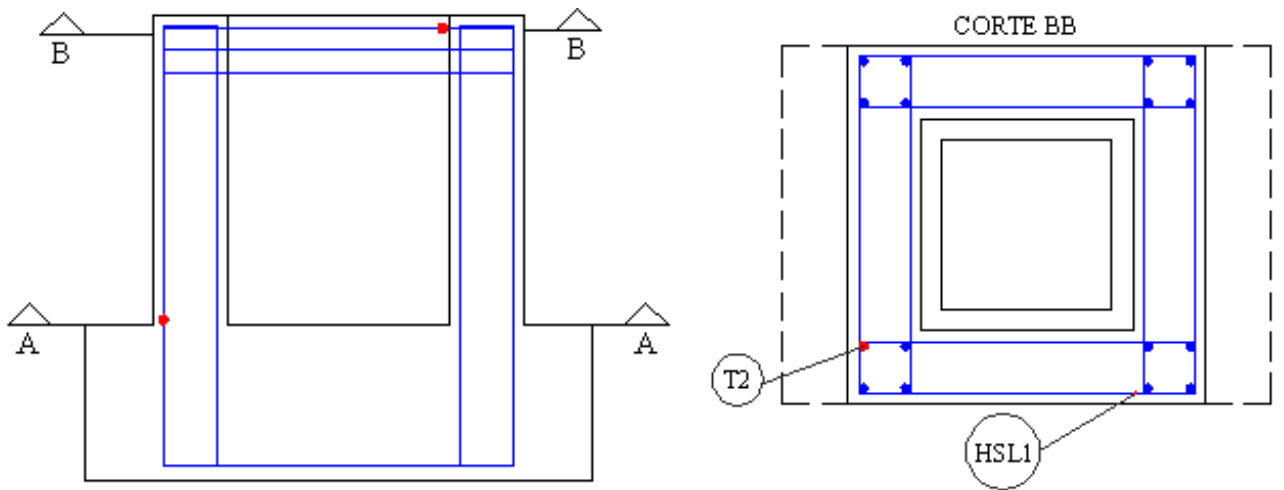

Figura 46 - Posição dos extensômetros

Canha (2004) observou que a ruína do modelo com ligação lisa ocorreu tanto pela plastificação limite das armaduras verticais dos tirantes quanto da armadura secundária, na ligação da parede transversal 2 com o bloco. Este fato também foi observado no modelo numérico, conforme se pode ver nas Figura 47 e Figura 48, sendo que as cores em vermelho indicam os pontos de maiores tensões das armaduras.

Apesar do modelo numérico ter atingido praticamente a mesma força última, as deformações nos tirantes na posição T2 foram menores que as obtidas no ensaio experimental. Observa-se, no entanto, uma semelhança formal nas curvas numérica e experimental forçadeformação no tirante T2 (Figura 48). 


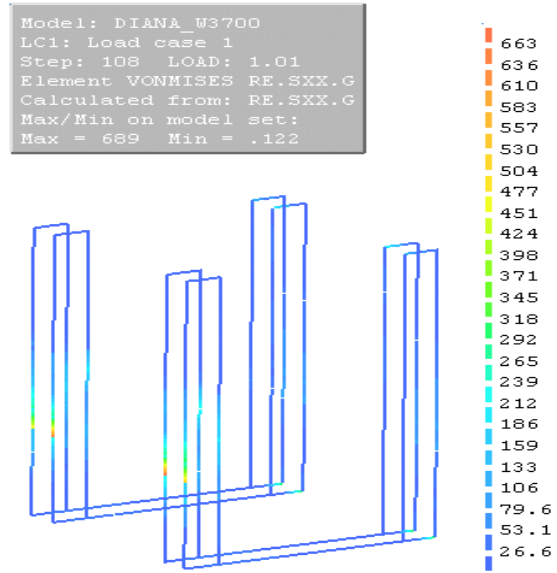

Figura 47 - Tirantes verticais: Tensão em MPa.

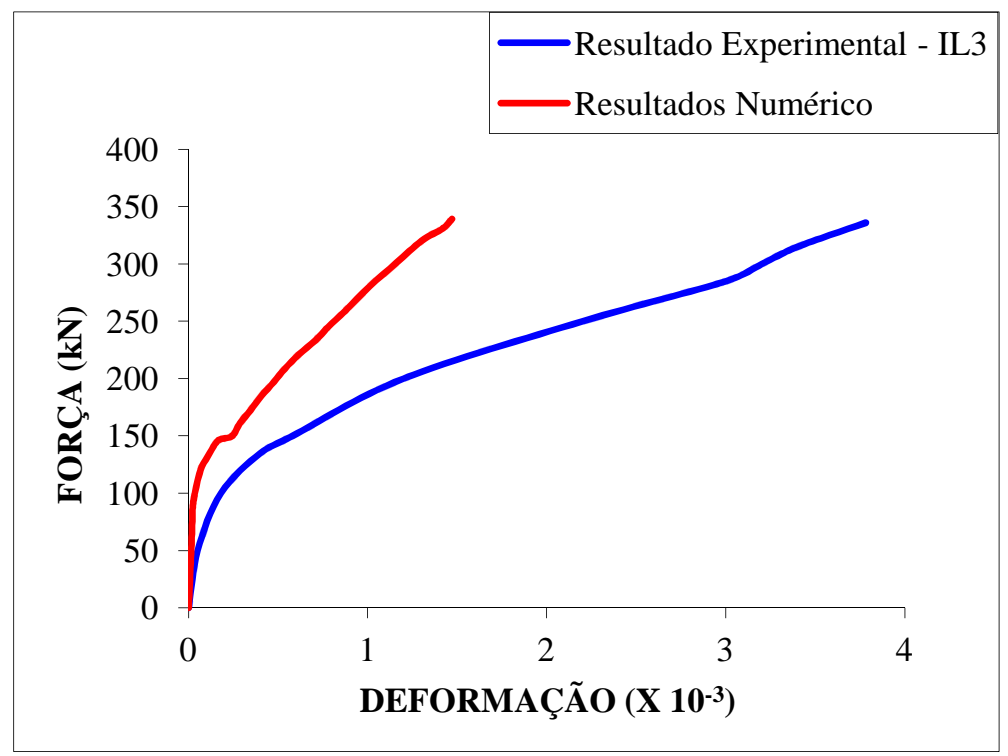

Figura 48 - Força versus deformação tirante T2 ligação lisa.

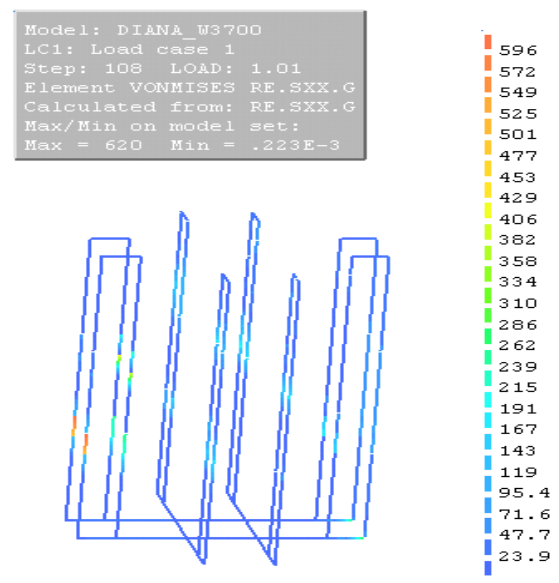

Figura 49 - Armaduras verticais secundárias: Tensão em MPa. 
As curvas numérica e experimental força-deformação do ramo interno da armadura do tirante horizontal localizado nas paredes 3 e 4, na posição HSL1, apresentaram a mesma tendência. Para forças inferiores a $120 \mathrm{kN}$ as curvas praticamente se superpõem, conforme se observa na Figura 51.

Canha (2004) notou que as deformações no meio do vão destes estribos são inferiores às do canto da ligação com a parede transversal 1. Observando a Figura 50, verifica-se que estas armaduras tiveram o mesmo comportamento no modelo numérico. Os resultados experimentais, assim como os numéricos, também indicaram que os ramos internos desta armadura foram mais solicitados que os externos, sendo que estas tensões atingiram valores elevados a ponto do ramo interno atingir a tensão de escoamento.

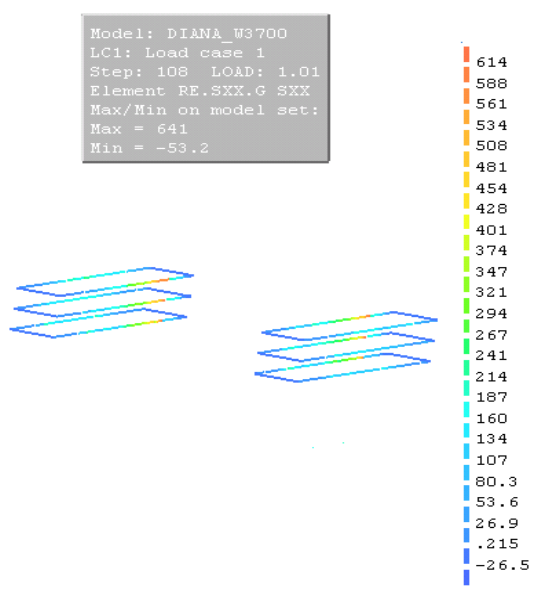

Figura 50 - Tirantes horizontais da parede transversal: Tensão em MPa.

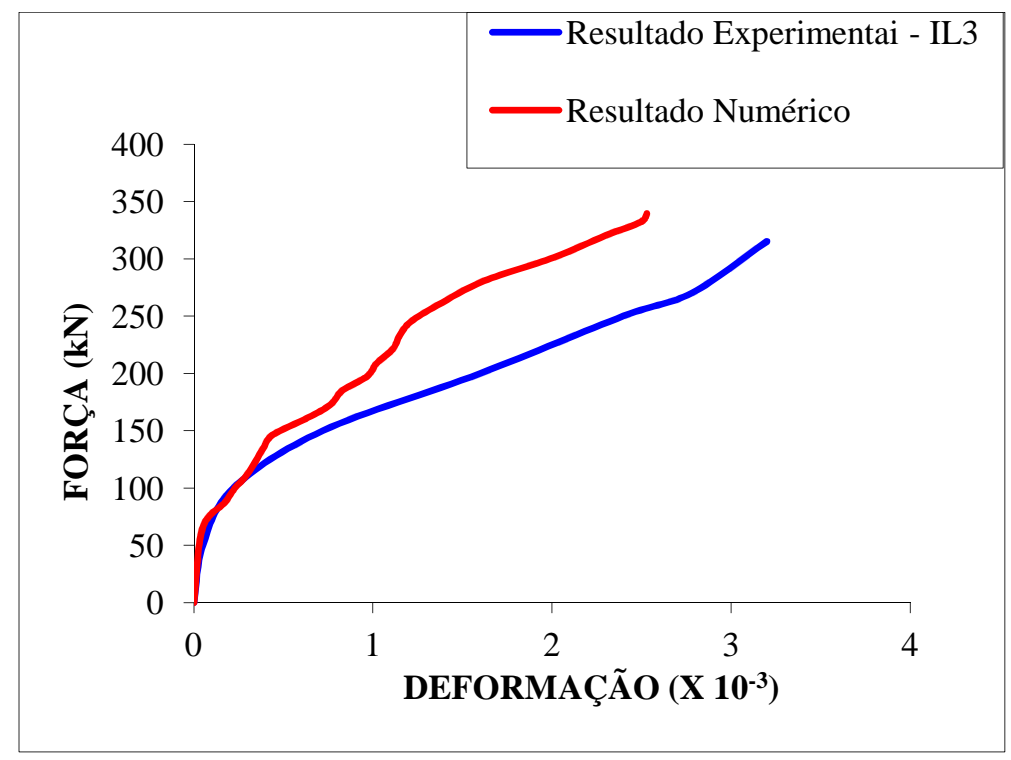

Figura 51 - Força versus deformação armadura horizontal HSL1 ligação lisa. 
As armaduras principais da parede transversal 1 apresentaram-se tracionadas. $\mathrm{O}$ ramo externo foi submetido a uma intensidade de tensão maior que o interno, conforme representado na Figura 52. Este comportamento foi verificado por Canha (2004) comprovando que a parede estava submetida à flexo-tração.

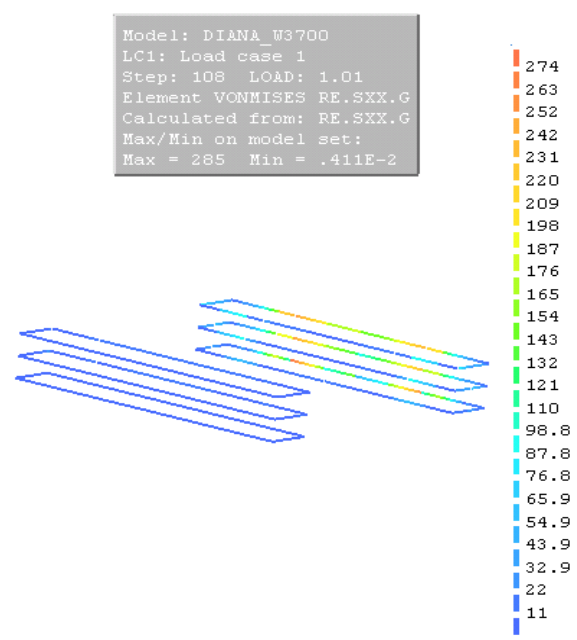

Figura 52 - Armadura principal superior da parede da frente: Tensão em MPa.

A configuração das fissuras no modelo numérico foi semelhante à observada no modelo físico em todas as paredes.

Na parede da frente 1 a fissuração foi mais pronunciada na parte superior (Figura 53), assim como foi observado por Canha (2004). Outra constatação que pode ser feita a partir da fissuração do modelo numérico é que parte da carga é transferida diretamente para a parede da frente e as fissuras são direcionadas para os cantos dessa parede (Figura 53-d e Figura 53-e). Isso também foi observado por Canha (2004). 


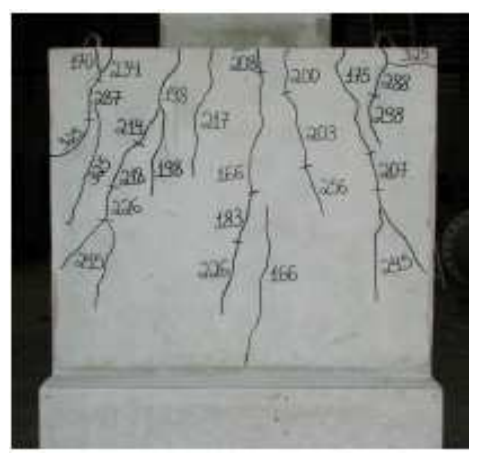

(a)

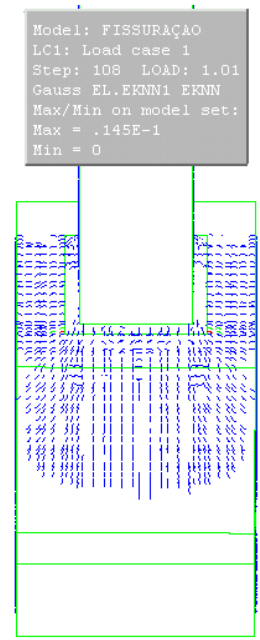

(d)
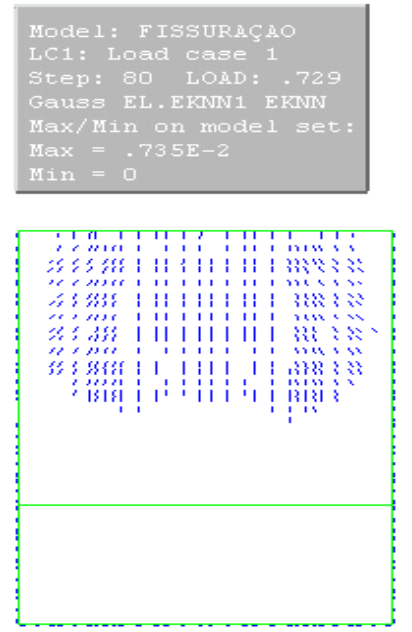

(b)
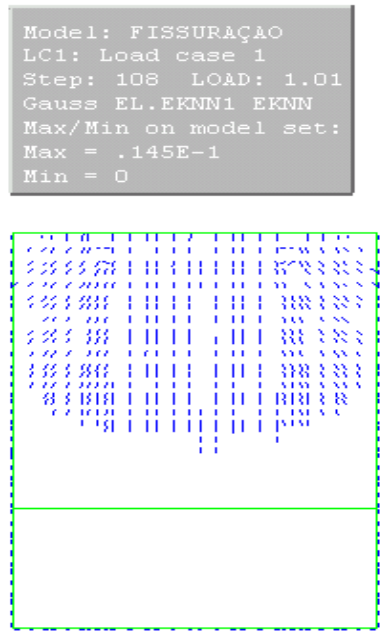

(c)

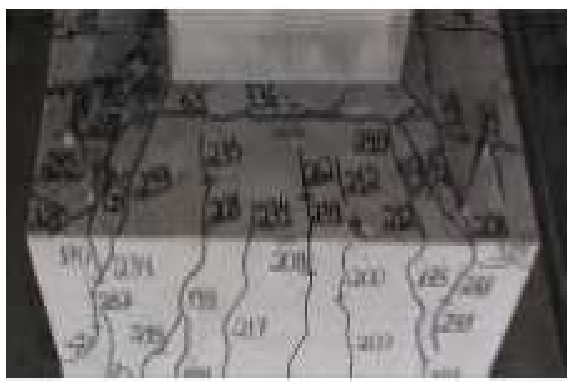

(e)

Figura 53 - Fissuração parede frente 1 IL3: a) e e) fotografia ensaio experimental (Canha 2004); b) resultado obtido numericamente para $73 \%$ força última; c) resultado obtido numericamente para $100 \%$ força última; d) resultado obtido numericamente para $100 \%$ força última.

$\mathrm{Na}$ face frontal da parede transversal 2, surgiram fissuras principais com tendência horizontal, uma na ligação colarinho-base da fundação e outra acima desta, conforme Figura 54.

Na região dos cantos onde estão posicionados os tirantes, a fissuração foi mais intensa que na região central. Também se percebe que, nos cantos, as fissuras são horizontais enquanto, no centro da parede, estas fissuras são verticais, fato também observado nos ensaios experimentais. 


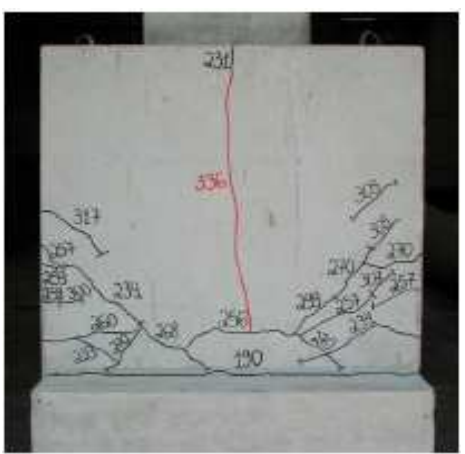

(a)
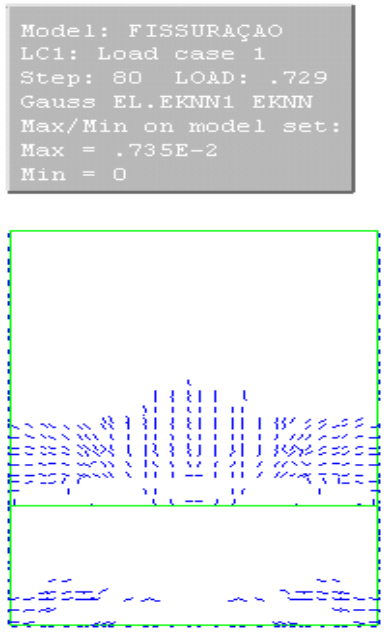

(b)
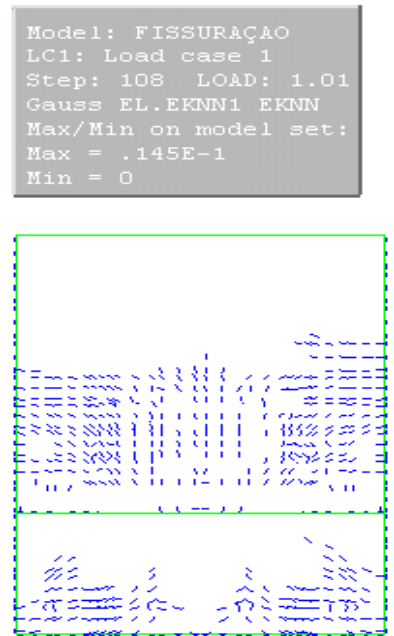

(c)

Figura 54 - Fissuração Posterior: a) fotografia ensaio experimental (Canha 2004); b) resultado obtido numericamente para $73 \%$ força última; c) resultado obtido numericamente para $100 \%$ força última.

Infere-se que as paredes laterais trabalham de acordo com o modelo de bielas e tirantes. Isto pode ser observado na Figura 55, onde a formação das bielas na diagonal da parede que é bem nítida, em conformidade com o que ocorreu no ensaio experimental.

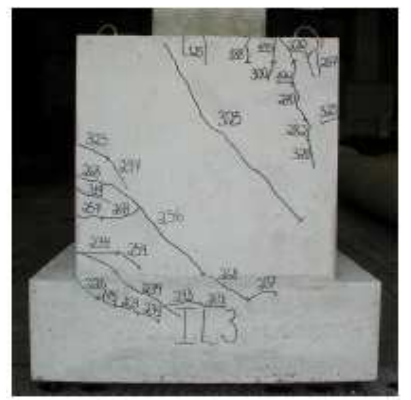

(a)

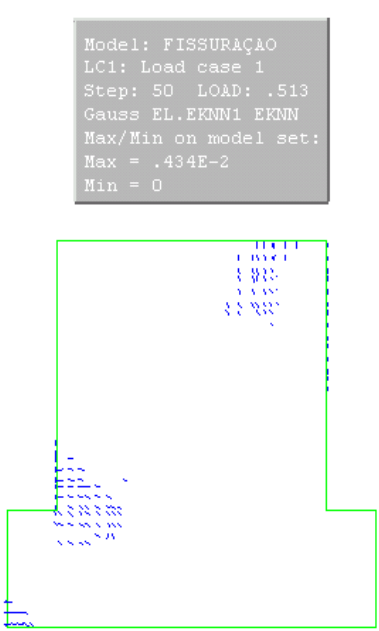

(c)
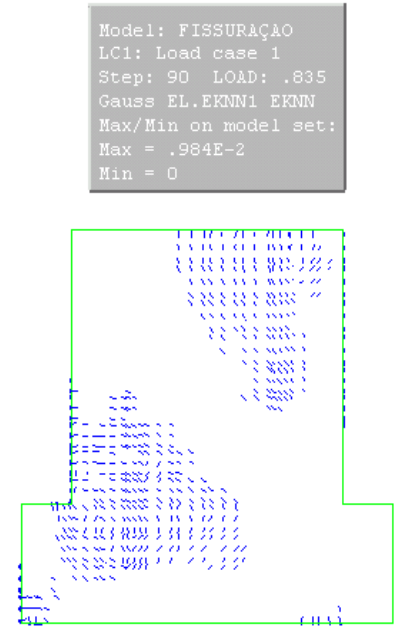

(d)

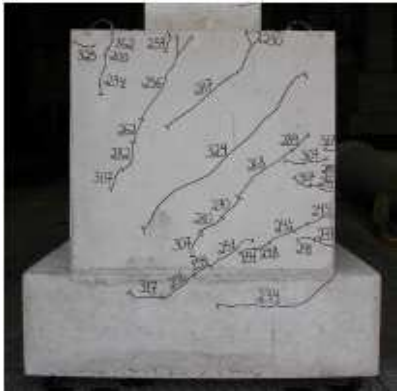

(b)
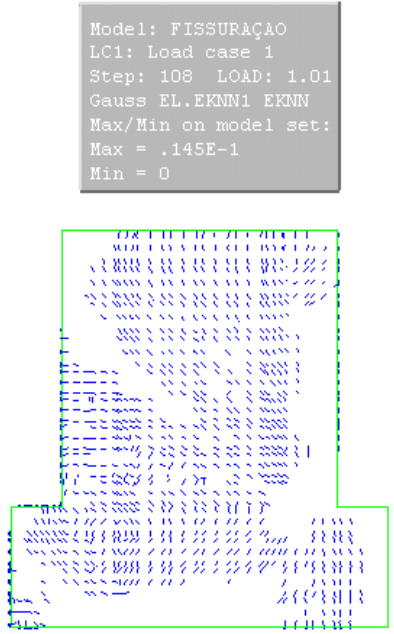

(e)

Figura 55 - Fissuração paredes laterais: a) e b) fotografia ensaio experimental (Canha 2004); c) resultado obtido numericamente $51 \%$ força última; d) resultado obtido numericamente para $83 \%$ força última; d) resultado obtido numericamente para $100 \%$ força última. 


\subsubsection{Modelo de Chan e Poh (2000)}

$\mathrm{Na}$ simulação do bloco ensaiado por Chan e Poh (2000), a força no último passo de carga obtida foi de $1237,48 \mathrm{kN}$. No ensaio experimental, esta força foi de $1230 \mathrm{kN}$. A diferença entre as forças de ruína foi de $0,6 \%$.

Na Figura 56 observa-se um corte diagonal do modelo numérico dos blocos. Na Figura 56-a, estão representadas as direções das tensões principais máximas de compressão, observase que há um fluxo de tensões bem definido que conduz as forças do pilar para a cabeça das estacas, caracterizando a formação de duas bielas de concreto comprimido. Na Figura 56-b, em que estão representadas as tensões principais mínimas de tração, observa-se que existe uma tração perpendicular as bielas, fato relatado em outras pesquisas.

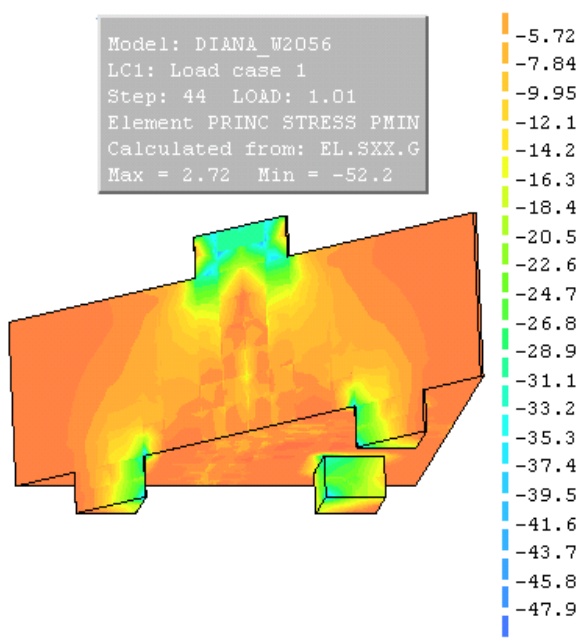

(a)

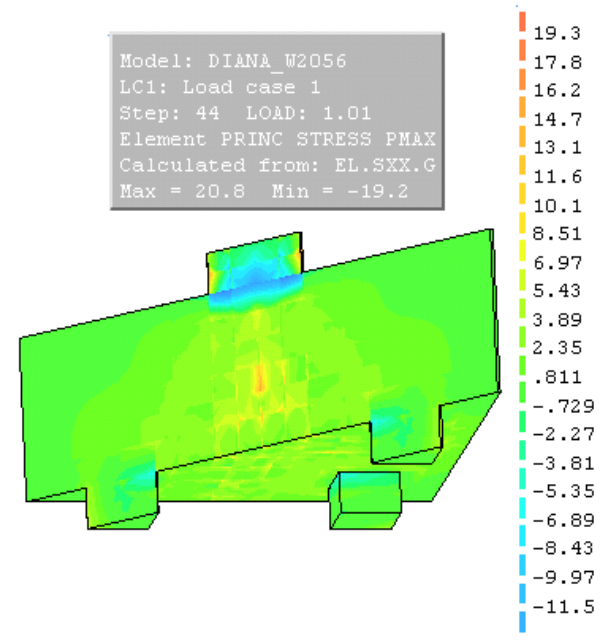

(b)

Figura 56 - Bloco Chan e Poh (2000): a) tensão máxima em MPa; b) tensão mínima em MPa.

Observa-se por meio da comparação das curvas força-deslocamento numérica e experimental (Figura 57) que o modelo numérico se apresenta menos deslocável. As possíveis justificativas para este comportamento são o desconhecimento de algumas propriedades dos materiais (o módulo de elasticidade do aço e do concreto não foram fornecidos e foram determinados segundo a ABNT NBR 6118:2003) e dos comprimentos das estacas, que tem grande influência na deformação global do modelo. 


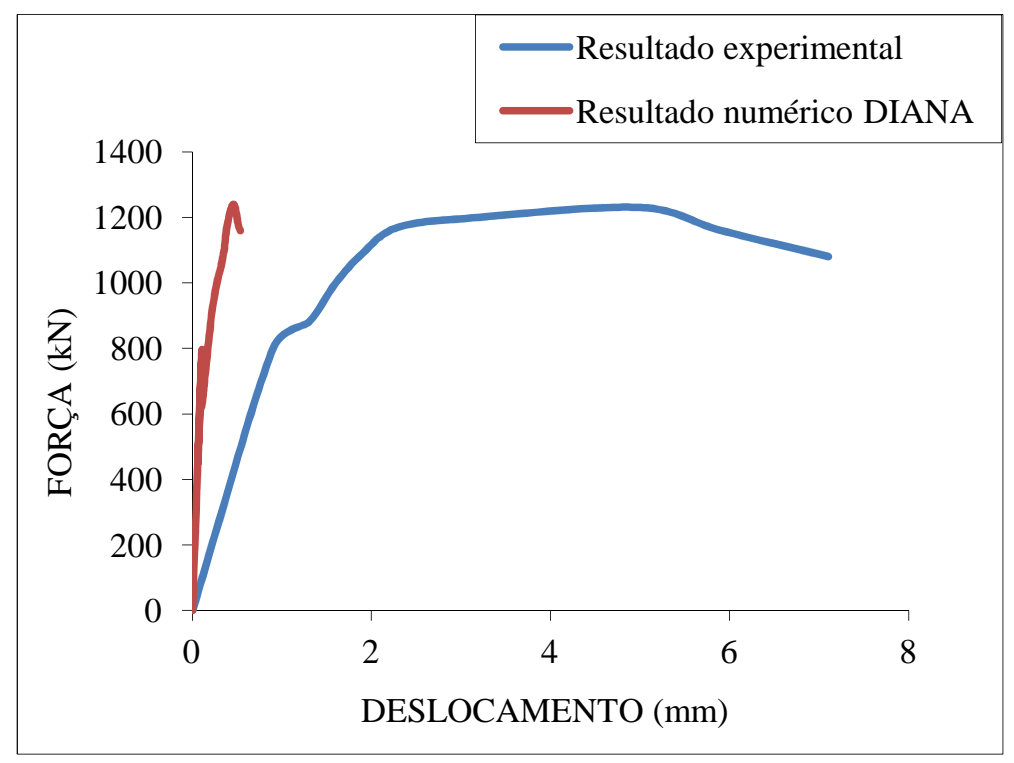

Figura 57 - Força-deslocamento vertical no meio do bloco modelo de Chan e Poh (2000)

A força para a qual surgiram as primeiras fissuras do modelo numérico foi de 553,37 $\mathrm{kN}$. No ensaio experimental, os pesquisadores observaram as primeiras fissuras para uma força de $840 \mathrm{kN}$. A força de fissuração apresenta uma diferença significativa, no entanto isto pode ser justificado pelo fato de que no ensaio experimental certas fissuras não são visíveis a olho nu embora sejam representadas no modelo numérico.

Na Figura 58, pode-se observar a evolução da fissuração no modelo numérico. As fissuras iniciaram no fundo e no ponto central do bloco propagando-se para as laterais do bloco até atingir a face superior do mesmo. Se comparado o panorama de fissuração do modelo numérico com o panorama de fissuração observado nos ensaios experimentais (Figura 58-e), verifica-se a semelhança entre os dois. 


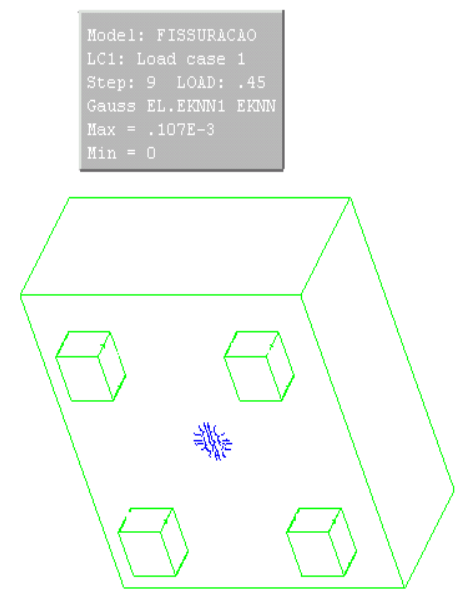

(a)

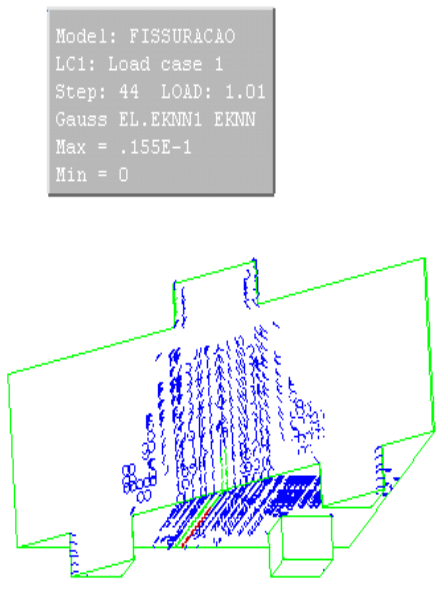

(d)

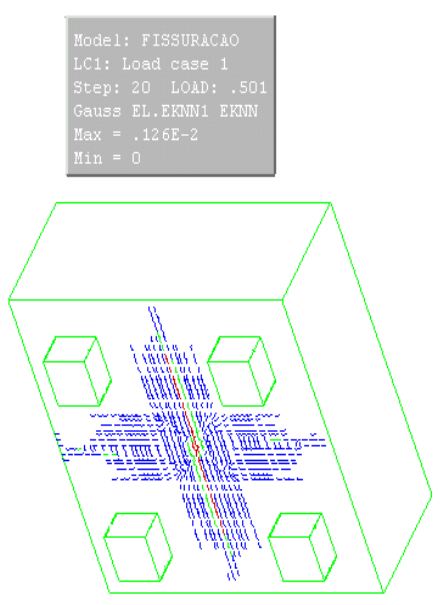

(b)

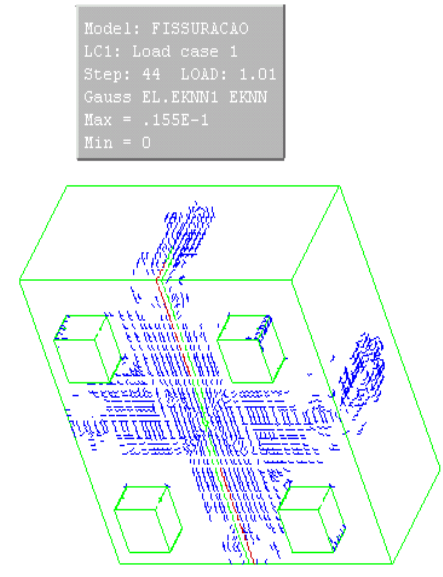

(c)

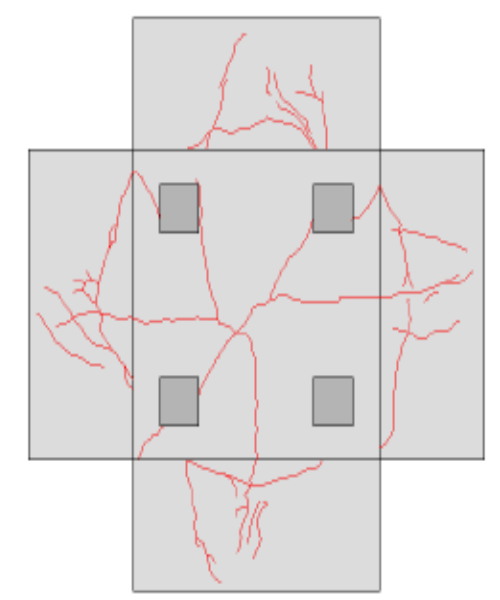

(e)

Figura 58 - Fissuração do modelo de Chan e Poh (2000): a) resultado obtido numericamente para $45 \%$ força última; b) resultado obtido numericamente $50 \%$ força última; c) resultado obtido numericamente para $100 \%$ força última; e) figura adaptada de Chan e Poh (2000).

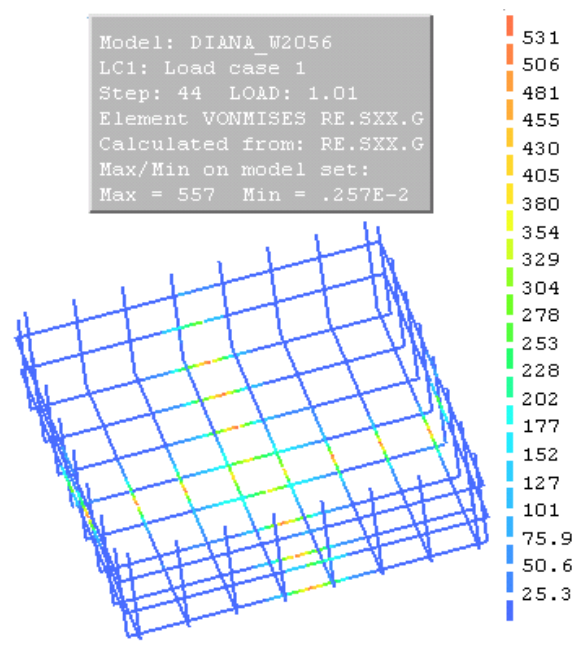

Figura 59 - Armaduras: Tensão em MPa. 
Semelhante ao observado pelos pesquisadores, as armaduras distribuídas no fundo do bloco atingiram a tensão de escoamento, na região média entre as estacas. Este fato ocorreu nas duas direções como pode ser observado na Figura 59.

\subsection{Considerações Finais}

A simulação numérica apresentou, para todos os modelos, um modo de ruína coerente com o observado experimentalmente.

Também em relação à força de ruína se obtiveram bons resultados. Nas simulações alcançaram-se, para forças últimas de convergência, valores da ordem $100 \%$ da experimental para o caso de modelos do colarinho com ligação lisa e para o modelo de Chan e Poh (2000). No caso do modelo do colarinho com ligação rugosa observou-se para o modelo numérico uma força última de convergência igual a $88 \%$ da força de ruína do modelo físico.

As curvas força-deformação numéricas das armaduras, para os modelos de colarinho, possuem comportamento semelhante às experimentais, embora o modelo numérico se apresente mais rígido. A diferença na rigidez é mais acentuada para maiores intensidades de forças.

Os panoramas de fissuração em todos os modelos apresentam-se muito semelhantes aos observados nos ensaios experimentais.

O modelo numérico do bloco analisado por Chan e Poh (2000) apresentou-se menos deslocável que o experimental. Essas diferenças podem ser justificadas pela falta de informações sobre as propriedades dos materiais e pela influência do comprimento das estacas.

De forma geral, apesar de não se conseguir reproduzir com perfeição o comportamento de todos os modelos analisados, acredita-se que seja possível obter resultados satisfatórios aplicando os mesmos modelos numéricos para a análise de blocos com cálice parcialmente embutido apresentada no Capítulo 4. 


\section{BLOCOS SOBRE QUATRO ESTACAS COM CÁLICE PARCIALMENTE EMBUTIDO}

\subsection{Considerações iniciais}

Os blocos com cálice parcialmente embutido podem ser uma alternativa mais econômica que a solução de embutimento total ou cálice externo. Estudos a respeito deste tipo de estruturas são raros de modo que o real comportamento das mesmas é desconhecido, sobretudo se consideradas a atuação de forças verticais e momentos nas duas direções e a geometria retangular do bloco.

Na maioria das estruturas de galpões industriais e de edifícios, os pilares transmitem às fundações não apenas forças verticais, mas também momento. $\mathrm{O}$ dimensionamento dos blocos, nestes casos, é geralmente realizado por aproximações feitas ao método das bielas e tirantes ou pela teoria da flexão, com ajustes feitos pelo engenheiro projetista de forma intuitiva.

Neste capítulo, são apresentados os resultados da análise numérica de dois blocos projetados e construídos em edificações, um como elemento de fundação de estrutura industrial e outro de um prédio comercial.

Foi dado um enfoque para a análise dos resultados em relação à força última, fluxo de tensões, tensão na armadura, tensão nas cabeças das estacas e na base do pilar, reações das estacas, fissuração dos modelos e tipo de ruína, no caso de ser possível a identificação.

Foram estudadas as influências das armaduras e da rugosidade da ligação nos dois modelos.

\subsection{Modelos analisados}

Os modelos estudados são de blocos sobre quatro estacas com cálice parcialmente embutido, solicitados por força centrada e momento nas duas direções. Optou-se por simular dois modelos de blocos que foram construídos em edificações, pois não foram encontrados na 
literatura ensaios experimentais de blocos submetidos a momento e com o tipo de ligação que se pretendia estudar. Desse modo, pode-se ter pelo menos como referencial que os modelos numéricos devem superar as forças atuantes da estrutura, já que nas edificações construídas estes blocos suportam, de fato, o peso próprio e parcela das ações variáveis.

Os modelos foram simulados com toda a armadura dimensionada pelo projetista e também com apenas parte das armaduras, para verificar influência delas no comportamento do bloco e na sua resistência.

Nos modelos, foram analisadas as ligações com a interface rugosa (como executada em obra) e com a interface lisa, sem alterações na geometria e na disposição das armaduras. Cabe observar que os comprimentos de embutimento para os modelos com ligação lisa deveriam ser maiores, e conseqüentemente a armadura do colarinho deveria ser ajustada, entretanto, considerou-se que isso se configuraria em mais uma variável nas análises e prejudicaria a comparação entre os modelos.

Os modelos são referenciados por uma nomenclatura do tipo MOn_XX_YY, onde:

O campo n especifica o tipo de modelo e pode assumir os valores 1 ou 2;

O campo XX especifica o tipo de ligação entre o pilar e o colarinho sendo IR correspondente à ligação rugosa e IL à ligação lisa;

O campo YY define que armaduras foram consideradas no modelo numérico e suas respectivas posições, podendo ser:

AR1 - Armaduras nas posições N2, N3 e N20;

AR2 - Armaduras nas posições N2, N3, N20, N10 e N17;

AR3 - Armaduras nas posições N2, N3, N20, N10, N17, N9 e N16;

AR4 - Armaduras nas posições N2, N3, N20, N10, N17, N9, N16, N12, N19 e N21;

AR5 - N2, N3, N20, N10, N17, N9, N16, N12, N19, N21, N11 e N18;

AR6 - Todas as armaduras detalhadas.

\subsubsection{Modelo 1 - MO1}

Este bloco foi dimensionado para ligação rugosa, conforme a geometria apresentada na Figura 60. 

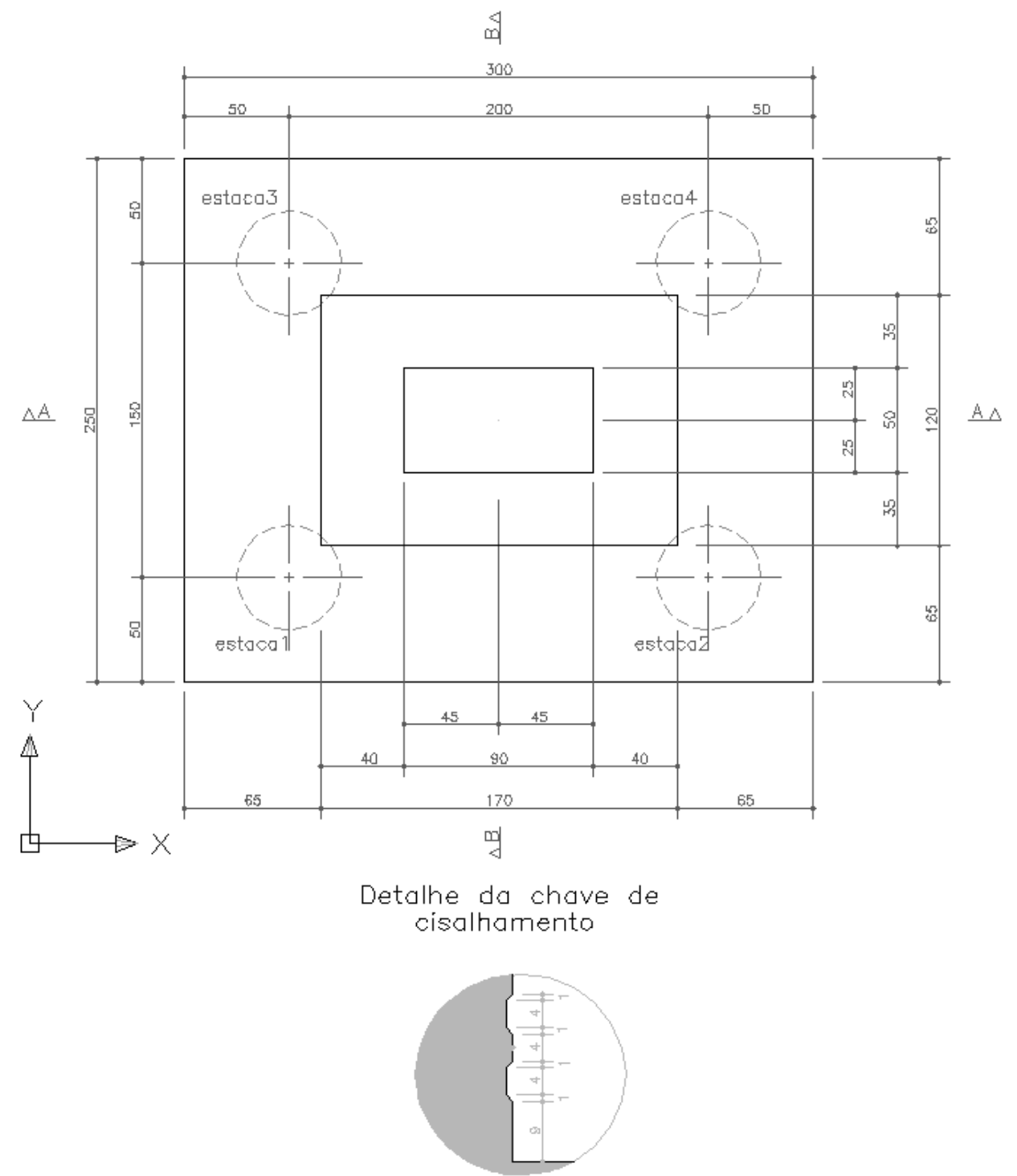

Corte A
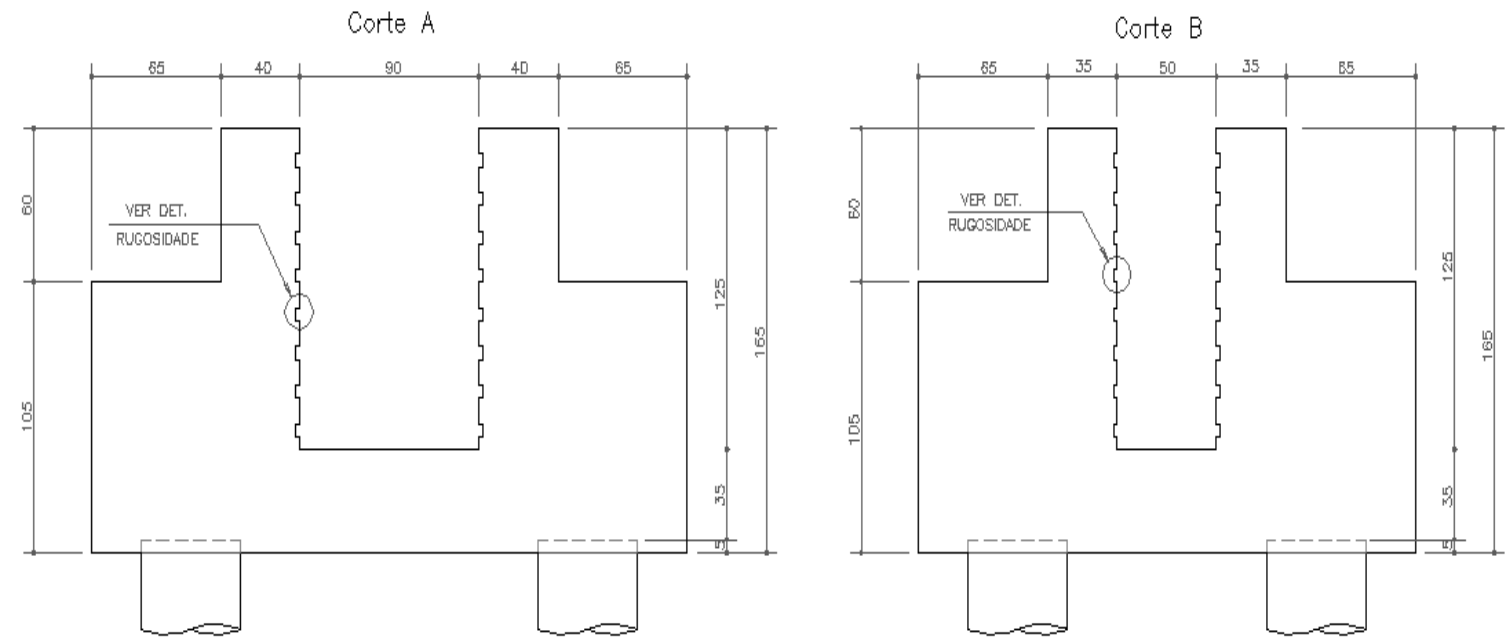

Figura 60 - Geometria do modelo MO1-IR. (Fonte: Migliore e Pastore Engenharia).

Observa-se que este modelo tem maior altura que o convencional e sua biela apresenta inclinação maior do que os $55^{\circ}$ recomendados por Blévot e Frémy (1967). A altura é 
justificada pela necessidade de um grande comprimento de embutimento do pilar e de uma laje de fundo com espessura adequada, em virtude da intensidade do momento e da força normal de projeto para estes blocos

As solicitações características e de projeto para esses blocos, fornecidas pelo engenheiro projetista, estão indicadas na Tabela 8. Informa-se que a ação das forças horizontais foi simulada por um momento igual ao produto entre a força horizontal e o braço de alavanca. Este é definido pela distância entre a cabeça da estaca e a posição da resultante da pressão que atua na parede do colarinho. A adequação deste procedimento poderia ser verificada por meio de estudos considerando estas forças e a iteração do solo com a estrutura. Não se pode realizá-los em função do tempo que demandariam, portanto esta é uma sugestão para trabalhos futuros.

\section{Tabela 8 - Carregamento do modelo MO1}

\begin{tabular}{c|c|c}
\hline Solicitação & Característica & Projeto \\
\hline Força Vertical $\mathrm{F}_{\mathrm{v}}(\mathrm{kN})$ & 1463,0 & 2014,0 \\
\hline Força horizontal $\mathrm{H}_{\mathrm{x}}(\mathrm{kN})$ & 93,0 & 130,2 \\
\hline Força horizontal $\mathrm{H}_{\mathrm{y}}(\mathrm{kN})$ & 20,0 & 28,0 \\
\hline Momento $_{\mathrm{x}}(\mathrm{kN} . \mathrm{m})$ & 120,0 & 208,0 \\
\hline Momento $\mathrm{M}_{\mathrm{y}}(\mathrm{kN} . \mathrm{m})$ & 735,0 & 1432,0 \\
\hline
\end{tabular}

As armaduras dos tirantes foram calculadas para suportar a força resultante do equilíbrio do nó correspondente a estaca mais solicitada. As reações nas estacas foram determinadas pela equação 2.1 .

O colarinho foi dimensionado pelo método de Leonhardt e Mönnig (1977) e ABNT NBR 9062:1985. Outras armaduras secundárias também foram adotadas. O detalhamento das armaduras está representado nas Figura 61, 62 e Figura 63.

As áreas das barras das armaduras secundárias referenciadas por N12 e N19, denominadas pelo projetista de armaduras de fretagem, foram determinadas seguindo o modelo de cálculo para blocos parcialmente carregados.

Os projetistas verificaram a punção na seção de contorno do pilar para uma força de $2 / 3$ da força permanente. 

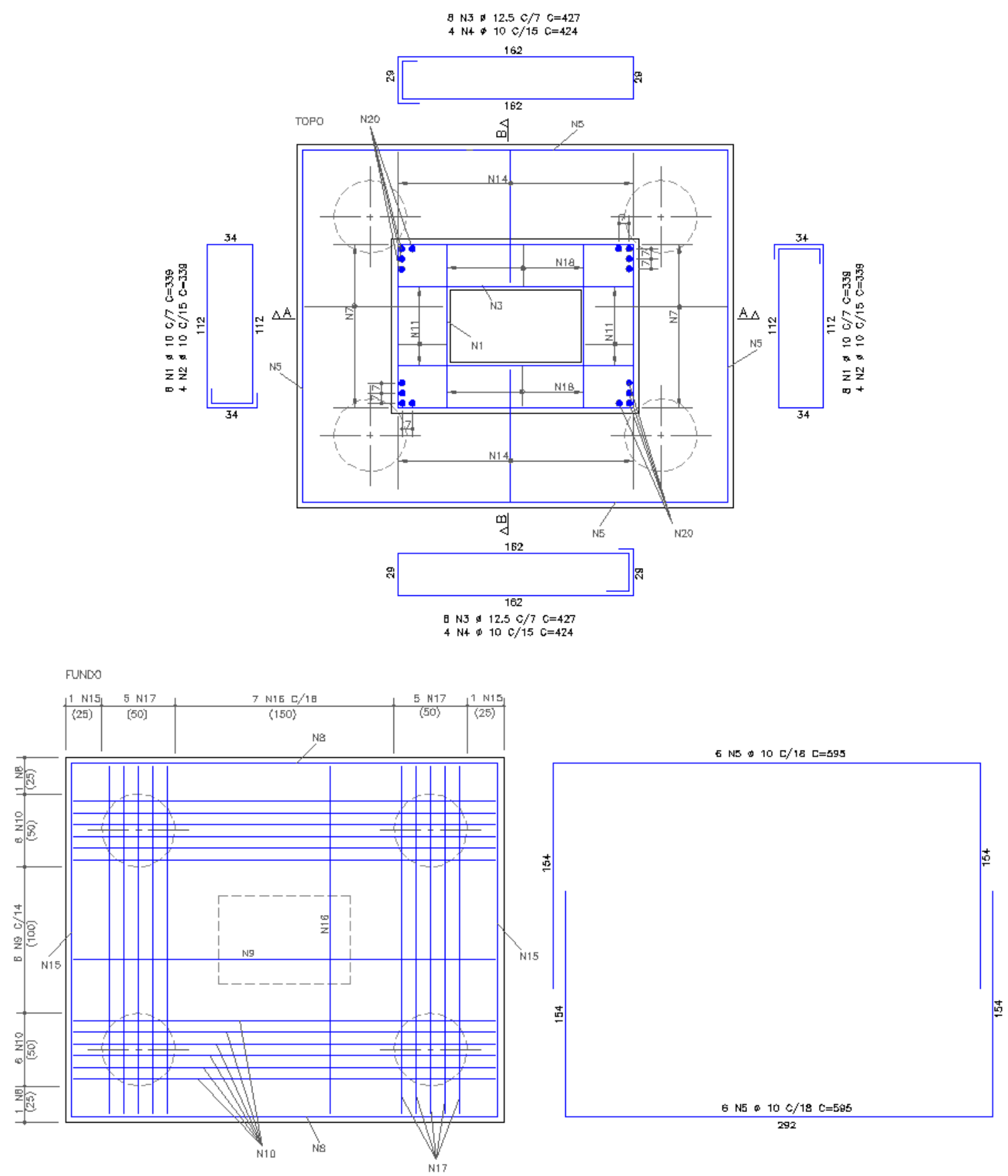

Figura 61 - Detalhamento MO1 vista topo e de fundo. (Fonte: Migliore e Pastore Engenharia). 

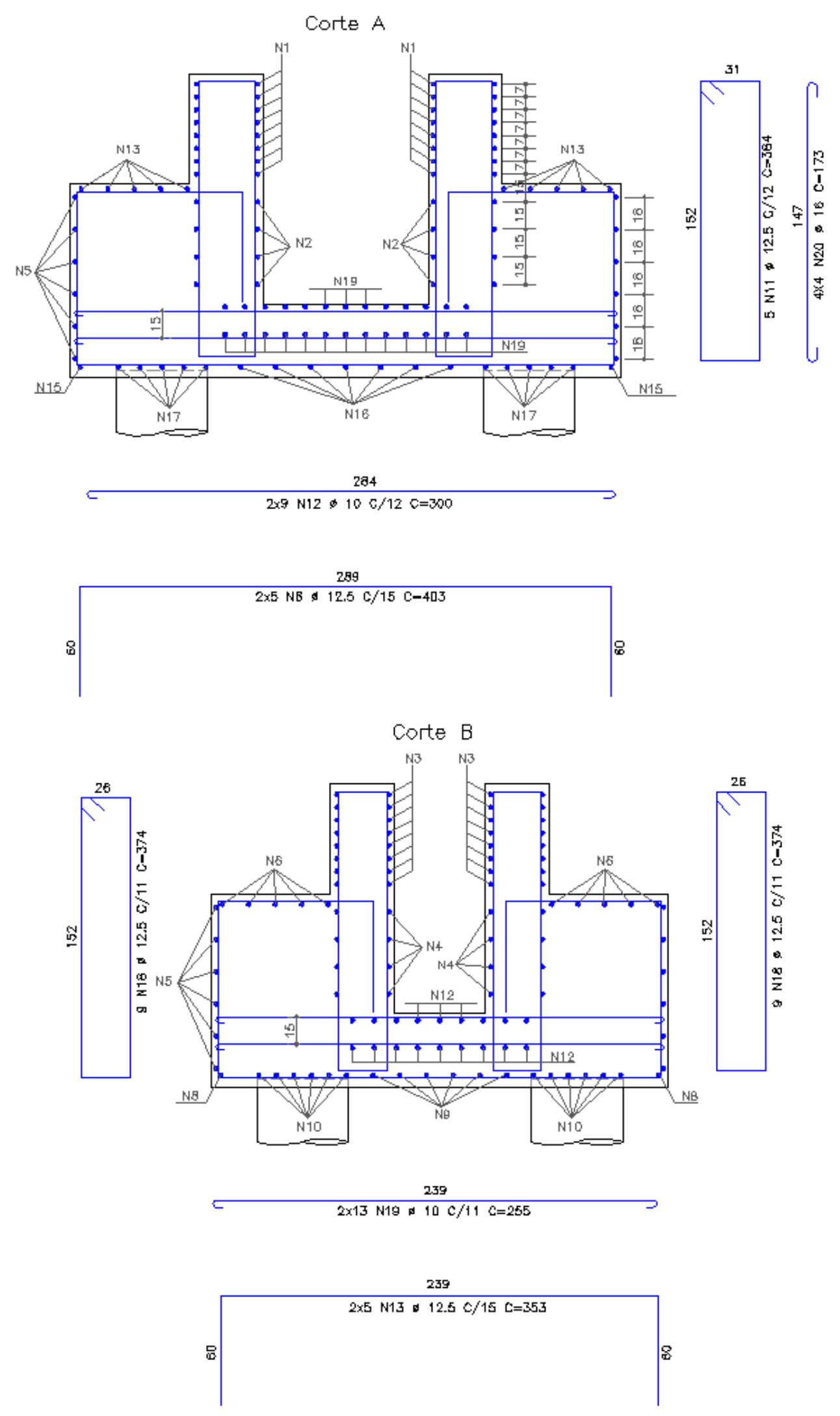

Figura 62 - Detalhamento MO1 parte 1. (Fonte: Migliore e Pastore Engenharia). 

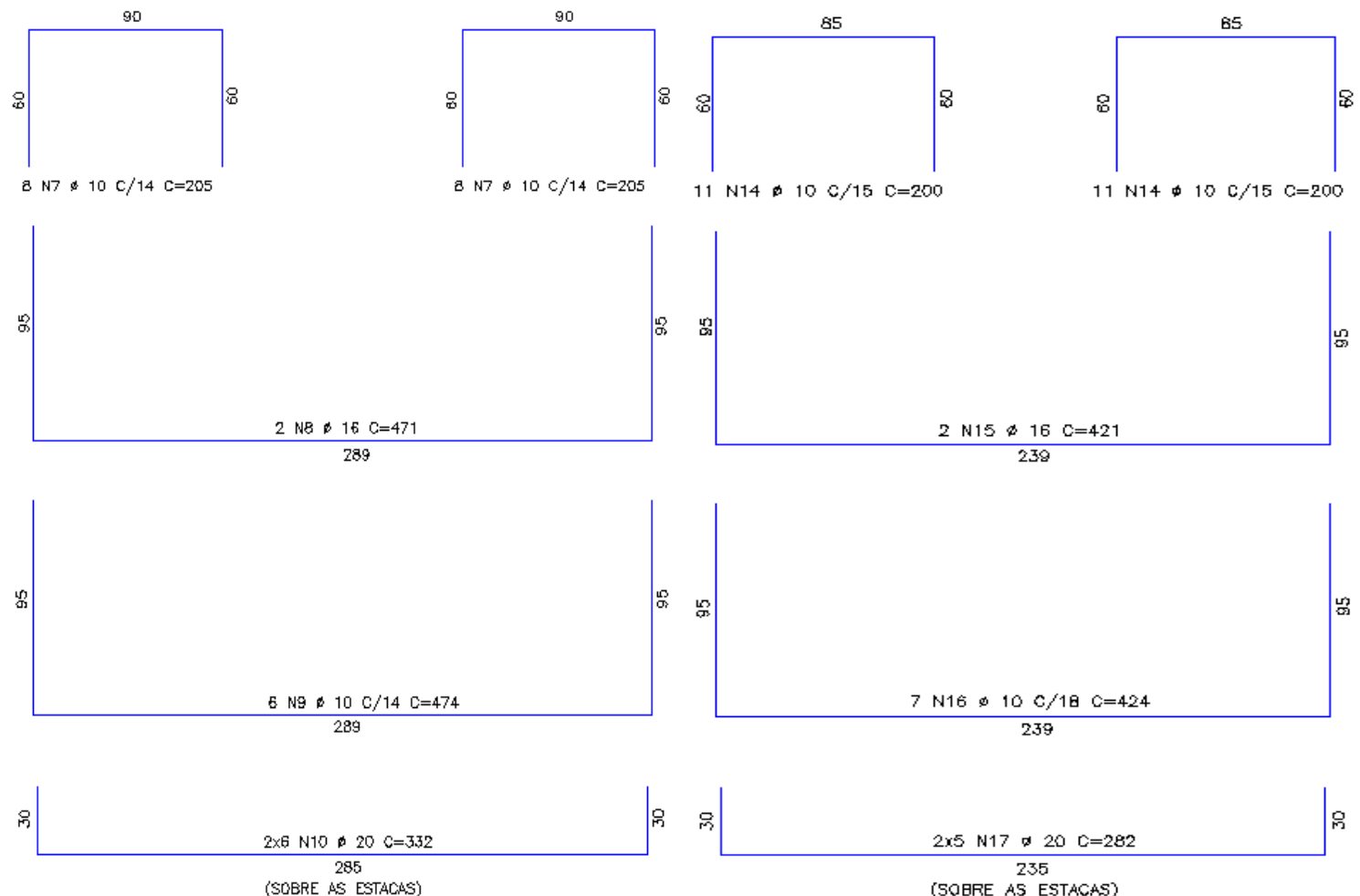

Figura 63 - Detalhamento do modelo MO1 parte 2. (Fonte: Migliore e Pastore Engenharia).

Os modelos foram analisados também com interface lisa mantendo-se os comprimentos de embutimento e as quantidades e disposições das barras das armaduras.

\subsubsection{Modelo 2 - MO2}

O modelo 2 (MO2), assim como o modelo 1 (MO1), apresenta inclinações das bielas acima do limite de $55^{\circ}$ recomendado por Blévot e Frémy (1967), pelos mesmos motivos apresentados no item 4.2.1. Assim como o modelo MO1 o modelo MO2 também foi dimensionado, considerando a ligação rugosa entre pilar e o cálice.

Os modelos apresentam diferenças na geometria conforme se percebe na comparação das Figura 60 e Figura 64. O modelo 2 tem comprimento e largura menores que o modelo 1 e laje de fundo com maior espessura. Os valores característicos e de projeto da força vertical são maiores e os momentos são menores. Estes valores, fornecidos pelo projetista, estão indicados na Tabela 9. 
Tabela 9 - Carregamento atuante no bloco MO2

\begin{tabular}{c|c|c}
\hline Solicitação & Característica & Projeto \\
\hline Força Vertical $\mathrm{F}_{\mathrm{v}}(\mathrm{kN})$ & 1843,57 & 2581,00 \\
\hline Força horizontal $\mathrm{H}_{\mathrm{x}}(\mathrm{kN})$ & 5,0 & 7,0 \\
\hline Força horizontal $\mathrm{H}_{\mathrm{y}}(\mathrm{kN})$ & 40,0 & 56,0 \\
\hline Momento $\mathrm{M}_{\mathrm{x}}(\mathrm{kNm})$ & 10,0 & 24,00 \\
\hline Momento $\mathrm{M}_{\mathrm{y}}(\mathrm{kNm})$ & 140,0 & 272,00 \\
\hline
\end{tabular}

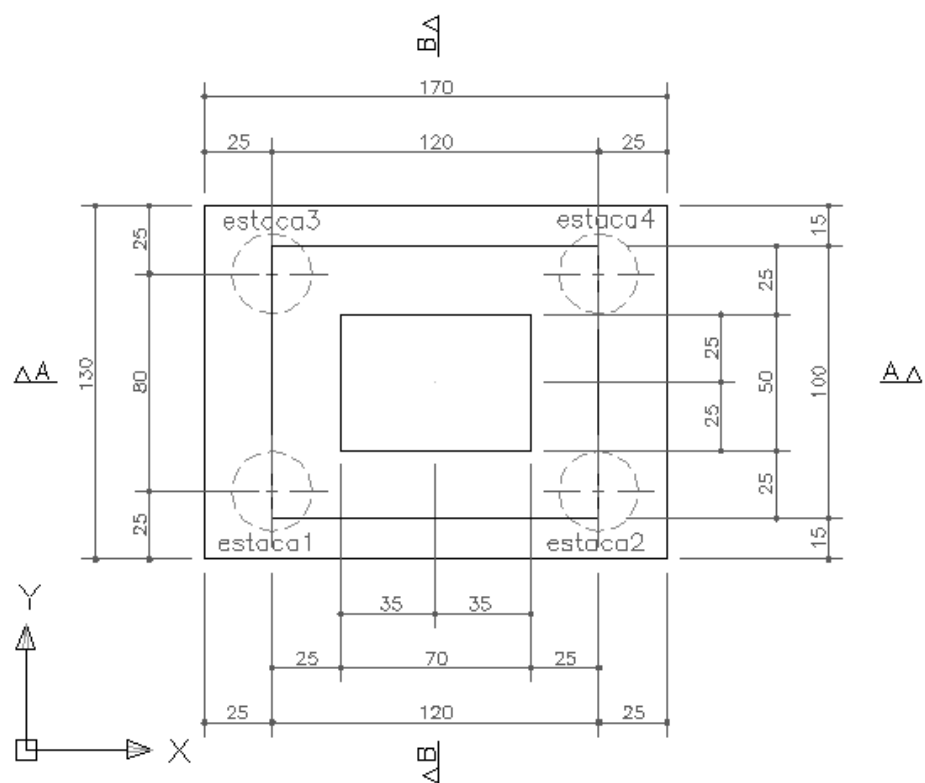

Corte A

Corte B

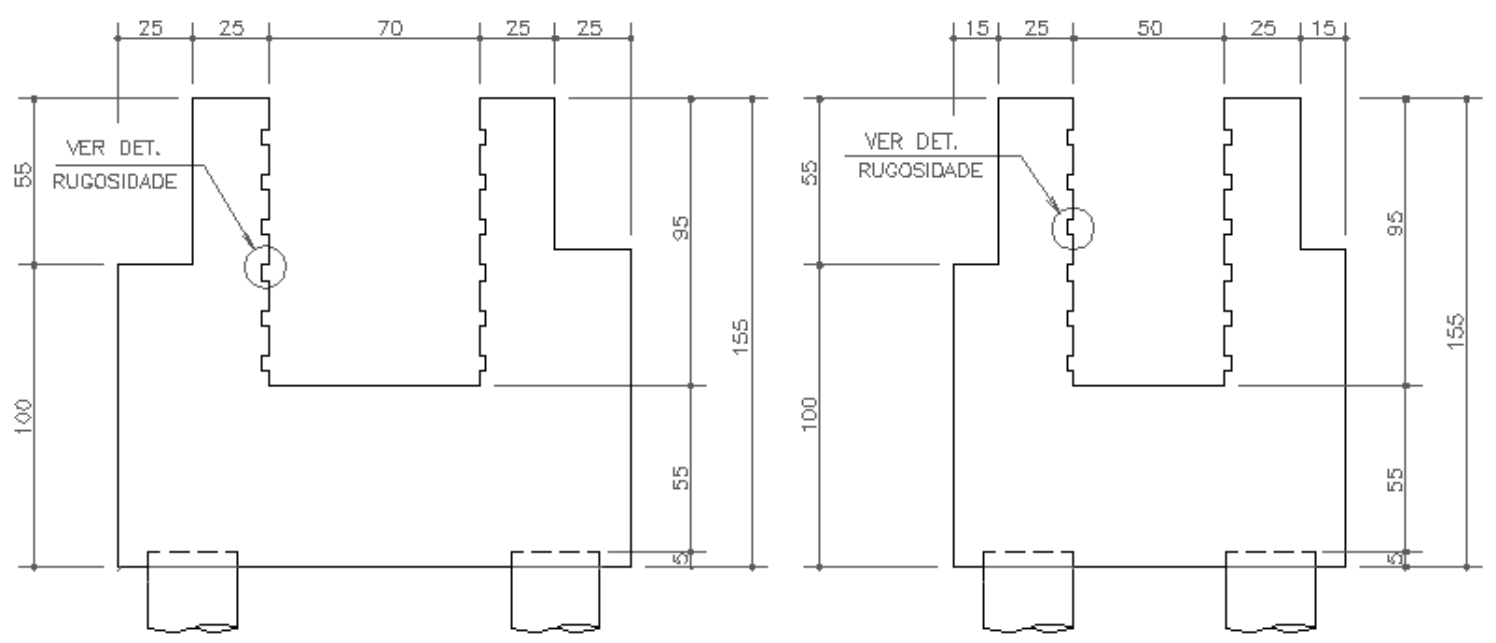

Figura 64- Geometria do modelo MO2. (Fonte: Migliore e Pastore Engenharia).

O dimensionamento e as considerações feitas foram iguais às descritas para o modelo 1, no item 4.2.1 O detalhamento do modelo 2 está indicado nas Figura 65 e Figura 66. 

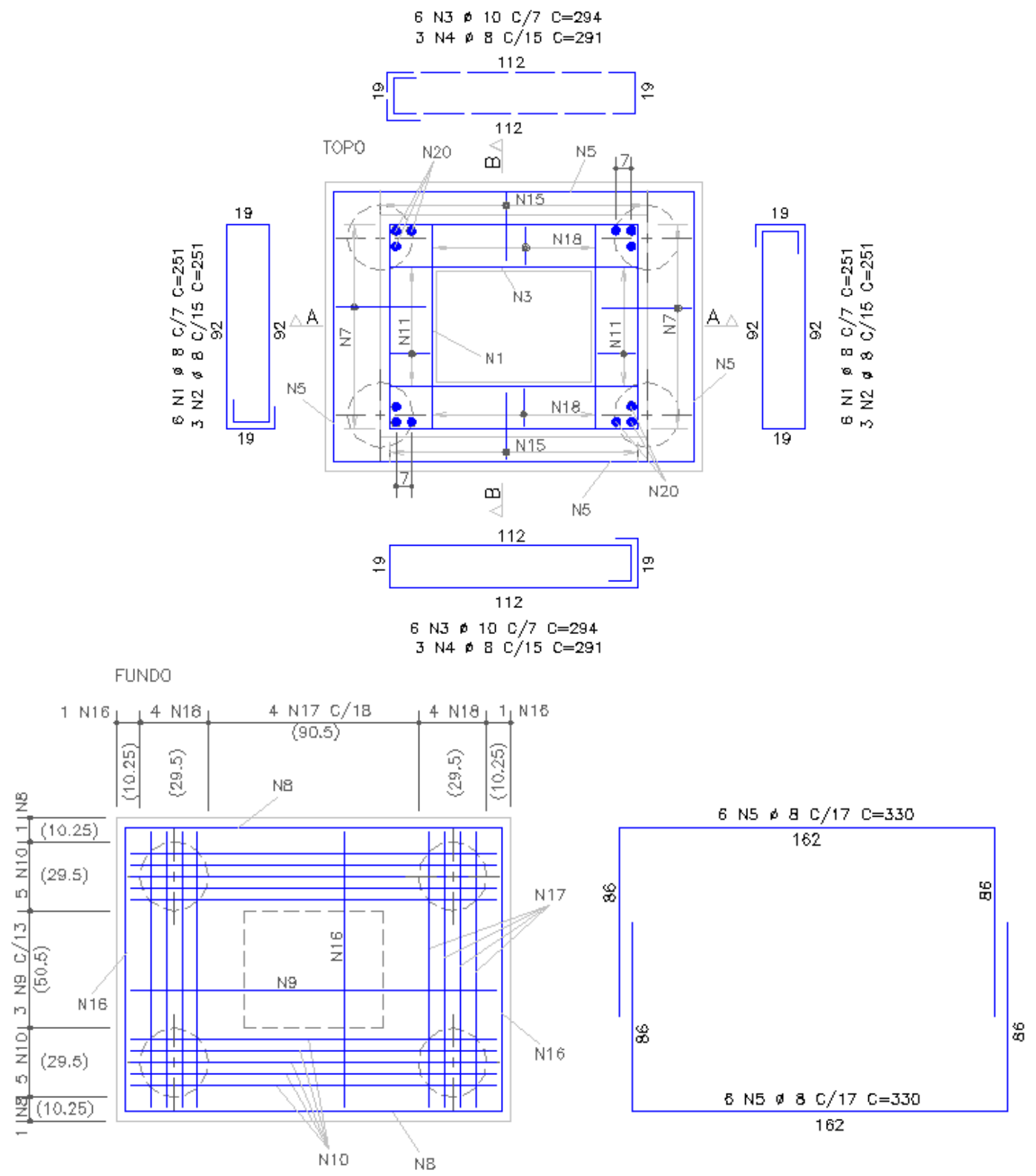

Figura 65 - Detalhamento MO2 vista topo e de fundo. (Fonte: Migliore e Pastore Engenharia). 

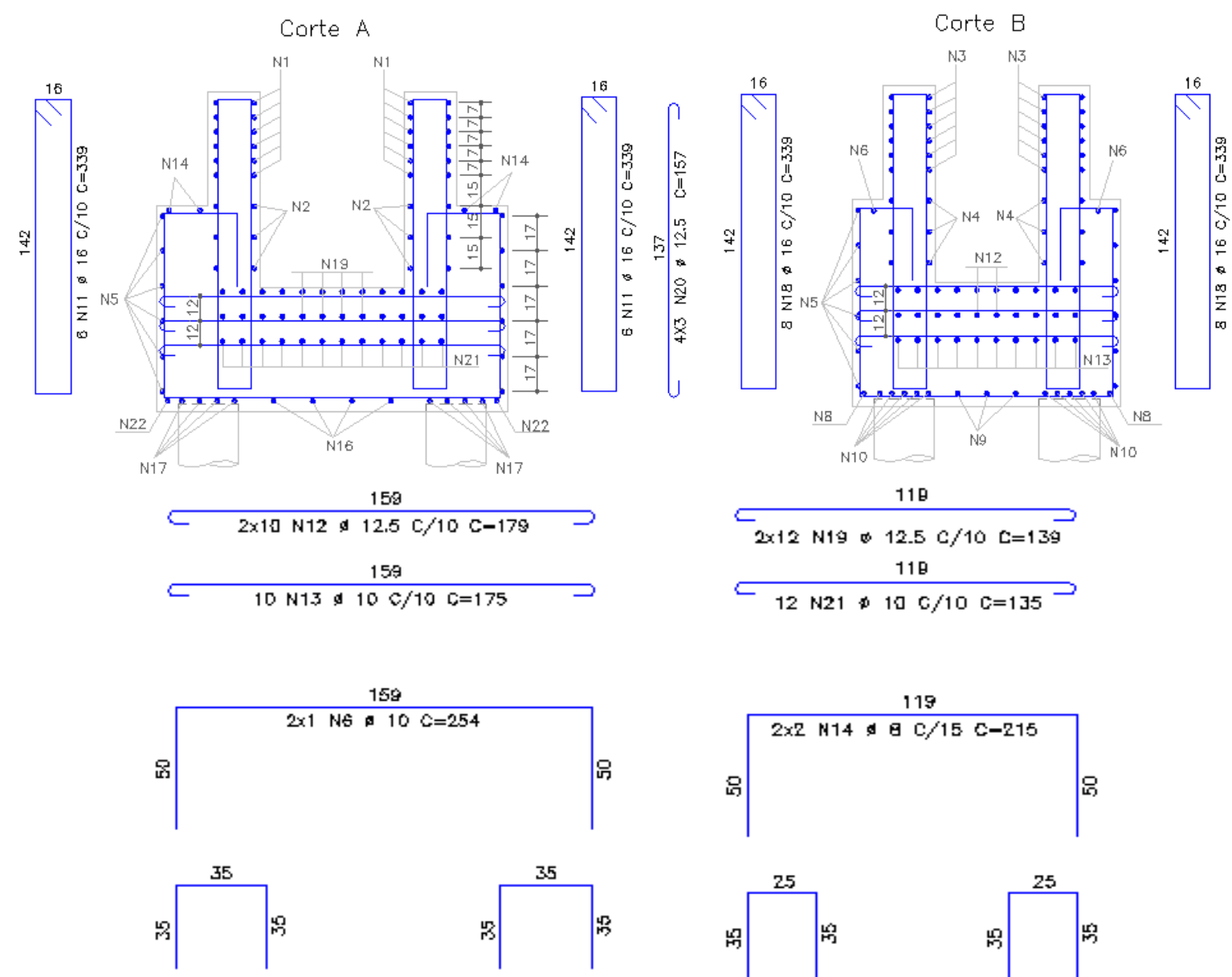

6 N7 \& $8 / 15 \quad c=101$
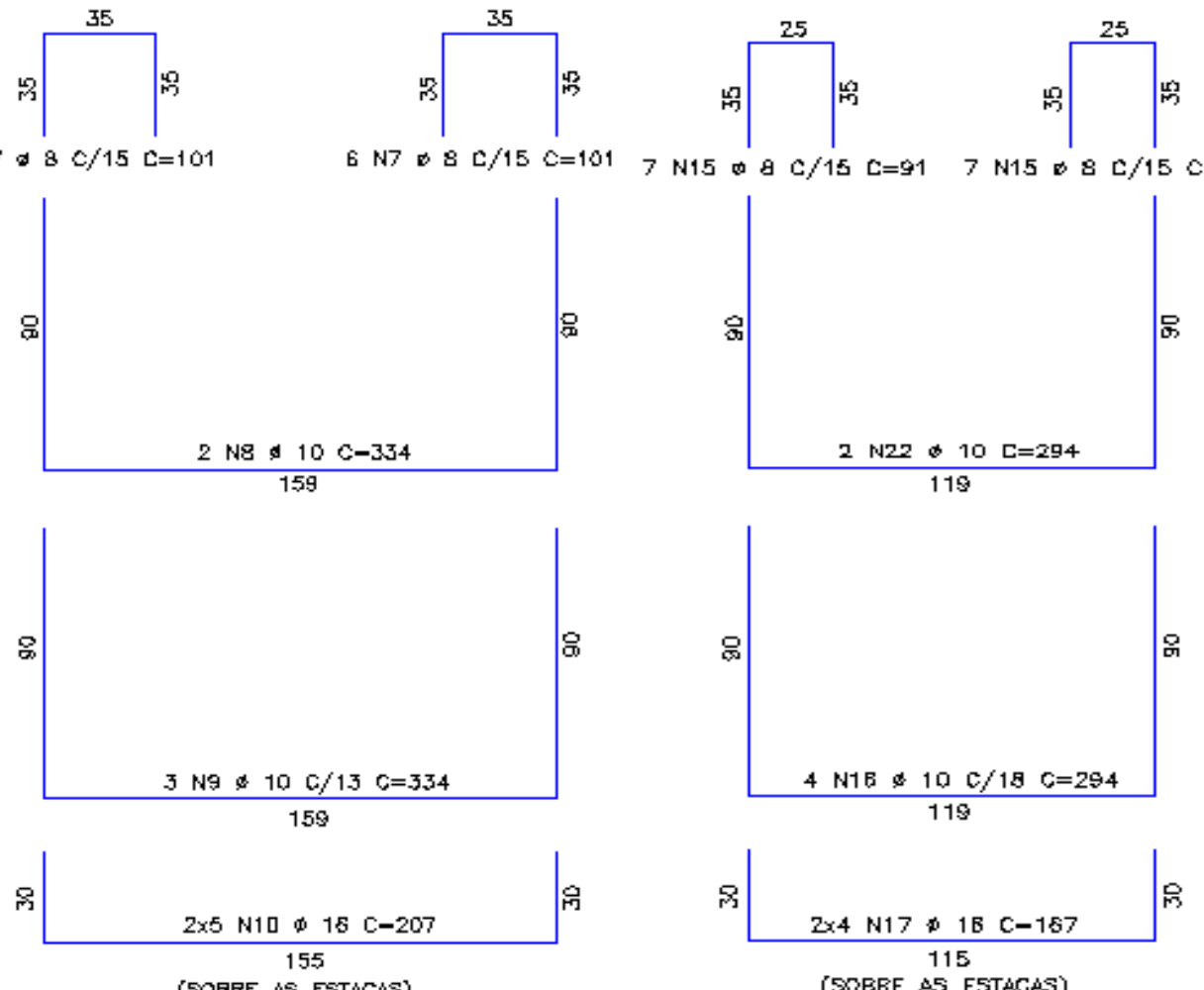

(5ORRE AS ESTACAS)

(SOBRE AS ESTACAS)

Figura 66 - Detalhamento do modelo MO2. (Fonte: Migliore e Pastore Engenharia). 


\subsection{Propriedades dos materiais}

O comportamento das barras de aço é considerado elasto-plástico perfeito com ruptura governada pelo modelo de Von Mises. Adotou-se resistência de escoamento de $500 \mathrm{MPa}$ e módulo de elasticidade de $210 \mathrm{GPa}$, conforme recomendação da ABNT NBR 6118:2003. O coeficiente de Poisson foi adotado igual a 0,2.

As resistências dos concretos utilizadas nas simulações foram: $25 \mathrm{MPa}$ para colarinho e bloco; $50 \mathrm{MPa}$ para estacas e pilar. A maior resistência do pilar e da estaca foi adotada em função do bloco apresentar grande rigidez, não sendo possível atingir a força de ruína no bloco para resistência do concreto do pilar inferior. O resumo das propriedades dos concretos é apresentado na Tabela 10, assim como o modelo constitutivo utilizado.

\begin{tabular}{l} 
Tabela 10 - Propriedades do concreto adotadas nos modelos e modelo constituti \\
\begin{tabular}{c|c|c}
\hline & Pilar; Junta e Estacas & Bloco e Colarinho \\
\hline$f_{c k}(\mathrm{MPa})$ & 50 & 25 \\
\hline$f_{c t k}(\mathrm{MPa})$ & 4,07 & 2,56 \\
\hline$G_{c}(\mathrm{MPa} \cdot \mathrm{mm})$ & 0,09255 & 0,04842 \\
\hline$G_{f}(\mathrm{MPa} \cdot \mathrm{mm})$ & 9,25 & 4,84 \\
\hline$E(\mathrm{MPa})$ & 33658 & 23800 \\
\hline$\mu$ & 0,2 & 0,2 \\
\hline Modelo constitutivo & \multicolumn{2}{|c}{ Total strain fixed crack } \\
\hline Curva na tração & \multicolumn{2}{|c}{ Exponencial } \\
\hline Curva na compressãólica
\end{tabular} \\
\hline
\end{tabular}

Para o cálculo da energia de fratura a tração $G_{f}$, determinada segundo equação 3.1 , utilizou-se o $f_{c m}$ igual ao $f_{c k}$. Em virtude das conclusões em relação ao modelo numérico, obtidas por meio do estudo apresentado no Capítulo 3, a energia de fratura à tração adotada foi de $85 \%$ do valor calculado.

Para os modelos com ligação lisa, as propriedades da interface, rigidez normal e tangencial, foram tomadas iguais as adotadas nas simulações dos modelos de colarinho apresentados no Capítulo 3. As demais propriedades foram determinadas conforme formulação apresentada no mesmo capítulo.

Na Tabela 11 é apresentado um resumo das propriedades das interfaces. 
Tabela 11 - Propriedades dos elementos de interface

\begin{tabular}{c|c}
\hline Rigidez normal para elementos a compressão $\left(\mathrm{N} / \mathrm{mm}^{3}\right)$ & $50 \times 10^{3}$ \\
\hline Rigidez normal para elementos a compressão $\left(\mathrm{N} / \mathrm{mm}^{3}\right)$ & 0,0001 \\
\hline Rigidez tangencial $\left(\mathrm{N} / \mathrm{mm}^{3}\right)$ & 10 \\
\hline Coesão $\left(\mathrm{N} / \mathrm{mm}^{2}\right)$ & 7,10 \\
\hline Ângulo de atrito $\left.{ }^{0}\right)$ & 31 \\
\hline Ângulo de dilatância $\left(^{0}\right)$ & 31 \\
\hline
\end{tabular}

\subsection{Forma da aplicação de forças e restrições das estacas}

As restrições adotadas para as estacas foram apenas à translação vertical. Em virtude deste modelo ser hipostático foi também considerado na estaca menos solicitada a restrição as traslações horizontais. O carregamento foi aplicado em forma de pressão no topo do pilar, conforme esquema ilustrado na Figura 67.

As Forças horizontais, $F_{h x}$ e $F_{h y}$, simulam um momento equivalente ao momento solicitante de projeto.

A força vertical de projeto foi convertida em uma pressão aplicada na área do topo do pilar. Pressões horizontais foram aplicadas em duas áreas (Figura 67) de modo que as resultantes destas formam um binário cujo momento tem intensidade igual a do momento de projeto.
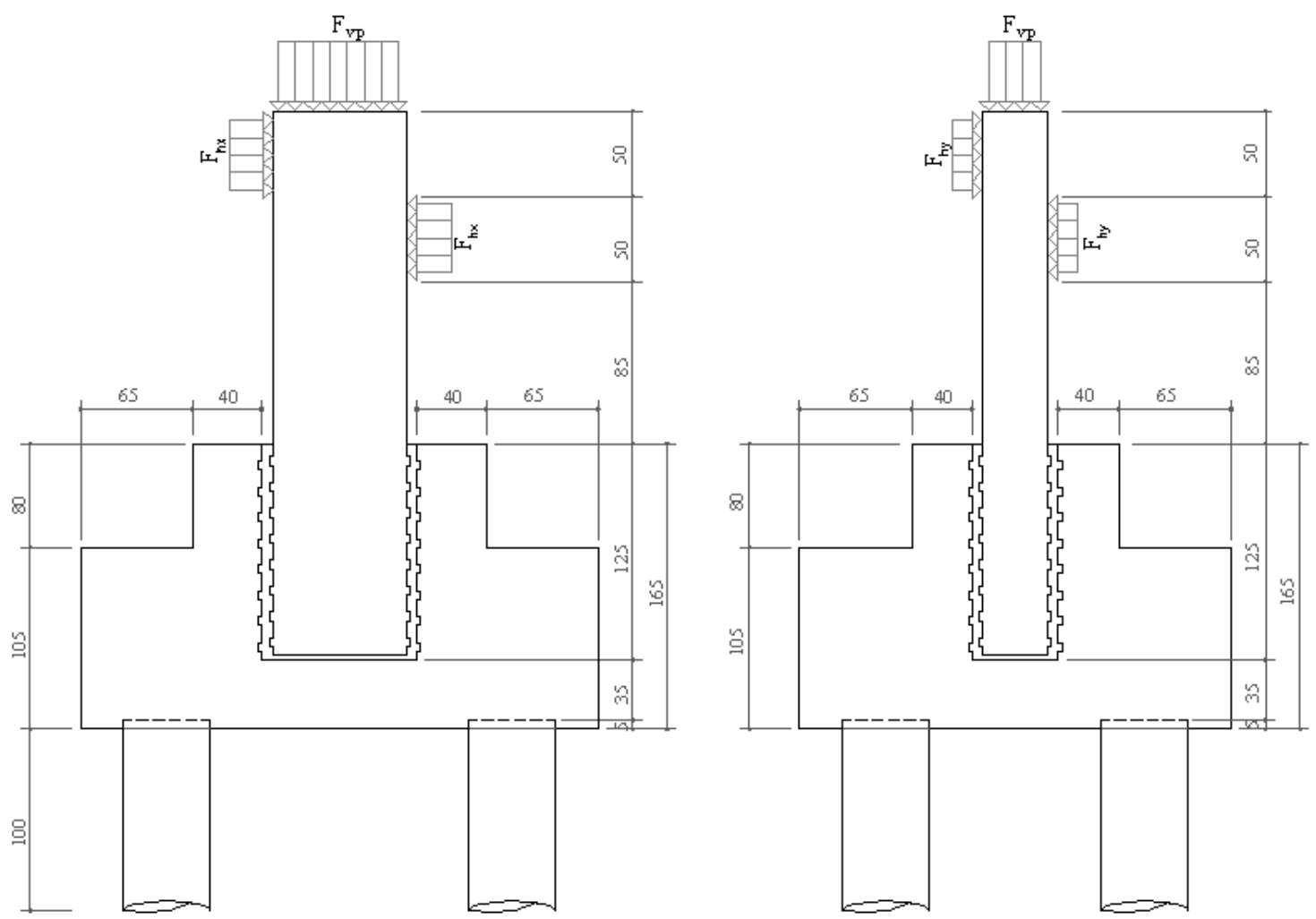

Figura 67 - esquema de carregamento dos modelos 


\subsection{Análise dos Resultados}

\subsubsection{Forças verticais}

As forças últimas, momentos e deslocamentos verticais na parte inferior e no meio do bloco, obtido nas simulações numéricas estão indicados nas Tabela 12 a Tabela 15. Destacase que, como ocorre usualmente em projetos, a área de aço adotada nos blocos foi superior àquela calculada com base na força de projeto em função da utilização de barras com bitolas padronizadas. O item "força resistente" nas Tabela 12 e Tabela 13 indicam o valor da força que o bloco suporta com a armadura adotada, mantendo-se as excentricidades nas direções $\mathrm{X}$ e Y. Esta força foi determinada pelo equilíbrio do nó da estaca mais solicitada, mesmo processo aplicado para o dimensionamento do bloco. Esta mesma análise não foi efetuada para os modelos com ligação lisa, pela dificuldade de se estimar a configuração das bielas.

Em todos os modelos numéricos, as máximas forças obtidas foram superiores às forças características.

Nos modelos MO1_IR, a força vertical máxima que o modelo numérico atingiu foi de $243 \%$ da força característica e $96 \%$ da força resistente. Porcentagens semelhantes foram obtidas para o modelo MO2_IR que atingiu uma força vertical de $196 \%$ da força vertical característica e $102 \%$ da força resistente, indicando que ambos os blocos resistiriam a solicitações de intensidade superior as quais são solicitados. Justifica-se que nesta comparação foram utilizados os resultados dos modelos com terminação AR2, que correspondem aos blocos armados exclusivamente com as armaduras dos tirantes, pois somente elas foram consideradas para determinação da força resistente.

Nos blocos da série MO1_IL, apesar da proximidade da força atingida no modelo numérico com a força resistente, os modelos diferem quanto ao modo de ruína. Não foi observado no modelo numérico a ruína por escoamento da armadura prevista no modelo analítico. Já na série MO2_IL, o modo de ruína foi mais compatível com os modelos analíticos pois em ambos a ruína foi governada pela resistência à compressão do concreto na cabeça das estacas.

As forças atingidas nos modelos com ligação lisa, apesar do comprimento de embutimento ser inferior ao recomendado pela ABNT NBR 9062:2006 e deste não ter sido dimensionado para tal situação, foram de $179 \%$ da força vertical característica para o modelo MO1_IL e de 187\% da força característica para o modelo MO2_IL_AR5 e MO2_IL_AR6. Os demais modelos desta série resistiram a forças menores. Isto indica que, mesmo que não 
houvesse transmissão de esforços na ligação entre as paredes do pilar e do colarinho, os blocos resistiriam à solicitação de projeto.

Uma consideração importante é feita em relação à intensidade da força atingida nos modelos MO1_IR_AR1 e MO2_IR_AR1. No primeiro, esta força foi de $96 \%$ da força atingida no modelo MO1_IR_AR6 e no segundo de 68\% do modelo MO2_IR_AR6. Apesar do concreto ter pequena resistência à tração há uma contribuição considerável na resistência do modelo numérico, em função da grande área resistente. Esta influência se torna ainda mais importante no caso em que as bielas se formam quase na vertical resultando em uma força de tração pequena na parte inferior do bloco. Entretanto, estes resultados devem ser melhor investigados, preferencialmente com ensaios experimentais.

Os deslocamentos verticais foram pequenos, da ordem de décimos de milímetros, indicando que os blocos são estruturas pouco deformáveis. Isso também foi observado nos ensaios de outros pesquisadores, como Adebar et al. (1990) e Yer e San (1995).

Tabela 12 - Resultado das forças máximas dos modelos MO1-IR.

\begin{tabular}{c|c|c|c|c}
\hline MODELO & $\begin{array}{c}\text { Força Vertical } \\
\mathrm{F}_{\mathrm{v}} \\
(\mathrm{kN})\end{array}$ & $\begin{array}{c}\text { Momento } \\
\text { atuante } \\
\mathrm{M}_{\mathrm{x}} \\
(\mathrm{kNm})\end{array}$ & $\begin{array}{c}\text { Momento } \\
\text { atuante } \\
\mathrm{M}_{\mathrm{y}} \\
(\mathrm{kNm})\end{array}$ & $\begin{array}{c}\text { Deslocamento } \\
\text { vertical no } \\
\text { meio do bloco } \\
(\mathrm{mm})\end{array}$ \\
\hline MO1_IR_AR1 & 3387,52 & 349,52 & 2409,12 & 0,2141 \\
\hline MO1_IR_AR2 & 3492,25 & 360,32 & 2483,60 & 0,2185 \\
\hline MO1_IR_AR3 & 3508,36 & 361,98 & 2495,06 & 0,2194 \\
\hline MO1_IR_AR4 & 3524,47 & 363,65 & 2506,52 & 0,22 \\
\hline MO1_IR_AR5 & 3518,43 & 363,02 & 2502,22 & 0,22 \\
\hline MO1_IR_AR6 & 3516,41 & 362,81 & 2500,79 & 0,22 \\
\hline Característico & 1438,55 & 148,42 & 1023,07 & \\
\hline $\begin{array}{c}\text { Força } \\
\text { resistente }\end{array}$ & 3626,46 & 374,17 & 2579,06 & \\
\hline
\end{tabular}

Tabela 13 - Resultado das forças máximas dos modelos MO2-IR.

\begin{tabular}{c|c|c|c|c}
\hline MODELO & $\begin{array}{c}\text { Força Vertical } \\
\mathrm{F}_{\mathrm{v}} \\
(\mathrm{kN})\end{array}$ & $\begin{array}{c}\text { Momento } \\
\text { atuante } \\
\mathrm{M}_{\mathrm{x}} \\
(\mathrm{kNm})\end{array}$ & $\begin{array}{c}\text { Momento } \\
\text { atuante } \\
\mathrm{M}_{\mathrm{y}} \\
(\mathrm{kNm})\end{array}$ & $\begin{array}{c}\text { Deslocamento } \\
\text { vertical no } \\
\text { meio do bloco } \\
(\mathrm{mm})\end{array}$ \\
\hline MO2_IR_AR1 & 2764,25 & 25,60 & 291,31 & 0,4753 \\
\hline MO2_IR_AR2 & 3621,14 & 33,67 & 381,61 & 0,4721 \\
\hline MO2_IR_AR3 & 3672,76 & 34,15 & 387,05 & 0,4786 \\
\hline MO2_IR_AR4 & 3672,76 & 34,15 & 387,05 & 0,4787 \\
\hline MO2_IR_AR5 & 3670,18 & 34,12 & 386,78 & 0,4818 \\
\hline MO2_IR_AR6 & 4077,98 & 37,92 & 429,76 & 0,5848 \\
\hline Característico & 1843,57 & 17,14 & 194,28 & \\
\hline $\begin{array}{c}\text { Força } \\
\text { resistente }\end{array}$ & 3536,23 & 32,88 & 372,66 & \\
\hline
\end{tabular}


Tabela 14 - Resultado das forças máximas dos modelos MO1-IL

\begin{tabular}{c|c|c|c|c}
\hline MODELO & $\begin{array}{c}\text { Força Vertical } \\
\mathrm{F}_{\mathrm{v}} \\
(\mathrm{kN})\end{array}$ & $\begin{array}{c}\text { Momento } \\
\text { atuante } \\
\mathrm{M}_{\mathrm{x}} \\
(\mathrm{kNm})\end{array}$ & $\begin{array}{c}\text { Momento } \\
\text { atuante } \\
\mathrm{M}_{\mathrm{y}} \\
(\mathrm{kNm})\end{array}$ & $\begin{array}{c}\text { Deslocamento } \\
\text { vertical no } \\
\text { meio do bloco } \\
(\mathrm{mm})\end{array}$ \\
\hline MO1_IL_AR2 & 2656,44 & 274,08 & 1889,20 & 0,3334 \\
\hline MO1_IL_AR3 & 3194,18 & 329,57 & 2271,62 & 0,6466 \\
\hline MO1_IL_AR4 & 3043,13 & 313,98 & 2164,20 & 0,3755 \\
\hline MO1_IL_AR5 & 2589,98 & 267,23 & 1841,93 & 0,2517 \\
\hline MO1_IL_AR6 & 2581,92 & 266,40 & 1836,20 & 0,2489 \\
\hline
\end{tabular}

Tabela 15 - Resultado das forças máximas dos modelos MO2-IL

\begin{tabular}{c|c|c|c|c}
\hline MODELO & $\begin{array}{c}\text { Força Vertical } \\
\mathrm{F}_{\mathrm{v}} \\
(\mathrm{kN})\end{array}$ & $\begin{array}{c}\text { Momento } \\
\text { atuante } \\
\mathrm{M}_{\mathrm{x}} \\
(\mathrm{kNm})\end{array}$ & $\begin{array}{c}\text { Momento } \\
\text { atuante } \\
\mathrm{M}_{\mathrm{y}} \\
(\mathrm{kNm})\end{array}$ & $\begin{array}{c}\text { Deslocamento } \\
\text { vertical no } \\
\text { meio do bloco } \\
(\mathrm{mm})\end{array}$ \\
\hline MO2_IL_AR2 & 2512,09 & 23,36 & 264,73 & 0,3877 \\
\hline MO2_IL_AR3 & 2537,89 & 23,60 & 267,45 & 0,3916 \\
\hline MO2_IL_AR4 & 2551,06 & 23,72 & 268,84 & 0,3933 \\
\hline MO2_IL_AR5 & 3453,37 & 31,96 & 362,04 & 0,5849 \\
\hline MO2_IL_AR6 & 3448,21 & 32,06 & 363,39 & 0,5842 \\
\hline
\end{tabular}

Os resultados indicaram que as diferentes quantidades de armaduras utilizadas não influenciaram de forma significativa a força última dos modelos com ligação rugosa.

Para os modelos com ligação lisa observou-se a influência da quantidade de armadura na força última. No caso dos blocos da série MO2_IL, os modelos suportaram mais força de acordo com o acréscimo de armaduras nas posições indicadas anteriormente. Para os blocos da série MO1_IL, houve um acréscimo de força até o modelo MO1_IL AR4, no entanto quando se acrescentou o restante da armadura os blocos desta série suportaram uma força menor. Acredita-se que este fenômeno tenha ocorrido devido a problemas de convergência do modelo numérico.

\subsubsection{Tensões principais}

Nas Figura 68 a Figura 71 estão representadas as tensões principais máximas e as tensões principais mínimas para os passos de carga correspondente a força máxima atingida nos modelos numéricos. Para melhor visualização do fluxo de tensões principais, os blocos foram cortados nas diagonais. 
Optou-se por apresentar apenas as figuras que representam as tensões máximas e mínimas dos modelos MO1_IR_AR6, MO2_IR_AR6, MO1_IL_AR6 e MO2_IL_AR6, já que os resultados dos demais modelos de cada série foram praticamente iguais.

Na Figura 68, observa-se que, no lado mais solicitado do bloco MO1_IR_AR6, há a formação de bielas comprimidas de concreto que iniciam na parte superior do colarinho e terminam na cabeça da estaca com concentração de tensão de compressão na parte superior do colarinho, região representada em cor azul nas figuras. Nas outras direções, apesar de pouco nítida, também há a formação destas bielas no entanto essas apresentam área de seção transversal menor.

Diferente do que sugere o modelo de bielas de Blévot e Frémy ( 1967) as inclinações das bielas com a horizontal não são iguais. Nas estacas menos solicitadas as inclinações são menores, em acordo ao que é sugerido nos modelos para blocos submetidos a momento apresentados por Souza et al. (2007) e Nori e Tharval (2007) .

Para o caso do modelo MO2_IR_AR6 (Figura 69), como os momentos nas duas direções tem intensidade menor, observa-se que as bielas de concreto comprimido se formaram mais bem definidas em todos os lados. Da mesma forma como foi observado no modelo MO2_IR_AR6, há uma tendência da inclinação com a horizontal dessas bielas serem diferentes.

Nos modelos MO2_IR, observa-se que há uma concentração de tensão na cabeça da estaca, justificando-se assim a verificação desta como sugerem Blévot e Frémy (1967).

Tanto nos modelos MO1_IR como nos modelos MO2_IR, observou-se que a transferência das ações do pilar para o colarinho se inicia na parte superior da ligação, de modo que a biela se forma a partir do inicio do comprimento de embutimento.

Em todos os modelos com interface rugosa, observa-se que as bielas se formam com inclinações elevadas, quase na vertical. Isso pode ser justificado, pela tendência das tensões de utilizar o caminho relacionado às forças e deformacões mínimas como observado por Schlaich et al (1987). Nos modelos analisados, este caminho é quase vertical já que a projeção do colarinho intercepta a da estaca e a transmissão das ações se inicia a partir do comprimento de embutimento. Este fato foi observado também nos ensaios experimentais realizados por Delalibera (2006), nos modelos onde as seções dos pilares eram maiores e suas projeções interceptavam a projeção da seção da estaca.

Em relação às tensões mínimas, observa-se que em todos os modelos há tensões de tração na parte inferior do bloco. 


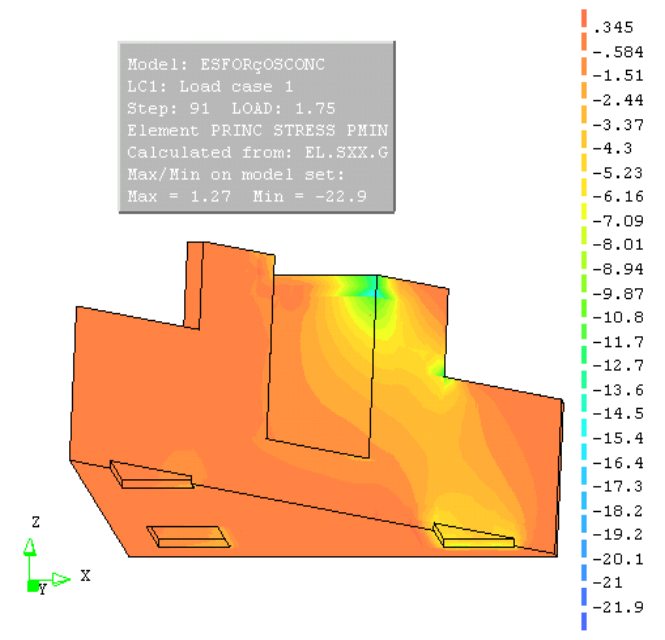

(a)

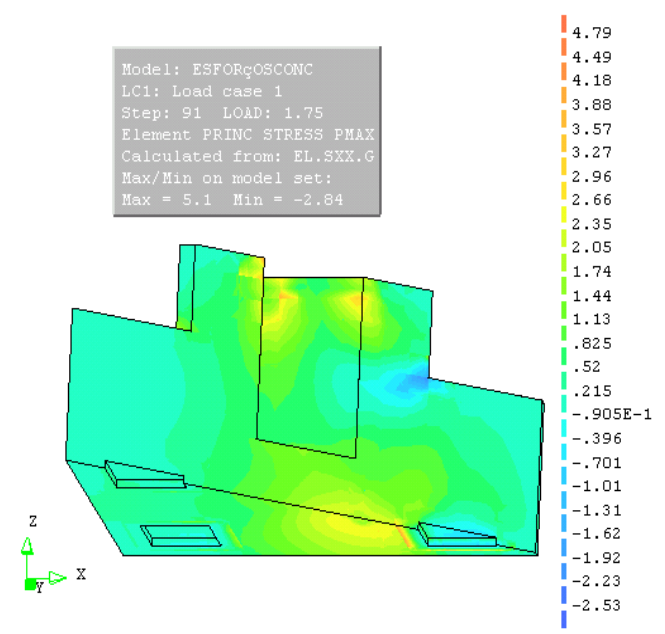

(c)

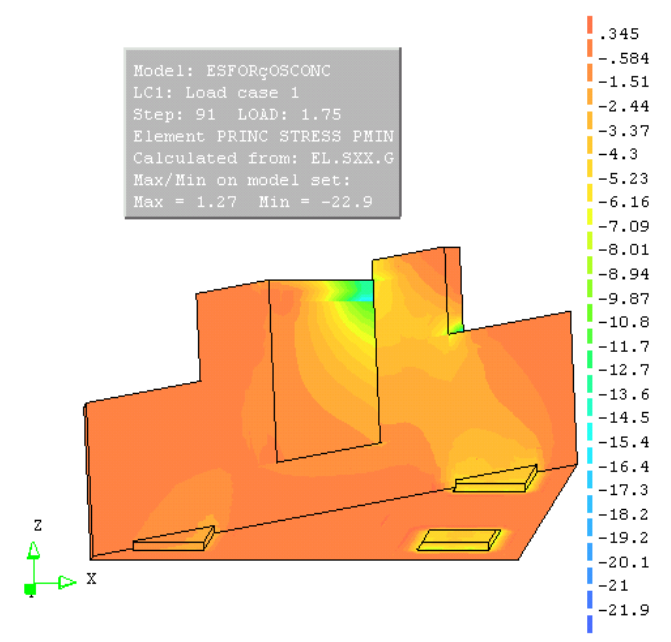

(b)

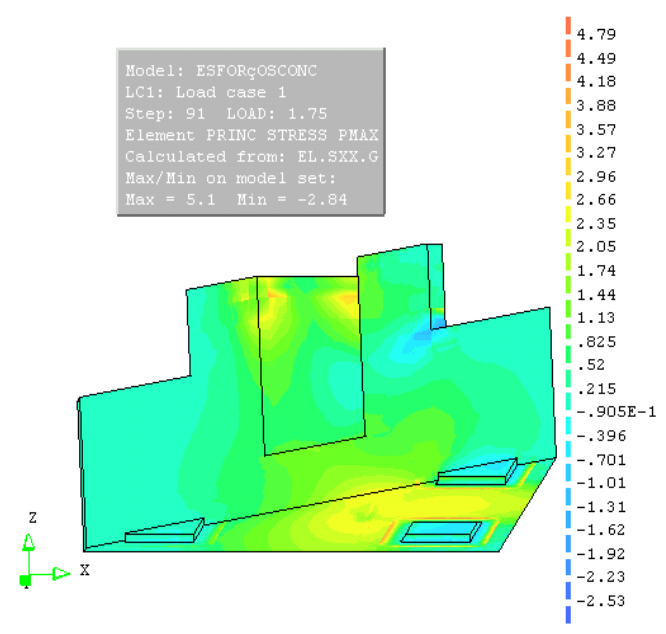

(d)

Figura 68 - Modelo MO1_IR_AR6: a) e b) cortes diagonais para visualização da tensão máxima em MPa; c) e d) cortes diagonais para visualização da tensão mínima em MPa. 


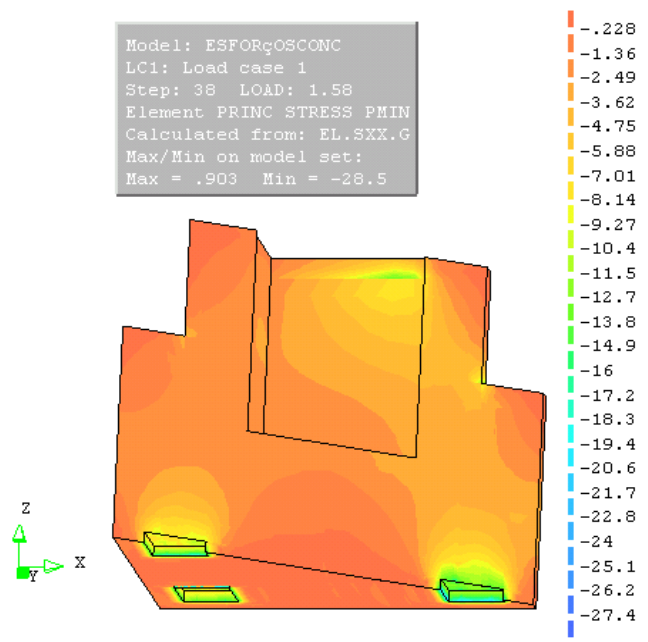

(a)

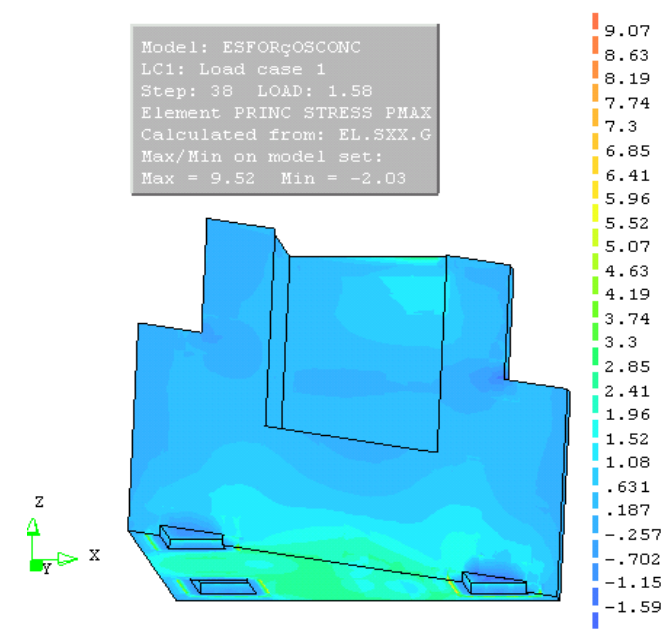

(c)

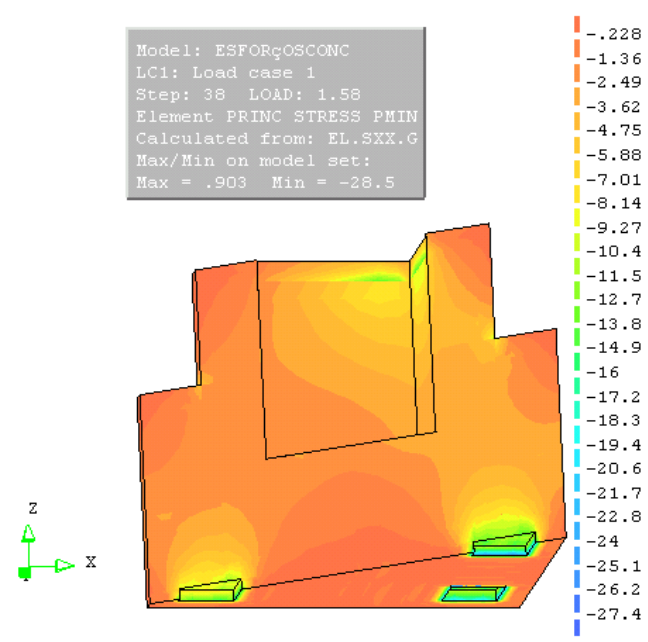

(b)

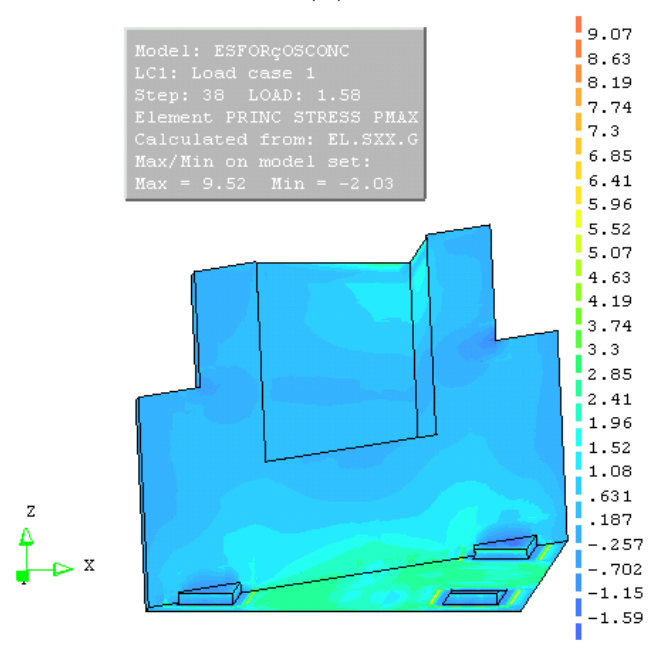

(d)

Figura 69 - Modelo MO2_IR_AR6: a) e b) cortes diagonais para visualização da tensão máxima em MPa; c) e d) cortes diagonais para visualização da tensão mínima em MPa.

Nos modelos MO1-IL e MO2-IL, como se pode concluir pela observação das Figura 70 e Figura 71, a transferência das ações do pilar para o bloco ocorreu de dois modos. Uma parte foi transferida pelo atrito entre as paredes do colarinho e do pilar, formando bielas desde o início do embutimento. A parcela maior dos esforços foi transferida pela região inferior do pilar.

Quantificar a porcentagem das ações transferida por cada mecanismo e criar um modelo de dimensionamento para blocos com essas configurações é uma tarefa difícil que demandaria mais estudos e, principalmente, ensaios experimentais.

Como a maior parte da força vertical é transferida pela base do pilar é interessante que estes modelos sejam verificados à punção, principalmente nos modelos com laje de fundo menor como é o caso do modelo MO1-IL, onde se observa uma concentração de tensão abaixo do pilar. 
Para o modelo MO2-IL, sendo a laje de fundo espessa, observa-se a formação das bielas de forma mais clara as quais conduzem a força do fundo do pilar para a cabeça das estacas, com concentração de tensão, representada pelas cores mais escuras, nas cabeças das estacas e na base do pilar. Assim, as limitações das tensões nestes dois pontos recomendadas por Blévot e Frémy (1967) se aplicariam nestes casos.

Nestes modelos, como no anterior, também percebe-se que além da maior parte da força ser transmitida pela base do pilar, uma parcela é transferida pelo atrito das paredes do pilar com o colarinho.

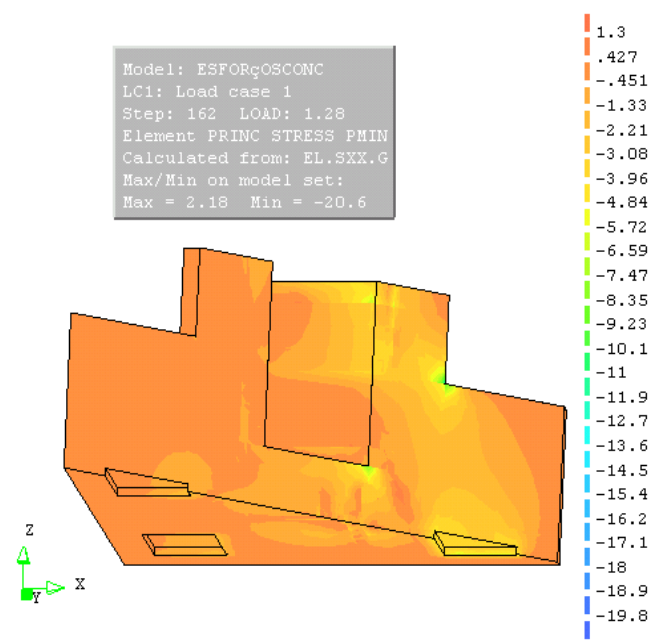

(a)

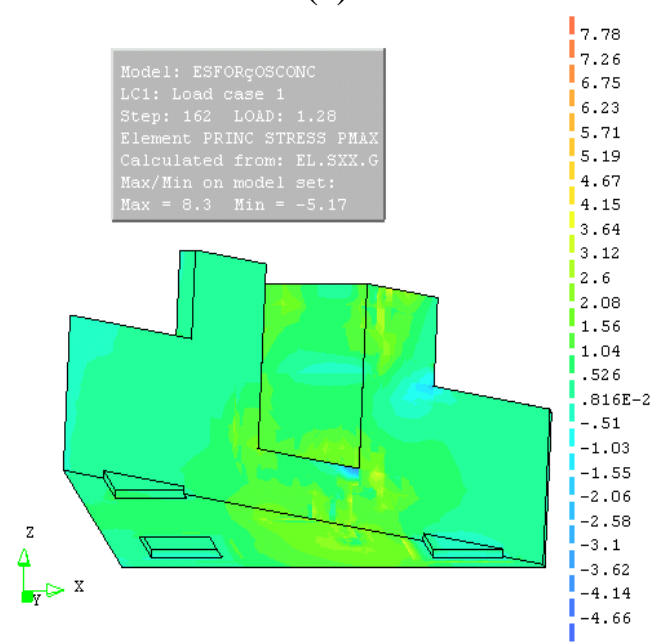

(c)

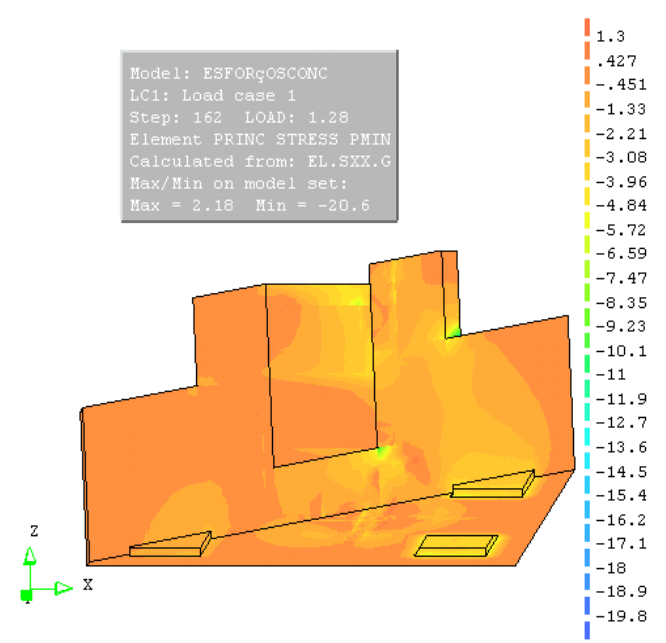

(b)

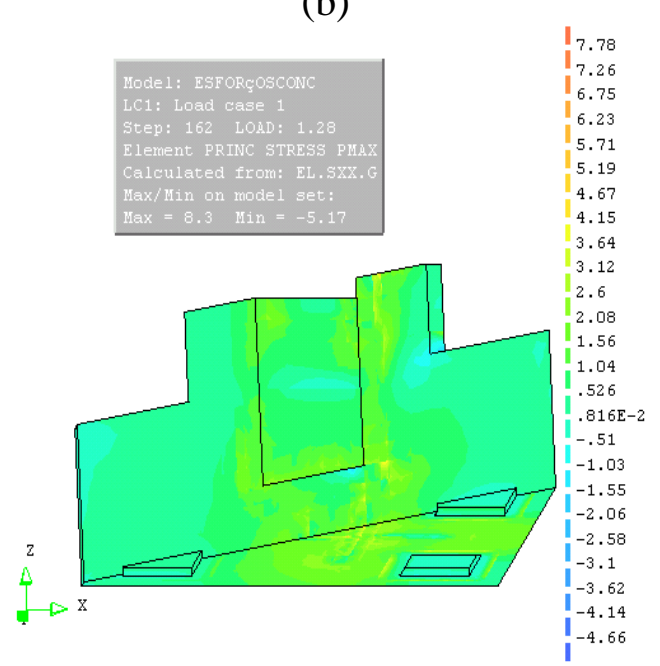

(d)

Figura 70 - Modelo MO1_IL_AR6: a) e b) cortes diagonais para visualização da tensão máxima em MPa; c) e d) cortes diagonais para visualização da tensão mínima em MPa. 


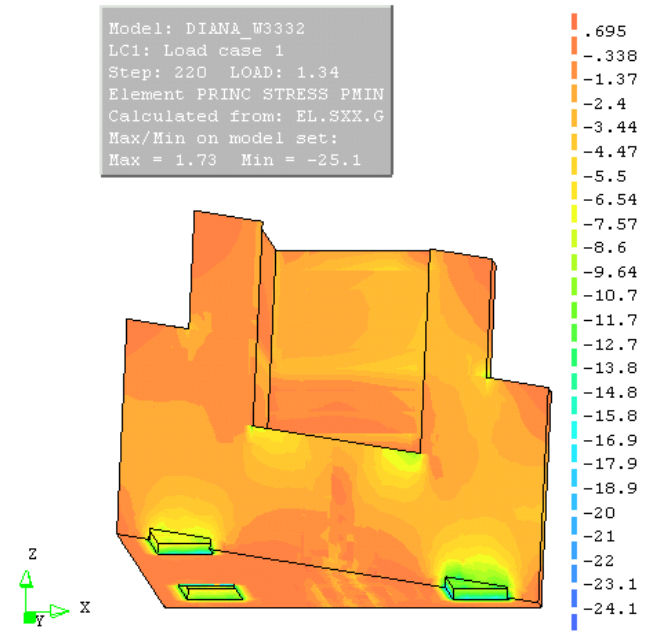

(a)

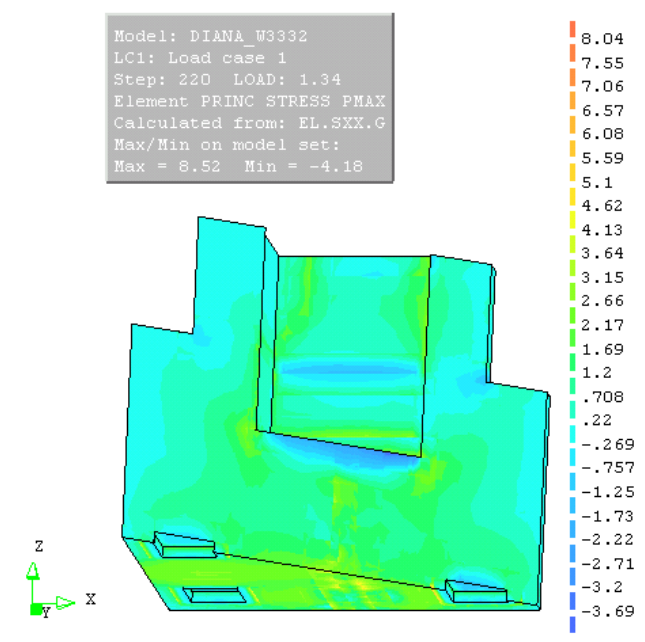

(c)

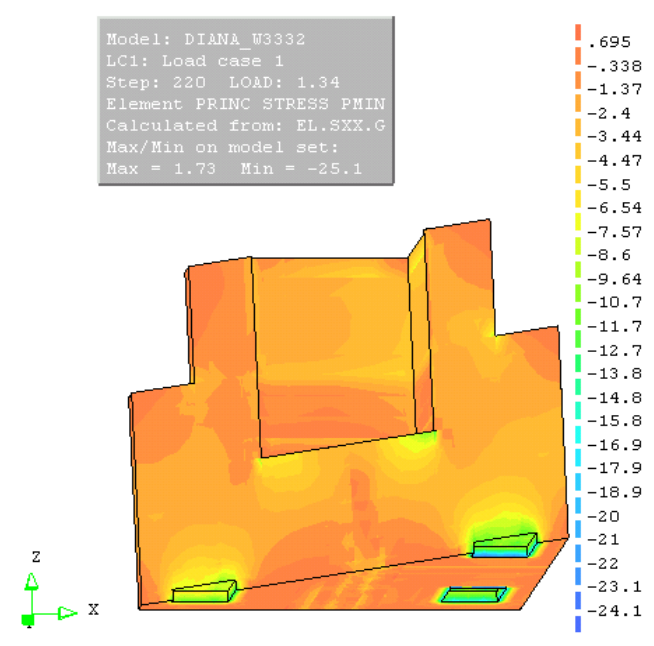

(b)

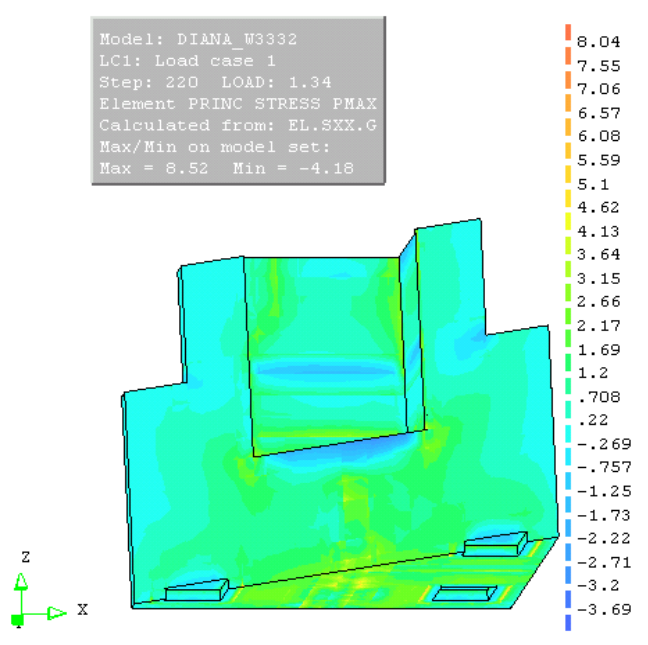

(d)

Figura 71 - Modelo MO2_IL_AR6: a) e b) cortes diagonais para visualização da tensão máxima em MPa; c) e d) cortes diagonais para visualização da tensão mínima em MPa.

\subsubsection{Fissuração dos modelos}

As fissuras do modelo MO1_IR apareceram, inicialmente, no contorno das estacas e, posteriormente, no meio do bloco. Estas fissuras foram se propagando com o acréscimo da força como pode ser observado na Figura 72.

As fissuras se propagaram de forma brusca no passo de carga seguinte a carga máxima de convergência do modelo numérico. Após isso o modelo numérico conseguiu convergir por mais alguns passos de carga, entretanto, nestes passos, a força foi menor que a máxima.

As primeiras fissuras apareceram para uma carga de 1,32 vez a força de projeto, indicando que estes blocos não apresentam problemas em relação às condições de serviço. 
Observou-se uma fissuração na parte superior da parede tracionada do colarinho em função do momento atuante.

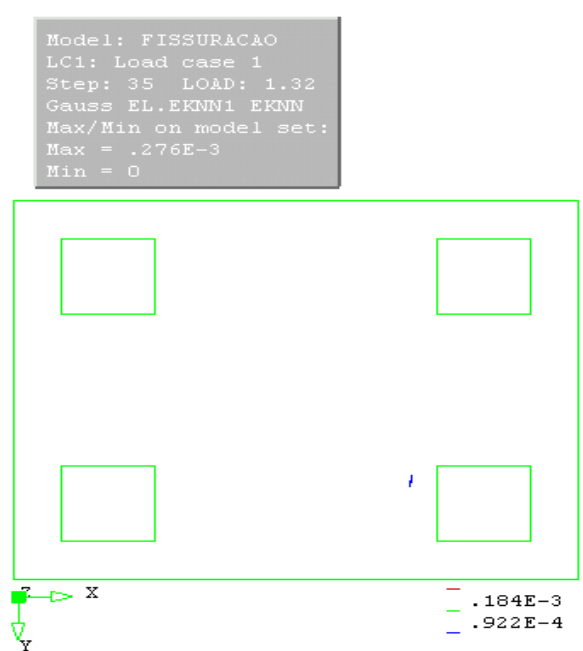

(a)
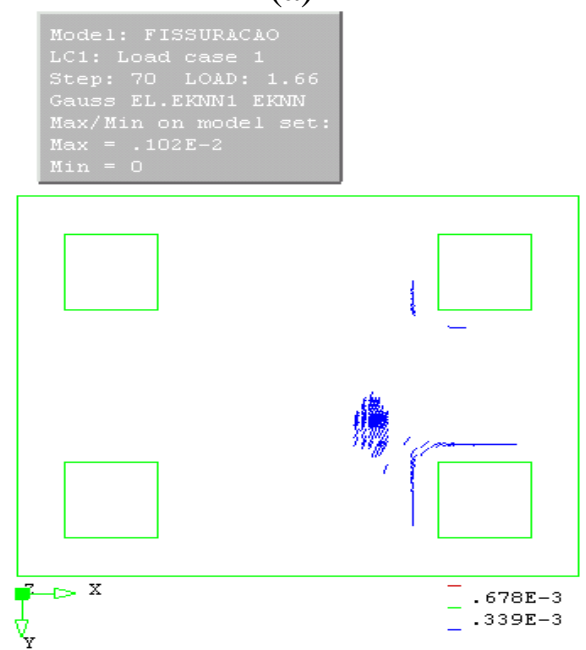

(c)

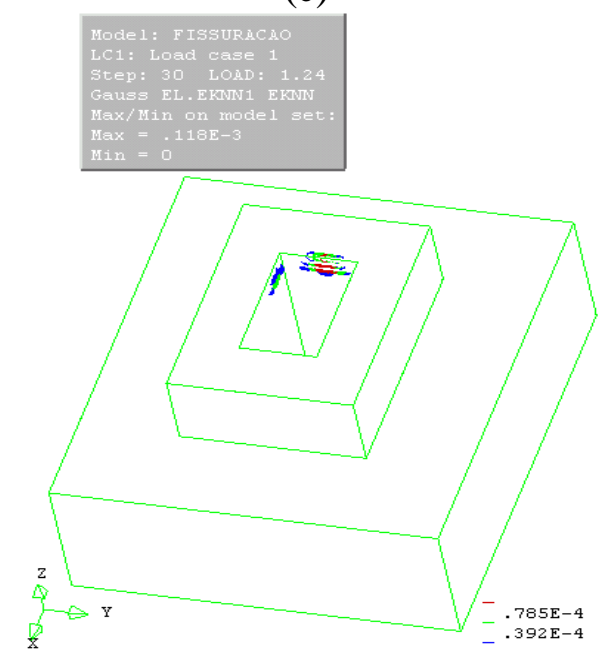

(e)

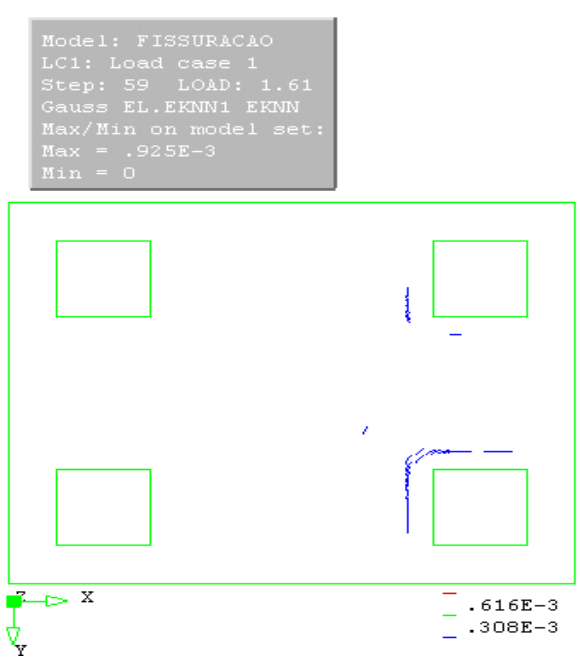

(b)

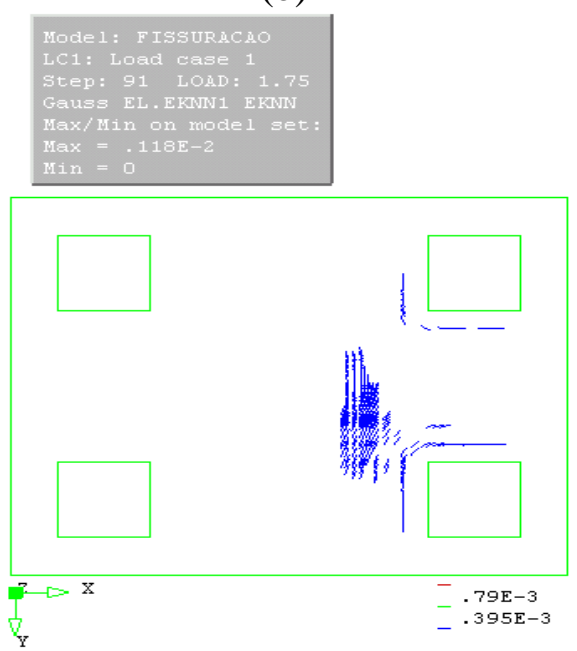

(d)

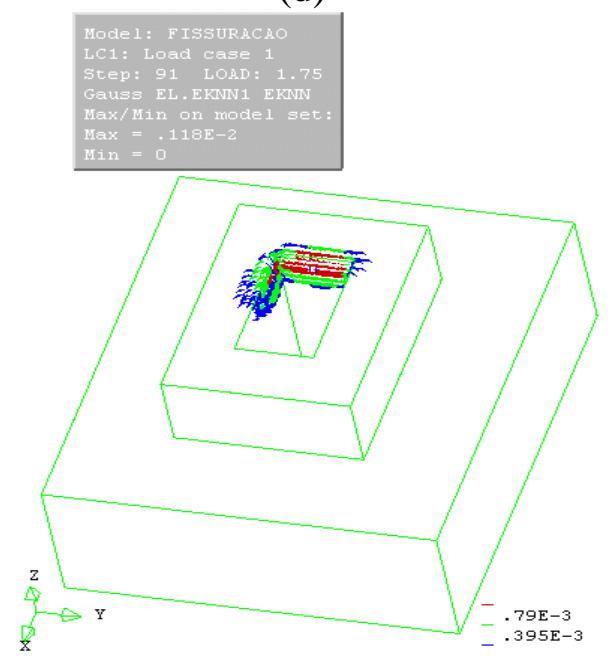

(f)

Figura 72 - Fissuração MO1_IR_AR6: a) bloco para 75\% força última; b) bloco para 92\% força última; c) bloco para $94 \%$ força última; d) bloco para $100 \%$ força última; e) colarinho para $70 \%$ força última; f) colarinho para $100 \%$ força última. 
A fissuração no modelo MO2_IR, foi diferente da observada nos modelo MO1_IR. Neste modelo, as fissuras se iniciaram entre as estacas, na posição onde estariam os tirantes. Com o aumento da solicitação, as fissuras entre as estacas mais afastadas tenderam para o centro do bloco. A evolução da fissuração é observada na Figura 73.

As primeiras fissuras no bloco surgiram para a força igual à força caracteristica, entretanto o modelo parou de convergir antes que o bloco apresentase um panorama de fissuração muito pronunciado. Neste modelo, não foi observada fissuração nas paredes do colarinho, e nem nas larterais do bloco.

Para os modelos MO1_IL, observou-se que as fissuras se iniciaram na parte inferior e em uma seção que dista aproximadamente 0,15.d da face do pilar, mesma distância recomendada pelo modelo de cálculo de verificações à resistência para momento fletor sugerida pelo CEB-FIP (1990). Posteriormente, estas fissuras se propagaram para as laterais do bloco. A evolução das fissuras pode ser observada na Figura 74.

No colarinho, a maior fissuração ocorreu nos cantos da parede da frente. Esta parede também fissurou na parte externa de forma semelhante ao observado nas simulações dos modelos ensaiados por Canha (2004), sugerindo que ela está submetida a uma flexo-tração. Pontua-se que para a solicitação atuante o comprimento de embutimento deveria ser maior.

No modelo MO2_IL, as primeiras fissuras surgiram na parte inferior do bloco e na região central. Posteriormente estas se propagaram para as laterais e entre as estacas mais afastadas, com tendência a dividir o bloco em duas partes.

Próximo a força máxima atingida pelo modelo numérico, estas fissuras surgiram entre as estacas menos afastadas. É possivel observar a evolução das fissuras com o acréscimo de força através da Figura 75. Os passos de carga foram escolhidos de forma a melhor representar o panorama de fissuração. 

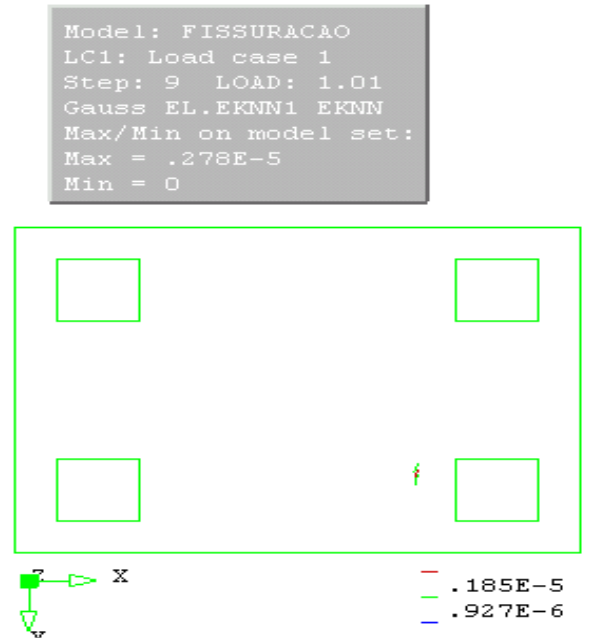

(a)

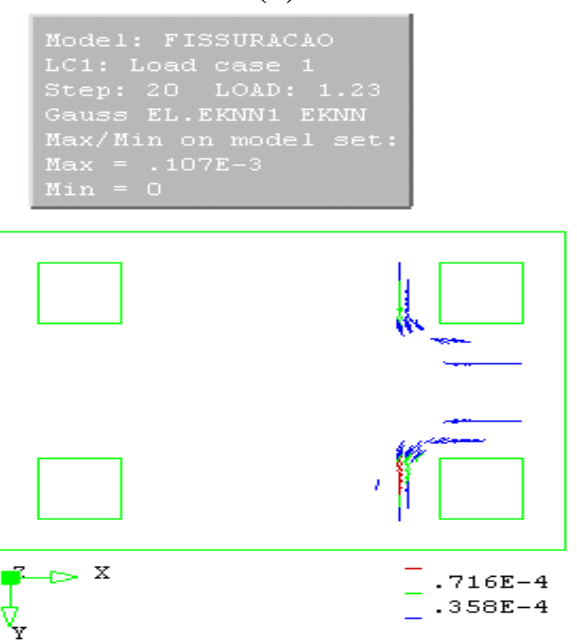

(c)

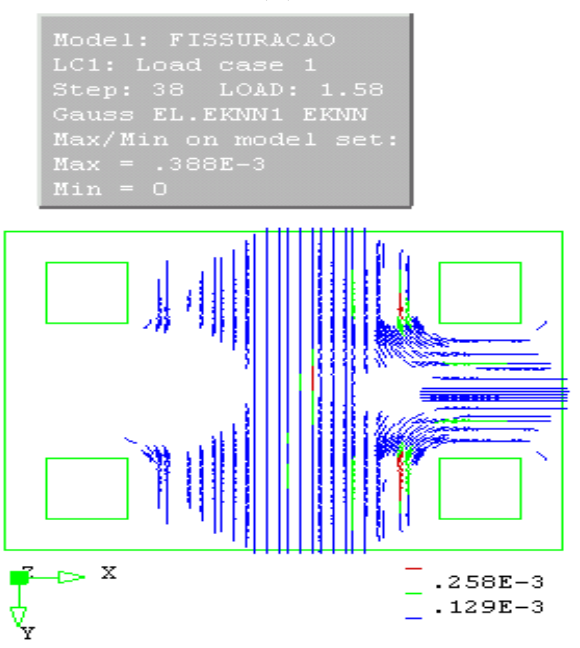

(e)

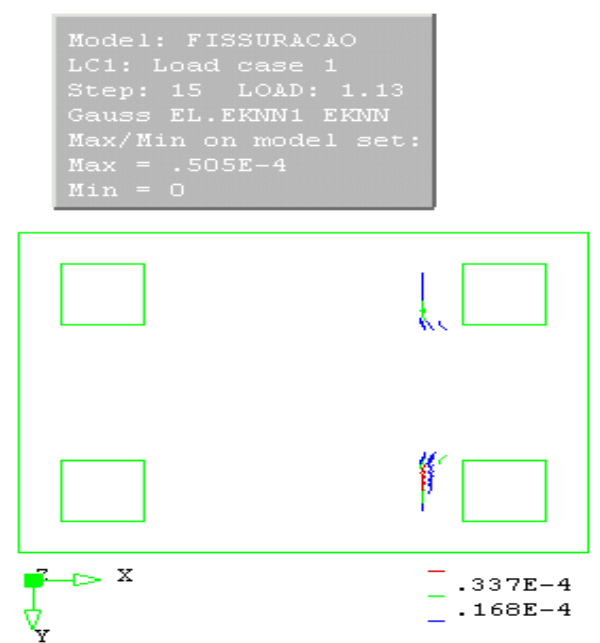

(b)
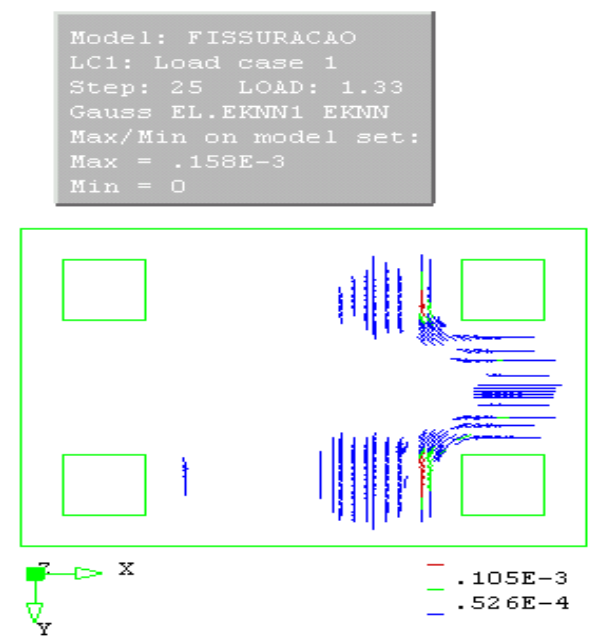

(d)

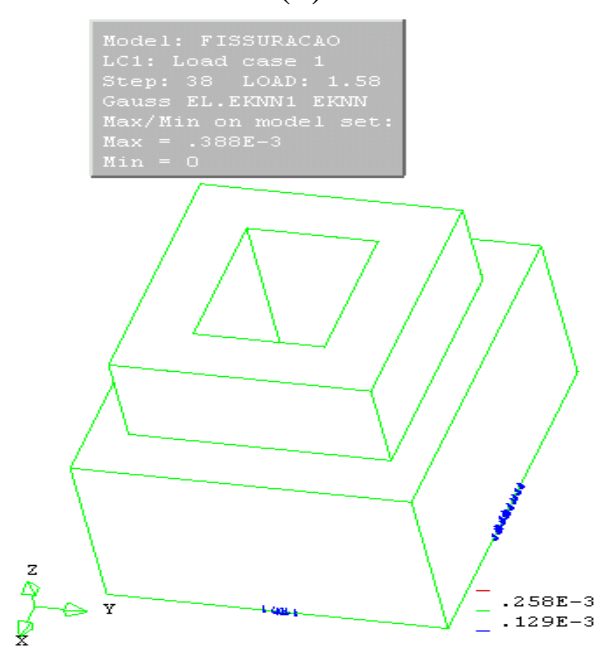

(f)

Figura 73 - Fissuração MO2_IR_AR6: a) bloco para 64\% força última; b) bloco para $71 \%$ força última; c) bloco para $77 \%$ força última; d) bloco para $84 \%$ força última; e) bloco para $100 \%$ força última; f) colarinho para $100 \%$ força última. 


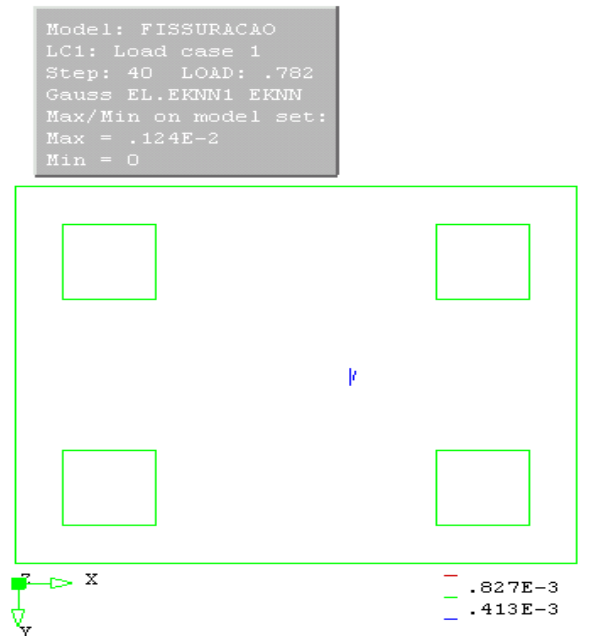

(a)

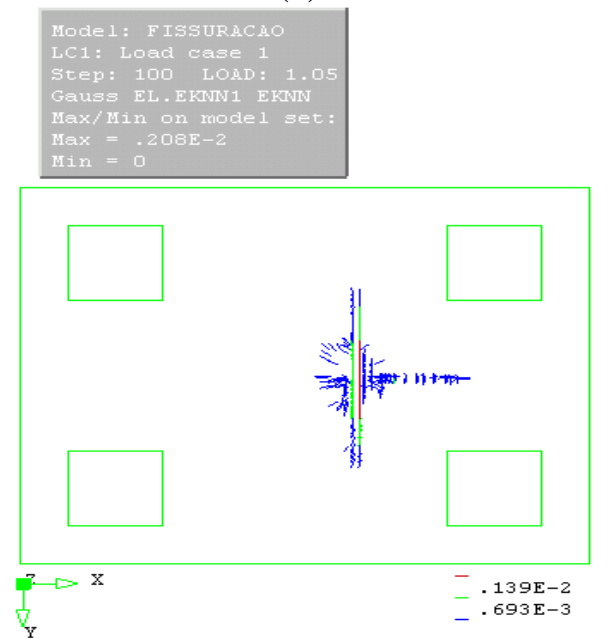

(c)

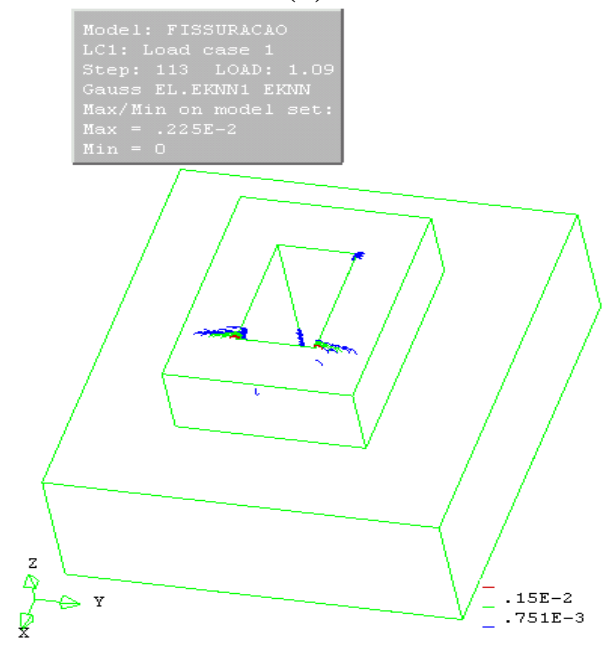

(e)

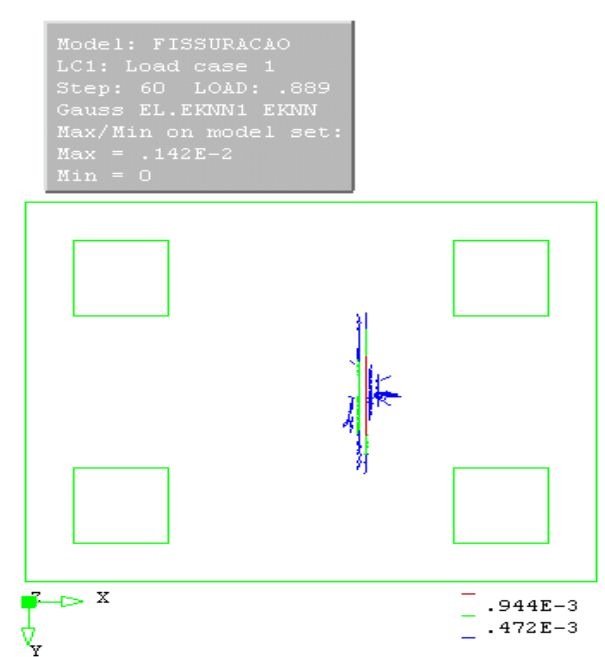

(b)

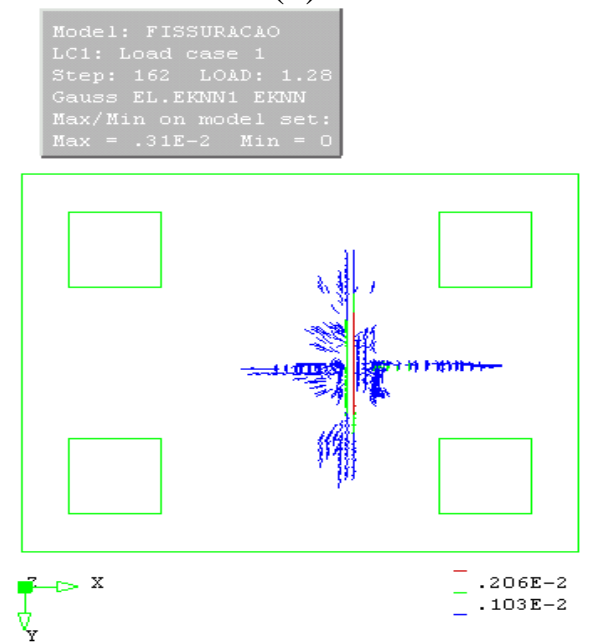

(d)

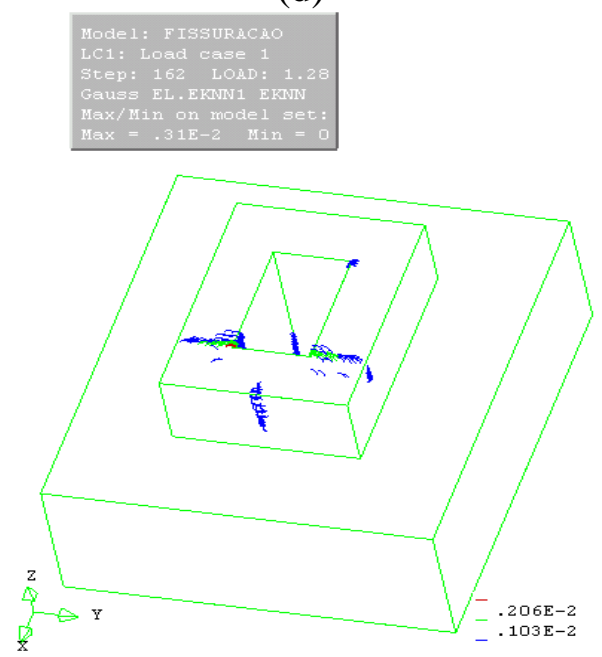

(f)

Figura 74 - Fissuração MO1_IL_AR6: a) bloco para 61\% força última; b) bloco para 69\% força última; c) bloco para $82 \%$ força última; d) bloco para $100 \%$ força última; e) colarinho para $85 \%$ força última; f) colarinho para $100 \%$ força última. 

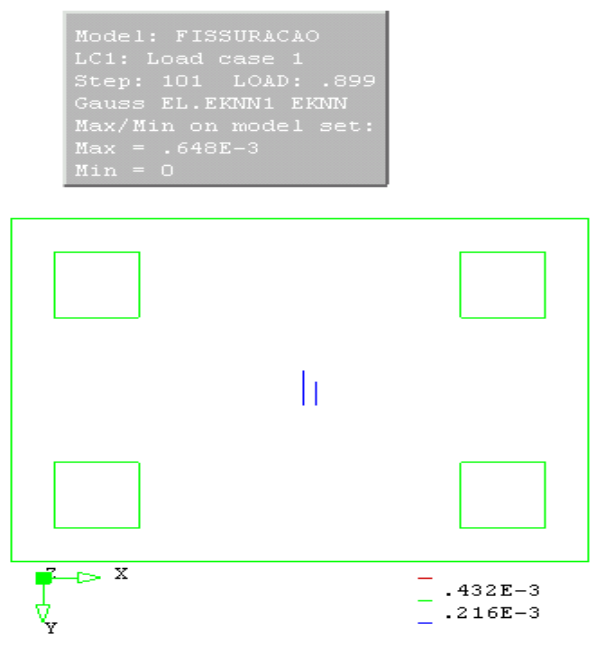

(a)
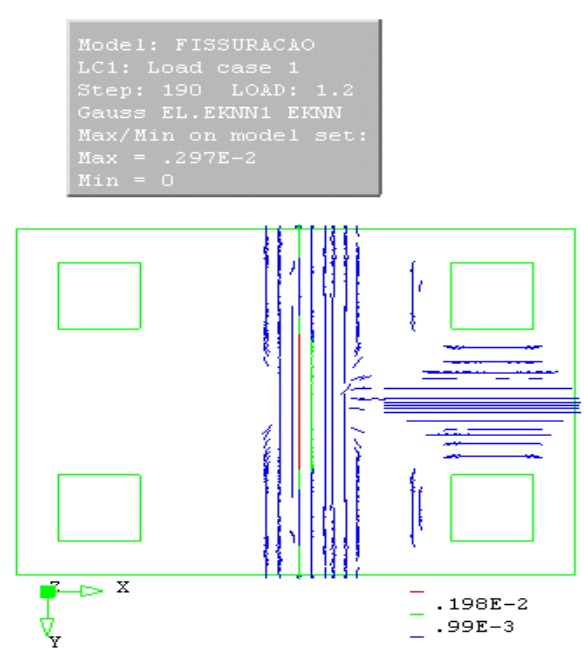

(c)

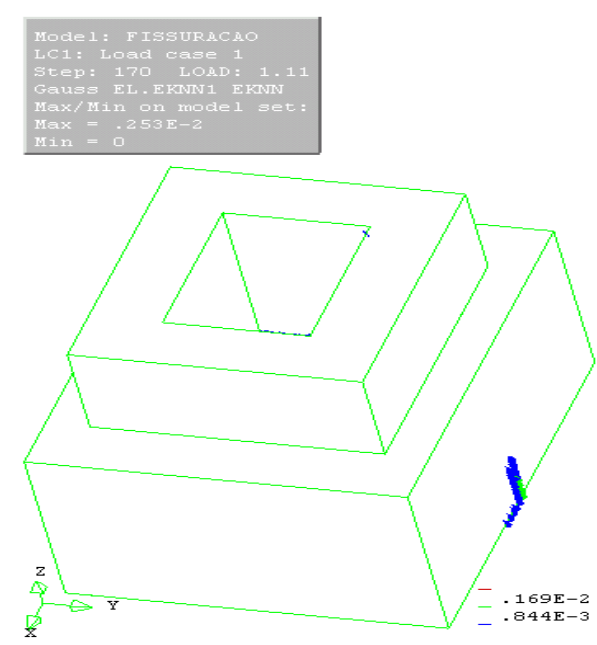

(e)
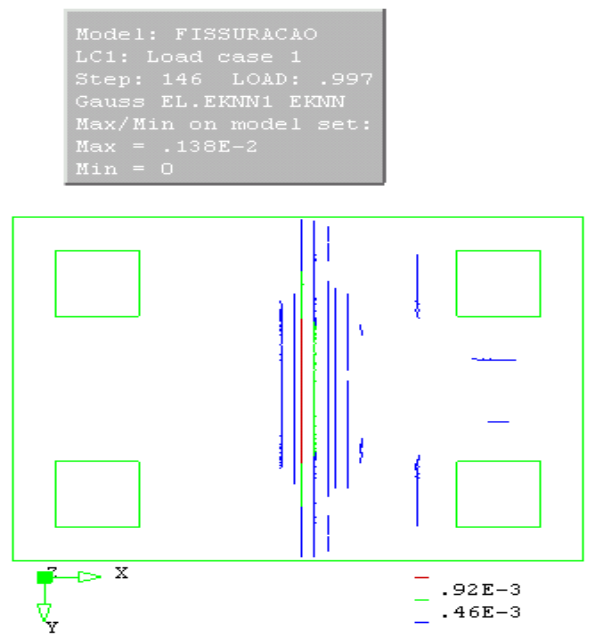

(b)

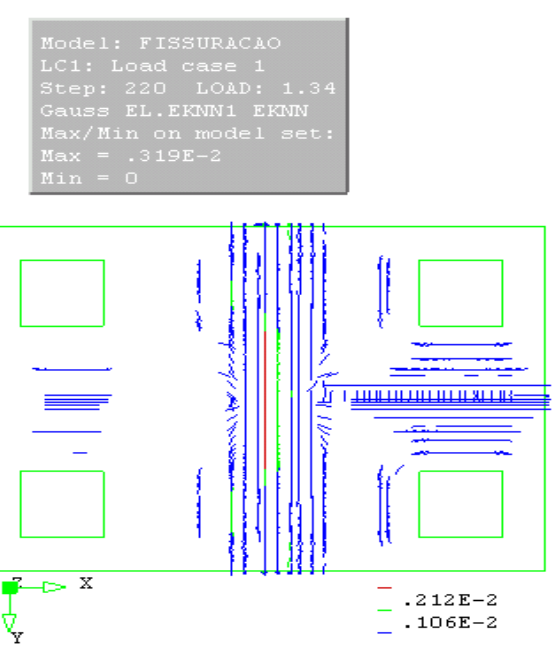

(d)

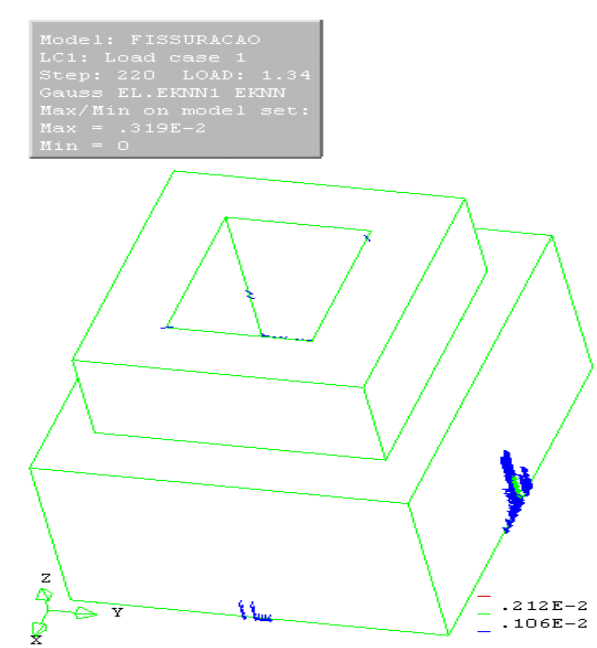

(f)

Figura 75 - Fissuração MO2_IL_AR6: a) bloco para $67 \%$ força última; b) bloco para $74 \%$ força última; c) bloco para $89 \%$ força última; d) bloco para $100 \%$ força última; e) colarinho para $83 \%$ força última; f) colarinho para $100 \%$ força última. 


\subsubsection{Tensões nas barras das armaduras}

Da mesma forma que nos itens anteriores, tendo em vista a semelhança dos resultados, aqui são apresentadas apenas as tensões nas armaduras dos modelos analisados com todas as armaduras.

Na Figura 76, é apresentada a tensão nas armaduras do modelo MO1_IR_AR6. Podese observar que os valores das tensões são menores que a resistência de escoamento do aço indicando que todas as armaduras estão pouco solicitadas, inclusive as dos tirantes do bloco.

Estes resultados sugerem que as forças se transferem diretamente do pilar para a estaca, corroborando com a hipótese de que as bielas se formam quase na vertical. Estes blocos estariam se comportando de forma semelhante a blocos parcialmente carregados.

Outra justificativa para as armaduras serem pouco solicitadas são as dimensões tanto do bloco como do colarinho. Em relação ao colarinho, sendo as paredes de grande espessura o fluxo de tensão não corresponde aos modelos sugeridos por Leonhardt e Mönig (1977) e Canha (2004). Neste caso, o modelo pode ser considerado como um bloco com cálice embutido já que, também nestes, pelo mecanismo de formação das bielas, o concreto nos cantos é pouco solicitado, não influenciando no comportamento geral do modelo.

Para as armaduras dos tirantes do bloco, a pequena tensão pode ser justificada por dois fatores: as bielas têm inclinações elevadas, como consequência, a força horizontal para equilibrar o nó da estaca mais solicitada é baixa; o concreto, no modelo numérico, é capaz de absorver parcialmente a força horizontal. 


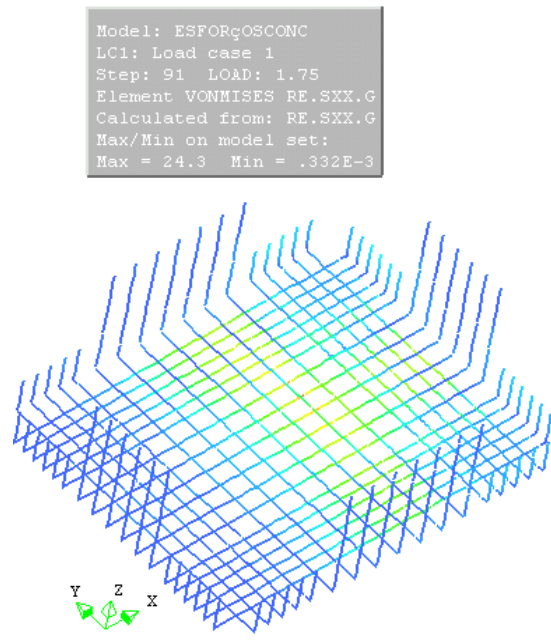

(a)
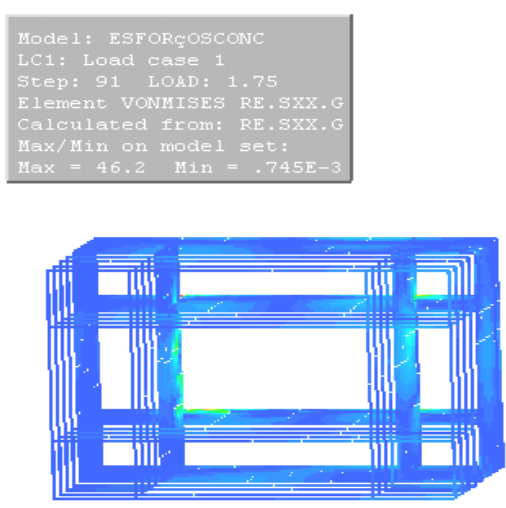

${ }^{\mathrm{A}} \mathrm{x}$

(c)

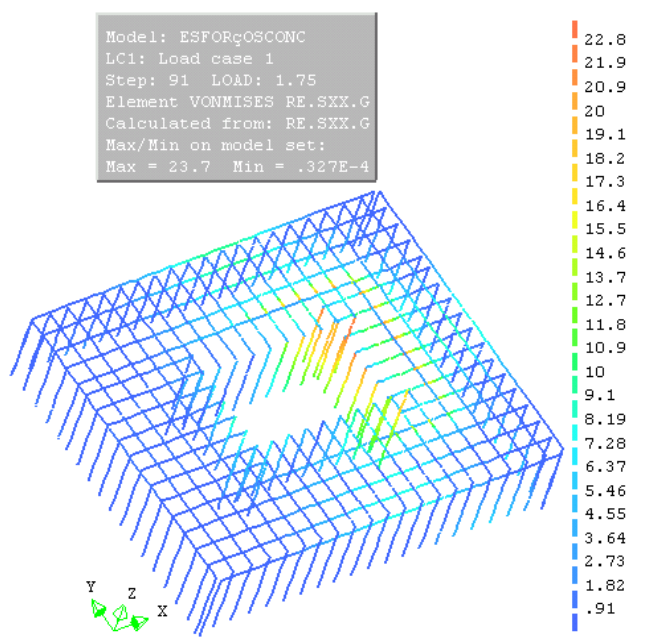

(e)

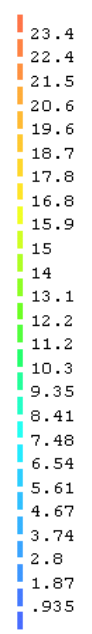
$R_{2}$
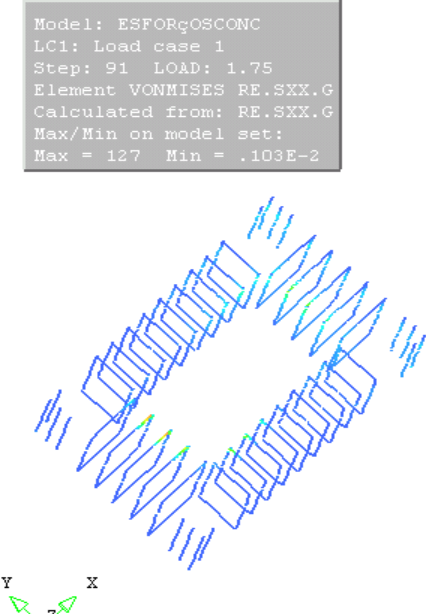

(b)
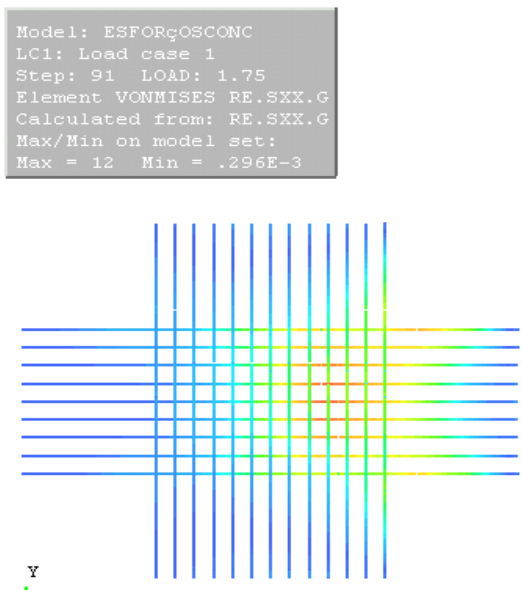

(d)

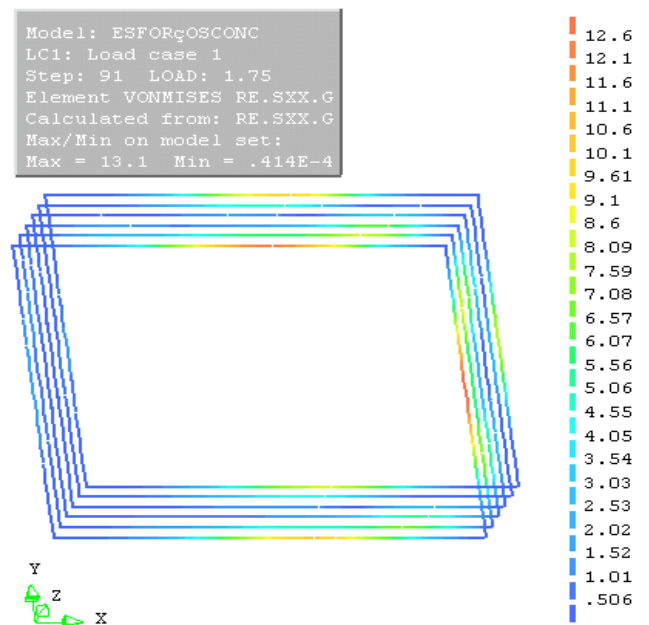

(f) 
Na Figura 77, são apresentadas as tensões nas armaduras do modelo MO2_IR_AR6. Da mesma forma como apresentado no MO1_IR_AR6, as tensões nas armaduras foram pequenas e as justificativas são as mesmas apresentadas anteriormente.

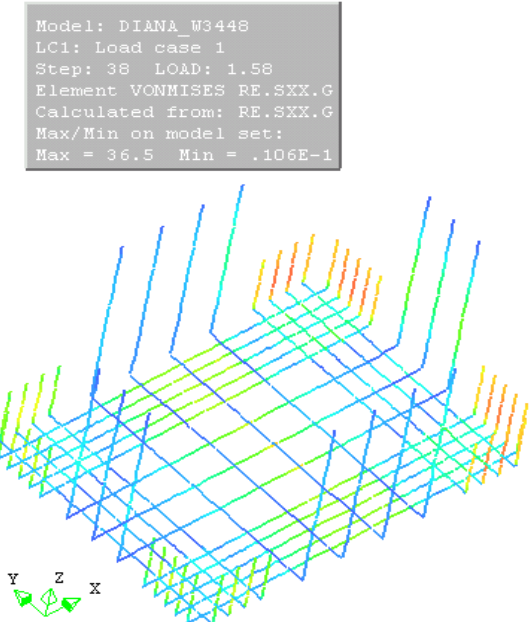

(a)

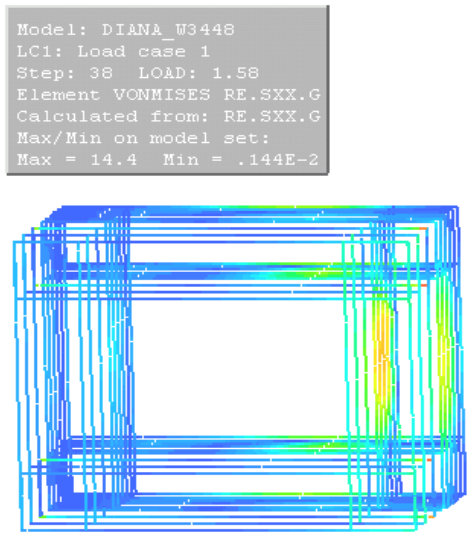

${ }^{\mathrm{Y}} \mathrm{x}$

(c)
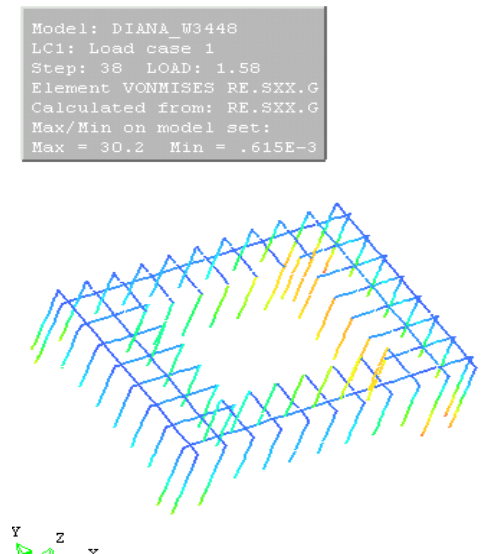

(e)

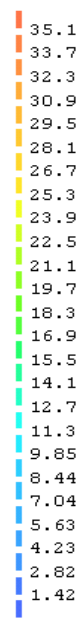

33.7

32.3
30.9

30.9
29.5

28.1
26.7

26.7
25.3
23.9

23.9
22.5

21.1
19.7

18.3

16.9
15.5
14.1

14.1

11.3

9.85
8.44
7.04

7.04
5.63
4.23

2. 82

$x_{2}$
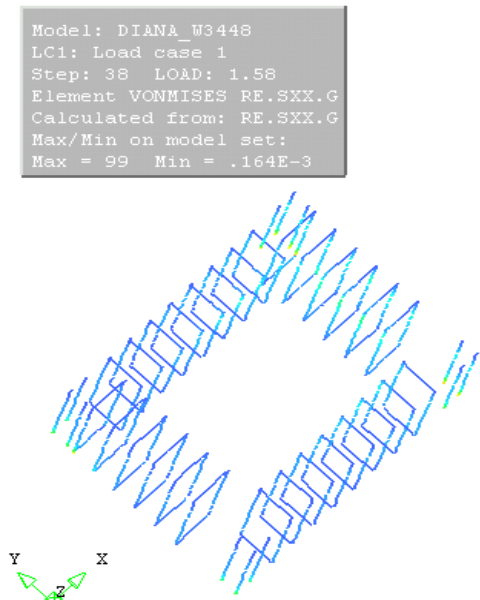

(b)
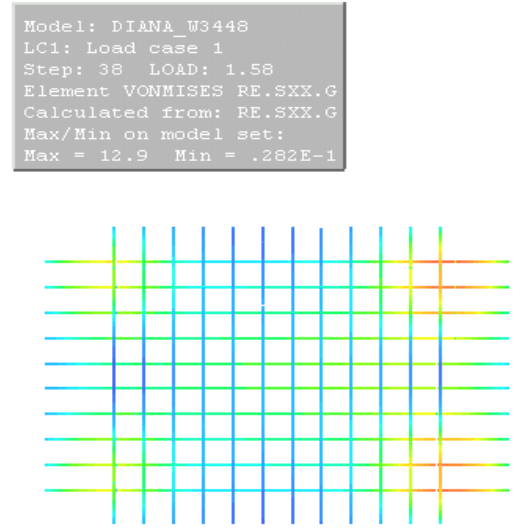

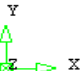

(d)

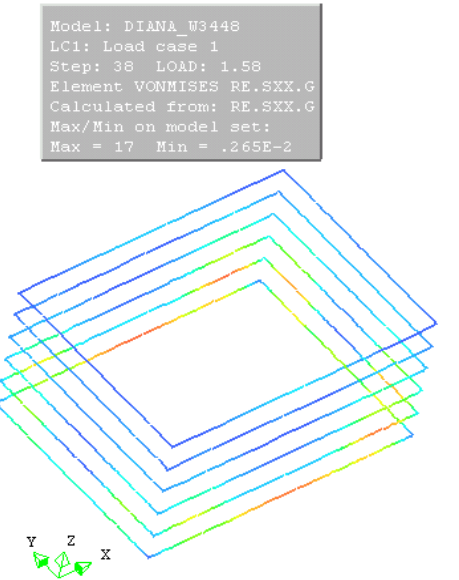

\begin{tabular}{|l}
16.3 \\
15.7 \\
15 \\
14.4 \\
13.7 \\
13.1 \\
12.4 \\
11.8 \\
11.1 \\
10.5 \\
9.81 \\
9.15 \\
\hline 8.5 \\
7.85 \\
7.19 \\
6.54 \\
5.89 \\
5.23 \\
4.58 \\
3.92 \\
3.27 \\
2.62 \\
1.96 \\
1.31 \\
.656
\end{tabular}

(f)

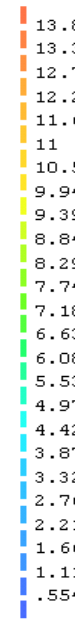

\begin{tabular}{|l}
29 \\
27.9 \\
26.7 \\
25.5 \\
24.4 \\
23.2 \\
23.1 \\
22.1 \\
20.9 \\
19.7 \\
18.6 \\
17.4 \\
16.3 \\
15.1 \\
13.9 \\
12.8 \\
11.6 \\
10.5 \\
$\mid 9.29$ \\
8.13 \\
\hline 6.97 \\
$\mid 5.81$ \\
4.65 \\
3.48 \\
2.32 \\
1.16
\end{tabular}

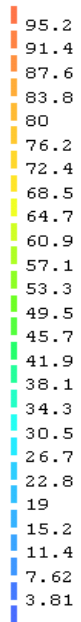

7.62

Figura 77 - Tensão nas armaduras modelo MO2_IR_AR6 em MPa: a) armaduras dos tirantes e distribuída do bloco; b) armadura vertical do colarinho; c) armaduras horizontais do colarinho; d) armadura de fretagem do bloco; e) armadura de fissuração do bloco; f) armadura horizontal para fissuração. 
As armaduras do modelo MO1_IL_AR6, indicadas na Figura 78, tiveram um comportamento diferente das dos modelos com interface rugosa, apresentando as tensões maiores em pontos diferentes.

Neste modelo, apesar das armaduras dos tirantes serem pouco solicitadas, as armaduras distribuídas no meio do bloco atingiram valores próximos a tensão limite, indicando neste caso que a maior parcela da força está sendo transmitida para o bloco pela parte inferior do pilar. As armaduras verticais do colarinho também apresentaram tensões de maior intensidade na parte inferior, mais precisamente, na região onde o pilar toca a laje de fundo do bloco.

As armaduras horizontais do colarinho foram mais solicitadas nos cantos onde as paredes transversais estão ligadas à parede da frente, e no meio desta parede, semelhante ao observado para os modelos com ligação lisa ensaiados por Canha (2004).

As armaduras de fretagem, da mesma forma que nos demais modelos, não contribuíram para a resistência dos modelos, entretanto estas foram mais solicitadas.

As demais armaduras colocadas para evitar a fissuração não seriam necessárias, de acordo com resultados observados.

Cabe resaltar que, de acordo com a ABNT NBR 6118:2003, os modelos simulados devem conter armadura de suspensão, pois a distância entre estacas é maior que 3 vezes o diâmetro, entretanto os resultados indicaram que esta armadura é pouco solicitada. 


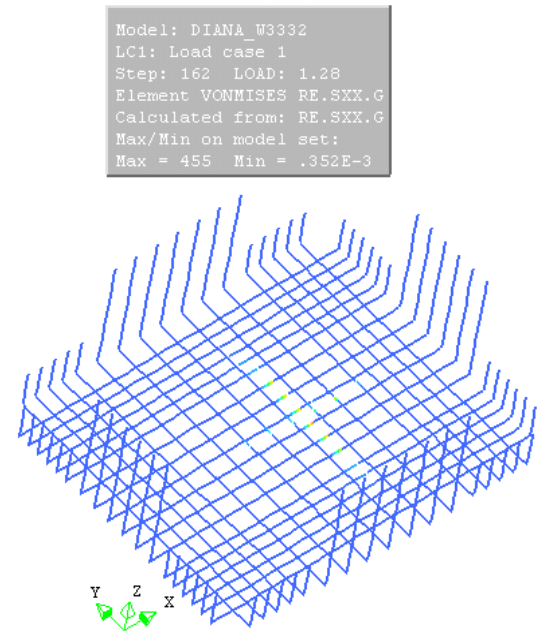

(a)
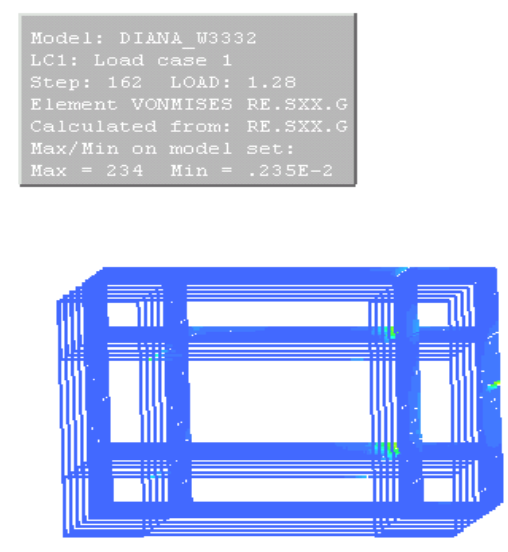

$\stackrel{\mathrm{P}}{\mathrm{A}}$

(c)

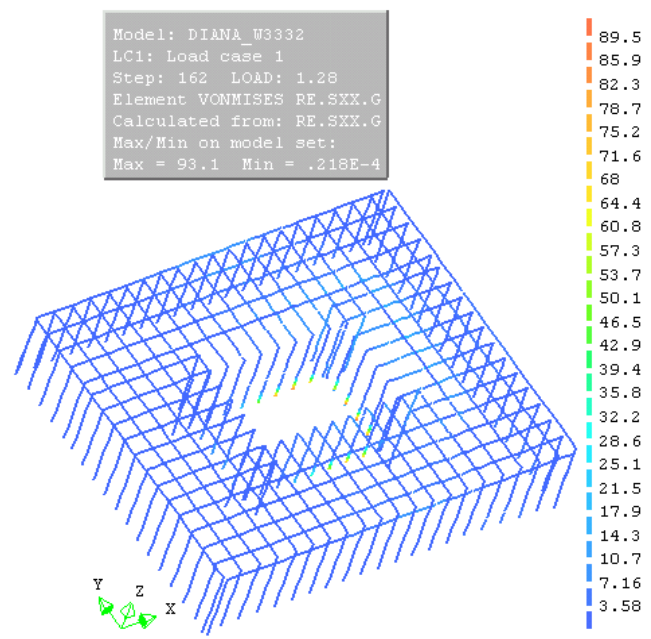

(e)

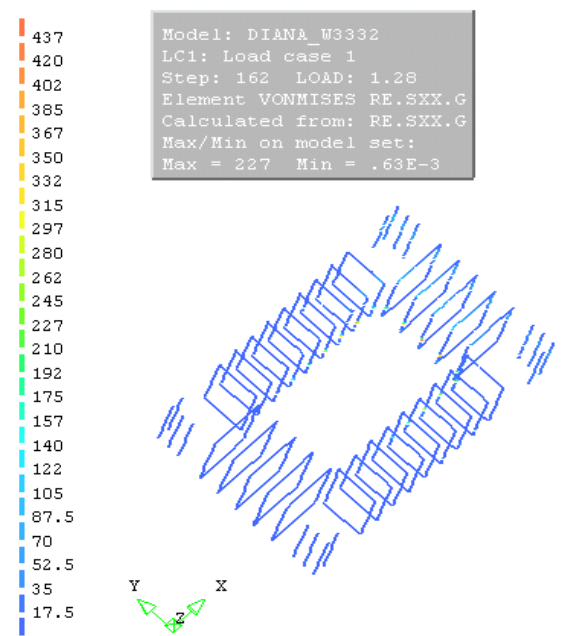

(b)

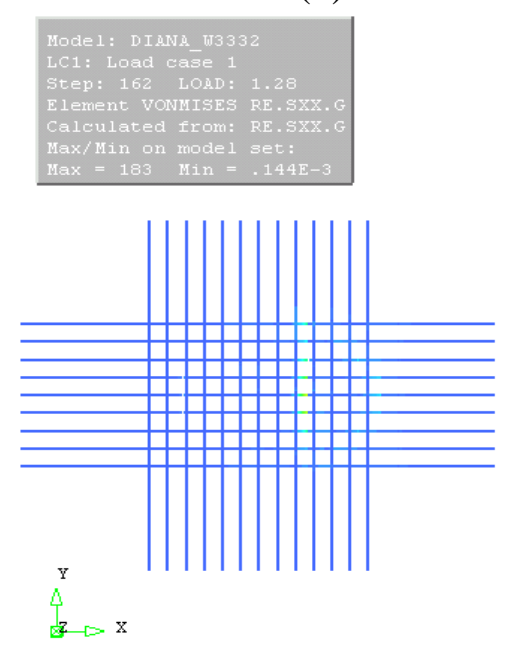

(d)

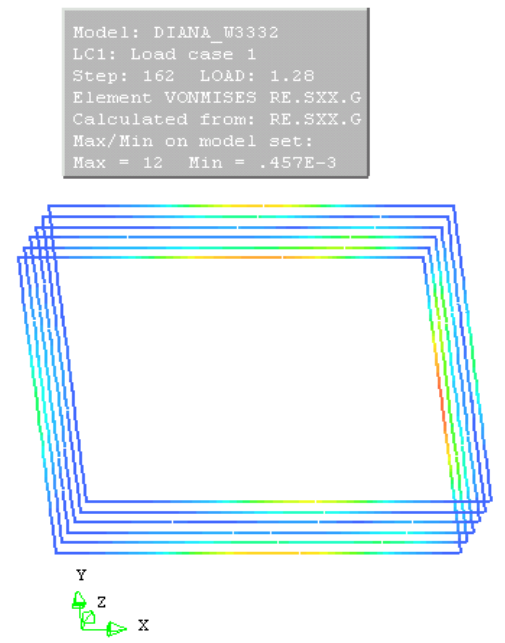

\begin{tabular}{|l} 
\\
11.5 \\
11.1 \\
10.6 \\
10.1 \\
9.67 \\
9.21 \\
8.75 \\
8.29 \\
7.83 \\
7.37 \\
6.91 \\
6.45 \\
5.99 \\
5.53 \\
5.07 \\
4.6 \\
4.14 \\
3.68 \\
3.22 \\
2.76 \\
2.3 \\
1.84 \\
1.38 \\
.921 \\
.461
\end{tabular}

(f)

Figura 78 - Tensão nas armaduras modelo MO1_IL_AR6 em MPa: a) armaduras dos tirantes e distribuída do bloco; b) armadura vertical do colarinho; c) armaduras horizontais do colarinho; d) armadura de fretagem do bloco; e) armadura de fissuração do bloco; f) armadura horizontal para fissuração. 


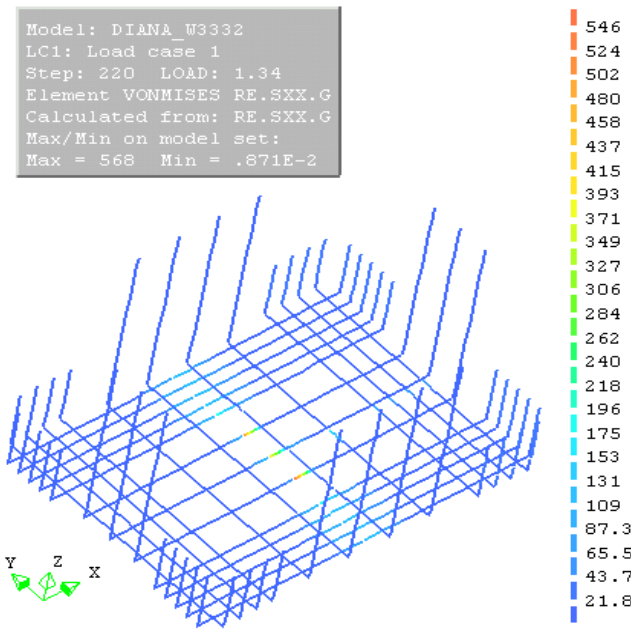

(a)
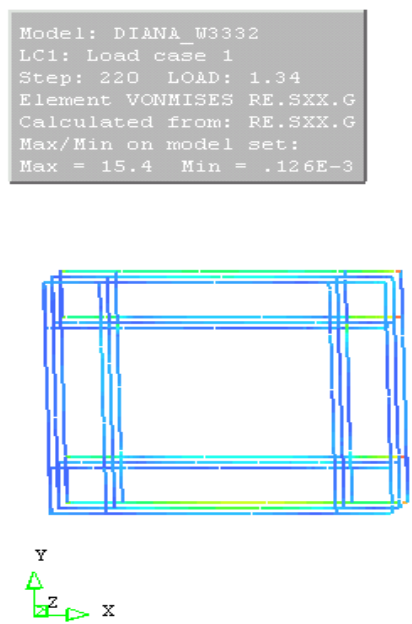

(c)
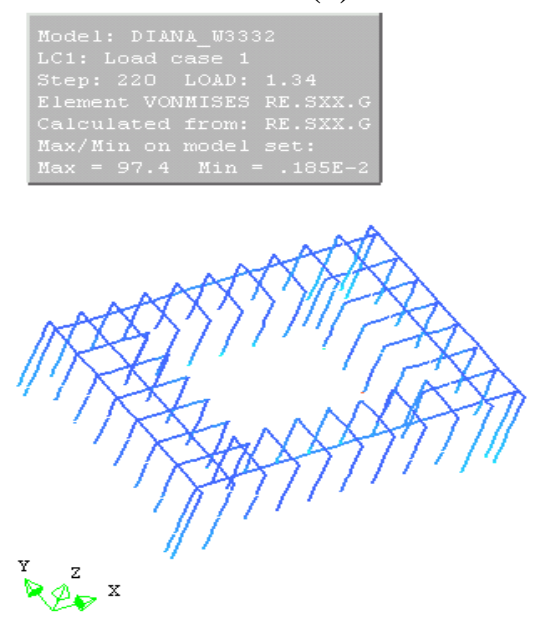

(e)

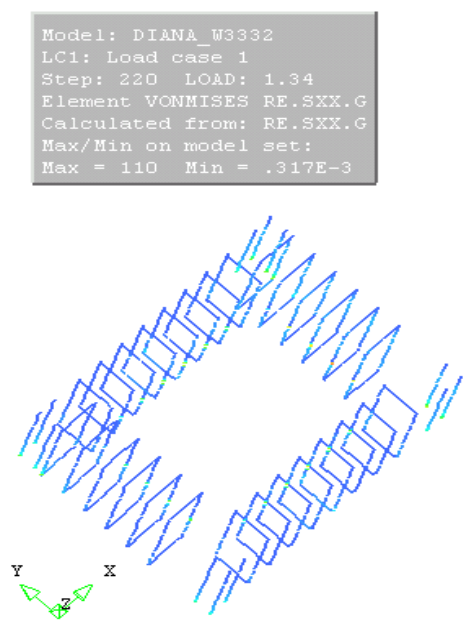

106
102
97.7
93.4
89.2
84.9
80.7
76.4
72.2
67.9
63.7
59.4
55.2
51
46.7
42.5
42.5
38.2
34
29.7
25.5
21.2
17
12.7
8.49
4.25
1

(b)
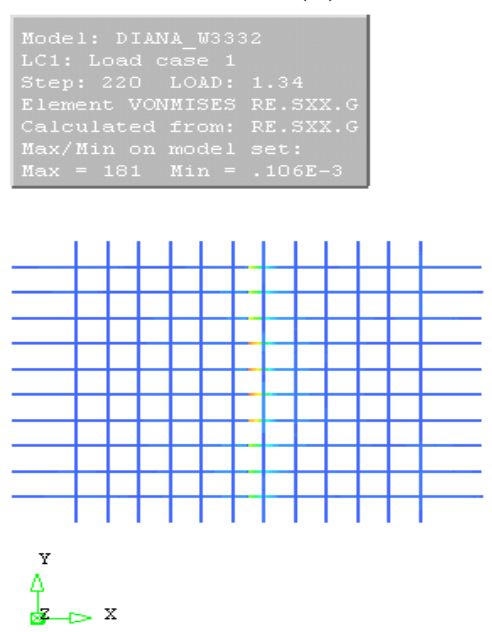

(d)

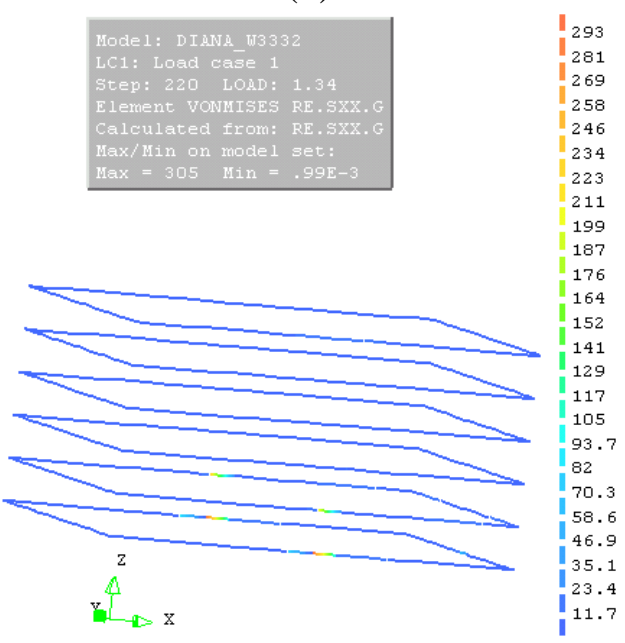

(f)

Figura 79- Tensão nas armaduras modelo MO2_IL_AR6 em MPa: a) armaduras dos tirantes e distribuída do bloco; b) armadura vertical do colarinho; c) armaduras horizontais do colarinho; d) armadura de fretagem do bloco; e) armadura de fissuração do bloco; f) armadura horizontal para fissuração. 
No modelo MO2_IL_AR6, foram mais solicitadas as armaduras de distribuição posicionadas no fundo do bloco e numa região central, em linha, entre as estacas mais afastadas, sugerindo que o bloco está se dividindo em duas partes.

As demais armaduras, como pode ser observado na Figura 79, foram pouco solicitadas, similarmente ao que occorreu no outro modelo com interface lisa.

\subsubsection{Reações nas estacas}

As reações das estacas, obtidas nos modelos numéricos, estão indicadas nas Tabela 16 a Tabela 189. Nestas, também estão indicados os resultados analíticos obtidos com a expressão 2.1 .

Observa-se que os resultados obtidos com a expressão analítica, tanto para a ligação rugosa quanto a lisa, são praticamente os mesmos que os obtidos numericamente.

A relação para os demais modelos, das duas séries onde se alterou a armadura e mesmo no bloco sem armadura, foi a mesma.

Tabela 16 - Reações nas estacas para o modelo MO1-IR-AR6.

\begin{tabular}{c|c|c|c}
\hline \multicolumn{4}{|c}{ REACÕES NAS ESTACAS } \\
\hline & Método Analítico & Numérico & Analítico/Numérico \\
\hline Estaca1 & 132,76 & 159,156 & 0,834 \\
\hline Estaca2 & 1383,37 & 1367,410 & 1,012 \\
\hline Estaca3 & 374,83 & 374,151 & 1,002 \\
\hline Estaca4 & 1625,44 & 1616,704 & 1,005 \\
\hline
\end{tabular}

Tabela 17 - Reações nas estacas para o modelo MO1-IL-AR6.

\begin{tabular}{c|c|c|c}
\hline \multicolumn{4}{|c}{ REACÕES NAS ESTACAS } \\
\hline & Método analítico & Numérico & Analítico/Numérico \\
\hline Estaca1 & 97,48 & 128,47 & 0,76 \\
\hline Estaca2 & 1015,74 & 992,78 & 1,023 \\
\hline Estaca3 & 275,22 & 266,38 & 1,033 \\
\hline Estaca4 & 1193,48 & 1194,02 & 1,00 \\
\hline
\end{tabular}

Tabela 18 - Reações nas estacas para o modelo MO2-IR-AR6.

\begin{tabular}{c|c|c|c}
\hline \multicolumn{4}{|c}{ REACÕES NAS ESTACAS } \\
\hline & Método analítico & Numérico & Analítico/Numérico \\
\hline Estaca1 & 899,41 & 820,90 & 1,096 \\
\hline Estaca2 & 1114,29 & 1172,64 & 0,95 \\
\hline Estaca3 & 924,69 & 865,97 & 1,068 \\
\hline Estaca4 & 1139,57 & 1219,42 & 0,935 \\
\hline
\end{tabular}


Tabela 19- Reações nas estacas para o modelo MO2-IL-AR6.

\begin{tabular}{c|c|c|c}
\hline \multicolumn{4}{|c}{ REACÕES NAS ESTACAS } \\
\hline & Método analítico & Numérico & Analítico/Numérico \\
\hline Estaca1 & 760,51 & 695,30 & 1,094 \\
\hline Estaca2 & 942,21 & 990,28 & 0,951 \\
\hline Estaca3 & 781,90 & 730,92 & 1,070 \\
\hline Estaca4 & 963,59 & 1032,20 & 0,934 \\
\hline
\end{tabular}

\subsubsection{Comparação com modelos analíticos}

As barras das armaduras dos tirantes dos blocos foram determinadas para resistir a uma força de tração calculada a partir do equilíbrio do nó da ligação entre biela e tirante da estaca mais solicitada.

Com o objetivo de comparar os resultados numéricos com os obtidos de acordo com os modelos analíticos comumente empregados nos escritórios de cálculo, determinaram-se as forças nas bielas a partir da tensão média nas armaduras e das reações das estacas obtidas nos modelos numéricos.

Os resultados dos modelos númericos foram comparados com os resultados obtidos por meio de dois prcocedimentos analíticos aqui denominados de analítico1 e analítico2.

O modelo analítico1 corresponde a determinação das forças nos tirantes e nas bielas por meio do equilíbrio do nó correspondente á estaca mais solicitada. Neste modelo considera-se que todas as bielas se formam partindo das regiões centrais dos quartos de área do pilar até as cabeças das estacas, estando, assim, todas com as mesmas inclinações com a horizontal, semelhante ao apresentado aos modelos de Blévot e Frémy (1967).

No modelo analítico2 as forças nas bielas e nos tirantes foram determinadas pelo equilíbrio dos nós da ligação da estaca com os tirantes e as bielas. No entanto, diferentemente do modelo analítico1, as bielas se formam a partir do ponto correspondente à excentricidade da força até á cabeça das estacas, corforme Figura 80. Este modelo foi proposto por Souza et al. (2007) e nele as inclinações das bielas com a horizontal são diferentes. O princípio deste método sugere que os tirantes tenham área de aço calculadas para cada região. Considera-se que a força vertical atua a uma profundidade m (Figura 80) do topo do colarinho. Em ambos os modelos analíticos, $\mathrm{m}$ corresponde a 1/6 do comprimento de embutimento como recomendado por Leonhardt e Mönnig (1977) e Canha (2004). 


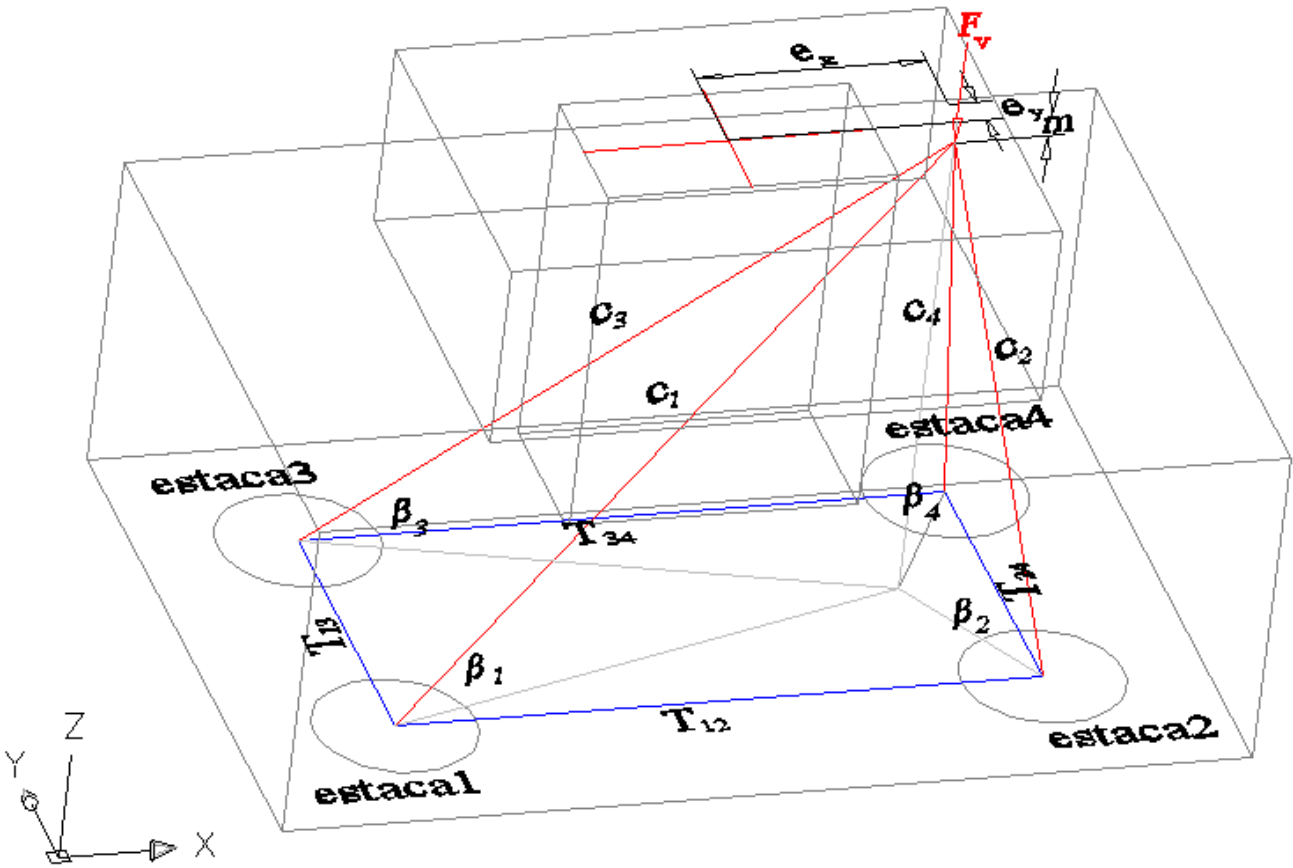

Figura 80 - Modelo espacial adaptado de Souza et al (2007).

Observando os resultados apresentados na Tabela 20, percebe-se que há uma diferença significativa nas forças dos tirantes, obtidas por meio dos modelos analíticos em relação aos resultados numéricos. Entretanto, cabe ressaltar que a força obtida no modelo numérico corresponde apenas à parte absorvida pelas armaduras dos tirantes, desprezando-se a contribuição das armaduras de distribuição e da parcela resistida pelo concreto.

Quanto à inclinação das bielas, observa-se, pelos resultados da Tabela 21, que os resultados numéricos indicam que estas são mais inclinadas do que os modelos analíticos, mas estas seguem a mesma tendência no modelo analítico 2 que considera inclinações diferentes para as bielas.

Tabela 20 - Forças nos tirante obtidos pelos modelos analíticos e pelo modelo numérico.

\begin{tabular}{c|c|c|c|c|c}
\hline & \multicolumn{5}{|c}{ Força nos tirantes $(\mathrm{kN})$} \\
\hline \multirow{2}{*}{ Analítico 1 } & Modelo & $\mathrm{T}_{12}$ & $\mathrm{~T}_{34}$ & $\mathrm{~T}_{13}$ & $\mathrm{~T}_{24}$ \\
& MO1_IR_AR6 & 916,40 & 780,11 & 171,68 & 744,57 \\
\cline { 2 - 6 } & MO2_IR_AR6 & 402,59 & 386,99 & 189,8 & 284,71 \\
\hline \multirow{2}{*}{ Analítico2 } & MO1_IR_AR6 & 348,58 & 264,27 & 131,76 & 780,57 \\
\cline { 2 - 6 } & MO2_IR_AR6 & 452,15 & 431,6 & 250,44 & 357,16 \\
\hline \multirow{2}{*}{ Numérico } & MO1_IR_AR6 & 28,97 & 24,66 & 3,93 & 21,98 \\
\cline { 2 - 6 } & MO2_IR_AR6 & 21,82 & 20,36 & 6,05 & 7,53 \\
\hline
\end{tabular}


Tabela 21 - inclinação das bielas determinadas pelos diferentes métodos

\begin{tabular}{l|c|c|c|c|c}
\hline & \multicolumn{5}{|c}{ Inclinação das bielas } \\
\hline & Modelo & $\beta_{1}$ & $\beta_{2}$ & $\beta_{3}$ & $\beta_{4}$ \\
\hline \multirow{2}{*}{ Analítico 1 } & MO1_IR_AR6 & 54,00 & 54,00 & 54,00 & 54,00 \\
\cline { 2 - 6 } & MO2_IR_AR6 & 68,40 & 68,40 & 68,40 & 68,40 \\
\hline \multirow{2}{*}{ Analítico 2 } & MO1_IR_AR6 & 37,78 & 63,45 & 36,56 & 57,57 \\
\cline { 2 - 6 } & MO2_IR_AR6 & 58,99 & 64,83 & 58,70 & 64,42 \\
\hline \multirow{2}{*}{ Numérico } & MO1_IR_AR6 & 85,53 & 88,71 & 81,08 & 88,61 \\
\cline { 2 - 6 } & MO2_IR_AR6 & 88,52 & 88,93 & 88,50 & 88,91 \\
\hline
\end{tabular}

Tabela 22 - Forças nas bielas obtidas pelos modelos analíticos e pelo resultado numérico

\begin{tabular}{c|c|c|c|c|c}
\hline & \multicolumn{5}{|c}{ Força nas bielas $(\mathrm{kN})$} \\
\hline & Modelo & $\mathrm{C}_{1}$ & $\mathrm{C}_{2}$ & $\mathrm{C}_{3}$ & $\mathrm{C}_{4}$ \\
\hline \multirow{2}{*}{ Analítico 1 } & MO1_IR_AR6 & 463,19 & 2008,81 & 164,44 & 1710,06 \\
\cline { 2 - 6 } & MO2_IR_AR6 & 929,52 & 1314,39 & 878,59 & 1263,46 \\
\hline \multirow{2}{*}{ Analítico 2 } & MO1_IR_AR6 & 471,50 & 1912,86 & 367,65 & 1536,95 \\
\cline { 2 - 6 } & MO2_IR_AR6 & 1003,34 & 1355,03 & 960,65 & 1297,83 \\
\hline \multirow{2}{*}{ Numérico } & MO1_IR_AR6 & 375,29 & 1617,10 & 161,09 & 1367,81 \\
\cline { 2 - 6 } & MO2_IR_AR6 & 866,26 & 1172,84 & 821,17 & 1219,64 \\
\hline
\end{tabular}

As forças nas bielas obtidas pelo modelo analítico 2 se aproximaram mais dos resultados numéricos que as obtidas pelo analítico 1, mas mesmo assim há uma diferença significativa entre os resultados numéricos e os analíticos. 


\section{CONCLUSÃO}

Neste trabalho se analisou numericamente o comportamento de blocos sobre quatro estacas submetidos a momentos nas duas direções e força centrada com ligação do pilar prémoldado por meio de cálice parcialmente embutido. Em função do ineditismo da proposta e da inexistência de trabalhos experimentais análogos (blocos submetidos a momentos de grande intensidade) ressalta-se que seus resultados apontam tendências e não esgotam as questões sobre o tema. Ao contrário disso, trazem a tona novas perguntas a serem respondidas e reforçam a necessidade de que se realizem ensaios experimentais que forneçam resultados capazes de embasar métodos de dimensionamento mais eficientes.

A partir dos resultados obtidos podem-se apresentar as seguintes conclusões que servem de alerta para possíveis problemas e para direcionar os estudos futuros.

- Os blocos analisados com interface rugosa e submetidos a momentos nas duas direções apresentaram a formação de bielas comprimidas de concreto que transmitem a força do pilar para as estacas. Entretanto, não se comprova o modelo analítico apresentado por Blévot e Frémy (1967), principalmente porque as armaduras dos tirantes dos blocos estão submetidas a tensões pequenas. Pontua-se que as dimensões dos blocos analisados não respeitam as limitações deste modelo;

- as armaduras de fretagem consideradas no dimensionamento destes blocos pouco ou nada contribuíram para a resistência e limitação da fissuração dos modelos;

- as forças que os modelos numéricos atingiram são superiores às forças características adotadas nos projetos dos blocos. Mesmo para as forças de projeto, não se verificou fissuração significativa, garantindo assim que os blocos não apresentaram problemas com relação à resistência nem ao comportamento em serviço; 
- nos modelos com interface rugosa, as bielas se formaram a partir do comprimento de embutimento. As bielas que conduzem a força para as estacas mais solicitadas se formam com maior inclinação em relação à horizontal. Sendo assim, as bielas possuem inclinações diferentes;

- nos modelos com interface lisa, a transferência da força ocorreu pela força de atrito e pelo contato das paredes do colarinho com a do pilar, formando bielas comprimidas. A maior parte é transferida pela base do pilar, entretanto não foi possível quantificar qual a porcentagem transferida por cada mecanismo, ficando assim como uma das questões a ser analisada em trabalhos futuros;

- a verificação à punção da seção de contorno do pilar se torna necessária principalmente nos casos de blocos com interface lisa e a laje de fundo com pequena espessura;

- todos os blocos apresentaram ruína, sem fissuração intensa. Talvez esse fato tenha ocorrido por causa dos modelos estarem muito armados. Em virtude disso pode ter ocorrido a ruptura do concreto em certos pontos, entretanto sem mais análises e sem ensaios experimentais não é possível garantir este comportamento;

- foi verificado por meio do fluxo de tensões que as bielas tem inclinações elevadas. Este fato aliado à contribuição do concreto, justificariam as pequenas solicitações nas armaduras.

- o fato das bielas se formarem quase na vertical, conduzindo as forças diretametne para as estacas se configura numa situação desejavel, entretanto é necessário que se tomem certos cuidados com o esmagamento do concreto e com o tipo de ruína do bloco;

- nos blocos da série MO1, apesar da proximidade da força atingida no modelo numérico com a força resistente, os modelos diferem quanto ao modo de ruína. Não foi observado no modelo numérico a ruína por escoamento da armadura prevista no modelo analítico. Já na série MO2, o modo de ruína foi mais compatível com os modelos analíticos 
pois em ambos a ruína foi governada pela resistência à compressão do concreto na cabeça das estacas.

A partir das observações realizadas, dúvidas e dificuldades encontradas neste trabalho e, principalmente, para desenvolvimento do conhecimento do comportamento dos blocos para ligação de pilar pré-moldado, ficam as seguintes sugestões de estudo:

- Realização de ensaios experimentais de blocos sobre quatro estacas submetidos a momentos com grande excentricidade. Só assim é possível esclarecer o comportamento destas estruturas e ter parâmetros para poder ajustar os modelos numéricos e realizar simulações com garantias de bons resultados;

- estudar variações na geometria dos blocos e do colarinho, assim como o comprimento de embutimento do pilar;

- estudar a influência do comprimento das estacas e da interação com o solo, pois estes parâmetros influenciam diretamente no comportamento do bloco;

- estudar blocos submetidos a ações horizontais;

- a partir de ensaios experimentais verificar o comportamento da ligação assim quantificar os parâmetros necessários para a utilização nas simulações numéricas, principalmente no caso de interface lisa. 


\section{REFERÊNCIAS BIBLIOGRÁFICAS}

ADEBAR, P.; KUCHMA, D.; COLlINS, M. P. Strut-and-Tie Models for the Design of Pile Caps: An Experimental Study. ACI Structural Journal, v. 87, n. 1, p. 224-273, jan.-fev.1990.

ADEBAR, P.; ZHOU, Z. Design of Deep Pile Caps by Strut-and-Tie Models. ACI Structural Journal, v. 93, n. 4, p. 1-12, jul.-ago. 1996.

ALONSO, U. R. Exercícios de Fundações. São Paulo: Ed. Edgar Blücher, 1983. 201 p.

AMERICAN CONCRETE INSTITUTE. Committee 318 (ACI 318-08): Building Code Requirements for Structural Concrete and Commentary. Detroit, Michigan, 1983.

AMERICAN CONCRETE INSTITUTE. Committee 318 (ACI 318-08): Building Code Requirements for Structural Concrete and Commentary. Detroit, Michigan, 2008.

ASSOCIAÇÃO BRASILEIRA DE NORMAS TÉCNICAS. NBR 6118: Projeto de Estruturas de Concreto: Procedimento. Rio de Janeiro, 2003.

. NBR 9062: Projeto e Execução de Estruturas de Concreto Pré-Moldado. Rio de Janeiro, 2006.

. NBR 9062: Projeto e Execução de Estruturas de Concreto Pré-Moldado. Rio de Janeiro, 1985.

BARROS, R. Análise de Blocos de Concreto Armado sobre Duas Estacas com Cálice Totalmente Embutido Mediante Presença de Viga de Travamento. 2009. 196 p. Dissertação (Mestrado em Engenharia de Estruturas) - Escola de Engenharia de São Carlos, Universidade de São Paulo, São Carlos, 2009. 
BLÉVOT, Jean; FRÉMY, Robert. Semelles sur Pieux. Annales de L'Institut Technique Du Bâtiment et des Travaux Publics, Paris, v. 20, n. 230, p. 224-273, fev. 1967.

BRUGGELING, A. S. G.; HUYGHE, G. F. Prefabrication with Concrete. Rotterdam: A. A. Balkema, 1991. 405 p.

BUtTIGNOL, T. E. T. Análise Computacional de blocos sobre estacas. 2011. 200 p. Dissertação (Mestrado em Engenharia de Estruturas) - Faculdade de Engenharia Civil, Arquitetura e Urbanismo da Universidade Estadual de Campinas, Campinas, 2011.

CALAVERA, José. Cálculo de Estructuras de Cimentación. 4ª ed. Madrid: Infoprint, 2000. $529 \mathrm{p}$.

CAMPOS, G. M. Recomendações para o projeto de cálices de fundação. 2010. 183 f. Dissertação (Mestrado) - Escola de Engenharia de São Carlos, Universidade de São Paulo, São Carlos, 2010.

CAMPOS, L. A. Análise experimental de bloco de fundação sobre duas estacas, sob carga centrada, para estrutura pré-fabricada. 2007. 163 f. Dissertação (Mestrado) - Universidade Federal de Santa Catarina, Florianópolis, 2007.

CANADIAN STANDARDS ASSOCIATION. CSA A23.3-04: Design of Concrete Structures with Explanatory Notes. Ontario, 2004.

CANHA, R. M. F. Estudo Teórico-Experimental da Ligação Pilar-Fundação por meio de Cálice em Estruturas de Concreto Pré-Moldado. 2004. 155 f. Tese (Doutorado em Engenharia de Estruturas) - Escola de Engenharia de São Carlos, Universidade de São Paulo, São Carlos, 2004.

CANHA, R. M. F. e EL DEBS. M. K. Análise crítica dos modelos e recomendações para o projeto da ligação pilar-fundação por meio de cálice em estruturas de concreto pré-moldado. Revista IBRACON de Estruturas. V. 2, n, 2. p. 95-136, jun. 2006. 
CHAN, T. K.; POH, C. K. Behavior of Precast Reinforced Concrete Pile Caps. Constructing and Building Materials, v. 14, n. 4, p. 73-78, jan. 2000.

CHEN, W. F. Plasticity in Reinforced Concrete. New York: Ed. McGraw-Hill, 1982. 474 p.

COMISIÓN PERMANENTE DEL HORMIGÓN. EHE: Instrucción Española de Hormigón Armado. Ministerio de Fomento, Centro de Publicaciones, Madrid, 2008.

COMITÉ EURO-INTERNATIONAL DU BÉTON. CEB-FIP Model Code 1990. London, 1993.

COMITE EUROPÉEN DU BÉTON. Recommandations Particulières au Calcul et à L'Exécution des Semelles de Fondation. Bulletin D'Information. Paris, Fascicule 4, n. 73, p. 27-35, 1970.

DELALIBERA, R. G. (2006). Análise teórica e experimental de blocos de concreto armado sobre duas estacas submetidos a ação de força centrada e excêntrica. Tese (Doutorado) Escola de Engenharia de São Carlos, Universidade de São Paulo, São Carlos.

DIANA. Finite Element Analysis: Users Manual release 9 - Material Library. Delft, Netherlands: TNO DIANA, 2005a. 534 p.

DIANA. Finite Element Analysis: Users Manual release 9 - Element Library. Delft, Netherlands: TNO DIANA, 2005b. 662 p.

DIANA. Finite Element Analysis: Users Manual release 9 - Analysis Procedures. Delft, Netherlands: TNO DIANA, 2005c. 636 p.

EBELING, E. B. Análise da Base de Pilares Pré-Moldados na Ligação com Cálice de Fundação. 2006. Dissertação (Mestrado em Engenharia de Estruturas) - Escola de Engenharia de São Carlos, Universidade de São Paulo, São Carlos, 2006. 
EL DEBS, M. K. Concreto Pré-moldado: Fundamentos e Aplicações. São Carlos: EESCUSP, 2000. 456 p.

ELLIOTT, K. S. Multi-Storey Precast Concrete Framed Structures. Oxford, Blackwell Science, 1996.

FEENSTRA, P. H. Computational Aspects of Biaxial Stress in Plain and Reinforced Concrete. PhD thesis, Delft University of Technology, 1993.

FUSCO, P. B. Técnica de Armar as Estruturas de Concreto. São Paulo: Ed. Pini, 2000.

JAGUARIBE JÚNIOR, K. B. Ligação Pilar-Fundação por meio de Cálice em Estrutuas de Concreto Pré-Moldado com Profundidade de Embutimento Reduzida. 2005. Dissertação (Mestrado em Engenharia de Estruturas) - Escola de Engenharia de São Carlos, Universidade de São Paulo, São Carlos, 2005.

LEONHARDT, F.; MÖNNIG E. Construções de Concreto: v. 3. Rio de Janeiro: Ed. Interciência, 1977. 288 p.

MAEKAWA, K.; PIMANMAS, A.; OKAMURA, H. Nonlinear Mechanics of Reinforced Concrete. London: Ed. Spon Press, 2003.

MAUTONI, M. Blocos sobre Dois Apoios. São Paulo: Grêmio Politécnico, 1972.

MAREK FILHO, C. A. Análise do Comportamento de Blocos sobre Quatro Estacas com Cálice Embutido. 2010. 190 f. Dissertação (Mestrado) - Escola de Engenharia de São Carlos, Universidade de São Paulo, São Carlos, 2010.

MIGUEL, G. M.. Análise experimental e numérica de blocos sobre três estacas. Tese (Doutorado) - Escola de Engenharia de São Carlos, Universidade de São Paulo, São Carlos, 2000. 
MONTOYA, P. J.; MESEGUER, A. G.; CABRÉ, F. M. Hormigón Armado: v. 1. $14^{\mathrm{a}}$ ed. Barcelona: Ed. Gustavo Gilli, 2000.

MORAES, M. C. Estruturas de Fundações. São Paulo: Ed. McGraw-Hill do Brasil, 1976.

MUNHOZ, F. S. Análise do Comportamento de Blocos de Concreto Armado sobre Estacas Submetidos à Ação de Força Centrada. 2004. 80 f. Dissertação (Mestrado em Engenharia de Estruturas) - Escola de Engenharia de São Carlos, Universidade de São Paulo, São Carlos, 2004.

NORI, V.V.; THARVAL, M. (2007). Design of pile caps - Strut and tie model method. The indian concrete journal, Point of view. p. 13-19, Abril.

NUNES, V. C. P. Estudo do Cálice de Fundação com Ênfase nos Esforços das Paredes Transversais do Colarinho. 2009. Dissertação (Mestrado em Engenharia de Estruturas) Escola de Engenharia de São Carlos, Universidade de São Paulo, São Carlos, 2009.

OLIN, J.; HAKKARAINEN, T.; RÄMÄ, M. Connections and Joints between Precast Concrete Units. Espoo, Julkaisija-Utgivare, 1985.

OSANAI, Y.; WATANABE, F.; OKAMOTO, S. Stress Transfer Mechanism of Socket Base Connections with Precast Concrete Columns. ACI Structural Journal, v. 93, n. 3, p.226- 276, mai.-jun. 1996.

PROENÇA, S. P. B. Análise Não-Linear de Estruturas. Notas de Aula - Escola de Engenharia de São Carlos, Universidade de São Paulo, São Carlos, 2010.

RAMOS, F. A. C. Análise Numérica de Blocos sobre Dez Estacas: Cálculo das Reações de Apoio. 2007. Dissertação (Mestrado em Engenharia de Estruturas) - Escola de Engenharia de São Carlos, Universidade de São Paulo, São Carlos, 2007. 
RILEM, Draft Recommendation, 50-FMC Committee Fracture Mechanics of Concrete, Determination of the Fracture Energy of Mortar and Concrete by means of Three-Point Bending Tests on Notched Beams, Materials and Structures, v. 85, n. 85, p. 285-290, 1985.

ROTS, J. G.; BLAAUWENDRAAD, J. Crack Models For Concrete: Discrete or Smeared Fixed, Multi-Directional or Rotating? HERON. v. 34, n. 1, 59 p., 1989.

SAM, C.; IYER, P. K. Nonlinear Finite Element Analysis of Reinforced Concrete Four-Pile Caps. Computers \& Structures, v. 57, n. 4, p. 605-622, 1995.

SCHIEL, F. Estática das Construções. Publicação N. ${ }^{\circ} 10$ - Escola de Engenharia de São Carlos, Universidade de São Paulo, São Carlos, 1957.

SELBY, R. G.; VECCHIO, F. J. Three-dimensional Constitutive Relations for Reinforced Concrete. Technical Report, n. 93-02, University of Toronto, Department of Civil Engineering, Canada, 1993.

SOUZA, R. A. Concreto Estrutural: Análise e Dimensionamento de Elementos com Descontinuidades. 2004. 442 f. Tese (Doutorado em Engenharia de Estruturas) - Escola Politécnica, Universidade de São Paulo, São Paulo, 2004.

SOUZA, R. A.; KUCHMA, D.; PARK, J. BITTENCOURT, T. Non-Linear Finite Element Analysis of Four-Pile Caps Supporting Columns Subjected to Generic Loading. Computers and Concrete, v. 4, n. 5, p.363-373, 2007.

SCHLAICH, J.; SCHAFER, K.; JENNEWEIN, M. (1987). Toward a consistent design of reinforced structural concrete. Journal of Prestressed Concrete Institute, v. 32, n. 3, p. 74- 150, May-June;

TAYLOR, H. P. J.; CLARKE, J. L. Some Detailing Problems in Concrete Frame Structures. The Structural Engineer, v. 54, n. 1, p. 19-32, jan. 1976. 
VECCHIO, F. J.; COLLINS, M. P. The Modified Compression Field Theory for Reinforced Concrete Elements Subjected to Shear. ACI Journal, v. 83, n. 2, p. 219-231, mar.-abr. 1986.

WILLERT, O.; KESSER, E. Foundations for Botton-end Fixed Precast Columns. Betonwerk+Fertigteil-Technik, v. 49, n. 3, p. 137-142, 1983. 